\title{
METHODOLOGY TO SET THE X-FACTOR FOR PRICE CAP REGULATION IN TOLL ROADS: VALIDATION FOR THE CASE OF BRAZIL
}

\author{
Mariana Rodrigues Brochado
}

\author{
Supervisor: \\ José Manuel Vassallo \\ Dr. Ingeniero de Caminos, Canales y Puertos
}

Madrid, 2016 



\section{UNIVERSIDAD POLITECNICA DE MADRID}

D.15

Tribunal nombrado por el Mgfco. y Excmo. Sr. Rector de la Universidad Politécnica de Madrid, el día....

Presidente D.

Vocal D.

Vocal D.

Vocal D.

Secretario D.

Suplente D.

Suplente D.

Realizado el acto de defensa y lectura de la Tesis el día.........de............................de 2016 en la E.T.S. de Ingenieros de Caminos, Canales y Puertos de la U.P.M.

Calificación:

EL PRESIDENTE

LOS VOCALES 

Ao George por aceitar viver essa aventura comigo. 



\section{AGRADECIMIENTOS}

A mi tutor, Profesor José Manuel Vassallo, por su acogida, enseñanza y apoyo a lo largo de esa jornada.

A todos los profesores y personal administrativo de la Escuela de Caminos y de TRANSyT. A Andrés Monzón por haberme proporcionado estar en TRANSyT. A todos mis compañeros del curso.

A Thais Rangel, Antonio Sanchez Soliño y María de los Ángeles Baeza por las contribuciones y mejorías sugeridas en la prelectura de la tesis.

A Agencia Nacional de Transporte Terrestre por la oportunidad de poder dedicarme a los estudios.

A Javier Faulin que fue mi primer contacto en España, antes de iniciar el curso.

A Lawrence por todo ánimo y enseñanza del inglés.

A mi madre Marina, a mi padre Daniel, toda mi familia y amigos que fueran mi mayor incentivo para estudiar en el extranjero y un apoyo durante mi estancia, mismo estando un océano lejos.

A George por la motivación, cariño, paciencia y, principalmente, por estar a mi lado todos los días y haciéndome feliz en el camino. 



\section{ABSTRACT}

For the last few decades, the private sector has increased its participation in transport infrastructure provision worldwide. This change has brought new challenges for regulators, including the definition of the method of tariff adjustment. For this reason, methods of economic regulation have been made substantial progress, seeking to achieve maximum performance from the concessionaires.

The price cap is a mechanism of incentive regulation to control the price level of the operator. It sets a ceiling to the price level according to an index formula based on the rate of inflation, which is RPI - X. The X-factor is an efficiency factor, which should reflects the expected efficiency gains of the firms, in order to share them with the users.

Therefore, it is imperative for regulators to implement a comprehensive methodology to set the $X$-factor that considers the efficiency of the firms. In this way, the purpose of this research is to develop a framework to set the X-factor of the price cap formula, based on the efficiency of the firms, applied for road infrastructure concessions.

For that end, Data Envelopment Analysis (DEA) is used to measure the efficiency of the firms. In addition to include the productivity of the firms in the calculation of the X-factor, the use of DEA method allows measure the efficiency of the firms, making a comparison among the productivities of the firms and identifying best practices.

The proposed framework is validated by an application for the case of Brazilian federal road concessions, in an effort to present the implementation of the framework and challenges associated with it.

This thesis significantly enhances the application of price cap regulation in practice by taking the efficiency concept into account and also contributes to expand its reach, encouraging regulators to use price cap regime in road concession contracts. 



\section{RESUMEN}

A lo largo de las últimas décadas, el sector privado ha incrementado su participación en la provisión de infraestructuras de transporte en todo el mundo. Este cambio ha resultado en nuevos retos para los reguladores, incluido la definición del método de ajuste de tarifas. Por esta razón, los métodos de regulación económica han hecho progresos sustanciales, con el objetivo de obtener el máximo desempeño de los concesionarios.

El price cap es un mecanismo de regulación por incentivos para controlar el nivel de precios del operador. Para eso se establece un límite máximo para la tarifa de acuerdo con una fórmula que está basada en la tasa de inflación, que es IPC - X. El factor X es un factor de eficiencia, que debe reflejar las ganancias de eficiencia esperadas de las empresas, con el fin de compartirlas con los usuarios.

Por lo tanto, es imprescindible que los reguladores apliquen una metodología completa para determinar el factor $X$ que considere la eficiencia de las empresas. De esta manera, el objetivo de esta investigación es desarrollar una sistemática para determinar el factor $X$ de la fórmula del price cap, basado en la eficiencia de las empresas, para las concesiones viales.

Para ese fin, se utiliza el Análisis Envolvente de Datos (DEA) para medir la eficiencia de las empresas. Además de incluir la productividad de las firmas en el cálculo del factor $\mathrm{X}$, el uso del método DEA permite evaluar la eficiencia de las empresas, comparando las productividades de las empresas e identificando las mejores prácticas.

La sistemática propuesta es validada con una aplicación para el caso de las concesiones de autopistas federales en Brasil, con el objetivo de presentar la aplicación de la sistemática y los retos asociados a ella.

Esta tesis mejora significativamente la aplicación en la práctica de la regulación por el método price cap por medio la inclusión del concepto de eficiencia y también contribuye para ampliar su alcance, fomentando a los reguladores a utilizar el método price cap en los contratos de concesión viales. 



\section{INDEX}

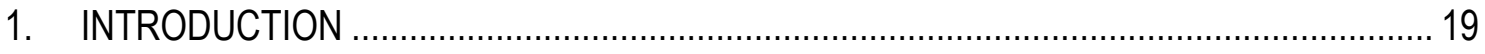

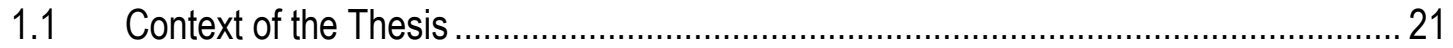

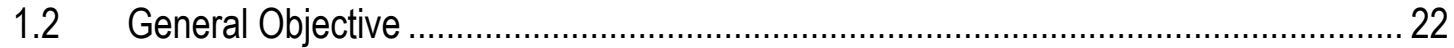

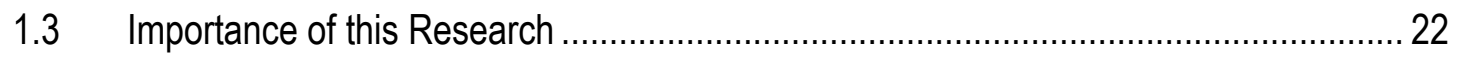

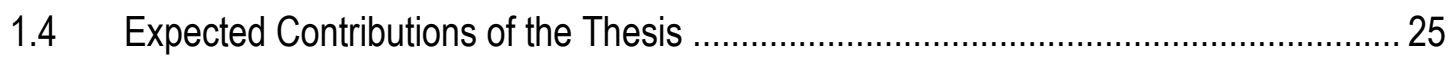

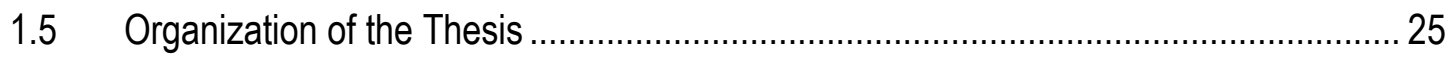

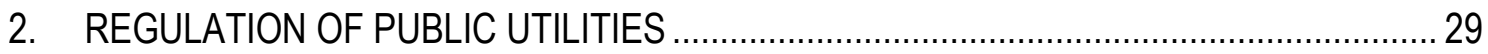

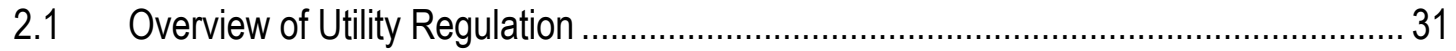

2.2 Evolution of Economic Regulation ........................................................................ 34

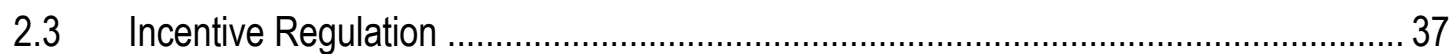

2.4 Experiences of Price Cap in Road Projects ........................................................... 43

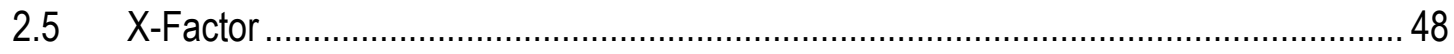

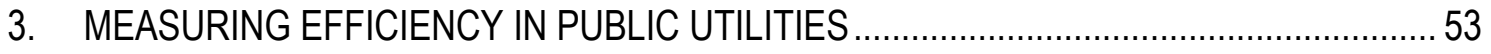

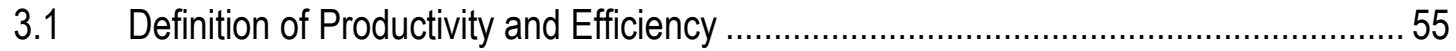

3.2 Efficiency Measurement Methods .........................................................................

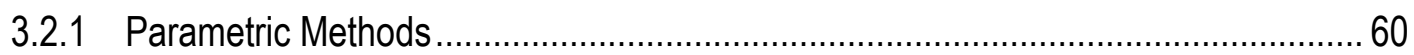

3.2.2 Non-parametric Methods ................................................................................. 61

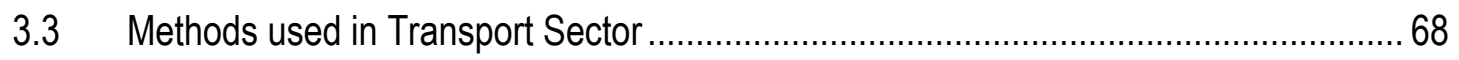

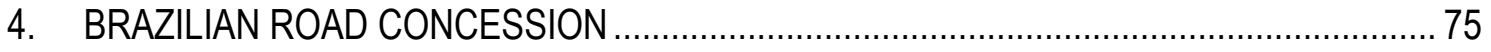

4.1 Overview of Road Concessions in Brazil ................................................................. 77

4.2 Innovations in the Road Concession Program …………….................................... 82

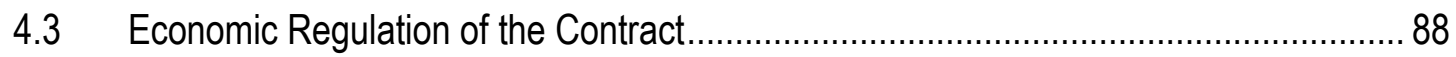

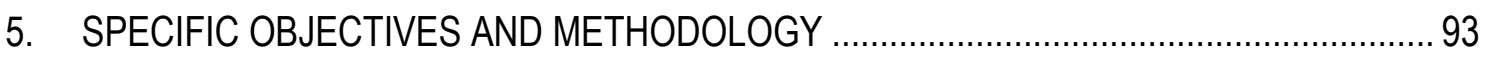

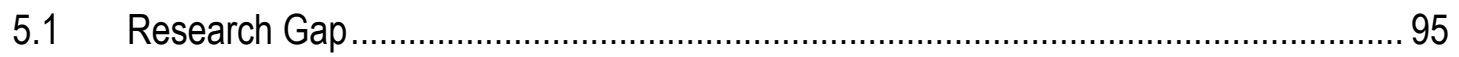

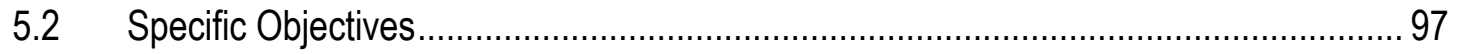

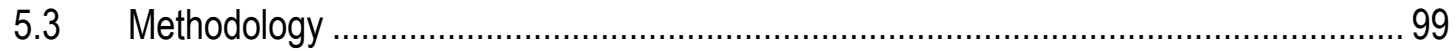

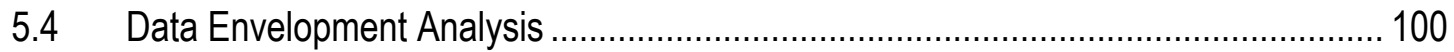

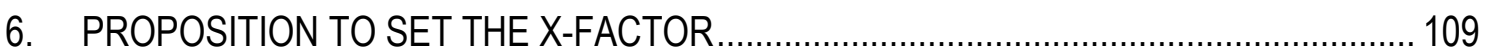

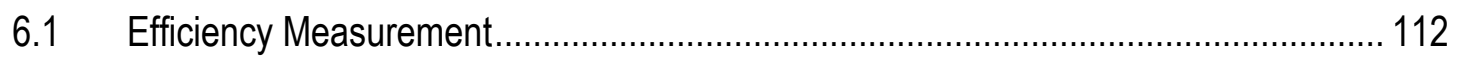

6.2 Define Objective and Select DMUs.................................................................... 113

6.3 Determination of input and output variables........................................................ 117 


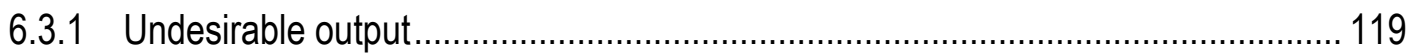

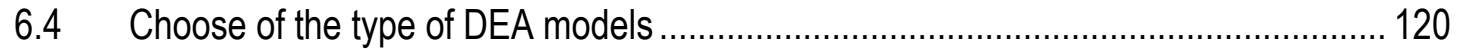

6.5 Applications of DEA models and analysis of results ............................................. 123

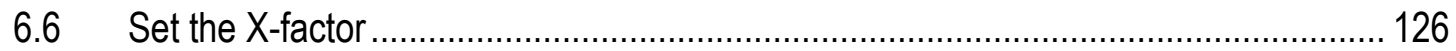

7. APPLICATION OF THE FRAMEWORK PROPOSED TO SET THE X-FACTOR ..............131

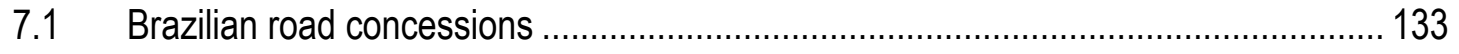

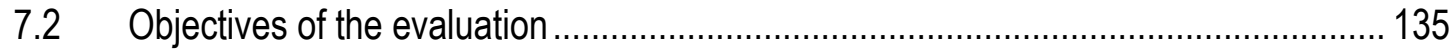

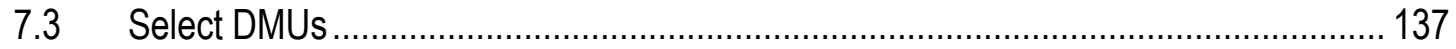

7.4 Determination of inputs and outputs variables .................................................... 138

7.5 Application of DEA model and analysis of results ................................................ 149

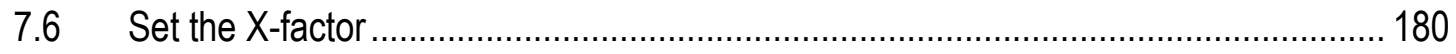

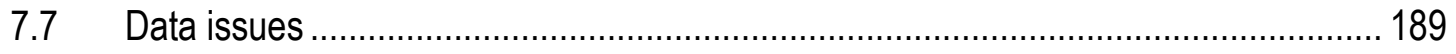

8. CONCLUSIONS AND FURTHER RESEARCH ........................................................... 193

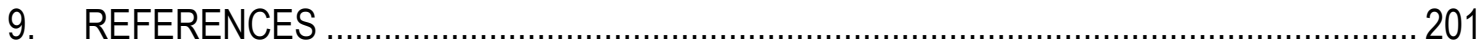

10. APPENDIX

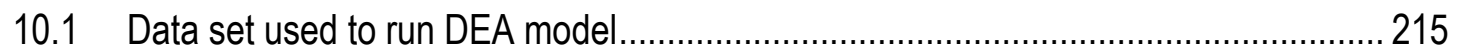

10.2 Correlation between variable of models tested ….................................................. 221 


\section{INDEX OF TABLES}

Table 1 - Comparison of the two main approaches to construct the production frontier ...............67

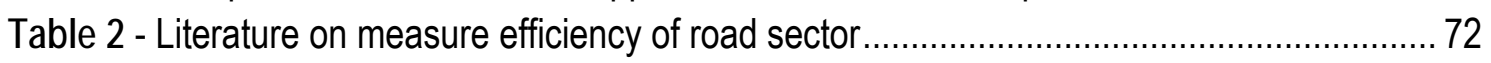

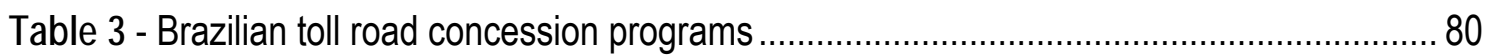

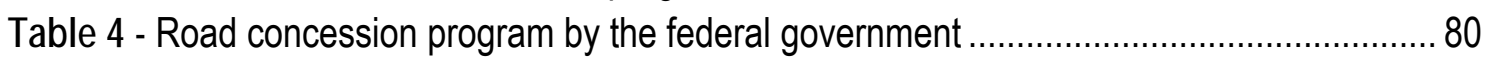

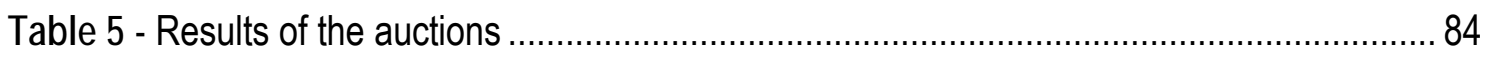

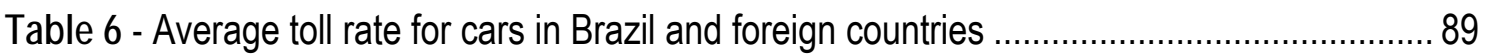

Table 7 - Difference between the toll rate growth due to inflationary adjustments and inflation

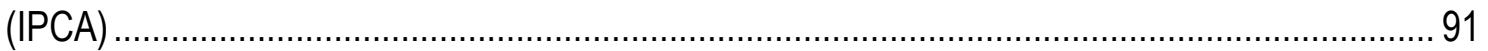

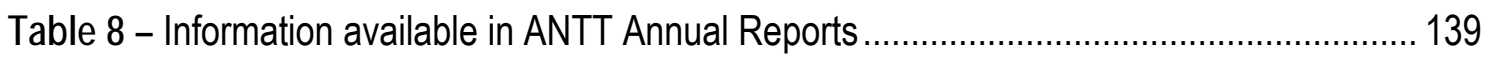

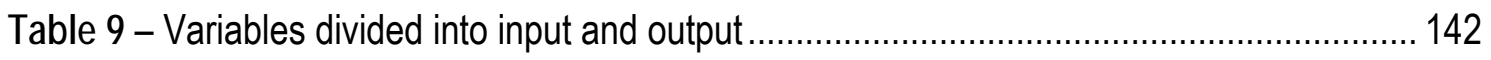

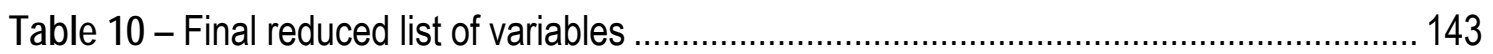

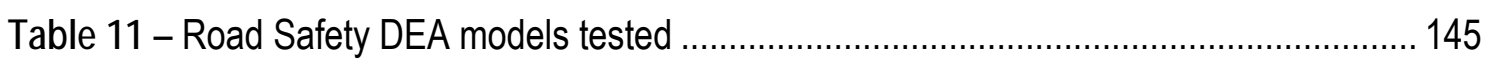

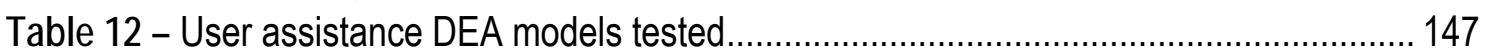

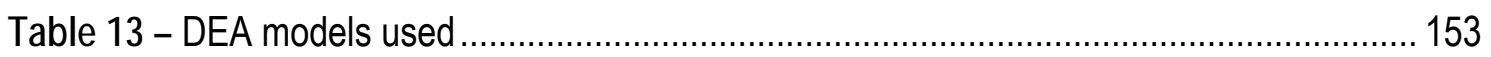

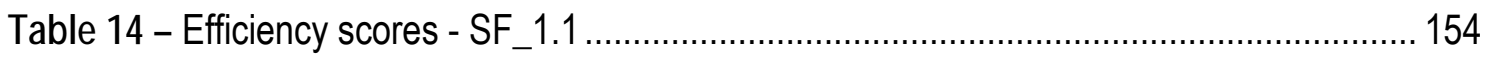

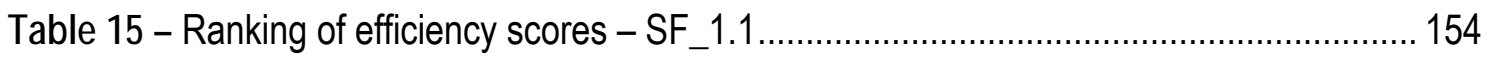

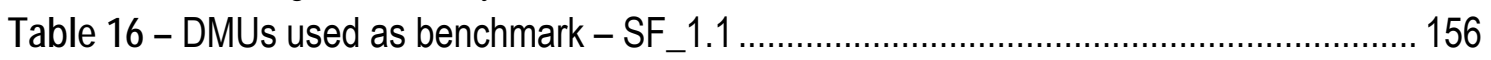

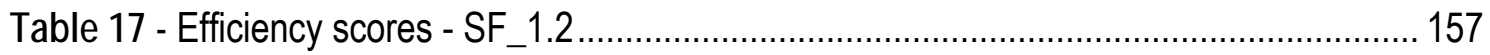

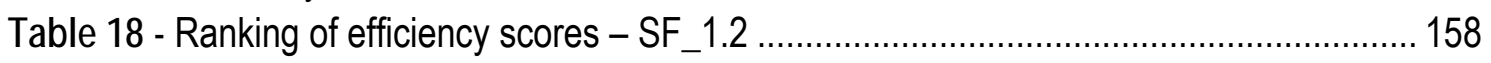

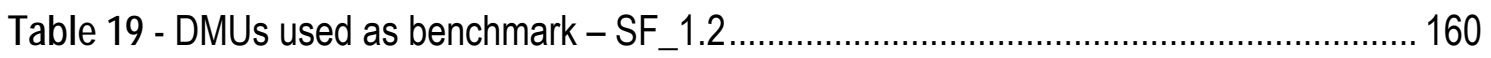

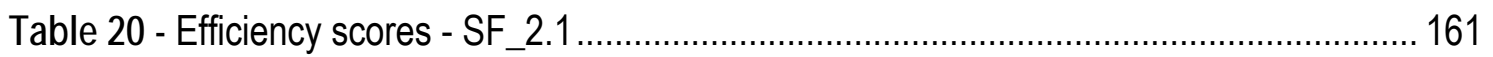

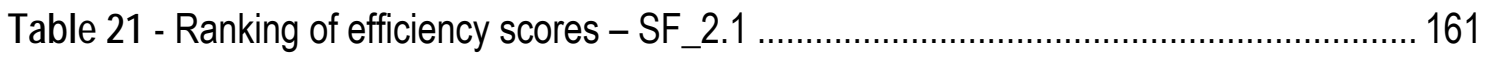

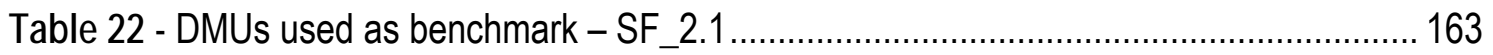

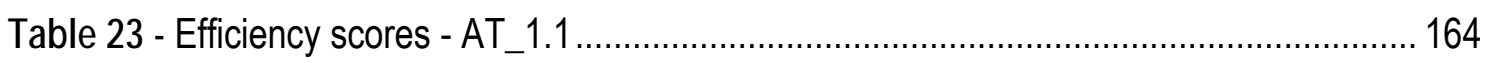

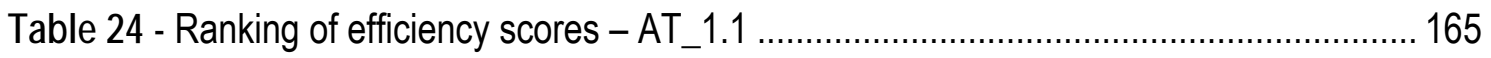

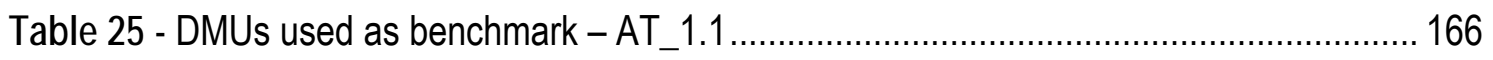

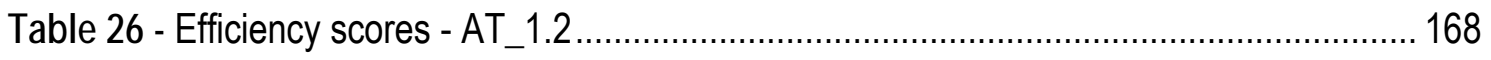

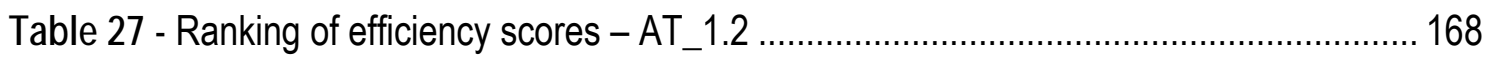

Table 28 - DMUs used as benchmark - AT_1.2 _............................................................ 170

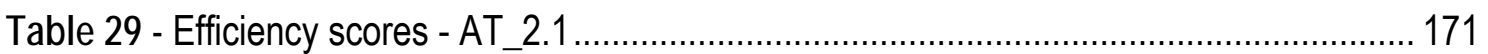

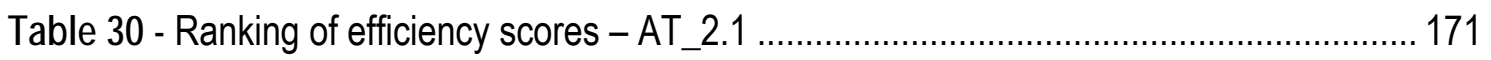

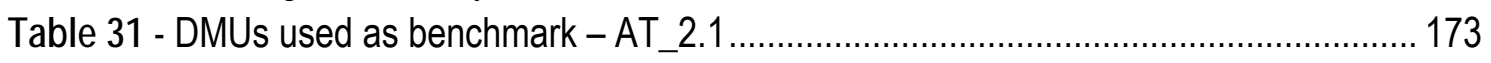

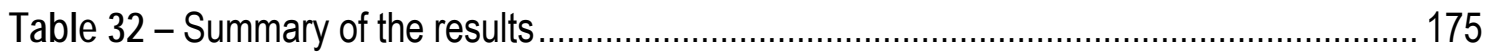

Table 33 - X-factor calculation for concessionaires of $1^{\text {st }}$ stage -1 st period ............................... 182

Table 34 - X-factor calculation for concessionaires of 1 st Stage $-2^{\text {nd }}$ period............................. 183

Table 35 - X-factor calculation for concessionaires of $2^{\text {nd }}$ stage -1 st period .............................. 184

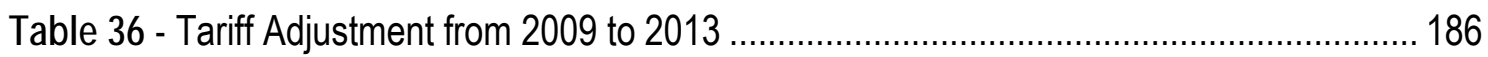

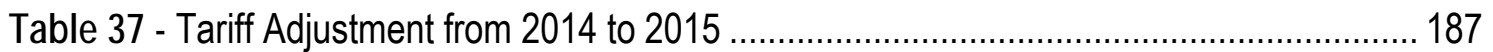

Table 38 - Recommended data to be used to run DEA models.............................................. 191 



\section{INDEX OF FIGURES}

Figure 1 - Transport investment and as percentage of Brazilian GDP ...................................... 24

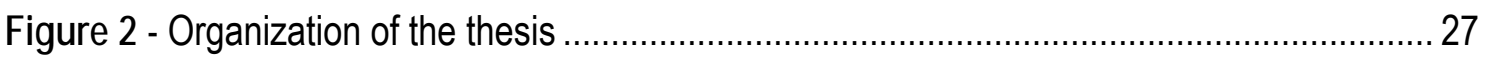

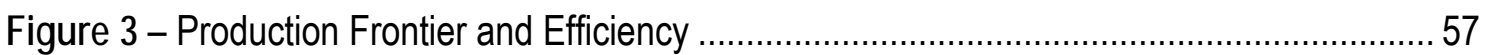

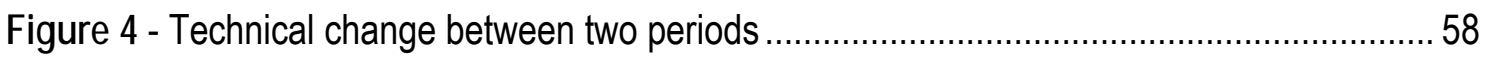

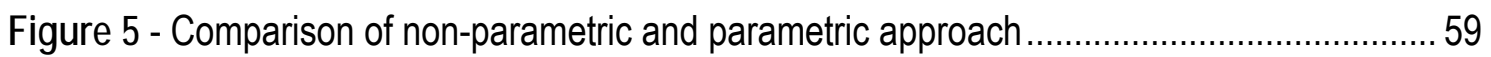

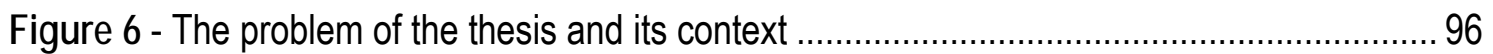

Figure 7 - Motivation, Problem Statement, Objectives and Main Contributions of the thesis...... 98

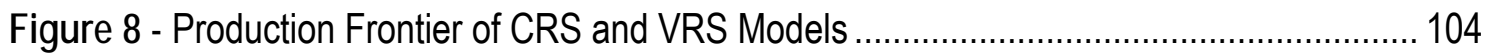

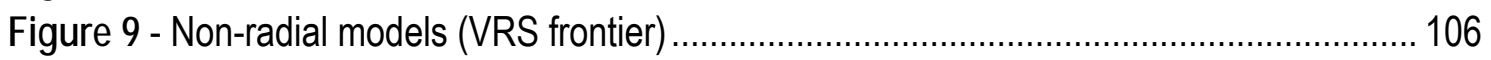

Figure 10 - Proposed Framework to Set the X-factor ........................................................ 111

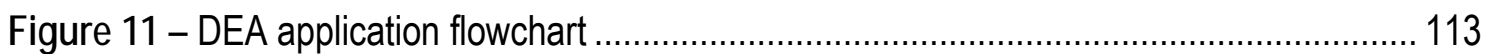

Figure 12 - Flowchart of the decisions to choose the DEA model ........................................... 123

Figure 13 - Expansion of the federal road concession program in Brazil ................................. 134

Figure 14 - DEA model to evaluate the Road Safety.......................................................... 146

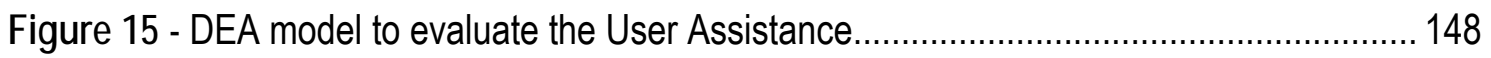

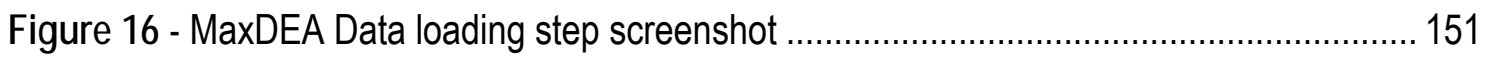

Figure 17 - MaxDEA Specifications of DEA model screenshot ............................................ 151

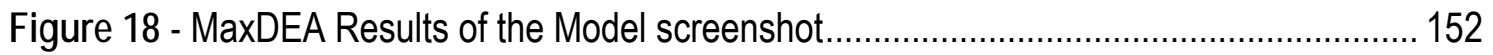

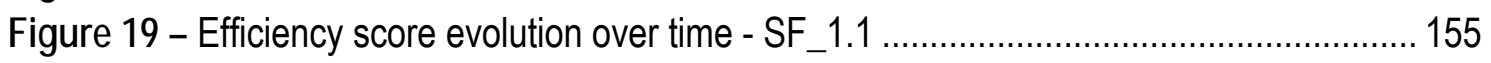

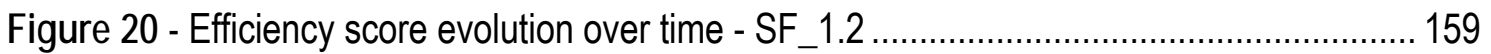

Figure 21 - Efficiency score evolution over time - SF_2.1 ….............................................. 162

Figure 22 - Efficiency score evolution over time - AT_1.1 …..................................................... 166

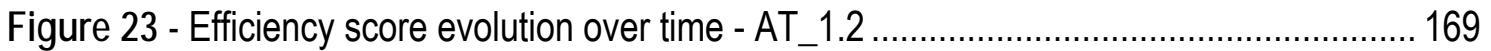

Figure 24 - Efficiency score evolution over time - AT_2.1 …................................................ 172

Figure 25 - Evolution of Intangible asset x Efficiency - Concer (2004-2008) ........................... 177

Figure 26 - Evolution of Intangible asset x Efficiency - Concer (2009-2013) ........................... 178

Figure 27 - Evolution of Intangible asset x Efficiency - Autopista Fernão Dias (2009-2013) .... 179 

1. INTRODUCTION 

This first chapter starts introducing the context of the thesis, in order to give a broad outline of the current situation concerning toll road concessions and the economic regulation of these contracts. Afterwards, it describes the overall objective of this research and the importance of the study to improve the regulation process of toll road concessions. Then, expected contributions of this research are presented. Finally, the framework of the thesis is presented, showing how this research is organized.

\subsection{Context of the Thesis}

Infrastructure investment was traditionally undertaken by governments, and funded through public budget. However, during the last decades, public administration around the world had budget and public debt constraints, which reduced the public expenditure and the ability of governments to finance infrastructure adequately to face growing needs. Then, governments needed to look for new and innovative ways to finance their infrastructure projects.

As a result, many countries carried out concession projects and privatization of public utilities, such as telecommunications, energy, transport and water supply, in order to expand private sector participation in infrastructure investment. Regarding the transport sector, a road concession is defined as a legal arrangement in which a firm obtains from the government the right to provide a particular service, which includes a variety of road works as construction, rehabilitation, maintenance and operation.

In this new scenario, the government is no longer a direct operator and has to assume the role of regulator. It requires changes in the organization of government entities responsible for concession programs and the suitability of the legal and regulatory environment.

Regulation objectives are summarized by Jamison et al. (2004) as: an effective control of the market power, facilitation of competition, protection to operators and customers from politically-driven decisions and search for continuous improvements in welfare. In order to perform its regulatory function satisfactorily, the institutional framework has to incentivize the private operator to improve efficiency, as well as reduce market failures.

Regarding economic regulation, rules of price adjustment over the time for the service provided have the objective to ensure that the concessionaire will continue to face pressure to 
seek efficiencies, but will also be able to earn a reasonable rate of return. The price cap is a mechanism of incentive regulation widely used to control the price level of the operator.

In the price cap regulation, prices are adjusted by the formula "RPI-X", which represents an index of inflation (RPI) during the revision period, minus a factor reflecting expected efficiency gains (X-factor). The aim of the price cap is to incentivize the private operator to improve efficiency and to share efficiency gains with the users.

However, one of the most important advantages of the price cap approach, which is to provide stronger incentives for efficiency, depends on the proper exercise of regulatory power when setting the X-factor. At the time of revision, prices should be adjusted to reflect the new level of efficiency as well as future expected efficiency gains, and should not be readjusted so as to retroactively eliminate the profits made during the previous period.

\subsection{General Objective}

In this context, it is possible to note that setting the X-factor correctly is essential to achieve the aim of price cap regulation. Therefore, the overall objective of this thesis is to study the price cap regime in order to help regulators to improve the decision-making process and include the efficiency analysis in the process to set the $\mathrm{X}$-factor for road concessions.

In summary, the purpose of this research is to develop a method to set the X-factor of the price cap formula for road concessions, using a systematic way to measure the efficiency by scientific techniques, and present an example application of this framework so as to illustrate the full implementation of such framework.

\subsection{Importance of this Research}

Transport infrastructure promotes economic and social development as it generates employment and promotes regional integration. So, in order to achieve economic development, a country requires efficient and proper transport systems. 
Concessions have been widely used in recent years to finance construction, maintenance and operation of road infrastructure. This thesis studies the regulation process of road concession contracts, contributing to define clear rules to the process of price adjustments, with a systematic methodology the set the X-factor within the price cap formula. This is believed to generate benefits for all involved in the process: governments, concessionaires and users, which show the importance of this research to achieve social welfare.

In addition, having clear rules for regulated services also generates indirect effects, such as attract more investors and enhance competition in the tender, which is one of the objectives of regulation, increase competitiveness on monopoly sectors. Improving these aspects also makes more projects feasible, and consequently help to expand the sector.

Furthermore, lack of accuracy in setting the X-factor can increase the cost of capital of the private firm and make its investment become inefficient. This fact can generate contrary effects and will not incentivize private operator to improve efficiency. So, it points to another particular relevance of the present study.

Regarding the election to use the Brazilian road concession program to illustrate the systematic proposed, it is a very interesting case to study because it is an emerging country that needs large investment in infrastructure and it has a satisfactory economic, regulatory and political environment to implement concession projects, as demonstrated by recent data.

Brazil has one of the longest road networks under private concessions and it is expanding. Comparing Brazilian data about investment in transport and Gross Domestic Product (GDP), we noticed that investments in this sector have grown in recent years. However, even with this increase, investments in the sector are still inadequate, when we consider its role in the national economy. As seen in Figure 1, in 2009 investments in roads were only $0.35 \%$ of Brazilian GDP (R\$10.9 billion). 


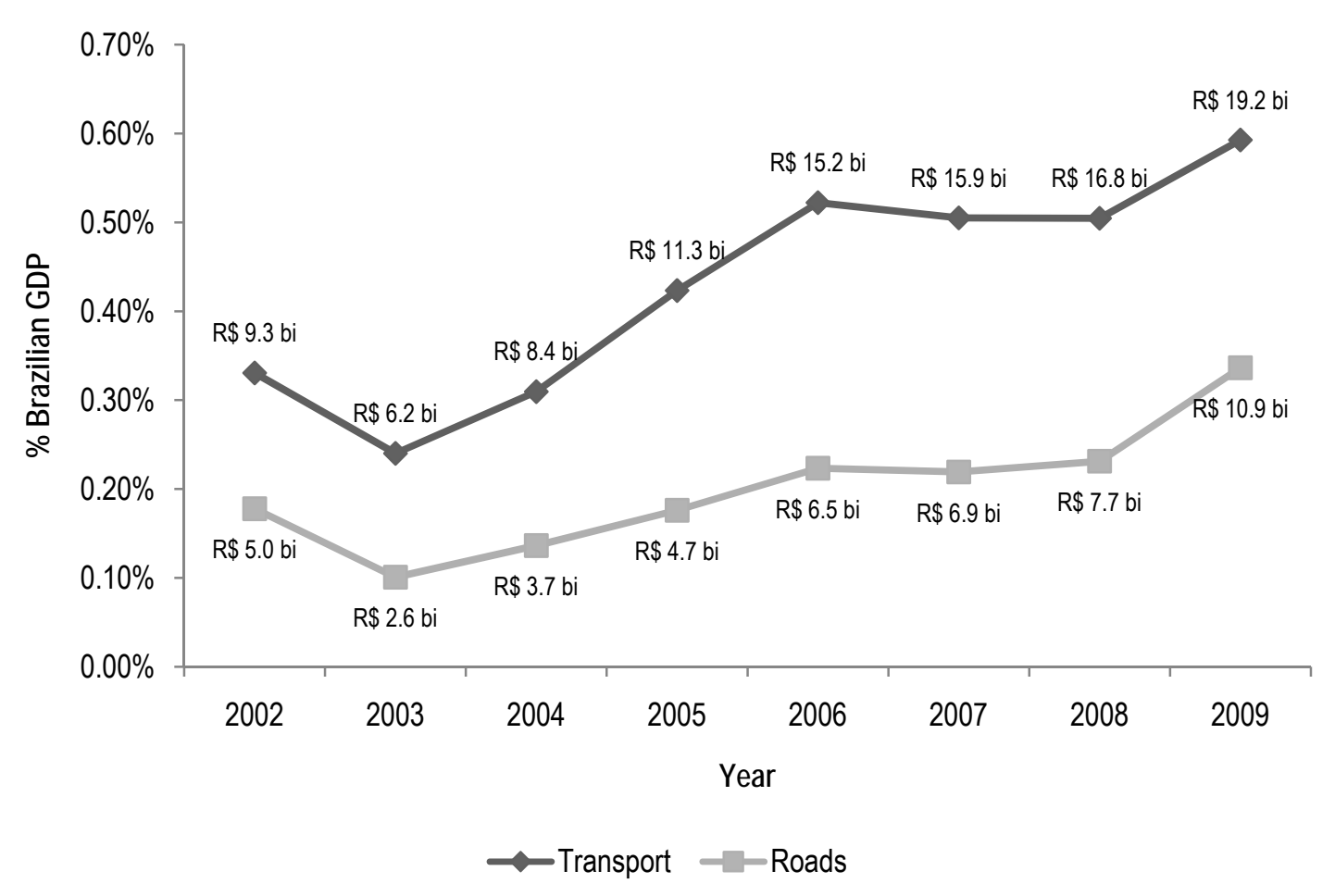

Data base: December/2009 (R\$ billion), exchange rate: $\mathrm{R} \$ 1.74 / \mathrm{US} \$$

Source: Adapted from IPEA (2011)

Figure 1 - Transport investment and as percentage of Brazilian GDP

Another point of great importance of the work is the study of the efficiency of public services under concession, with the aim to increasing the productivity of sectors. According to Cook and Seiford (2009), efficiency measurement has been important to improve productivity of firms and for this reason they are very interested in this subject. To reinforce this idea, they quote Farrel (1957), which stated that the problem of measuring the productive efficiency of an industry is important to both the economic theorist and the economic policy maker.

Thus, efficiency is a very important dimension of overall performance and it should be considered by the regulators as an indispensable element when measuring the performance of concession contracts. As this research takes the efficient concept into account, it can be noted that the present thesis also helps to improve the way employed nowadays to measure the performance of road concessions. 


\subsection{Expected Contributions of the Thesis}

This research is expected to contribute to the improvement of the mechanisms used to adjust the price level of private operators of public utilities, mainly those that use the price cap regime and need a method to set the $X$-factor. It also contributes to the body of knowledge of the road concession sector by applying a scientific framework to measure the efficiency of road operators.

This work can be significant, relevant and broadly applied by regulatory agencies, which aims to incentivize the productive of the firms. Therefore, this thesis can contribute to widen the use of the price cap regime in road concession contracts worldwide. In addition, it contributes to achieve the expected results during the application of the price cap, providing adequate incentives to improve the productivity of the sector and reaching equity share of the efficiency gains between firms and users.

There are also indirectly contributions, because the use of well-conceived ex-ante rules to adjust the price level of services provided by private firms can avoid regulatory disputes and contract renegotiations, also helps to reduce regulatory capture by the private operator.

This thesis also contributes to the development of the body of knowledge of the efficiency measurement of services, showing an application of this method using real data of road concessionaires.

\subsection{Organization of the Thesis}

This thesis is composed by 5 stages that are organized in the following structure (see Figure 2):

First stage - Introduction: this stage is composed by the chapter 1 , which introduces the context of the thesis and presents the general objective of the research. Then it describes the importance of the study and presents contributions of the thesis to the body of knowledge, regarding the regulation of road concessions contracts. Finally, the framework of the thesis is presented. 
Second stage - Literature review: this stage aims to detail the literature review which is divided into three chapters. The chapter 2 contains a general literature review about public utilities regulation, presenting the evolution of the theory and the methods of economic regulation. This chapter also focuses in the price cap regulation, describing its experiences in road concession projects and discussing about the X-factor. The chapter 3 describes the methods to measure the efficiency in public utilities, also presents the methods most used in transport sector. The last chapter of the literature review is chapter 4 which reviews the road concessions experience in Brazil, describing the main aspects about regulation and innovation of the contracts.

Third stage - Definition of the problem, specific objectives and methodology: this stage is represented by chapter 5 which presents the research gap identified in the literature review and defines specific objectives of this thesis. Then, it describes the methodology used to carry out this research. Finally, it details the Data Envelopment Analysis (DEA) method, which was chosen to evaluate the efficiency of the road concessionaires in the framework proposed.

Fourth stage - Analysis and results: this stage analyzes and exposes the results of this research. It consists of two chapters. Chapter 6 delineates a systematic proposal to set the Xfactor, and Chapter 7 implements the proposed systematic, to the Brazilian case of the federal road concession program.

Fifth stage - Conclusions and contributions: this stage is composed by the chapter 8 , which presents the conclusions and contributions of this thesis. It also suggests future researches which can complement the study. 
STAGES

Introduction

Literature review

Definition of the problem, specific objectives and methodology

Analysis and results

Conclusions and contributions

\section{CHAPTERS}

1. Introduction, general objective, importance of the research, contributions of the thesis and framework

2. Public utility regulation, economic regulation, price cap regulation and $\mathrm{X}$ factor

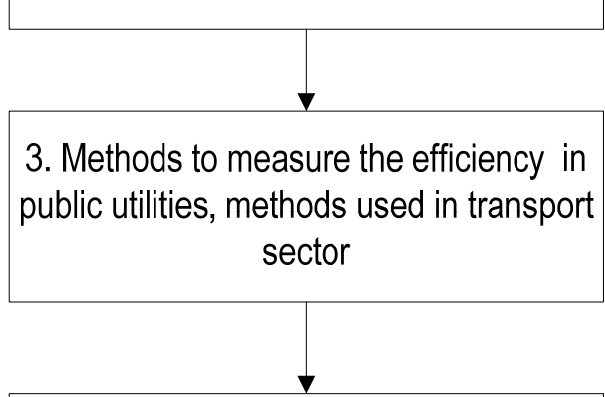

4. Brazillan road concession experience, regulation and innovations

5. Research gap, specific objectives, methodoloy and Data Envelopment Analysis (DEA)

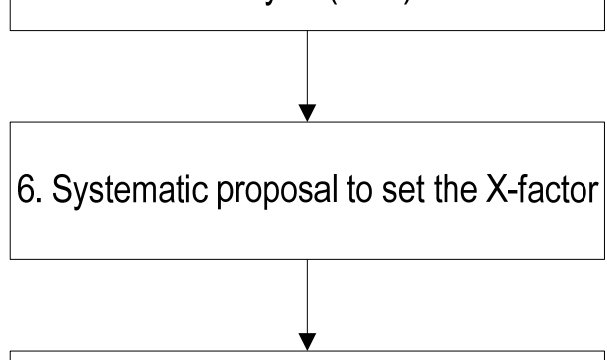

7. Implementation of the proposed systematic for the Brazilian case

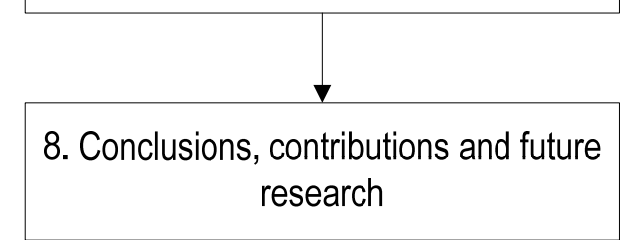

Figure 2 - Organization of the thesis 

2. REGULATION OF PUBLIC UTILITIES 

The purpose of this chapter is to provide a broad description about regulation and review the studies up to date about incentive regulation and X-factor. First we define regulation, describe the motivations for regulation, the aims of utilities regulation, examine who are the stakeholders of the process, who is in charge of regulation activities and how the regulatory policies are implemented. Afterwards, we review the evolution of the theory of regulation, focusing on the methods of economic regulation. Then, we define incentive regulation, describe methods of tariff regulation, and present international experience in the use of price cap regulation for toll road. Finally, we explain the X-factor features and calculation.

\subsection{Overview of Utility Regulation}

Regulation is the intervention of the government in the economy through official rules to improve sector performance. This is a broad activity that involves the creation of laws, decrees and rules. Regulation is desirable when social, economic and environmental objectives of the government - as new investments, service expansion and low prices - are different from the operator's objective - maximize profits - or when operator has an information advantage over the government (Jamison et al., 2004).

According to Pires and Piccinini (1999), regulation has the following aims:

- seek economic efficiency, ensuring lowest cost to the user;

- prevent abuse of monopoly power, ensuring smallest difference between prices and costs, consistent with required levels of quality of service;

- ensure universal service;

- ensure quality of service;

- establish channels of communication to handling complaints of users or consumers about services supply;

- stimulate innovation;

- ensure technological standardization and compatibility among devices;

- $\quad$ ensure safety and protect the environment.

In the case of monopoly industries, regulation exists in order to correct market failures, preventing companies to practice abusive prices and assuring high level of production and 
quality. In this way the best regulation is the one that imitates the competition, where companies seek efficiency, offering a product with adequate quality and affordable price.

Public utilities are considered as natural monopolies because they have as main characteristics: technologies are usually considered to be specific, that is, their investments are not recoverable (sunk investments) and require high investments; large economies of scale (high fixed cost and low marginal cost) in planning and network management and low competition. In addition, infrastructure investment needs long term planning to achieve success. These are the reasons why public utilities have been long public owned and management.

In the last decades, governments had difficulties to reach the demand for investment in infrastructure due to budget and fiscal constraints. Seeking more agility in investments and increase efficiency in service provision, many countries overtook a public sector reform, introducing private participation in investment and operation of public services through privatizations or concessions.

Infrastructure concession consists in conferring monopoly rights to an operator in order to maximize their economies. As a monopoly market does not stimulate competition, neither incentive efficiency management, expansion of production and price reduction, the aim of the regulation is to generate theses incentives indirectly. In this way, from the entry of private operator in monopoly industries, the development of new regulatory frameworks becomes crucial, in order to guarantee profitability to enable long-term investment, to meet the needs of consumers and increase economic efficiency. In summary, regulation aim is to protect users, private rights, also to make rules stable.

Under this analysis we can identify the following stakeholders involved in the regulatory system. The first is the operator of public service, which is the company that holds the monopoly right. The second is the user, as the citizen who pays a fee for the service. The third is the government, responsible for the service provision. The last is the regulator, which is a public authority or a government agency responsible for exercising autonomous authority in a supervisory function over a specific area.

Each of the stakeholders has specific interests, for example, on one hand operator wants to obtain the best rate of return from his investment, on the other hand, users expect to get the best quality at the lowest price. However, the government interest is the most difficult to manage, because it has interests related to social aspects, like ensuring low tariffs, but also related to 
private side, as assuring a lucrative project to achieve its success. Furthermore, the government has more power to intervene in the process than the other stakeholders, because it is responsible for formulating public policies, defining the rules and handling with conflicts to balance all these interests.

Thus, in order to provide independence in regulatory acts, governments should create an institutional design structure with independent regulatory agencies to be in charge of regulatory duties. These institutions should have a greater level of independence and integrity in decision making, financing and accountability. It will ensure that administrative procedures and regulatory decisions are transparent and non-discriminatory. Malyshev (2006) says that evidence of OECD countries experiences offer a wide range of alternatives in terms of institutional design to ensure regulatory independence.

One of the greatest preoccupations about personnel in regulatory agency is the capture, which is when regulators are influenced by some of the interest groups. Thus, autonomy in regulatory agencies is crucial to avoid capture. Independency in technical and decision seek to limit the influence of the political and economic interest groups.

Concerning the particularities of infrastructure activity, a regulatory agency can support the implementation of long-term economic policies, coordinating long-term investments with short periods of electoral mandate, also ensuring efficiency of service by monitoring the performance of the concessionaire.

The main instruments of regulatory policies are: control of entry and exit of firms in the market - control of entry allows companies to exploit the economies of scale and produce at the lowest possible cost and control of exit avoids problems in the continuity of service -, prevention of anti-competitive practices and abuse of economic power, promotion of competition, tariff controls - which promotes efficiency incentive and earning sharing with consumer - and enforcement of concession contracts.

Therefore, regulatory policy can be applied in several forms based on a mix of economic, legal, and public management principles. OECD (1997) divides government interventions into three categories:

(1) Economic regulations: intervene directly in market decisions such as pricing, competition, market entry or exit. 
(2) Social regulations: protect public interests such as health, safety, the environment, and social cohesion. The economic effects of social regulations may be secondary concerns or even unexpected, but can be substantial.

(3) Administrative regulations: are paperwork and administrative formalities through which governments collect information and intervene in individual economic decisions. They can have substantial impacts on private sector performance.

The study of regulation involves: economic theory, international experience and legal system. There is a long investigation in the area of regulation and a large development of regulation theories. It occurs because contracts that give monopoly rights to a firm have been used a long time ago and studies about these contracts performance have a huge influence on public policy, as it is seen in the next section.

\subsection{Evolution of Economic Regulation}

Contracts regulated by franchise for the provision of utility services, as electricity and water, were utilized prior to the beginning of the $20^{\text {th }}$ century in Europe and United States. For example, according to Priest (1993), in the United States regulation by franchise was introduced for gas in 1820s and for street railway transportation (powered by horses) in 1830s. These franchise contracts incorporated terms limiting price and mandating features of service quality, attempting to control monopolization problem. Then the use of this kind of contracts was extended to other public services.

In this period, there was an increasing urbanization which resulted in changes in the conditions of market, as supply and demand. However, the initial franchise agreements were often general and suffered difficult in their execution in long term, mainly to adapting it overtime to new conditions.

From the end of the Second World War, there was a lot of criticism of the regulation system. Most of literature published in the Journal of Law and Economics, demonstrated the influence of private interest, showing that theories of regulation approach ignore the interaction of regulators and regulated firms, also the excessive cost of service regulation. In summary, articles argued that welfare was not maximized under arrangements utilized at that time. 
Seeking for improvements in the regulatory model, Demsetz (1968) provides the first suggestion to insert competition in infrastructure utilities under regulation. He proposed the competition for the field in franchise contracts, by auction the right to manage the utility for a limited period of time. Operators would compete for the market and the bidder who offered the optimum combination of price and quality would win the right to be the service provider. The bid has the objective to stimulate competition, which would lead operators to offer prices near to the average cost, allowing fair profits.

It is important to note that competition for the field is different from competition in the market, when all elements of the utility service can be competitive, as in the currently example of mobile telecommunication service. In this case, regulator should remove barriers to entry or competition.

Demsetz (1968) concludes that monopolization could be controlled without continuous regulation follows directly. Consequently, the role of the regulator would change to be in charge only with the bidding process. Later articles criticized his ideas, because his analyses still were too simplistic, for example, post-auction regulation may still be necessary if prices need to be adjusted to unanticipated events.

The regulation debate expanded and Stigler (1971), based on Demsetz (1968) study, postulated that the theory of demand and supply could be applied to analyze regulation. He proposed that regulation is subject to the forces of demand and supply, as well as any other commodity and can be analyzed like it. In the regulation case, the demand is represented by the private groups, who want to operate public utilities, and the supply by the legislators or regulators, who have the right to operate them. This article is currently considered as the origin of the discussion of the economic theory of regulation. Its most important contribution is to insert the analysis of political behavior in the economic analysis.

Some years later, Posner (1974) included other two theories to the theories of regulation debate. The first one was the public interest theory, when regulation is imposed by the government to correct market failures in order to benefit consumers. The other one is the capture theory, when interest groups seek to promote their private interests in the regulation process. As a result, public interest goals would be under the influence of the industries subject to regulation. 
In the 1980s and 1990s the process of regulation and privatization of public services started in various countries, due to neoliberal ideas and insufficient capacity for funding capital to infrastructures projects.

Privatization, according to the Library of Economics and Liberty, is the sale or long-term lease, of a state-owned enterprise to private investors. It was the choice in sectors, such as telecommunication and air transport, which development in technology allowed increasing in demand and changed the natural monopoly market into a competitive form, permitting private companies to become economic viable to provide public services.

Other sectors, with natural monopoly features like road and rail transport, preferred the use of concessions or Public Private Partnership (PPP) contracts, which is the granting of a long-term franchise under which the private sector finances, builds, and operates a major infrastructure project. It can be considered as an evolution of the franchise model.

Under this new scenario, the regulation also had to be adapted. The literature calls this phase regulatory reform. According to OECD (1997), regulatory reform refers to changes that improve regulatory quality, that is, enhance the performance, cost-effectiveness, or legal quality of regulations and related government formalities. For example, reform of economic regulation aims to increase economic efficiency by reducing barriers to competition and innovation, often through deregulation and use of efficiency-promoting regulation, and by improving regulatory frameworks for market functioning and prudential oversight.

On one hand reform can be very specific, as the revision of a specific law, or very broad, like a rebuilding of an entire regulatory regime and its institutions. On the other hand deregulation means a regulatory reform in order to complete or partial elimination of regulation in a sector to improve economic performance.

The concept of regulatory reform has changed over the years. The focus in the 1990s was on steps to reduce the scale of government, because the role of the state in the economy changed from provider to regulator. From 2005, the goal of regulatory reform is to enhance the abilities of the governments to adapt to change, through reducing regulatory burdens and improving the quality and cost-effectiveness of regulations (OECD 2005).

In several countries, the introduction of incentive regulation was an important part of the regulatory reform agenda. Under this approach, regulators use mechanisms to control the overall price level, which enable firms to take certain pricing decisions. Consequently, using private 
privilege information about operation, the company can reduce cost and increase profit. The incentive regulation was first used by U.K. telecommunications regulators in the 1980 s and it has been used worldwide, adopted in various forms and in several industries. For this reason, this method is reviewed in the following section.

\subsection{Incentive Regulation}

In general, incentive regulation is implemented by using regulatory methods to control the price level of the operator (Jamison et al., 2004). The aim of this mechanism is to provide more incentives for regulated firms to reduce costs, improve investment and service quality, stimulate operation efficiency and guarantee consumers benefits from productivity gains. The tariff regulation used does not consider only the economic balance, but also includes penalties and rewards for productivity increase and share these gains with users.

Over the years, governments have been applying many different tariff regulatory methods. However, it is not always easy to identify a particular type, since the transition from one regulatory model to another does not necessarily occur leaving behind all practices. In summary, it is possible to mention the main methods as follows.

\section{Rate of return regulation}

The rate of return regulation (ROR) was the most used tariff method for many years, because this method allows private operator recover incurred costs, including a rate of return on capital in accordance with the market. Under ROR regulation, the regulators analyze the company's operating expenses, overall depreciation, cost of capital and base rate, in order to estimate the total revenue needed for the company to cover its expenses. Basically, the method uses a calculation system for setting the prices that equal revenue with operating plus capital costs. Equation (1) presents how the required revenue is calculated:

$$
R R_{i, t}=O E_{\mathrm{i}, \mathrm{t}}+D_{i, t}+T_{i, t}+\left(R B_{i} * R O R_{i}\right) t
$$

Where:

$R R_{i}=$ required revenue

$O E_{\mathrm{i}}=$ operating expenses 
$D_{i, t}=$ depreciation expense

$T_{i, t}=$ tax expense

$R B_{i}=$ rate base

$R O R_{i}=$ rate of return

The ROR regulation method has been criticized in the literature for the fact that when the cost changed, the operator could ask for a new set of prices. Consequently, it does not provide incentives for cost saving and improvements in efficiency, which turns out to reward companies that have higher operating costs. This inefficiency, also called X-Inefficiency, is caused by the lack of competition (Jamasb and Pollitt, 2000).

As a result of the ROR regulation's deficiencies, other methods that use incentive-based regulation have been recommended, such as price cap, revenue cap, sliding scale, partial cost adjustment, yardstick competition, targeted incentive, and other hybrid schemes, which are revised as follows.

\section{Price Cap Regulation}

The application of the price cap system to utility regulation is a notable innovation in utility regulation and alternative to ROR regulation. This method was initially proposed in Littlechild 1983 Report and various versions of this method have since been adopted in the regulation of infrastructure and utility industries around the world.

The price cap regulation establishes the operator's overall price level by indexing the price level according to a price cap index. This index is obtained taking rate of inflation, determined by the Consumer Price Index (CPI) - or Retail Prices Index (RPI) in the United Kingdom - and deducting expected efficiency savings, called $X$-factor. Hence the method is also mentioned to as the "RPI - X" regulation. In other words, price cap regulation essentially separates the profits of the regulated utility from its costs by establishing a price ceiling and provides strong incentives to cut costs, unlike the ROR regulation, which limits the profit a company can earn on its investment.

For each revision period, 3 to 5 years on average, the price cap for each year is established based on the Retail Price Index (RPI) and an efficiency factor X. Consequently, the utility keeps the achieved cost during this period that prices remains fixed. For this reason, the application of price cap regulation resembles a rate of return regulation, but it still gives 
companies a better incentive to reduce costs. Equation (2) shows how the price ceiling is calculated.

$$
P_{i, t}=P_{i, t-1} *\left(1+R P I-X_{i}\right) \pm Z_{i}
$$

Where:

$P i, \mathrm{t}=$ price ceiling

$R P I=$ inflation index

$X_{i}=$ efficiency factor

$Z_{i}=$ exogenous effects

The equation shows that the price ceiling $\left(P_{t}\right)$ for a given period is determined based on the price ceiling of previous year $\left(\mathrm{P}_{\mathrm{t}-1}\right)$ adjusted by RPI minus the efficiency factor $\mathrm{X}$ established by the regulator. The $X$-factor reflects the expected efficiency improvements during the time period of the price adjustment. The $X$-factor might be calculated using different procedures, which will be studied in detail in section 2.5. The $Z$ is a correction factor adopted to adjust the price ceiling to the effects of exogenous extraordinary events affecting the utility's costs, like network expansion, and improved quality of service. In general, the adoption of the price index represents some degree of independence to companies in establishing the individual tariffs.

\section{Revenue Cap Regulation}

The revenue cap method is similar to the price cap regulation, but in this case it uses "RPI - X" to establish revenue caps, rather than prices. This model regulates the maximum allowable revenue that a utility can gain in a given period. Consequently, operator has an incentive to increase its profits by minimizing costs and keeping cost savings obtained during the period without revision. The revenue cap equation is presented in Equation (3).

$$
\bar{R}_{i, t}=\left(\bar{R}_{i, t-1}+C G A_{i} * \Delta \text { Cust }_{i}\right)^{*}\left(1+R P I-X_{i}\right) \pm Z_{i}
$$

Where:

$\bar{R}_{i, t}=$ authorized revenue

$C G A_{i}=$ customer growth adjustment factor (\$/customer)

$\Delta$ Cust $_{i}=$ change in the number of customers 
$X_{i}=$ efficiency factor

$Z_{i}=$ exogenous effects

In the revenue cap regulation, rather than price cap, the regulated utility company does not deal with quantity risk, indicated for cases when the operator does not have the control of the demand, such as electricity distribution. Revenue caps also relieve the regulator from the duty of overseeing price structures, which in some cases can be costly to regulate because they are complex. However, according to Jamasb and Pollitt (2000), revenue cap regulation has been criticized for limiting the powerful incentive to increase the sales and competition and has therefore been characterized as inefficient for cases when the operator has ability to manage the risks.

\section{Sliding Scale (ROR bandwidth)}

In the sliding scale or ROR bandwidth regulation approach, the utility's allowed rate of return can slide or move along a pre-specified dead-band. The utility rate of return is benchmarked against a reference ROR. In the interim of the regulatory lag, the ROR can fluctuate within the dead-band without any rate revisions. However, if the company's ROR is located outside the band it can trigger a mechanism of profit sharing or rate review. Equation (4) demonstrates the calculation of ROR bandwidth.

$$
r_{t}=r_{t-1}-\lambda\left(r_{t-1}-r^{*}\right)
$$

Where:

$r_{t}=$ allowed rate of return for the period under consideration

$r_{t-1}=$ actual return in the previous period

$r^{*}=$ benchmark rate of return

$\lambda=$ sharing parameter

The sharing parameter will be equal to zero if the allowed rate of return $r_{t-1}$ is within a pre-specified dead-band. However, if $r_{t-1}$ is below or above this reference band, the sharing parameter can take values between zero and one. 


\section{Yardstick Regulation}

The yardstick regulation approach is used to compare the performance of a regulated utility operator with a group of comparable utility companies. This method promotes indirect competition by comparing the efficiency and effectiveness of operators in different markets or performing in geographically separate markets, rewarding those operators that provide better performance. For instance, if all the companies face the same operating conditions, the mean of the costs of a group can serve as performance benchmark to compare the cost of a given utility firm or regulators can set prices based on this level. Therefore, each company has an incentive to reduce its costs. The calculation method can be seen in Equation (5).

$$
P_{i, t}=\alpha_{i} C_{i, t}+\left(1-\alpha_{i}\right) \sum_{j=1}^{n}\left(f_{j} C_{j, t}\right)
$$

Where:

$P_{i, t}=$ overall price cap for firm $\mathrm{i}$

$\alpha_{i}=$ share of firm's own cost information ( $\mathrm{p}=0$ representing pure yardstick regulation)

$C_{i, t}=$ unit cost of firm

$f_{j}=$ revenue or quantity weights for peer group firms $\mathrm{j}$

$C_{j, t}=$ unit costs (or prices) for peer group firms $\mathrm{j}$

$n=$ number of firms in peer group

This method was first proposed by Shleifer in 1985. From 1995 there were some publications presenting the complexities related with the application of the method and well succeed implementation of the method. In practice, the companies will face different operating conditions, and these must be taken into account when applying the method. Green and Rodríguez-Pardina (1999) present solutions, as estimating a regression equation that shows how the companies' costs vary with exogenous variables, like population density.

\section{Partial Cost Adjustment}

Another approach to incentive regulation is to provide cost minimization incentives. The partial cost adjustment regulation consisting of linking the price adjustments to changes in the utility's own costs observed in a reference year. The periodic revision of prices provides cost 
minimization incentive, because these adjustments are less than proportional to the changes in the real costs. Equation (6) shows the calculation using this approach.

$$
P_{i, t}=C_{i}^{*}+\lambda\left(C_{i, t}-C_{i}^{*}\right)
$$

Where:

$P_{i, t}=$ adjusted price in year $\mathrm{t}$

$C_{i}^{*}=$ reference cost per unit output

$C_{i, t}=$ the actual cost per unit in year $\mathrm{t}$

$\lambda=$ sharing parameter

\section{Menu of Contracts}

The menu of contracts method approach is used when the aim is to reduce the information asymmetry between the regulator and regulated utility company. Asymmetric information is the private information about the firm's ability to operate efficiently. Under this method the regulator offers to the utility company a menu of incentive plans that provide constant consumer welfare. The operator has to choose among the incentives alternatives. As a result, this flexible process reveals the firm welfare-enhancing preferences. The most difficult step of this method is to design an appropriate scheme, as it requires information about distribution of efficiency and reward.

\section{Targeted Incentive Regulation}

The targeted incentive approach seeks target specific aspects of the operation of the utility and reaches results that would not certainly come from the incentive approaches. Despite of the critiques related to distortion of efficient allocation of resources, targeted incentive regulation may be applied to promote a better quality of service, environmental standards, technical efficiency also demand side management measures.

\section{Hybrid Schemes}

The methods explained earlier are regularly seen combined to obtain better results. Then, hybrid schemes derive from integrating features of incentive regulation. For instance, incentive regulation schemes can be reinforced by targeted incentive schemes. In the same way, elements of benchmarking can support the method to set the X-factor used in the price cap formula. 
In conclusion, among the methods of incentive regulation, the price cap is broadly used to regulate contracts of public utilities. Then, in the following section, international experience concerning the use of price cap to regulate public-private partnership (PPP) arrangements in road sector is presented, which is the study area of this thesis.

\subsection{Experiences of Price Cap in Road Projects}

As well as other public utilities, a road concession is a grant by the public authority to a firm in order to construct, maintain and operate an infrastructure for a given period. In recent years, private participation in roads has been increasing worldwide for many reasons: the need to reduce government deficit and improve private financing, better identification of attractive investment projects and efficiency gains reached by private management.

According to Bousquet and Fayard (2001), two main characteristics are linked to concessions: risk transfer from the concession authority to the concession company and operation of the infrastructure, which involves both responsibility for a construction programme and a long-term service of maintenance and users assistance.

A concessionaire is remunerated through the form of a price paid by the users or the public authority, usually according to the demand. Subsequently, the concessionaire will use the revenue to cover the investments and services required in the contract.

European experience in the area of road concessions are recognized worldwide, but various countries apply a diversity of systems. For example, regarding the regulatory regime, formulas for determining toll charges and its evolution also differ throughout Europe. This aspect is of great interest for regulators because each formula corresponds to a particular level of risk sharing and can affect project feasibility.

As seen previously, price cap is the form of incentive regulation most used to public utilities. For this reason, in this section we investigate international experience in price cap regulation in road concessions in many countries, such as Italy, Spain, Chile, France and Peru. Brazil also use price cap regulation and its features are presented in the section 4.3 , where the Brazilian road concession program is describe in detail, as this country is the focus of the case study of this thesis. 


\section{Italy}

Between 1960 and 1975 the first roads were granted in Italy to public owned firms (Benfratello, lozzi and Valbonesi, 2009). During the 1990s a reformulation of the industry started, including a change in the structure of the ownership of concessionaires, by replacing government with private firms. This transformation results in the creation of a regulatory framework in 1996 and introduces a form of incentive regulation.

In 1996 the price cap mechanism was implemented for tariff adjustments, according to Equation (7).

$$
\Delta P \leq \Delta R P I-X+\beta \Delta Q
$$

Where:

$\Delta P=$ toll price adjustment

$\triangle R P I=$ change in the retail price index

$X=$ productive factor

$\beta \Delta Q=$ change in a composite quality index $Q$, multiplied by a scaling factor $\beta$

The parameters of this formula are reviewed every five years. The X-factor is set on the basis of the expected productivity gains and it takes into account many factors: return on capital, investment plans, objectives of productivity variations and expected demand changes. According to Borgia (2006), the purpose of the X-factor is to stimulate the concessionaires to pursue policies to enhance efficiency. The negative effect - represented by the negative sign in the formula - is only achieved if concessionaires do not improve their productivity more than the expected targeted amount of company's productivity.

The quality factor $Q$, is a weighted average of two specific quality indicators: number of accidents (per $\mathrm{km}$ ) and the roughness of the surface. The factor $\beta$ is a coefficient and its value is related to the $\mathrm{Q}$ factor average of the last five years. Then, quality index intends to measure the quality of the road based on safety level and structural condition of the pavements. Of course this factor omits many features that ultimately affect the quality of service, as congestion or toll charge system. However, it is important to note that, despite its weakness, the quality factor was designed with the correct aim and objective, giving a quality premium - higher toll prices to higher increase in the quality -, in accordance with the price cap principles. 
As the regulatory framework was modified in 2004 and 2007, the adjustment formula suffered a series of changes with the introduction or elimination of its parameter, adapting to the new legislation. In addition, at this time the price cap regulation also received a lot of criticism, as the scarce of transparency in the interpretation of the X-factor and that the extra profits gained by the concessionaire thanks to the increased efficiency in productivity were not transferred to the users in tariff.

After 2008, the price cap changed to a new simplified formula (see Equation (8)).

$$
\Delta P \leq \alpha \times \Delta R P I
$$

This new formula consists of a fixed percentage of $70 \%$ of the RPI, plus the full remuneration of investments included in the periodic financial plans. It no longer considers the $X$ factor as representing the efficiency gains, now it is only a pure accounting function in order to remunerate the investments. Despite the fact that it is still called as a price cap regime, this new formula had substituted the previous approach completely removing incentives, which has also been criticized.

\section{Spain}

Spain has a long experience in road concession contracts, granting its first contract to private sector in 1967 (Baeza and Vassallo, 2010). To regulate toll increases, the Toll Motorway Concession Law 8/1972 was updated in 2000, when a passed the Law 14/2000.

Regarding the economic regulation of the contract, maximum toll rates are established in the concession contracts, and, until 1990, there was not an automatic price adjustment rule. At that time, the concessionaires have the right to claim an adjustment but the amount of increase was determinate from a bilateral negotiation between the government and the firm (Albalate, Bel and Fageda, 2009).

In 1990, a national law established a general rule for yearly price adjustments, using the following formula: $C=0.95$ ( $\triangle \mathrm{RPI}$ mean), where $\mathrm{C}$ stands for change in price, and RPI is expressed in percent.

In 2000, when private toll motorways were increasing due to new concession awards, the Law $14 / 2000$ changed the adjustment formula to a price cap regulation, according to Equation (9). 


$$
\begin{gathered}
P_{t}=P_{t-1} \times(1+R P I-X) \\
X=\left(\frac{1}{100}\right)\left(\frac{A D T_{\text {real }}-A D T_{\text {forecast }}}{A D T_{\text {forecast }}}\right)
\end{gathered}
$$

Where:

$P_{t}=$ toll price in year $\mathrm{t}$

ADT $=$ Average Daily Traffic

As general rule: $0 \leq \mathrm{X} \leq 1$

It is worth to note that the $\mathrm{X}$-factor in this price cap formula represents the deviation between the expected and real traffic (see Equation (10)). Therefore, the price cap regulation as used in Spain only introduces a mechanism to reduce toll increases if real traffic is higher than expected, in order to avoid concessionaires' windfall profits in case of high actual traffic, and sharing unexpected earning with users.

However, this $\mathrm{X}$-factor formulation is not in accordance with literature theory, because it does not consider the efficiency gains of the concessionaire or features like service and quality. In addition, this $\mathrm{X}$-factor formula can also be perceived as an oppose incentive to road productivity, whereas in an incentive regulation the $X$-factor should be reduced (increasing prices) as higher is the productivity (traffic).

\section{Chile}

Among the Latin America countries, Chile has a mature and successful highway concession system (Engel, Fischer and Galetovic, 2009). In 1991 the Chilean congress passed a law that allows the government to concession different public utilities. By the end of 2007, 26 roads had been granted, including all main highways.

Road concession in Chile is characterized by a flexible legislation, so the contract can be adapt to each project. For example, the tendering can include many variables as: user fees, a subsidy from the state, the term of the concession, income guaranteed by the state, revenue paid by the franchise holder to the state for preexisting infrastructure, risk assumed by the bidder during the construction or operation stages, quality of the technical offer, fraction of revenue shared with the state, and total income from the concession. 
The annual adjustment of the road concession projects are based on $100 \%$ of the RPI. In addition, according to Vassalo, Saldaña, Sierra and Baeza (2010), a variable factor related to the road safety is added in the adjustment formula, up to a maximum of $5 \%$. This mechanism intends to incentivize the concessionaire to increase investment in road elements, such as pavement and road sign, in order to reduce accidents.

However, as the factor is an addition in the adjustment formula, rather than a subtraction, and there is no negative economic effect, the concessionaire has the option of do not increase investments, and consequently not pursue better safety results.

The economic regulatory model of Chile can be consider as a price cap scheme, but with the X-factor based only on safety aspects, instead of efficiency improvement. Moreover, the $X$ factor acts as an additional benefit for private firms, which can lead to the concessionaire not to strive to reduce accidents.

\section{Other countries}

In many European countries, as France, Norway and Portugal, the evolution of the toll rate is proportional to the inflation (ASECAP, 2006). Regarding the formula, this model of toll adjustment can be considered similar to the price cap regime, but setting the $\mathrm{X}$-factor as zero. In other words, we can say that these regulators consider that there is not productivity gain in the industry to be shared with the users.

Peru is also an example that applies only the RPI in the toll adjustment for road concessions. However, they use the complete principles of price cap method - and calculate the X-factor - for other sectors, as telecommunications, ports and airports. For this reason, Flor and Rojas (2007) investigated this issue and concluded that the efficiency gains in the Peruvian road concessions are positive. Therefore, when regulators assume the $\mathrm{X}$-factor equal to zero, it could result in extra profits for the firms and burden the users.

Although there is a consensus that price cap regulation is better than others regulatory methods, the success in its application depends on the correct setting of the X-factor, which represents the incentive of this regulatory scheme. Thus, it is fundamental that regulators devote attention to the method to set the X-factor, which is a key aspect in the application of price cap regime. As the study of the methodology to set the X-factor is the contribution of this thesis, the following chapter focuses on the features of the $\mathrm{X}$-factor and its calculation. 


\section{$2.5 \quad \mathrm{X}$-Factor}

As previously seen, incentive regulation can be applied using many methods. However, the most used form to regulate public utilities involves the application of price cap, because it can provide incentives to the regulated firm to reduce production costs and improve its operating efficiency. Therefore, the main incentive of price cap regulation is when firms can make their costs increase less than the RPI-X increase, so they can earn the difference. As a result, they raise the rate of return of the capital also increase profit.

By definition, the $X$-factor represents the expected gains due to efficiency improvements that regulated firm will have during the time period of price adjustment. In the general practice, the price adjustment process should be participative. Thus, when setting the $\mathrm{X}$-factor, regulators should receive suggestions from stakeholders and inform about decisions. The typical time period between price adjustments is five years.

In order to foster incentive, the X-factor must be set correctly, because it will enable firms to earn a fair rate of return on capital if they achieve an efficient level of costs. In addition, using an inadequate value for $X$-factor can affect project feasibility. If it is too high, tariff may not cover real costs and companies might lose money and could have financial problems to carry out the project, and probably the government has to intervene or rescue the concession. The contrary is also harmful, if $X$-factor is too low, tariff can be significantly higher than actual costs and firms can gain excessive profit, which will not be efficient from public interest view. Both scenarios are not desirable to promote incentive in regulatory regimes.

The price cap formula "RPI - X" seems to be very simple at first sight, but its implementation in practice is very complex, mainly because of the task of setting the $X$-factor. The first element, RPI, refers to the overall rate of inflation in the economy, which is a very common index, largely used in the economy. The X-factor reflects the industry productivity growth, which is much more difficult for regulators to set, especially considering that firms are operated by private entities.

Based on literature review, authors generally agree that productivity growth can be set based on the two central elements of the Total Factor Productivity (TFP) measures, that is, the inflation in the operator's input prices relative to the average firm in the economy (inflation offset) and the ability of the operator to gain efficiencies (changes in prices relative to its costs) relative to the average firm in the economy (productive offset). In summary, the X-factor is intended to 
capture the difference between the operator and the average firm in the economy with respect to inflation in input prices and changes in productivity (Jamison et al., 2004).

Concerning the calculation to set X-factor, Bernstein and Sappington (1999) provide a theoretical formulation for its implementation, based on the firm's profits (difference between revenues and costs). Equation (11) shows that the X-factor represents an offset and is the sum of: the difference in total factor productivity growth rates in the regulated industry and the rest of the economy $\left(\dot{T}-\dot{T}^{E}\right)$; and the difference in input price growth rates between the rest of the economy and the regulated sector $\left(\dot{W}^{E}-\dot{W}\right)$. Note that the regulated firm's total factor productivity growth $(\dot{T})$ is the difference between the growth rate of the firm's outputs and the growth rate of its inputs.

$$
X_{0}^{b}=\left(\dot{T}-\dot{T}^{E}\right)+\left(\dot{W}^{E}-\dot{W}\right)
$$

This approach has been widely used in the United States, so it is known as the American model. However this is a primarily approach because it sets the $\mathrm{X}$-factor for a particular regulated sector using the whole economy as benchmark. In addition, it is required more specific analysis to calculate productivity gains among different companies within the regulated sector, regarding also aspects of the quality of service.

Diewert and Nakamura (2002) propose the Total Factor Productivity Growth (TFPG) as a mechanism to measure productivity. Equation (12) shows that TFPG is equal to the rate of margin growth $(m)$ times the rate of growth of input prices $(w)$ divided by the rate of growth of output prices $(p)$. Note that if the margins are zero, then TFPG reduces to $\left(w_{1}^{t} / w_{1}^{S}\right) /$ $\left(p_{1}^{t} / p_{1}^{s}\right)^{1}$.

$$
T F P G=\left[\left(1+m^{t}\right) /\left(1+m^{s}\right)\right]\left[\left(w_{1}^{t} / w_{1}^{s}\right) /\left(p_{1}^{t} / p_{1}^{s}\right)\right]
$$

In economic theory, the productivity can be measured by these formulas. In practice, there are alternatives methodological approaches to measure the $X$-factor by index number. Ondrej and Jiri (2012) indicate the Malmquist, Törnqvist and Fisher indices as the most commonly used. The first one, Malmquist index, is based on distance function, which requires optimization

\footnotetext{
${ }^{1} t$ and $s$ refer to two time periods. However, in the literature they are also used to refer to two firms in the same time period.
} 
problem solving, as data envelopment analysis (DEA) or regression methods, which measure the distance from a real, but unknown frontier. The other ones, Törnqvist and Fisher indices, require data about input and output prices, and can be derived directly from empirical data.

Under the approach of index number, a simple method can be considered at first in order to illustrate how to set the X-factor (see Equation (13)). Primary regulator should define productivity using a traditional ratio measure, for example, in the case of air transport, number of passengers/cost. Then, considering a 5 years revision period, the regulator has to gather information about how the industry has improved its productivity in the past years (TFPG ${ }^{I}$, e.g. $1 \%$ per year) and how is the productivity of the firms compared to others, calculating the difference between the productivity of the best firm and the firm under analysis $\left(T F P G_{B}^{F}-\right.$ $T F P G_{i}^{F}$, eg. 10\%). Finally, given this information, the regulator has to add the expected improve of the industry (e.g. 1\% per year), plus the difference between the productivity of the best firm and the firm under analysis divided by the time period (e.g. $2 \%$ per year). It results in the X-factor at $3 \%$ per year for the next 5 years.

$$
X_{i}=T F P G^{I}+\left[\left(T F P G_{B}^{F}-T F P G_{i}^{F}\right) / n\right]
$$

Where:

$X_{i}=\mathrm{X}$-factor of the firm under analysis

$T F P G^{\mathrm{I}}=$ Annual index of the Total Factor Productivity Growth of the industry in the period $T F P_{B}^{F}=$ Annual index of the Total Factor Productivity of the best firm in the period $T F P_{i}^{F}=$ Annual index of the Total Factor Productivity of the firm under analysis in the period $n=$ time period between revisions

Although this process seems very easy, it can have some problems in practice because of the differences between firms. Coelli et al. (2003), describe some issues: firms can differ in terms of average customer sizes and/or customer density, which would result in different productivities; some firms can be larger than others and therefore would be able to achieve economies of scale; input prices can differ across years or across firms, especially if they work in different regions; in the last five years may have occurred changes, in regulatory regime for example, that would affect productivity; some firms can not be able to achieve the industry average level of productivity growth, for example, if some concession is located in areas with low population growth. 
Another important issue when setting the $X$-factor is that regulators should continuously encourage the firms to pursue more efficiency. For instance, if the regulator assigns a $X$-factor equal the same amount of increase the firm had in recent years, it can lead to firm do not attempt to increase efficiency because it will result in a large $X$-factor in the future. Thus, regulator should also consider using market data, from a benchmark study of other firms, in order to maintain the incentives.

Regulators can find a solution for many of these problems pursuing two aspects: access good quality data and use more sophisticated productivity measurement methods. Regarding data reliability, Jaskow (2013) draws attention to the importance of information gathering, auditing, and accounting institutions, in order to an efficient implementation of incentive regulation mechanisms. An adequate design and manage of these institutions supports the reliability of the process and must be considered as a part of the foundation for implementing incentive regulation. 

3. MEASURING EFFICIENCY IN PUBLIC UTILITIES 

As seen in the previous chapter, when implementing some type of incentive regulation in a public utility, regulators should measure the efficiency. In the case of the price cap regulation, it uses the formula "RPI - X" to adjust the tariff. The X-factor represents a price reduction, with the aim to share the operating efficiency gains of the firm with users. Consequently, when regulator set the X-factor a crucial variable is the potential for productivity growth in the regulated firm. Coelli et al. (2003) summarize two essential information that regulators should have to calculate the X-factor: the rate of productivity growth in this industry in recent years and the extent that this firm is operating below best practice in the industry.

For this reason, in this chapter it is studied the methods to measure the efficiency in public utilities. This chapter starts explaining the concepts of productivity and efficiency. Then, it is presented the methods to measure efficiency, divided into parametric and non-parametric methods. Finally, it is presented a literature review of the methods that are most used to measure the efficiency in transport sector.

\subsection{Definition of Productivity and Efficiency}

First it is important to clarify the concepts often used, as productivity and efficiency (for a more detail explanation, see Coelli et al., 2005). Inputs are considered as the material, labour and capital used and output is relative to the product. From this standpoint, the productivity is the ratio of outputs to inputs. For example, a useful productive measure for an air company about its selling performance is the ratio of occupied seats to aircraft capacity.

That simple example has only one input and one output. When there is more than one input or more than one output we need to use weights to construct an output index and an input index. Equation (14) shows the formula of the total factor productivity (TFP) index, which refers to a productivity measure involving several factors of production.

$$
T F P=\frac{\sum_{m=1}^{M} a_{m} Y_{m}}{\sum_{k=1}^{K} b_{k} X_{k}}
$$


Where:

$T F P=$ total factor productivity

$Y_{m}=$ output

$X_{k}=$ input

$a_{m}, b_{k}=$ weights that reflect the relative importance of the various input and outputs

Of course, larger values of this ratio are associated with better performance. This method can also be used for making performance comparison. For instance, the performance of a firm can be compared to its performance in previous years or even to the performance of another firm working in the same sector. So, efficiency is the comparison of the productivity results by similar firms or at different time periods.

In general, a firm can be considered more productive than other because have taken decision that optimize the use of inputs. Because of this, in the efficiency analysis it is used to call firms, or the element under examination, as Decision Making Unit (DMU).

Therefore, efficiency is a relative concept. We can say a firm is efficient when it provides more products than other, without using more resources. This concept can be illustrated by the Figure 3. The line $O F^{\prime}$ represents a productive frontier that defines the relationship between input and output in a single production process, in which a single input is used to produce a single output. This frontier represents the maximum output to each input level. Firms can operate on the frontier, so they are considered technically efficient (e.g. points $B$ and $C$ ), or beneath the frontier, which are considered technically inefficient (e.g. point A). It is worth to note that all points between the production frontier $O F^{\prime}$ and the $\mathrm{X}$-axis (inputs), called feasible production set, are feasible combinations of input-output.

Inefficiency is measured by the distance between the point and the frontier. There are two basic ways that a firm can achieve technical efficiency. The first one, called input-oriented, is when a firm reduces its uses of inputs to produce a particular output level (e.g. move from point $A$ to $\mathrm{C}$ ). The second one, called output-oriented, refers to a firm achieves maximum output given a set of input (e.g. move from point $A$ to $B$ ). 


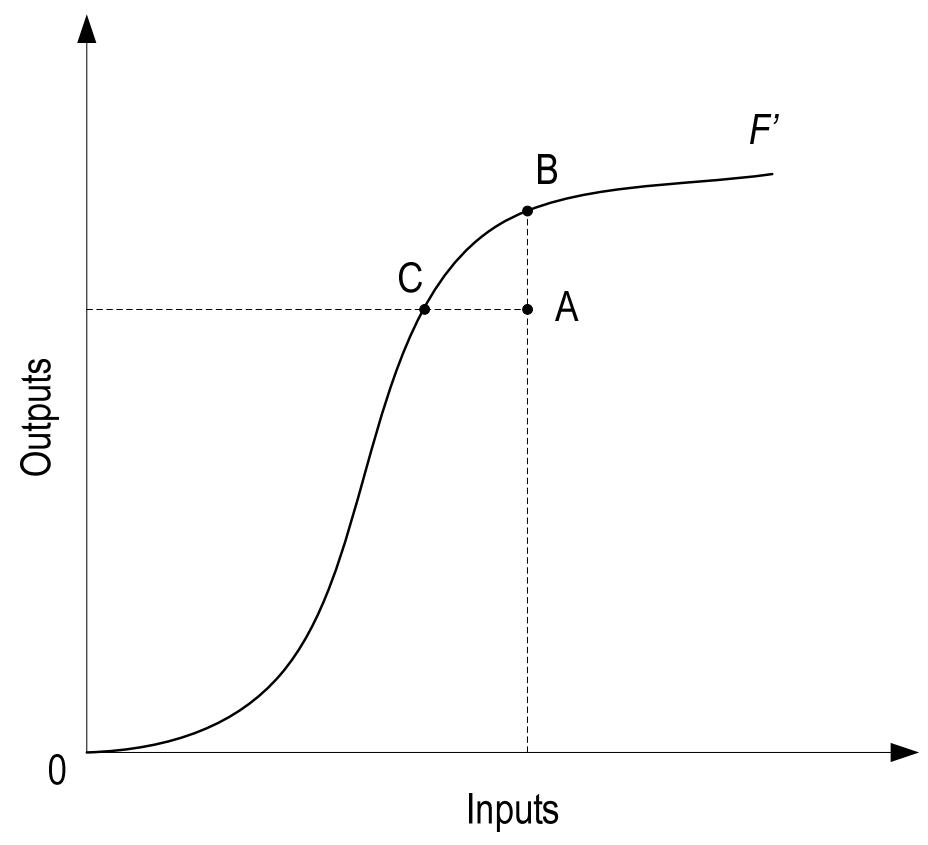

Source: Coelli et al. (2005)

Figure 3 - Production Frontier and Efficiency

It is also important to say that the economy efficiency measure combine two components: technical and allocative efficiency. Technical efficiency, as seen before, refers to the ability of a firm to minimize inputs proportionally to produce a given set of output. This analysis involves physical quantities and technical relationship. The allocative efficiency refers to the ability to combine inputs and outputs in optimal proportions, achieving minimum cost or maximum profit, given the prices of inputs and outputs and the production technology. It can be used when information on prices is available.

However, in general, when setting the $\mathrm{X}$-factor regulators should not consider the allocative efficiency to compare performance between firms (Coelli et al., 2003). The allocative inefficiency mostly comes from market distortions which are not under firms' control, so firms will not be able to improve efficiency during the time period between revisions. For example, the wages, that is, the price of the input labor force, in most cases are stipulated by labor unions agreements. The same can occur with fuel, which can be an important input for the production of a particular firm, and its price is not under control of the firm. In addition, input prices are not often available.

Another reason is that usually regulated firms do not have the right to change their output mix. For instance, the capital intensity of network firms is often largely determined by population density. In the case of a regulated firm of a public utility for energy supply, they can not decide to 
give up serving a set of small customers that is far from the core concentration of users, in order to maximize the profit. For this reason, regulators tend to focus only on the estimation of technical efficiency to set the $X$-factor of a firm.

The analysis that includes the time component, comparing productivity through time, is called technical change. This involves advances in technology that may be represented by an upward shift in the production frontier. Figure 4 shows the movement of the production frontier from $0 \mathrm{~F}_{0}^{\prime}$ in the period 0 to $0 \mathrm{~F}_{1}^{\prime}$ in period 1.

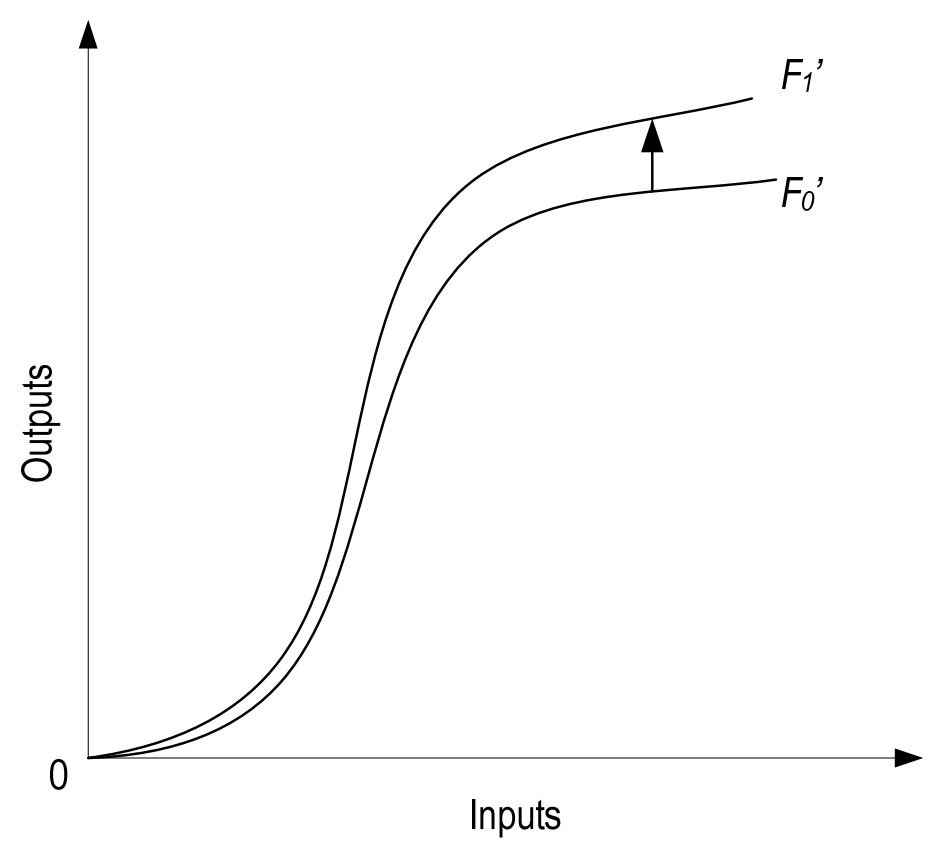

Source: Coelli et al. (2005)

Figure 4 - Technical change between two periods

According to Equation (13), which illustrates how to set the X-factor, the efficiency improvement target for a firm on the frontier, an efficient one, should be equal to the historical level of technical change (frontier shift), which represents the productivity growth in this industry in recent years. For the firms below the frontier, those inefficient ones, they should achieve the technical change plus some technical efficiency improvement, related to the extent that this firm is operating below best practice in the industry.

Therefore, the information about productivity is a requirement to evaluate the efficiency of regulated firms. In order to obtain this information, it is necessary to construct a production frontier. In the following section, we provide an overview of the methods used to measure productivity and efficiency. 


\subsection{Efficiency Measurement Methods}

Overall in the literature, the efficiency measurement methods are divided into two groups: parametric methods, the ones that use a production function; and non-parametric methods, the ones that do not use a production function. Figure 5 illustrates the main difference in the construction of the production frontier through parametric and non-parametric methods. The production line of the parametric methods is represented by the "regression line" in Figure 5. It goes through the average of data points and the firms above this line can be consider as efficient and the firms below this line as inefficient. The magnitude of the inefficiency can be estimated by the deviation from the line.

In the non-parametric methods, the production frontier is represented by the "efficient frontier" in Figure 5. It is designed by the best performance firms and the firms on the frontier are considered as efficient, and the firms below the frontier as inefficient. The inefficiency is measured by the deviation from the frontier. From Figure 5 we note that the fundamental difference between the approaches is that benchmarks set by non-parametric methods (e.g. DEA) depend on best performance of firms, and using parametric methods (e.g. regression analysis) depends on the average performance of the firms.

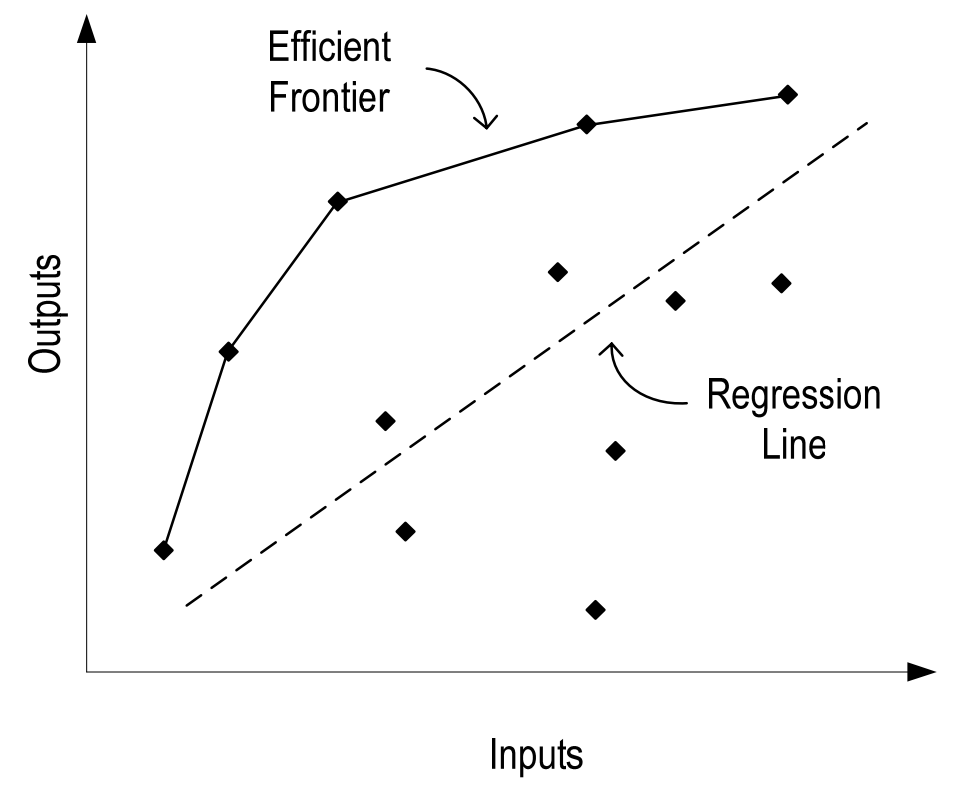

Source: Adapted from Cooper, Seiford and Tone (2007).

Figure 5 - Comparison of non-parametric and parametric approach 
Based on this classification, this section presents the most used models of parametric and non-parametric methods to measure the efficiency in the regulatory sector.

\subsubsection{Parametric Methods}

The parametric approach uses an econometric methodology to estimate the production function. From regression analysis, it is created the production function and then estimates the efficiency of the firms, comparing the performance of individual firms with the frontier.

The advantage of this approach is that it attempts to account for the effects of data noise, like data errors and omitted variables and one can use standard statistical tests, such as t-tests, to test the significance of variables included in the model. The main disadvantage is that econometric models need a priori assumptions about the relationship between the inputs used and the outputs produced. Moreover, the requirements of econometric techniques, in order to estimate the unknown parameters of the function, can result in econometric difficulties (e.g. multicollinearity).

According to Coelli et al. (2003), the stochastic frontier analysis (SFA) is the most common econometric production model applied to measure the efficiency of regulated firms. It is defined as Equation (15) (Kumbhakar and Lovell, 2000).

$$
Y_{i}=f\left(x_{i}, \beta\right) e^{v_{i}} \times T E
$$

Where:

$Y_{i}=$ outputs of the firm

$f\left(x_{i}, \beta\right)=$ the production frontier

$x_{i}=$ vector of inputs used

$\beta=$ vector of unknown parameters to be estimated

$e^{v_{i}}=$ error term

$T E=$ technical efficiency

According to Equation (15), technical efficiency $(T E)$ is measured by the ratio of production $Y_{i}$ to the best achievable target, defined by the production function $\left(f\left(x_{i}, \beta\right) e^{v_{i}}\right)$, leaving room for random shocks and measurement error. 
A number of different functional forms are used in the literature to model production functions, as Cobb-Douglas (linear logs of outputs and inputs), quadratic (in inputs), normalised quadratic and translog function (generalisation of the Cobb-Douglas function). According to Markovits-Somogyi (2011b), in the transport sector Equation (15) is frequently estimated using a translog function form, as Equation (16).

$$
\ln y=\beta_{0}+\sum_{n=1}^{N} \beta_{n} \ln x_{n}+\frac{1}{2} \sum_{n=1}^{N} \sum_{m=1}^{N} \beta_{n m} \ln x_{n} \ln x_{m}+v_{i}
$$

Satisfying the identifying condition $\beta_{m n}=\beta_{n m}$ for all $n$ and $m$, and where:

$y=$ dependent variable

$x_{n}=$ independent variable

$\beta_{n}, \beta_{n m}=$ unknown parameters to be estimated

$v_{i}=$ error term

FRONTIER is a computational program, designed by Coelli (1996), specifically to estimate the stochastic frontier (SFA) and the model of technical inefficiency effects. It uses simultaneous maximum likelihood estimation (MLE).

\subsubsection{Non-parametric Methods}

Conversely, the non-parametric approach does not use econometric estimation of a parametric function to estimate efficiency. The two major non-parametric methods used are: total factor productivity (TFP) indices and Data Envelopment Analysis (DEA).

Regarding the TFP methods, they use index numbers. An index number is defined as a real number that measures changes in a set of related variable. It can be used for comparison over time or space or both. Therefore, index numbers are used to measure price and quantity change over time, and to measure different levels across firms or regions. For example, the Consumer Price Index $(\mathrm{CPI})$ is a widely known index number to measure the changes in price of a range of consumer goods and services.

In the case of productivity measurement, an index number may be used to compare prices or quantities of output produced and inputs used by a firm over time or across firms. Index 
numbers can be used to measure productivity changes directly or also to create intermediate data series, which will be used in other models, like SFA and DEA.

An index number that has been used in many TFP studies is the Törnqvist index (Törnqvist, 1936). It is used in measuring changes in output and input prices in production over two time periods. The weights are given by the simple average of the values in the periods under analysis and it is usually applied in its log-change formula.

Törnqvist index can be calculated from observed empirical data without having to estimate the unknown production frontier. However, this index is calculated based on weighted observed prices of input and output factors. This aspect raises a main problem for regulators, who generally do not have good quality data about prices of output and input.

Malmquist productivity index is a TFP index which requires the construction of the production frontier using econometric or mathematical programming methods, like SFA and DEA, to estimate the efficiency change over time. This is the TFP measurement method most used by regulators. It was first proposed by Caves, Christensen, and Diewert (1982). This index is the geometric mean of the efficiencies for the same firm observed at two different time periods in relation to a given technological frontier. Equation (17) shows the output-oriented formula.

$$
M\left(x_{t}, y_{t}, x_{t+1}, y_{t+1}\right)=\sqrt{\frac{D_{t}\left(x_{t+1}, y_{t+1}\right)}{D_{t}\left(x_{t}, y_{t}\right)} \times \frac{D_{t+1}\left(x_{t+1}, y_{t+1}\right)}{D_{t+1}\left(x_{t}, y_{t}\right)}}
$$

Where:

$M=$ Malmquist productivity index

$D_{t}=$ efficiency score for a given firm in period $\mathrm{t}$

$x=\mathrm{a}$ vector of inputs

$y=$ a vector of outputs

The main advantage of the Malmquist productivity index method is that it is possible to decompose the index into two components, one measuring efficiency change and the other measuring technical change. Efficiency change, also called "catching up", is measured by the distance to the production frontier, while technical change, also called "frontier shift", measures the shift in the frontier in two time periods. 
The rearrangement of Equation (17), by Färe et al. (1994), results in the efficiency change (see Equation (18)) and technical change (see Equation (19)).

$$
\begin{gathered}
\text { Efficiency change }=\frac{D_{t+1}\left(x_{t+1}, y_{t+1}\right)}{D_{t}\left(x_{t}, y_{t}\right)} \\
\text { Technical change }=\sqrt{\frac{D_{t}\left(x_{t+1}, y_{t+1}\right)}{D_{t+1}\left(x_{t+1}, y_{t+1}\right)} \times \frac{D_{t}\left(x_{t}, y_{t}\right)}{D_{t+1}\left(x_{t}, y_{t}\right)}}
\end{gathered}
$$

Where:

$D_{t}=$ efficiency score for a given firm in period $\mathrm{t}$

$x=\mathrm{a}$ vector of inputs

$y=$ a vector of outputs

Another non-parametric approach is the Data Envelopment Analysis (DEA), first used by Charnes, Cooper and Rhodes (1978). This method constructs a production frontier using mathematical programming. It creates a benchmark from the data of the sample available and compares all of the firms to the best performing frontier. Therefore it is not necessary to make previous assumptions about the characteristics of the production or service.

DEA is extensively used by regulators in order to estimate efficiency, also in the transport sector. In the DEA analysis, generally it is used the term Decision Making Unit (DMU) for the firms under evaluation, because it is a broad and flexible term that covers any such entity able to be evaluated, as part of a collection of entities that utilizes similar inputs to produce similar outputs.

The efficiency is measured by the optimization of the ratio of sum of the weighted output, also called "virtual output", to sum of the weighted input, also called "virtual input" (see Equation (20)). The fractional programming problem is solved for each DMU in order to obtain values for the weights of input $\left(\mathrm{v}_{\mathrm{i}}\right)$ and output $\left(\mathrm{u}_{\mathrm{j}}\right)$, as variables. The objective is to obtain weights that maximize the efficiency of the DMU being evaluated $\left(\mathrm{DMU}_{0}\right)$, with the constraints that the ratio of "virtual output" vs. "virtual input" should not exceed 1 for every DMU (see Equations (21) and (22)). 


$$
\operatorname{Max} \theta_{0}=\left(\frac{\sum_{j=1}^{\mathrm{s}} \mathrm{u}_{\mathrm{j}} \mathrm{y}_{\mathrm{j} 0}}{\sum_{\mathrm{i}=1}^{\mathrm{r}} \mathrm{v}_{\mathrm{i}} \mathrm{x}_{\mathrm{i} 0}}\right)
$$

Subject to:

$$
\frac{\sum_{j=1}^{s} u_{j} y_{j k}}{\sum_{i=1}^{r} v_{i} x_{i k}} \leq 1, \forall k
$$

$$
\mathrm{v}_{\mathrm{i}}, \mathrm{u}_{\mathrm{j}} \geq 0, \forall \mathrm{i}, \mathrm{j}
$$

Where:

$\theta_{0}=$ Efficiency of the DMU being evaluated

$r=$ number of inputs

$s=$ number of outputs

$\mathrm{v}_{\mathrm{i}}=$ input weight, where $i=1,2, \ldots, r$

$\mathrm{u}_{\mathrm{j}}=$ output weight, where $j=1,2, \ldots, s$

$\mathrm{x}_{\mathrm{i} 0}=$ input data for DMU being evaluated

$\mathrm{y}_{\mathrm{j} 0}=$ output data for DMU being evaluated

$\mathrm{x}_{\mathrm{ik}}=$ input data for $\mathrm{DMU}_{\mathrm{k}}$, where $k=1,2, \ldots, n$

$\mathrm{y}_{\mathrm{jk}}=$ output data for $\mathrm{DMU}_{\mathrm{k}}$, where $k=1,2, \ldots, n$

$n=$ number of DMUs

In order to simplify the calculation of the fractional program, it can be converted into a linear program (LP). Therefore, it is necessary to change the constraints (see Equations (24) and (25)). Equation (23) presents the formulation of a linear programming problem of an inputoriented model with an assumption of constant return to scale (CRS). Alternative assumptions regarding orientation and returns to scale are discussed in section 5.4 . 


$$
\operatorname{Max} \theta_{0}=\sum_{j=1}^{s} u_{j} y_{j 0}
$$

Subject to:

$$
\begin{gathered}
\sum_{\mathrm{i}=1}^{\mathrm{r}} \mathrm{v}_{\mathrm{i}} \mathrm{x}_{\mathrm{i} 0}=1 \\
\sum_{\mathrm{j}=1}^{\mathrm{s}} \mathrm{u}_{\mathrm{j}} \mathrm{y}_{\mathrm{jk}}-\sum_{\mathrm{i}=1}^{\mathrm{r}} \mathrm{v}_{\mathrm{i}} \mathrm{x}_{\mathrm{ik}} \leq 0, \forall \mathrm{k} \\
\mathrm{v}_{\mathrm{i}}, \mathrm{u}_{\mathrm{j}} \geq 0, \forall \mathrm{i}, j
\end{gathered}
$$

Where:

$\theta_{0}=$ Efficiency of the DMU being evaluated

$r=$ number of inputs

$s=$ number of outputs

$\mathrm{v}_{\mathrm{i}}=$ input weight, where $i=1,2, \ldots, r$

$\mathrm{u}_{\mathrm{j}}=$ output weight, where $j=1,2, \ldots, s$

$\mathrm{x}_{\mathrm{i} 0}=$ input data for DMU being evaluated

$\mathrm{y}_{\mathrm{j} 0}=$ output data for DMU being evaluated

$\mathrm{x}_{\mathrm{ik}}=$ input data for $\mathrm{DMU}_{\mathrm{k}}$, where $k=1,2, \ldots, n$

$\mathrm{y}_{\mathrm{jk}}=$ output data for $\mathrm{DMU}_{\mathrm{k}}$, where $k=1,2, \ldots, n$

$n=$ number of DMUs

It is worth to note that it is necessary to solve one linear program for each DMU. Consequently the number of linear programs to solve is equal to the number of DMU. However, now this issue is not a drawback of the method, because there are some computer programs available to solve the linear program. As an example, we can cite two softwares that have free version: MaxDEA (www.maxdea.cn), and DEAFrontier (www.deafrontier.net). 
As we have seen, every method to measure the efficiency has its advantages and drawbacks. Hence, regulators should select the method they prefer to evaluate efficiency of regulated firms considering the main factors: data availability, the importance of data noise and the intended use of the results.

In general, regulators use both DEA and SFA approaches, to define the production frontier. In order to summarize, Table 1 shows a comparison of the main features of both methods.

TFP indices are not so common because they only consider past information in their analysis, also require information about cost. However, TFP indices are usually employed as complement of frontier methods, like using DEA technique to estimate technical efficiency and using Malmquist productivity index to measure productivity change over time.

Many studies have been conducted in order to compare the methods discussed previously. The review of the literature conduct to the conclusion that using DEA or SFA methods - with the same set of data to estimate the production frontier under the same assumption of return to scale - should produce similar results and both can be applied to evaluate efficiency of transport systems (Coelli et al., 2003 and Markovits-Somogyi, 2011b).

According to publications from experiences of regulators to estimate efficiency of regulated firms in order to set the X-factor, DEA is even more used than SFA. It occurs probably because DEA methods are easy to draw on diagrams, easy to calculate, and until recently SFA could not accommodate multiple outputs. In addition, when regulators set the X-factor using an averaged based benchmarking, as parametric methods, they do not have the reference of the most efficient operators, which can be adopted as a maximum limit of efficiency to be achieved by the inefficient firms. It also can lead to set a low $X$-factor, due to an overestimation of the relative performance of regulated firms.

As DEA is the most used method in measuring efficiency of regulated firms, in the next section we review previous studies that measure the efficiency of regulated firms in the transport sector and corroborate this conclusion. 
Table 1 - Comparison of the two main approaches to construct the production frontier

\begin{tabular}{|c|c|c|}
\hline Category & Stochastic Frontier Analysis (SFA) & Data Envelopment Analysis (DEA) \\
\hline Description & $\begin{array}{l}\text { An econometric method that estimates a } \\
\text { production frontier of the form: } y=f(x)+v-u \text {, } \\
\text { where } y \text { is the output, } f(x) \text { are all inputs, } v \text { is an } \\
\text { error term capturing unpredictable } \\
\text { perturbations and } u \text { captures technical } \\
\text { inefficiency. } \\
\text { A cost frontier (short run or long run) or a } \\
\text { distance function can be used instead. }\end{array}$ & $\begin{array}{l}\text { A linear programming method that constructs } \\
\text { a non-parametric production frontier by fitting } \\
\text { a piece-wise linear surface over the data } \\
\text { points. }\end{array}$ \\
\hline Data needs & $\begin{array}{l}\text { For a production frontier or distance function: } \\
\text { quantity data on inputs and outputs for a } \\
\text { sample of firms, ideally over a number of years. } \\
\text { For a long-run cost frontier: total costs, input } \\
\text { prices, and output quantities. } \\
\text { For a short-run cost frontier: variable costs, } \\
\text { variable input prices, and fixed input quantities } \\
\text { and output quantities. }\end{array}$ & $\begin{array}{l}\text { Quantity data on inputs and outputs for a } \\
\text { sample of firms, ideally over a number of } \\
\text { years. However, if price data are available, } \\
\text { you can also use it to calculate allocative } \\
\text { efficiency. }\end{array}$ \\
\hline Advantages & $\begin{array}{l}\text { Attempts to account for noise. } \\
\text { Environmental variables are easier to deal with. } \\
\text { Allows for the conduct of traditional statistical } \\
\text { tests of hypothesis. } \\
\text { Easier to identify outliers. } \\
\text { Cost frontier and distance function can deal } \\
\text { with multiple outputs. }\end{array}$ & $\begin{array}{l}\text { Identifies a set of peers firms (efficient firms } \\
\text { with similar output mixes) for each inefficient } \\
\text { firm. } \\
\text { Can easily handle multiple outputs. } \\
\text { Does not assume a functional form for the } \\
\text { frontier or a distributional form for the } \\
\text { inefficiency error term. }\end{array}$ \\
\hline Drawbacks & $\begin{array}{l}\text { The decomposition of the error term into noises } \\
\text { and efficiency components may be affect by } \\
\text { the particular distributional forms specified and } \\
\text { by the related assumption that error skewness } \\
\text { is an indication of inefficiency. } \\
\text { Requires large sample size for robust } \\
\text { estimates, which may not be available early on } \\
\text { in the life of a regulator. }\end{array}$ & $\begin{array}{l}\text { May be influenced by noise. } \\
\text { Traditional hypothesis test are not possible. } \\
\text { Requires large sample size for robust } \\
\text { estimates, which may not be available early } \\
\text { on in the life of a regulator. }\end{array}$ \\
\hline
\end{tabular}

Source: Adapted from Coelli et al. (2003). 


\subsection{Methods used in Transport Sector}

There are many publications applying different methods to measure efficiency for several sectors. These studies are widely used by regulators to evaluate privatization programs and to set the X-factor of price cap formulas, because they can be applied in many types of public utilities, as energy, water and sewerage, and transport.

For example, according to Estache, Perelman and Trujillo (2005), there is a clear interest of regulators to evaluate the benchmarking performance in the sector of energy distribution. This information can be used during tariff revision or to promote some form of yardstick competition. Among the studies in this area, DEA is the most common approach. However, there are also a large number of papers relying on both non-parametric and parametric approaches to check the robustness of the results.

Regarding the transport sector, efficiency is not an issue widely investigated by researchers. Markovits-Somogyi (2011a) reviewed 69 studies on the application of DEA in transport, in order to examine the data and supporting methods, as well as the choice of inputs and outputs for different transport modes. In general, the studies investigated use CRS or VRS DEA model, have around 30 DMUs and used three or four inputs to produce one or two outputs. An input always used is labour, as the number of employees or the cost of labour. In most cases outputs are dived into two: operational, representing the physical movement of vehicles or passengers and cargo, and fiscal, the ones that can be expressed in some monetary unit.

In addition, there is a list of references of DEA application for airports, ports, public transport companies, railways and airlines. She concluded that the majority of the studies deal with airports and ports, representing more than $50 \%$ of the studies. Some particularities of the application of DEA for each mode are presented below.

\section{Airports}

In the last years, the air transport sector has been experiencing a rapid growth and a series of changes in regulation policy have boosted competition on both the sides: air companies and airport operators. Likewise the evaluation of the efficiency in the airport sector has enjoyed significant contributions in recent years, in order to evaluate the impact of privatization on productivity. 
Regarding the most used methodology in the literature, 19 of 27 studies analysed by Gitto and Mancuso (2012) used DEA. Lai, Potter and Beynon (2012) also concluded that DEA approach has been the methodology traditionally used to reflect the multiproduction nature of the airport sector, while SFA and TFP have been limited use.

The most common input variables used can be divided into two categories: physical variables, as the number of employees, and number of gates or length of runway, and monetary variables, as operational cost and capital cost. The former are related to the services provided by the airport, and the latter to financial performance.

The output variables can also be divided: as services (the number of passengers, amount of cargo, and number of aircraft movement) and financial aspects (operational revenue, nonoperational revenue, aeronautical revenue, and non-aeronautical revenue).

\section{Ports}

Academic papers of economic efficiency in the port sector are quite scarce in the entire world. Estache, Perelman and Trujillo (2005) analysed 8 articles, focusing on developing countries. An interesting fact in ports studies is that, besides the ones that evaluate a specific country, some of them tend to be cross-country, promoting an international benchmarking. Probably because benchmarking regulation is suitable for the sector.

In general, the focus of the assessments in ports tends to be the production side rather than the cost side mainly because of data constraints. Therefore, the most common output measured is cargo handling services. On the input side, labor and capital tend to be present in every study.

Rail

Measuring economic efficiency of the rail sector has long attracted the interest of researchers because of its two basic features: multi-output production and natural monopoly. Therefore, through the analysis of the performance of railways services, the literature provides useful information on the impact of reforms and privatization. Regarding the methodology applied to evaluate the efficiency, Estache, Perelman and Trujillo (2005) reviewed 9 articles and most of them used DEA and Malmquist productivity index.

Concerning the input and output, most performance studies deal exclusively with physical quantities because cost minimization assumptions tend to be impossible to measure due to lack 
of data. In general the main inputs tend to be employment, $\mathrm{km}$ of tracks-electrified or not, rolling stock and energy (distinguishing between the various sources). The most used output measurements for freight transport are ton-km or train-km and for passengers transport is passenger-km, all traditional measurements of the productivity of the sector.

\section{Public Transport Companies}

In the literature of efficiency measurement, bus companies are the public transport companies most largely investigated. Comparing to other transport modes, there has been relatively extensive research of bus productivity, because bus companies are suitable to compare, since they usually operate in a defined geographical area and compete with other forms of transportation as well as with other bus companies.

Studies in the bus industry tend to employ non-parametric techniques, as DEA models. Jordà Lope (2012) reviewed many publications of technical efficiency on urban public bus from 1981 to 2010 and found 17 studies using parametric techniques and 29 using non-parametric models, most of them applying DEA radial models. In addition, Barros and Peypoch (2010) also reviewed 9 papers on bus efficiency and productivity using DEA method.

Concerning the variables, the inputs most used are the ones representing costs, as number of vehicles, number of employees and fuel consumption. The outputs usually used are the traditional measures of passenger transport production, as passenger-km or vehicle-kms travelled.

\section{Roads}

Usually researches on road sector had emphasized studies regarding material and construction techniques of highway. Despite PPP road projects are widely used in entire world, researches which can be useful for regulators, like performance of maintenance operators or efficiency of toll companies, are very scarce in the literature. According to Welde and Odeck (2011), the debate in this area has provided more attention to evaluate operating costs of congestion-charging system, as the London cordon toll.

However, there are some publications that use DEA approach to measure efficiency of road sector. Table 2 summarizes these studies and their relevant features. Most of them are case studies applied in different countries, as Brazil and Norway. Literature reviewed related to road sector can be dived into two groups: the ones that measure the efficiency of toll operators; and 
the ones that analyze the efficiency of public and private operators in charge of highway maintenance.

Most studies use input variables that reflect the cost of operation and maintenance, as number of employees, maintenance expenditure, operation cost, investment and equipment available, as car or machines used in related activities. On the output side, variables intend to represent the incomes or benefits generates by the activities produced. The most common outputs are: traffic, revenues, number of accidents and number of user assistances.

In addition, it is worth to say that there are also studies concerning the road sector which apply the DEA approach, but with different focus as: safety, sustainability or maintenance efficiency. For example, Shen et al. (2012) conducted a study comparing 27 European countries in terms of their road safety performance. With data from 2008, they used as input: population, passenger-kilometers travelled and passenger cars; and as output: number of road fatalities. This study is interesting to learn from the best-performance countries, provide practical targets and formulate action programmes for all of them.

Also about road safety, Cook and Zhu (2005) presented a study that, selecting a set of safety retrofit projects, prioritizes the highway accidents sites in order of effectiveness. In other words, they construct a ranking according to the ratio of the benefit (reduction in accidents) and to the cost of applying the recommended retrofit measures. They apply DEA model, as it can deal with the multi-dimensional nature of the problem. As input they use: transport ministry costs and user costs; and as output: accident types.

Shen et al. (2011) is an example of application of DEA model to evaluate the sustainability of road transport. They studied 27 European countries, with data from 1995 to 2007, using as inputs: passenger-kilometers travelled (pkm) and freight tone-kilometers travelled (tkm); and as outputs: total energy consumption, greenhouse gas emissions, and the number of fatalities.

Regarding the roadway maintenance, Cook and Zhu (2005) measured the efficiency of crews or patrols in Canada. They used as inputs: maintenance expenditures, capital expenditures and climatic factor; and as output: area served factor (extent of the road for which the patrol has responsibility), average traffic served, pavement rating change factor and accident prevention factor. 
Table 2 - Literature on measure efficiency of road sector

\begin{tabular}{|c|c|c|c|c|c|}
\hline Paper & Units & Method & Input & Output & Remarks \\
\hline \multirow[t]{2}{*}{$\begin{array}{l}\text { Gomes et } \\
\text { al. }(2004)\end{array}$} & $\begin{array}{l}5 \text { Brazilian } \\
\text { federal toll } \\
\text { roads. } \\
\text { Data from } \\
1999 \text { to } 2000 \text {. }\end{array}$ & $\begin{array}{l}\text { 1) DEA CRS } \\
\text { model }\end{array}$ & $\begin{array}{l}\text { Number of } \\
\text { accidents } / \mathrm{km}\end{array}$ & $\begin{array}{l}\text { Accumulated } \\
\text { investment } / \mathrm{km} ; \\
\text { traffic volume } / \mathrm{km}\end{array}$ & $\begin{array}{l}\text { Use two approaches to } \\
\text { combine both models. } \\
\text { The first one is the } \\
\text { benevolent, where inputs } \\
\text { are equal to } 1 \text { and outputs } \\
\text { are the efficiency scores } \\
\end{array}$ \\
\hline & & $\begin{array}{l}\text { 2) DEA CRS } \\
\text { model }\end{array}$ & $\begin{array}{l}\text { Number of } \\
\text { accidents } / \mathrm{km} ; \\
\text { daily revenue } / \mathrm{km}\end{array}$ & $\begin{array}{l}\text { Accumulated } \\
\text { investment } / \mathrm{km}\end{array}$ & $\begin{array}{l}\text { The second one is the } \\
\text { aggressive, where outputs } \\
\text { are the multiplication of } \\
\text { both efficiency scores. }\end{array}$ \\
\hline \multirow[t]{4}{*}{$\begin{array}{l}\text { Possamai } \\
(2006)\end{array}$} & $\begin{array}{l}7 \text { toll roads in } \\
\text { Rio Grande do } \\
\text { Sul State, } \\
\text { Brazil. } \\
\text { Data from } \\
2001 \text { to } 2004 \text {. }\end{array}$ & $\begin{array}{l}\text { 1) DEA VRS } \\
\text { model, input- } \\
\text { oriented }\end{array}$ & $\begin{array}{l}\text { Investment; } \\
\text { operational, labour } \\
\text { and administrative } \\
\text { cost; } \\
\text { maintenance } \\
\text { expenditure }\end{array}$ & 1) Revenues/length & $\begin{array}{l}\text { Measure business } \\
\text { efficiency from operator's } \\
\text { point of view }\end{array}$ \\
\hline & & $\begin{array}{l}\text { 2) DEA VRS } \\
\text { model, input- } \\
\text { oriented }\end{array}$ & & $\begin{array}{l}\text { 2) Potential revenue } \\
\text { (include escape } \\
\text { route) }\end{array}$ & $\begin{array}{l}\text { Measure potential } \\
\text { business efficiency from } \\
\text { operator's point of view }\end{array}$ \\
\hline & & $\begin{array}{l}\text { 3) DEA VRS } \\
\text { model, input- } \\
\text { oriented }\end{array}$ & & $\begin{array}{l}\text { 3) Users satisfaction } \\
\text { index }\end{array}$ & $\begin{array}{l}\text { Measure image efficiency } \\
\text { from users' point of view }\end{array}$ \\
\hline & & $\begin{array}{l}\text { 4) DEA VRS } \\
\text { model, input- } \\
\text { oriented }\end{array}$ & & $\begin{array}{l}\text { 4) Number of } \\
\text { accidents/length } x \\
\text { traffic }\end{array}$ & Measure safety efficiency \\
\hline $\begin{array}{l}\text { Odeck } \\
(2008)\end{array}$ & $\begin{array}{l}18 \text { road toll } \\
\text { companies in } \\
\text { Norway. } \\
\text { Data from } \\
2001 \text { to } 2004 \text {. }\end{array}$ & $\begin{array}{l}\text { DEA VRS model, } \\
\text { input-oriented }\end{array}$ & $\begin{array}{l}\text { Annual traffic; } \\
\text { number of lanes } \\
\text { offered }\end{array}$ & $\begin{array}{l}\text { Operational costs; } \\
\text { payments to the } \\
\text { board of governors }\end{array}$ & $\begin{array}{l}\text { Subsequent to DEA } \\
\text { analysis, the author used } \\
\text { Malmquist Productivity } \\
\text { index approach to } \\
\text { measure productivity } \\
\text { growth in the toll industry. }\end{array}$ \\
\hline $\begin{array}{l}\text { de la Garza, } \\
\text { Triantis and } \\
\text { Fallah-Fini } \\
(2009)\end{array}$ & $\begin{array}{l}\text { Highways } \\
\text { maintenance } \\
\text { in Virginia } \\
\text { (USA), } \\
\text { operated by } \\
\text { the } \\
\text { Department of } \\
\text { Transportation } \\
\text { and via PPP. } \\
\text { Data from } \\
2003 \text { to } 2007 \text {. }\end{array}$ & $\begin{array}{l}\text { DEA VRS model, } \\
\text { input-oriented }\end{array}$ & $\begin{array}{l}\text { Total area served; } \\
\text { annual average } \\
\text { daily traffic } \\
\text { (AADT) /length; } \\
\text { annual average } \\
\text { daily traffic } \\
\text { (AADT) x } \\
\text { equivalent single } \\
\text { axle } \\
\text { load (ESAL) } \\
\text { /length; } \\
\text { maintenance } \\
\text { expenditure }\end{array}$ & $\begin{array}{l}\text { Average traffic } \\
\text { served; } \\
\text { vehicle kilometers } \\
\text { travelled (VKT); } \\
\text { international } \\
\text { roughness index } \\
\text { (IRI); } \\
\text { critical condition of } \\
\text { pavement index } \\
\text { (CCI). }\end{array}$ & $\begin{array}{l}\text { Regression analysis and } \\
\text { Analytic Hierarchy } \\
\text { Process (AHP) were used } \\
\text { to evaluate input and } \\
\text { output variables. }\end{array}$ \\
\hline
\end{tabular}




\section{continues}

\begin{tabular}{|c|c|c|c|c|c|}
\hline Paper & Units & Method & Input & Output & Remarks \\
\hline $\begin{array}{l}\text { Wang and } \\
\text { Tsai (2009) }\end{array}$ & $\begin{array}{l}31 \text { highway } \\
\text { maintenance } \\
\text { sections in } \\
\text { Taiwan } \\
\text { operated by } \\
\text { the Directorate } \\
\text { General of } \\
\text { Highways. } \\
\text { Data from } \\
2002 .\end{array}$ & $\begin{array}{l}\text { DEA CRS model, } \\
\text { input-oriented to } \\
\text { measure } \\
\text { productive } \\
\text { efficiency. } \\
\text { Then used DEA } \\
\text { VRS model to } \\
\text { measure technical } \\
\text { efficiency. } \\
\text { Calculate scale } \\
\text { efficiency dividing } \\
\text { technical } \\
\text { efficiency by } \\
\text { productive } \\
\text { efficiency. }\end{array}$ & $\begin{array}{l}\text { total man power; } \\
\text { budget; } \\
\text { quantity of } \\
\text { maintenance } \\
\text { machines }\end{array}$ & $\begin{array}{l}\text { length of highway; } \\
\text { routine expenditure } \\
\text { on maintenance; } \\
\text { protection of bridges } \\
\text { and culverts; } \\
\text { expense on salvage; } \\
\text { revenue from helping } \\
\text { digging and mending } \\
\text { roads }\end{array}$ & $\begin{array}{l}\text { Categorizes the sections } \\
\text { into two types: hill and } \\
\text { plain. } \\
\text { Used Delphi-Analytic } \\
\text { Hierarchy Process } \\
\text { (DAHP) to identify and } \\
\text { analyze necessary inputs } \\
\text { and outputs. } \\
\text { Used weights restriction } \\
\text { for some inputs and } \\
\text { outputs. } \\
\text { As a result, propose short- } \\
\text { term and long-term target } \\
\text { of inputs to be reduced by } \\
\text { inefficient DMUs. }\end{array}$ \\
\hline
\end{tabular}

\begin{tabular}{|c|c|c|c|c|c|}
\hline $\begin{array}{l}\text { Clímaco, } \\
\text { Soares de } \\
\text { Mello and } \\
\text { Maeza } \\
(2010)\end{array}$ & $\begin{array}{l}5 \text { Brazilian } \\
\text { federal toll } \\
\text { roads. } \\
\text { Data from } \\
1999 .\end{array}$ & $\begin{array}{l}\text { Multiple Criteria } \\
\text { Data Envelopment } \\
\text { Analysis (MCDEA) } \\
\text { model, using DEA } \\
\text { CRS model }\end{array}$ & $\begin{array}{l}\text { Number of } \\
\text { accidents/km; } \\
\text { daily revenue/km }\end{array}$ & $\begin{array}{l}\text { Accumulated } \\
\text { investment/km; } \\
\text { traffic volume/km }\end{array}$ & $\begin{array}{l}\text { As the number of } \\
\text { highways is too small, } \\
\text { they use MCDEA method } \\
\text { to avoid ties in the } \\
\text { evaluation index. } \\
\text { Extended Gomes et al. }\end{array}$ \\
\hline
\end{tabular}
(2004) study.

\begin{tabular}{lllll}
\hline $\begin{array}{l}\text { Silveira, } \\
\text { Azevedo }\end{array}$ & $\begin{array}{l}\text { 6 Brazilian } \\
\text { federal toll }\end{array}$ & $\begin{array}{l}\text { DEA VRS model, } \\
\text { input-oriented }\end{array}$ & $\begin{array}{l}\text { number of } \\
\text { employees; }\end{array}$ & $\begin{array}{l}\text { Annual traffic volume; } \\
\text { number of user }\end{array}$ \\
$\begin{array}{ll}\text { number } \text { Soares } \\
\text { re Mello }\end{array}$ & Data from & & $\begin{array}{l}\text { number } \\
\text { vehicles of the }\end{array}$ & assistance \\
$(2010)$ & 2008. & & concessionaire &
\end{tabular}

Used traditional and inverted DEA approaches (Yamada, Matsui and Sugiyama, 1994). Then calculated a composite efficiency factor with the mean of them. Extended Gomes et al. (2004) study.

\begin{tabular}{|c|c|c|c|c|c|}
\hline $\begin{array}{l}\text { Welde and } \\
\text { Odeck } \\
(2011)\end{array}$ & $\begin{array}{l}20 \text { road toll } \\
\text { companies in } \\
\text { Norway. } \\
\text { Data from } \\
2003 \text { to } 2008 \text {. }\end{array}$ & $\begin{array}{l}\text { DEA model, input- } \\
\text { oriented and SFA }\end{array}$ & $\begin{array}{l}\text { Operational cost; } \\
\text { administrative cost }\end{array}$ & $\begin{array}{l}\text { Annual traffic / } \\
\text { number of lanes } \\
\text { served. }\end{array}$ & $\begin{array}{l}\text { Methods applied give } \\
\text { different results and DEA } \\
\text { results reveal such best } \\
\text { performances for } \\
\text { individual inefficient } \\
\text { companies. }\end{array}$ \\
\hline \multirow[t]{2}{*}{$\begin{array}{l}\text { Azevedo, et } \\
\text { al. (2012) }\end{array}$} & \multirow[t]{2}{*}{$\begin{array}{l}6 \text { Brazilian } \\
\text { federal toll } \\
\text { roads. } \\
\text { Data from } \\
2005 \text { to } 2008 \text {. }\end{array}$} & $\begin{array}{l}\text { 1) DEA VRS } \\
\text { model, input- } \\
\text { oriented }\end{array}$ & $\begin{array}{l}\text { number of } \\
\text { employees; } \\
\text { number of } \\
\text { vehicles of the } \\
\text { concessionaire }\end{array}$ & $\begin{array}{l}\text { Annual traffic volume; } \\
\text { number of user } \\
\text { assistance in a year }\end{array}$ & $\begin{array}{l}\text { Measure operational } \\
\text { efficiency of } \\
\text { concessionaires. } \\
\text { Extended Silveira, } \\
\text { Azevedo and Soares de } \\
\text { Mello (2010) study. }\end{array}$ \\
\hline & & $\begin{array}{l}\text { 2) DEA VRS } \\
\text { model, output- } \\
\text { oriented }\end{array}$ & $\begin{array}{l}\text { Number of } \\
\text { accidents } / \mathrm{km} \text {; } \\
\text { annual } \\
\text { revenue } / \mathrm{km}\end{array}$ & $\begin{array}{l}\text { Accumulated } \\
\text { investment } / \mathrm{km} ; \\
\text { traffic volume } / \mathrm{km}\end{array}$ & $\begin{array}{l}\text { Measure investment } \\
\text { efficiency regarding road } \\
\text { safety. Then multiply } \\
\text { operational and } \\
\text { investment efficiencies to } \\
\text { calculate a global } \\
\text { efficiency factor. } \\
\text { Extended Clímaco, } \\
\text { Soares de Mello and } \\
\text { Maeza (2010) study. }\end{array}$ \\
\hline
\end{tabular}

Source: Analysis of the author 
In conclusion, literature review shows that DEA approach is largely used to evaluate firms in the transport sector. This analysis includes a vary range of services, as airports, ports and public transport companies. In general, the studies apply traditional DEA models, like CRS and VRS. Regarding the road sector, DEA is also used and it was demonstrated as an appropriate methodology to measure the efficiency of regulated firms.

Given the fact that there are many inputs utilized by and outputs obtained as a result of the road concession process, the method to measure the efficiency to be proposed in the framework needs to incorporate all inputs and outputs to be able to identify the overall efficiency of a given unit's of road concession process. As discussed in this chapter, DEA approach addresses the challenges of this research, considering the complex nature of the process (i.e. road safety) that is examined in this study. Thus, DEA has been chosen as the approach to be used to develop the road concession efficiency measurement framework as proposed by this research. The main features and models of the DEA approach will be described in details in Chapter 5. 
4. BRAZILIAN ROAD CONCESSION 

This thesis uses the case of Brazilian federal road concessions to validate the systematic proposed to set the $\mathrm{X}$-factor for price cap regulation. Therefore, this chapter reviews the main features of toll roads in Brazil. First it is presented an overview of the toll road concession program in this country. After, there is an analysis regarding the evolution of the concession program, describing most important innovations included in recent concession contracts, concerning to tendering, risk allocation and financial sources. Finally it is described the features of the economic regulation of the contracts, focusing on the rules to adjust the toll rate.

\subsection{Overview of Road Concessions in Brazil}

The 80 's was, for countries in Latin America, the "lost decade" due to the world-wide debt crisis. At this time economic growth stagnated, unemployment rates rose to high levels and incomes dropped. Money was used to pay down the debt instead of for investment in infrastructure. Low investment and inadequate maintenance of existing infrastructure created a major road deficit in many Latin American countries (Engel, Fischer and Galetovic, 2003). As the public sector was unable to provide infrastructure investments because of the scarcity of public funds, many Latin American countries promoted economic liberalization and the privatization of public services (Rosa, Senna and Lindau, 2010).

According to Vassallo and Izquierdo (2010) the first countries in Latin America to promote road concessions programs - in the late eighties and early nineties -were Mexico, Argentina, and Colombia. Colombia and Mexico experienced substantial difficulties in their first concession programs (Carpintero and Gomez-lbañez, 2011; Carpintero et al, 2012), but both countries continued to make great efforts to improve their concession models over the years. In the midnineties Chile began its ambitious program of concessions, which is now considered as being one of the most successful (Vassallo, 2006). Brazil began to implement road concessions at the same time as Chile. Peru was the last big country in the region to start a broad public-private partnership (PPP) program in the late nineties.

It is worth mentioning that different Public Private Partnership (PPP) arrangements have been implemented around the world in order to build/upgrade, maintain, operate, and finance new or existing roads. All these models were based on different types of agreements that can be classified in many ways. Among those ways would be to classify according to where the revenue 
comes from: that is, either from users, through tolls, or from budgetary resources of the government. In toll-road PPP models, usually called concessions, most revenues come from explicit tolls directly collected by private developers from users. Consequently the pricing approach is bundled into the contract. User payments should be enough to generate sufficient cash flow for paying back the expenditures and the financial cost of the project.

The Brazilian transportation system has around 1.6 million $\mathrm{km}$ of roads, with only $14 \%$ of them being paved. Road transport is by far the most common mode of transportation in Brazil. In 2012, the road share was $61 \%$ for freight and $42 \%$ for interurban passenger transport (CNT 2012). Road networks in Brazil are managed at different governmental levels, according to their functional roles. Networks whose main role is to connect different states (interstate networks) are owned and managed by the Federal Government, while roads that are mostly, or entirely, within a single state, are owned and managed by that state.

In the 1980s there was a reduction in the pace of road investment in Brazil because of budgetary constraints. The approval of a new constitution in 1988 was a crucial step leading to the implementation of road concession programs, which appeared as a solution to increase investment. With the aim of enhancing Brazilian competitiveness and boosting economic growth, by promoting market integration among different regions, the Federal Government launched its first interstate Road Concession Program in 1995, in order to upgrade, maintain, and operate five brownfield stretches of road, totaling 854.5 kilometers. The contracts were based on the Rehabilitate, Operate and Transfer (ROT) model. Years later, some states, including São Paulo, Rio de Janeiro, and Rio Grande de Sul, also started their own road concession programs, with different approaches.

According to Ipea (2010) some of the specific reasons pointed out by the government for the implementation of the road concession program were: 1) the lack of resources allocated in the national budget to road transportation; 2) the higher managerial efficiency expected from the private sector; 3) the need for large investments to rehabilitate the many road networks, which had steadily degraded due to the lack of investment in previous years 4) the need to introduce more services for the road networks, such as rescue and mechanical assistance to the users, in order to improve the quality of service, especially as regards ensuring safety and reliability.

At the time of the implementation of the concession program, Brazil was facing a severe crisis characterized by monetary instability, high inflation rates, and fiscal unbalance. From 1990 
to 2003 the economy showed low levels of income and employment growth, due to high macroeconomic instability and strong fiscal measures limiting public debt (Ipea 2012a).

From 2004 to 2008, Brazil's economy experienced one of its longest and most robust cycles of growth in the last twenty years. In fact, during this period the gross domestic product (GDP) rose on average $4.8 \%$ per year, well above the average rise in GDP of the immediately preceding period, which for the period between 1995 and 2002 was 2.2\% per year. The main features of this cycle were the continued expansion of investment from 2004 on, and the increase in consumption both by private households and by governments. These outcomes were strengthened by the expansion of credit, by policies designed to reduce social inequality, and by the rise in the purchasing power of those less favored economically.

In 2008 this economic growth was affected by the world economic and financial crisis. At this time, the Brazilian government adopted extensive fiscal and monetary measures to mitigate the effects of the external crisis and, at the same time, to encourage the growth of the internal market.

By 2012 the Brazilian economy had changed from one of low and volatile growth, to one of moderate and relatively stable growth, due to lower interest rates that encouraged significant private and public investments. And among the beneficiaries of this growth and relative stability, was the road concession system. As of 2015 in Brazil - accounting for federal, state and municipal roads - there were a total of 57 road concession contracts, involving $19,020 \mathrm{~km}$ of paved roads (see Table 3), representing around $9 \%$ of the total-paved roads in the country.

By 2015, the Federal Government had granted concessions to the private sector amounting to $9,969 \mathrm{~km}$ of roads. The Federal Government launched concession programs in three different stages (see Table 4). In the first stage, from 1995 to 1998, six concessions were granted totaling $1,482.4 \mathrm{~km}$. These concessions now offer a track record that is sufficiently extensive to permit evaluation of their performance. The second stage, in 2008 and 2009, involved the granting of eight concessions amounting to a total of $3,280 \mathrm{~km}$. The third stage, which began in 2012 , has awarded seven concessions, covering $5,348.7 \mathrm{~km}$ of roads and has bids scheduled to take place on 2016. 
Table 3 - Brazilian toll road concession programs

\begin{tabular}{lccl}
\hline Road Owner & $\begin{array}{c}\text { Number of } \\
\text { concessions }\end{array}$ & Total (km) & \multicolumn{1}{c}{ Award criteria } \\
\hline $\begin{array}{l}\text { Federal } \\
\text { Government }\end{array}$ & 21 & $9,969.6$ & $\begin{array}{l}\text { Lowest toll rate } \\
\text { Lão Paulo }\end{array}$ \\
$\begin{array}{lccl}\text { Lowest toll rate and one fixed } \\
\text { payment to the government }\end{array}$ \\
$\begin{array}{l}\text { Paraná } \\
\text { Rio de Janeiro }\end{array}$ & 3 & $5,520.55$ & $\begin{array}{l}\text { Longest stretch and a fixed toll rate } \\
\text { Highest payment to the government } \\
\text { with a daily variable toll rate }\end{array}$ \\
Others & 7 & 214.83 & \\
Total & 57 & $19,020.72$ & \\
\hline Note: Data taken from ABCR (2015) and IPEA (2012b) &
\end{tabular}

Table 4 - Road concession program by the federal government

\begin{tabular}{cccc}
\hline Stage & Beginning of the contract & Number of concessions & Length $(\mathrm{km})$ \\
\hline 1 & June/1995 to July/1998 & 6 & $1,482.4$ \\
2.1 & February/2008 to March/2008 & 7 & $2,600.0$ \\
2.2 & October/2009 & 1 & 680.6 \\
3.1 & April/2016 a & 2 & $1,753.5$ \\
3.2 & April/2013 & 1 & 475.9 \\
3.3 & January/2014 to October/2014 a & 7 & $5,748.3$ \\
\hline
\end{tabular}

Note: Data taken from ANTT (2015)

a Bids scheduled

The concession program seems to be successful in attaining its objective: to improve maintenance and road conditions in Brazil. In 2012, $86 \%$ of the roads operated by concessionaires were in "very good" or "good" condition, considering aspects of pavement, road sign, and design. In contrast, only $27 \%$ of the roads managed by the government had achieved the same classification (CNT 2012). 
For the development of the first stage of the Federal Road Concession Program new legislation, the Concessions Law 8987/1995, was passed. It defined the obligations and rights of users, concessionaires, and the government, and established the bidding procedure and the pricing policy for these contracts. This law was further complemented by two later acts of legislation: Law 9074/1995, which laid out general rules applicable to granting concessions to private parties for supplying public services, and Law 9277/1996 which allowed local states in Brazil to set out for concessionary bids stretches of federal road within their complete jurisdiction.

According to this legislation, road infrastructure concessions are defined as the transference of the management of a defined stretch of road to a private company for a period of time contractually agreed upon in advance. During the contract term, concessionaires are committed to undertaking all the work necessary to ensure an adequate service to the users. The contract defines adequate service as that which meets the following conditions: regularity, continuity, efficiency, comfort, safety, fluid traffic flow, modernization, universality, courtesy toward the public, and reasonable tariffs. These conditions are monitored regularly by the government and, for some of them, there is a set of requirements imposed on the concessionaire to ensure compliance with minimum standards as to the following: cleaning and maintenance of the pavement, signage, drainage system, safety and structural elements. Concessionaires are, in turn, entitled to charge tolls to the users to finance their required activities. At the end of the period, the asset - that is, the road - will revert to the government in perfect operating, and maintenance conditions, as defined according to the contract.

Almost ten years after the approval of the concessions law, a new law related to infrastructure management was passed: the Public Private Partnerships (PPP) law 11079/2004. This law is applicable to any kind of infrastructure, and, unlike the concessions law, it allows for subsidies to be given to private sponsors in charge of managing public infrastructure assets. This law substantially broadened the possibility of transferring public assets to private sponsors, mainly those assets judged to be socially efficient and strategic for the country, but which were not financially feasible for private sponsors to assume responsibility for without public subsidies. It also enabled the government to implement social policies by setting up toll rates more affordable to everybody. In 2007 the States started to use this type of contract for roads. However, at the end of 2012, the Federal Government had not yet made use of it, basically because all the stretches of road awarded to private concessionaires by the Federal Government at that time were profitable by themselves and no further inducement, through subsidies, was necessary. 
The public institution entrusted to manage and regulate federal road concession contracts at present is the Agência Nacional de Transportes Terrestres (ANTT), or in English, the National Agency for Land Transport. This agency was created in 2001, five years after the first federal road concession was granted. The ANTT, which is in charge of regulating the land transport sector, including federal road concession, enjoys economic independence and the power to regulate concessions within its scope of competence. Specifically it is in charge of tendering the concessions and also of monitoring and regulating the contracts, once awarded, during the term of the concession.

In addition, the experience that the government obtained from the concession contracts awarded in the first stage enabled improvements in the concession process, introducing changes in the road concession model, which are described in the next section. These changes both improved the contract design and streamlined the bidding process.

\subsection{Innovations in the Road Concession Program}

This section presents the main changes in the features of the road concession contracts granted by the Brazilian federal government, during the history of the road concession program, concerning three key aspects: tendering, risk allocation and financial sources.

\section{Tendering}

Toll road concessions in Brazil are granted through a competitive tender process. Concession terms are fixed and defined in the contracts, and in most of the cases they last for 25 years. The main objective of tendering in contracts for public infrastructure with characteristics typical of natural monopolies is to promote competition among private operators for the right to construct and manage the infrastructure for a certain period of time. The tender will be more effective insofar as it is able to promote greater competition and consequently result ultimately in lower tolls for the users. In this respect, a higher tariff discount would presumably mean a more effective tendering process.

The tender procedure followed during the first stage, in the period from 1995 to 1998, has undergone some change in the subsequent stages. For the concessions granted in the first stage, the tender consisted of three phases: first, an open prequalification; second, a definition of the characteristics of the project conducted by the government along with the prequalified 
bidders; and third a final auction on the toll rates. The bidder offering the lowest toll will end up winning the tender. In the first stage of the Federal concession program only engineering and construction companies were allowed to present offers, while financial institutions were not allowed to submit bids.

The tender process used in the second and third stages, from 2008 on, changed because legislation as to such tenders, for road concessions in Brazil, has been modified. Important changes were introduced. Before launching the tender, the government was now required to present a basic project, so the second phase of the tender - the defining of the characteristics of the project - was eliminated. Instead of that the legislation introduced a new requirement: a series of public hearings about the technical and economic studies of the concession project even before beginning the auction.

In addition to the elimination of the second phase of the tender, the first and third phases of the tender were, in essence, now reversed. From 2008 on, in the first phase the most competitive offer will be quickly identified. Once this offer has been so identified, the following phase of the tender will be devoted to checking whether the qualifying documents of the best bidder are all in order. If the best offer qualifies in this phase, it will be awarded the contract. If it does not, the government will continue the process with the second best offer from the first phase of the tender. These changes resulted in faster auctions since they avoided the need for the government to evaluate the qualification documents of all the offers. Another change introduced in the second and third stages compared to the first one, was to permit the participation of many other types of bidders, including financial institutions, pension funds, and investment funds, within the bidding consortia.

It is possible to note the effect of these changes by examining the number of bidders per tender and the toll rate discount offered by the ultimate winning bidder, in the last tenders. We considered the last nine concessions awarded from 2007 to 2012, which belong to stages 2 and 3 (see Table 5).

There were 7 auctions within stage 2.1. They were attended by 29 groups, including domestic and foreign investors, with an average of ten bidders per project. The auctions in this stage were extremely successful, reaching toll rate discounts of up to $65 \%$ of the maximum toll rate set up by the government. The next auction corresponded to Stage 2.2. It took place in January 2009, a few months after the world financial crisis exploded. This fact prompted a substantial reduction of bidders, down to just two, even though the winner's toll rate also reflected 
a significant discount of $21 \%$. The auction of the Stage 3.2 was held in January 2012 , after the economic recovery. There were eight bidders and the winner's toll rate had a discount of $45 \%$.

It is noteworthy that there is almost a perfect correlation between the number of bidders that ultimately attended the tender and the final discount achieved. This fact seems to show that the larger the number of bidders in the tender the greater the efficiency obtained for the users, at least at the beginning, through the lower toll levels that result from such competition. This result is consistent with the findings obtained by Guasch (2004).

Table 5 - Results of the auctions

\begin{tabular}{|c|c|c|c|c|c|}
\hline Concessionaire & $\begin{array}{l}\text { Length } \\
(\mathrm{km})\end{array}$ & $\begin{array}{c}\text { Auction } \\
\text { date }\end{array}$ & $\begin{array}{c}\text { Number of } \\
\text { bidders }\end{array}$ & $\begin{array}{c}\text { Toll rate } \\
(\mathrm{R} \$ / 100 \mathrm{~km})\end{array}$ & Discount \\
\hline \multicolumn{6}{|l|}{ Stage 2.1} \\
\hline Autopista Fernão Dias & 562.1 & 09/10/07 & 15 & $1.56 \mathrm{a}$ & $65.42 \%$ \\
\hline Autopista Fluminense & 320.1 & 09/10/07 & 8 & 3.90 a & $40.95 \%$ \\
\hline Autopista Litoral Sul & 382.3 & 09/10/07 & 17 & $1.43 \mathrm{a}$ & $62.67 \%$ \\
\hline Autopista Planalto Sul & 412.7 & 09/10/07 & 10 & 3.27 a & $39.35 \%$ \\
\hline Autopista Régis Bittencourt & 401.6 & 09/10/07 & 13 & $2.24 \mathrm{a}$ & $49.19 \%$ \\
\hline Rodovia do Aço & 200.4 & 09/10/07 & 3 & 4.79 a & $27.17 \%$ \\
\hline Transbrasiliana & 321.6 & 09/10/07 & 10 & 3.23 a & $39.99 \%$ \\
\hline \multicolumn{6}{|l|}{ Stage 2.2} \\
\hline Rodobahia & 680.6 & 01/21/09 & 2 & $1.99 \mathrm{~b}$ & $21.00 \%$ \\
\hline \multicolumn{6}{|l|}{ Stage 3.2} \\
\hline BR-101 ES/BA & 475.9 & $01 / 18 / 12$ & 8 & $3.39 c$ & $45.63 \%$ \\
\hline Mean & & & 9.56 & & $43.49 \%$ \\
\hline Standard deviation & & & 5.03 & & $14.55 \%$ \\
\hline
\end{tabular}

Note: Data taken from Bovespa (2012). Data base: Federal road concessions from 2007.

a Data base: July/2007, exchange rate: R\$1.88/US\$

b Data base: December/2005, exchange rate: $R \$ 2.29 /$ US\$

c Data base: January/2009, exchange rate: $R \$ 2.31 /$ US $\$$

Despite the apparent advantage for users with the low toll rates obtained in the recent auctions, there is a lot of concern about it. In this kind of the tender process, basically an auction that awards the concession to the bidder who offers to do the work asked and is willing to rely on the lowest toll, concessionaires tend to submit aggressive offers characterized by low tolls, which are often supported by overestimates in their traffic forecasts. This situation might conceivably 
lead to a request by investors for a reduction in the investment originally planned, a worsening of the quality of service, or the demand for re-negotiations of the contract terms. This is a situation of which regulators should be aware, because changes ex post in the contracts could eliminate all the social benefits achieved in the original auction. Also huge toll rate increases, of course, are not desirable because they can eliminate the gains of a competitive bid and the road-using public suffers.

\section{Risk Allocation}

Concerning the risk allocation, a study conducted by Ke, Wang and Chan (2010) in four countries revealed that risks related to construction, design, finance, and operation are usually allocated to the private sector, whereas political risks are usually allocated to the public sector. The toll road concession approach implemented in Brazil transfers most of the key risks onto the private sponsors. Concessionaires bear traffic, finance, construction, maintenance, and operation risks. Expropriation risk is not that important because most of the concessions are brownfield projects.

Traffic risk, which is hardly manageable by any stakeholder, is borne completely by private concessionaries. This means that private sponsors will end up collecting windfall profits if traffic turns out to be higher than expected, but they might end up incurring large losses if traffic is lower than expected. Unlike other Latin American countries such as Chile and Colombia, Brazil has never implemented traffic risk mitigation guarantees (Vassallo and Izquierdo 2010). In this respect, different case studies show different results. Vassallo (2006) found that mitigating traffic risk is Chile was very effective.

Financial risks are also allocated to private sponsors in Brazil. Interest rates that are lower than expected will bring about sizeable windfall benefits to concessionaires, which will not be transferred to the users. This situation actually occurred in Brazil, where interest rates decreased dramatically over the years, so the refinancing of the initial loans was quite favorable for the sponsors.

The allocation of construction risk has evolved over time. The total cost of a work may be calculated as: quantity units $x$ unit cost. Originally, the risk related to the price of materials (unit cost risk) was allocated to concessionaires, whereas the risk of the amount of material used (quantity risk) was transferred to the users through the periodic revision of tolls. Consequently, a sharp variation in the price of a certain unit of work, such as material or labor force, which has to 
be borne by the concessionaire while using additional work units, that use amount of material or labor force different from the amounts calculated in the initial bid, will however ultimately be paid by users through higher revised tolls. This approach was shown not to be efficient since concessionaires did not have an incentive to employ fewer resources and, as a consequence of that, the approach was modified in the second and third stages.

The changes introduced in the second and third stages related to the approach for the allocation of construction risk were aimed at reducing the frequency of contract revisions and at incentivizing concessionaires to increase their productivity. From the second stage on, concessionaires had to bear the bulk of the construction risk, both as to quantity and unit cost. In addition, contracts entered into during the second and third stages distinguished between mandatory and non-mandatory works. Mandatory works have to be undertaken by the concessionaire following a pre-defined schedule, for example, third lanes should be built during the fifth year of the concession period. Non-mandatory works, however, have to be built by the concessionaire only if certain performance targets set up in the contract are eventually reached. Consequently, non-mandatory works do not have a fixed date when they must be constructed. For instance, the concessionaire may be required to build an additional lane only when traffic flows reach a certain volume, as determined by the terms of the contract. The concessionaire can not be certain, nor can the government, when that traffic volume will be reached, if it ever is.

Since 2008, maintenance and operation performance targets have been added to concession contracts belonging to the second and third stages. The performance targets selected for such inclusion refer to pavement, road signage, maintenance, and cleaning of the road. From Stage 2.2 onwards, a toll rate discount was triggered if and when certain performance levels set out in the contract were not achieved. This penalty was intended to punish the concessionaire for not meeting the standards as to quality which were stipulated in the contract.

\section{Financial Sources}

Regarding the road finance, in 1995, at the beginning of the first stage of the federal toll road concession program, Brazil was experiencing high inflation and high interest rates. As a matter of fact, project IRRs (internal rates of return) required by private sponsors hardly ever fell below $18 \%$ per year. The financial costs were consequently very high. In 2012, Brazil still ranked among the countries with the highest nominal and real interest rates in the world. However, from 1995 to 2009 there was a gradual reduction in both nominal and real rates. The interest rate in Brazil that most influences monetary policy, an overnight rate called Selic, was around $25 \%$ per 
year in the late 90 s. However, only ten years later, it had fallen to around $10 \%$ per year. This scenario has since 2005 created positive expectations among economic actors, encouraging a new cycle of private investments directed at the modernization and expansion of production capacity. The decrease in the interest rate has caused a substantial reduction in the financial costs of such projects. The IRR of the projects awarded from 2008 to 2012 was around $8.5 \%$ per year, much lower than it was at the first stage.

According to Lacerda (2005), the sources of money to fund the initial works of a toll road project in Brazil are, on average, distributed as follows: 25\% equity provided by the sponsors, $58 \%$ loans, and $17 \%$ cash generated by toll charges. Financial costs of requiring equity and debt are hence relevant for the project. Ultimately, loans and contributions from sponsors will be repaid by users from toll sources.

Because of the high interest rates then obtaining in Brazil, concessionaires relied very much on loans provided by the State Bank for Economic and Social Development (BNDES). This government-owned bank played a key role in the long-term financing of concession projects. In contrast, private banks charged high interest rates and did not feel comfortable providing longterm loans in the unstable scenario that characterized Brazil's economy at the beginning of the first concession stage.

For this reason, BNDES has been the main source of funding for investment in road concessions in Brazil, by reducing the financial costs of the projects through longer terms and subsidized rates. In 2010, BNDES supplied $64 \%$ of the total credit extended in the short and medium-term and $100 \%$ of the long-term credit (Brochado and Vassallo 2012). Its liabilities come mostly from money allocated from the Federal budget, or from the funds accumulated by the unemployment insurance system.

The BNDES credit line for the road sector has the following main characteristics (BNDES 2011):

- It offers 10-year loans with long grace periods of up to 5 years;

- It can finance up to $60 \%$ of the total capital cost;

- It offers lower interest rates, based on the Long-term Interest Rate (TJLP), which in 2012 was at $5 \%$ per year, while private banks use the Interbank Deposit Certificate (CDI), which stood at $8.4 \%$ in 2012; 
- It offers loans which are denominated in the Brazilian currency, the same currency, that is, in which the tolls are paid and toll revenues calculated.

Such a financing framework proved adequate to support the toll road concession program at its origins because of the tough financing conditions offered by the market at that time. According to Véron and Cellier (2010), with the expansion of the Brazilian capital markets, and the more favorable financing conditions, the picture changed, and emerging concessionaire groups increasingly refinanced early loans, as well as subsequent acquisitions, on the basis of debentures.

\subsection{Economic Regulation of the Contract}

The federal road concession program in Brazil is completely on the basis of toll roads, where the users are the ultimately payers. In this section it is described the evolution of the regulatory mechanism used to regulate the economics of the contract, and it is detailed the process used to update the toll rate.

Tolls are charged at toll plazas, both manually - with human toll-takers - and using machines that automatically record the toll. The road system is such that users going through a toll plaza are charged a fixed price irrespective of the distance they have already driven or will be driving subsequently. The low population density in Brazil makes it economically unfeasible to set up toll plazas at every access point. Toll plazas are located on the main points of the roads, but these are ordinarily located far from urban areas to minimize the traffic backup in denselypopulated locales. Toll rates applicable to vehicles other than cars are calculated as a multiplier of the toll rate for cars. The multiplier is equal to the number of axles used.

The Brazilian Institute of Applied Economic Research (IPEA, 2012b) presents the average toll rate charged by federal and state road concessions in Brazil, as well a calculation of Brazilian and international average toll rate, shown in Table 6.

It is important to remember that international experience differs significantly from the Brazilian experience in toll road concession. In most countries, the concessions are greenfield projects, as new assets are built. Thus, the Brazilian concessionaire investments are lower than those made abroad. So the comparison of Brazilian toll rate with other countries should be treated with caution. However, we can note that toll rates in Brazil are higher than other countries, 
which indicates that the risks taken by concessionaires in the Brazilian contracts generate a higher cost to the users.

Table 6 - Average toll rate for cars in Brazil and foreign countries

\begin{tabular}{|c|c|}
\hline Average toll rate (US\$ / $100 \mathrm{~km}$ ) & \\
\hline Average toll rate for federal concessions & US\$ 3.19 \\
\hline 1a stage of federal concessions & US\$ 6.16 \\
\hline $2^{a}$ stage of federal concessions & US\$ 1.85 \\
\hline Minas Gerais State & US\$ 4.04 \\
\hline Bahia State & US\$ 4.53 \\
\hline Paraná State & US\$ 5.43 \\
\hline Rio Grande do Sul State & US\$ 6.21 \\
\hline Espirito Santo State & US\$ 7.78 \\
\hline São Paulo State & US\$ 7.98 \\
\hline Rio de Janiero State & US\$ 8.08 \\
\hline Average toll rate for State concessions & US\$ 6.79 \\
\hline Average toll rate in Brazil & US\$ 5.65 \\
\hline International average toll rate & US\$ 5.50 \\
\hline
\end{tabular}

As road concessions are long-term contracts, one of the key aspects for guaranteeing users' welfare is to set affordable tolls over the life of the contract. In most concessions, mechanisms are set up for yearly toll update. Concessions will perform better for the users insofar as tolls are updated according to the purchasing power of the society. High toll rises will not be good for users, and this may tend to prove that the risk allocation approach set up in the contract was inadequate.

In federal road concessions, toll rates are updated every year according to two different triggers: revision and adjustment. The revision index affects directly the basic toll rate and it is applied to compensate the concessionaire for risks that were not allocated to it in the contract, such as, for example, additional works that the government may subsequently require. The adjustment index controls for the effect of inflation.

The revision is a means to compensate the concessionaire for those risks that, according to the contract terms, are not supposed to be borne by them. Those risks include, for example, 
force majeure risks, such as natural disasters, modification of direct taxes, or work delays caused by problems in the public sector. These all constitute risks that the concessionaire should not be responsible for, as they are not a foreseeable and normal part of the business. The current practice is that contracts are to be revised on an annual basis. However, in order to reduce the frequency of the revisions, the ANTT passed a provision whereby contracts will be completely revised every five years.

In addition, from 2009 on there was an important change in the way that the economics of the contracts were to be rebalanced in cases where new works were added by the government to the concessionaire's responsibilities. As these new works had not been expected at the time of the initial bid, the concessionaire could derive an extra benefit if the economic and financing conditions at the time of the revision were better than at the time of the beginning of the contract. The reverse was also true - the concessionaire might find that such conditions worsened from the time of the initial contract. To minimize this when new works are asked of the concessionaires by the government, they use a marginal cash flow for the new works to rebalance the contract that considers the economic scenario at the time of the revision, using the real traffic flow to calculate the incomes, the market prices to estimate costs, and a rate of return based on the long-term interest rate (TJLP) of the Development Bank of Brazil (BNDES), and the inflation rate. For the third stage, from 2012, the innovation in the contract was that the marginal cash flow now uses an internal rate of return based on the WACC (Weighted Average Cost of Capital).

Unlike the revision, the adjustment index compensates for inflationary losses. For the concessions dating back to the first stage, contracts granted in the period from 1995 to 1998 , the yearly adjustment was calculated on the weighted average of a basket of prices, replicating the main cost components for road works, including labor costs and materials for the construction industry. This calculation resulted in inflationary adjustments which were much higher than the growth in average consumer prices.

Table 7 compares the toll rate increase due to the approach of periodic adjustments with Brazil's most popular consumer price index (IPCA) for the same period. The values in Table 7 do not include the effect of toll rate revision explained above. This table shows how such yearly adjustments were far above the rise in consumer price indices. The result was that the tolls charged by the concessions became progressively more onerous for users. It is precisely this that ultimately led the government to change the adjustment approach in the concession contracts granted after 2008. 
Table 7 - Difference between the toll rate growth due to inflationary adjustments and inflation (IPCA)

\begin{tabular}{lcccc}
\hline Concessionaire & $\begin{array}{c}\text { Beginning of toll } \\
\text { charge }\end{array}$ & $\begin{array}{c}\text { Inflationary } \\
\text { adjustments } \\
\text { accumulated }\end{array}$ & $\begin{array}{c}\text { Inflation } \\
\text { growth } \\
\text { (IPCA) }\end{array}$ & Difference \\
\hline Nova Dutra & August/1996 & $228 \%$ & $154 \%$ & $74 \%$ \\
Ponte Rio-Niterói & August/1996 & $249 \%$ & $154 \%$ & $95 \%$ \\
CONCER & August/1996 & $210 \%$ & $154 \%$ & $56 \%$ \\
CRT & September/1996 & $213 \%$ & $153 \%$ & $60 \%$ \\
Concepa & October/1997 & $249 \%$ & $139 \%$ & $110 \%$ \\
Ecosul & March/2001 & $117 \%$ & $100 \%$ & $17 \%$ \\
\hline
\end{tabular}

Note: Data taken from ANTT - Annual Reports and IBGE (2012). Data base: Federal road concessions from 1996 to 2011.

The concession contracts belonging to the second stage, from the period 2008 to 2009 , used a specific inflation rate, the retail price index (RPI), which is known in Brazil as IPCA. In the third stage, from 2012 on, the contracts adopted the price cap regulation in order to incentivize efficiency and to share productivity gains made by the concessionaires with the users. The adjustment index is set on the basis of RPI - X, which uses the RPI less the efficiency factor, called the X-factor.

The contract establishes the $\mathrm{X}$-factor equal to zero at the beginning of the contract and it increases $0.25 \%$ at the end of every five-year period. In addition, the contract says that the $X$ factor can be revised every five years, based on market studies carried by the regulatory agency, in order to consider the projection of the productivity gains of the firms in the road sector.

As it was discussed in the chapter 2, in order to achieve success during the implementation of the price cap regulation it is essential to set the X-factor correctly, which represents ultimately the incentive of the method. For this reason, it is necessary to study and develop a methodology to estimate the productivity in the road sector, which will permit to set an adequate $X$-factor for road concession contracts. This corroborates the importance of this thesis, in terms of scientific development, originality, also covers a lack in practical application. In the following chapter, a methodology to set the $\mathrm{X}$-factor for road concessions is proposed. 

5. SPECIFIC OBJECTIVES AND

METHODOLOGY 

From the research of the literature regarding the economic regulation used in concession contracts, the methods used to measure the efficiency and the Brazilian road concession program, at this stage it is possible to explain the specific objectives and the methodology of this thesis. First this chapter shows the research gap identified from literature review. Then, the specific objectives of the thesis are defined, seeking to fill the gaps observed in the previous section. Afterwards, the methodology used in this thesis is described. This chapter finishes detailing the main features of DEA method.

\subsection{Research Gap}

In the entire world, concessions are used to achieve a more efficient management of infrastructure facilities. For the case of the public utilities which are considered as natural monopolies, the regulation is a very important issue. Through regulation rules, the regulator establishes limitations to the market, based on the public interest, in order to improve the performance of the sector.

Due to the increase in the number of concession contracts over the last few decades, the regulatory policy to control these contracts also evolved. Focusing on the economic regulation of the contract, there are many relevant topics studied in the literature that are of crucial importance. Studies regarding economic regulation mainly address issues about the financial remuneration of the private firm for the service provided, which can directly affect the feasibility of the project.

Giving particular attention to subjects concerning the control of the price level of the service provided, we can highlight the price cap method, which index the price level according to an index formula based on rate of inflation (RPI - X). This mechanism intends to incentivize the firms to reduce costs, by separating the profits of the regulated utility from its costs. The $X$-factor aims to share expected efficiency gains of the firms with the users.

Regarding the price cap formula, RPI-X, we can identify that the X-factor can reduce the increasing of the price charged by the operator. Therefore, the $\mathrm{X}$-factor is a source of uncertainty for the private investor, which may increase the risks of the project or even make it unattractive to the private sector. However, despite of the importance of the X-factor, in many contracts that adopt the price cap regime the $X$-factor is one of the few variables not defined at the time of signing the contract. 
Thus, the use of scientific methods to support the decision making process to set the Xfactor promotes credibility to the process, because it reduces possible arbitrariness that can be practiced by the regulator. Besides, a well structured process actually promotes incentives for the concession, since setting an inadequate $\mathrm{X}$-factor can generate losses for private firms or users.

The price cap regime has been used since 1983 in telecommunication privatized firms. It was later introduced for other utilities, such as water, airports, electricity, gas and transport, and it is still applied in recent years. However, researches regarding the experiences of the price cap regulation in road concessions are scarce.

Therefore, we can identify in the literature that there is an emerging need to implement a comprehensive methodology to set the X-factor, based on the measure and comparison the overall productivity of the operators of road concession.

In order to develop this research, first we need to comprehend the context of the problem investigated (see Figure 6). The analysis of the context starts with the road concession contract, where the tariff adjustment mechanism that will be used during the concession period is defined. Then, for the case of the concession contracts that adopt the price cap regime, which uses the $\mathrm{RPI}$ - $\mathrm{X}$ formula to calculate the tariff adjustment, it is necessary to set the $X$-factor. It is worth to note that the $\mathrm{X}$-factor represents the expected productivity gains achieved by the concessionaire. For this reason, the X-factor should be set based on the efficiency of the firms, which is the comparison of the productivity of the firms involved in the process. Therefore, the scope of the problem studied consists setting the X-factor and estimating the efficiency of the private operators.

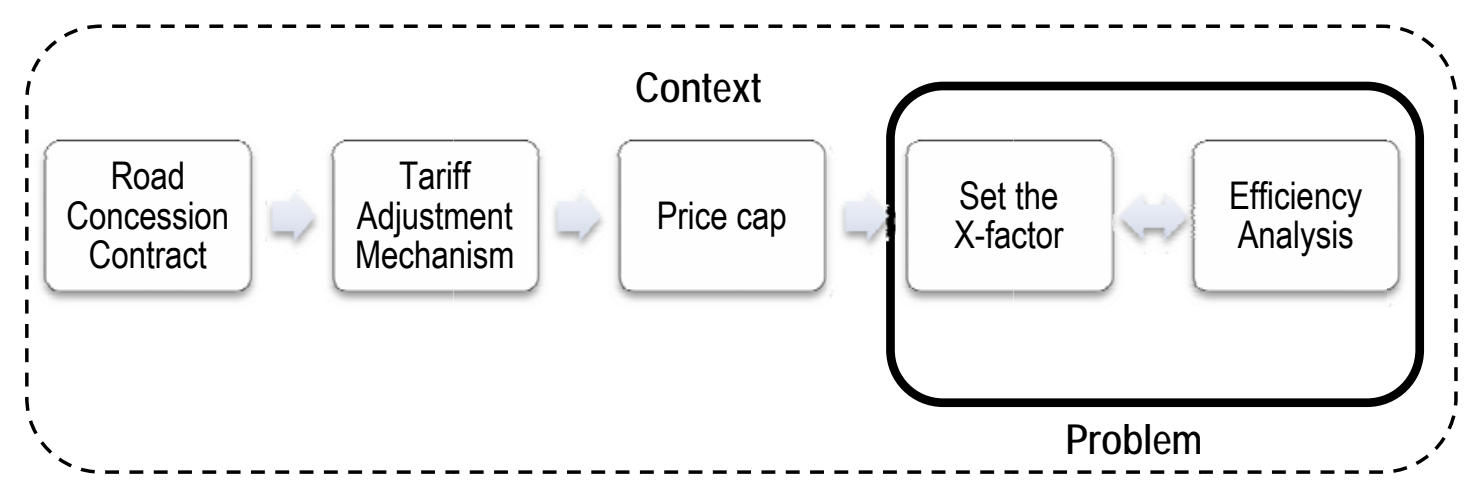

Figure 6 - The problem of the thesis and its context

Therefore, the hypothesis of this investigation is that the current model used for adjusting the price level in road concessions contracts can be improved through the development of a 
methodology to set the X-factor based on the efficiency of the operators, using appropriated techniques to measure the efficiency of regulated markets.

\subsection{Specific Objectives}

The main objective of this research is to propose a method to set the $X$-factor of the price cap formula for road concessions, using a systematic way to measure the efficiency by scientific techniques, and present an example application of this framework to illustrate the implementation of such framework.

The specific objectives to achieve the main goal of the thesis are:

1. Identify feasible tools to evaluate the efficiency of road concessionaires, according to its features and available data;

2. Measure the efficiency of the firms, based on input and outputs of the main aspects of road operation;

3. Identify best practices of the operators and provide information to regulators about possible efficiency improvements in the future to each unit evaluated;

4. Introduce the efficiency of road concessionaires in the process to set the X-factor of the price cap formula;

5. Propose a method to set the X-factor, based on the efficiency of the concessionaires.

After defining the objectives, Figure 7 provides a brief overview of this research, showing the relationship between the motivation, problem, objectives and the main contributions of the thesis. 


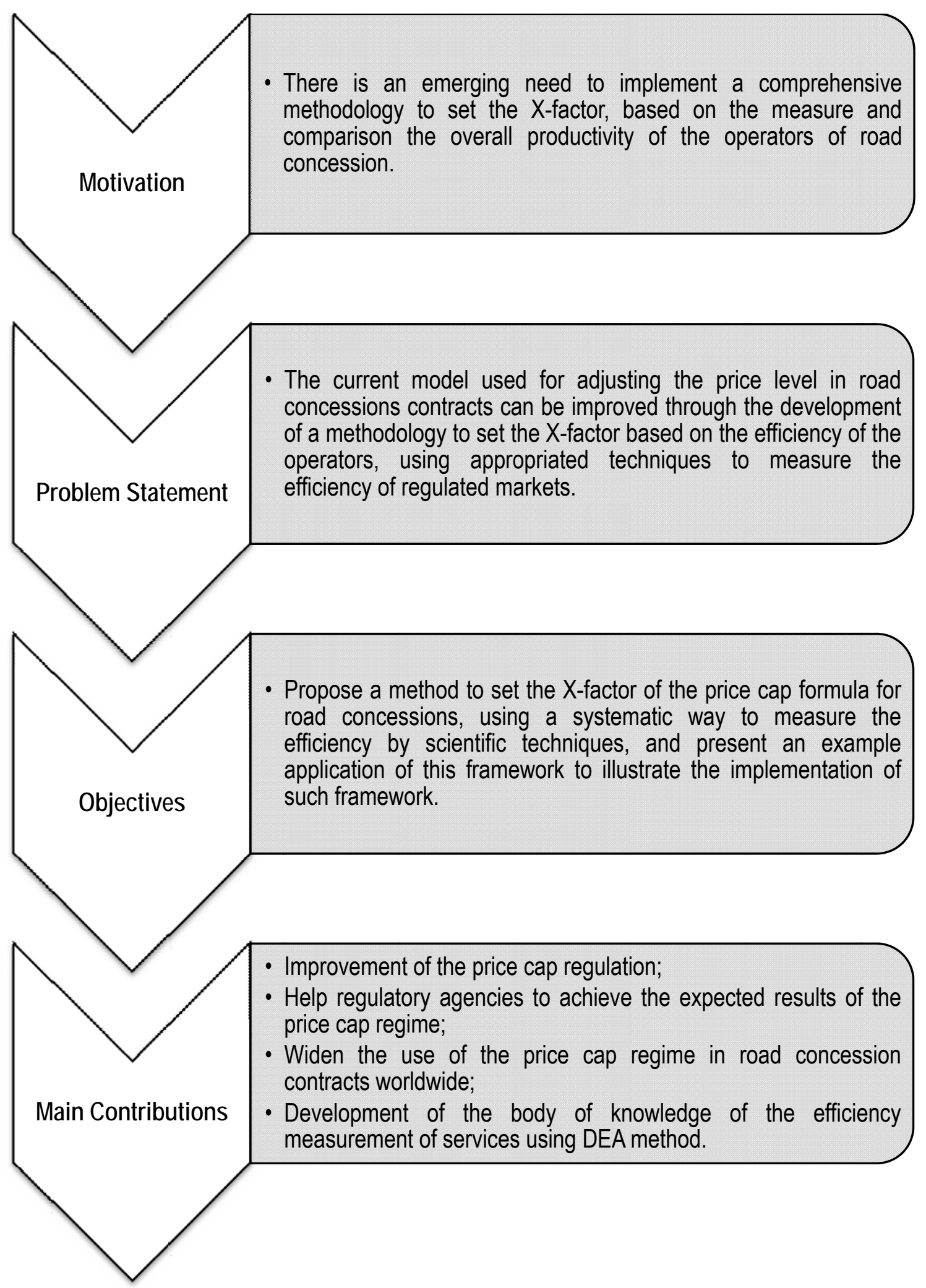

Figure 7 - Motivation, Problem Statement, Objectives and Main Contributions of the thesis 


\subsection{Methodology}

According to Singh (2006) the methodology of a research gives a broad vision of all procedures and techniques for conducting the study. Then, the methodology is the part of the research report that outlines the entire research plan, involving such general activities as: identifying problems, review of the literature, formulating hypotheses, procedure for testing hypotheses, measurement, data collection analysis of data, interpreting results and drawing conclusions.

Before describing in detail the research methodology of this thesis, it is essential to define the approach used in this work, regarding the two respects: quantitative and qualitative. The quantitative approach is employed in scientific research or inquiry, so it is most used in researches focused on practical aspects. The qualitative approach is applied to historical and philosophical researches, which aim to develop a theoretical part of the body of knowledge.

From these approaches, we can identify that the research methodology used in this thesis has quantitative approach, because it aims to measure the efficiency of the road concessionaires, including the use of specific techniques and real data. In addition, it also suggests a theoretical way to solve a typical problem of economic regulation, which is to set the variable $\mathrm{X}$-factor used in the price cap formula for road concessions.

Regarding the research methodology, first in this thesis the author carried out a review of the literature to identify the gap in the body of knowledge and defined the problem of the study. The review of the literature was also used to identify the best technique to measure the efficiency, concerning the particularities of the road concessions.

The method used to measure the efficiency is the Data Envelopment Analysis (DEA), by the application of the software MaxDEA. This software was chosen because it is a free version which contains a lot of tools that make possible to explore the various options of the DEA models and its results, besides it has an interactive interface.

The example application of the method proposed in this thesis was based on the Brazilian federal road concessions. The main reason for this choice is because Brazil is applying the price cap regulation in their new road concessions awards, from 2012 on, and the contracts do not establish a method to set the $\mathrm{X}$-factor. In addition, there are quite available historic data regarding 
the operational aspects of the current concessions, compared to others countries, which are published annually in the Regulatory Agency Reports that permits to apply the method proposed.

The limitations of this research became mainly from the nature of the road operation service and the difficulty to compare the productivity between road concessionaires, because every road has its particularities, considering traffic, design and region. For this reason, in this work road concessionaires were compared based on the similarity of the regulatory policies and contracts. Moreover, the data available imposed a limitation in the development of the models used to measure the efficiency.

From the results of the efficiency of concessionaire, it is possible to set the X-factor in a way that considers the productivity gains of the firms and allow sharing them with the users. The DEA method also provides information to regulators about best practices and indicates the aspects under evaluation that can be improved.

\subsection{Data Envelopment Analysis}

Among the methods studied in Chapter 3 to measure the efficiency of firms, Data Envelopment Analysis (DEA) approach is a method extensively used for benchmarking purpose by regulators worldwide. The reason why it occurs is because DEA methods are easy to draw on diagrams, easy to calculate, and can accommodate multiple inputs and output, which allows to identify the overall efficiency of a given unit's of the process.

In addition, as a non parametric method, DEA approach uses as benchmark the best operators rather than average performance, this means that when regulators use DEA to set the $\mathrm{X}$-factor they adopt the maximum limit of efficiency as benchmarking. Otherwise, when regulators use average based benchmarks, they will not limit the comparator group to the most efficient operators and the relative performance of the regulated utilities will be overestimated and the $X$ factor set too low.

Moreover, parametric methods are particularly vulnerable to the effect of small sample sizes, since the decomposition of variation into random and efficiency-related components requires a large number of data points to be statistically significant. Therefore, using regression techniques in small sample sizes can produce misleading results. DEA, which is a non-parametric 
technique, is not sensitive to small sample sizes and is less data-intensive than econometric methods.

Another advantageous characteristic of DEA is that it does not set constant output for all companies, which permits each company to present itself in its most favorable perspective. DEA is able to do this because it is a non parametric method for measuring comparative performance, and the general shape of the efficient frontier is not set a priori, instead it relies upon the data to approximate the efficient frontier.

Thus, after considering various techniques in Chapter 3, the DEA method has been chosen to develop the road concessionaire efficiency measurement as proposed by this research. Therefore, following the framework established in Chapter 6, DEA approach will be applied to the current road concessions in Brazil, in an effort to evaluate and compare the efficiency of different road concessionaires and to use as base to set the X-factor. As DEA method will be applied in this study, we detail the main features of this method in the present section.

\section{Evolution of the DEA approach}

As seen before, Data Envelopment Analysis (DEA) is used to construct the production frontier in order to estimate and compare the performances of the firms under evaluation. It can be applied in a wide range of different kinds of entities, and it is largely used to measure the efficiency of regulated firms.

It is important to remember that the term Decision Making Unit (DMU), usually used in DEA analysis, refers to any entity to be evaluated, which is part of a group that utilizes similar inputs to produce similar outputs. DMUs may include companies, banks, hospital, universities and so forth, or even departments inside a firm.

DEA method consists in identifying the efficient DMUs, in order to create the efficiency frontier. Then, the efficient DMUs will serve as benchmark to calculate the inefficiency of the DMUs that are below the frontier. In addition, the DMUs on the frontier will be useful to set the target of improvements in future performance.

DEA has been experiencing a huge evolution from its initial publication to the current days. Charnes, Cooper and Rhodes (1978) were the first to publish an article describing the methodology and labeling the approach as Data Envelopment Analysis. Researchers in a number of fields have quickly recognized that DEA is an excellent and easy methodology for modeling 
operational processes in order to evaluate performance (Cooper, Seiford and Tone, 2000). Thus, after this first publication, the methodology had a rapid growth and a widespread pace across disciplines (Seiford, 1996).

Early in the 1980's the first studies using DEA were published. At that time, the model choice was limited to the single constant-returns-to-scale (CRS), proposed by Charnes, Cooper, and Rhodes (1978), which measured only technical efficiency. This model is also called CCR, regarding the initials of their authors. Most of these publications apply the method to measure the relative efficiency of organizational profit units, and few studies were concerned to the public sector or non-profit firms.

By 1985, DEA theory was considerably more advanced and included a wide range of models. The most significant was the variable-returns-to-scale model (VRS) model, proposed by Banker, Charnes, and Cooper (1984), for measuring scale efficiency. This model is also called $\mathrm{BCC}$, referring to the initial of its authors. Areas of application also expanded, including public services, as hospitals, post offices and urban transport, as well as education.

Computational tools for DEA in 1980 were very primitive and this limitation continued until 1990. Therefore, during this period, the mainly development occurred in DEA theory and models.

From 1990 to 1995, theoretical refinements of DEA continued happening. The most relevant theoretical contribution from this period is the free disposal hull (FDH) (non-convex) model of Tulkens (1993). However, practice application evolved most extensively due to the progress of computation facilities. In addition, computational development permitted to rise the number of studies comparing the DEA models, and the comparison of DEA results with other analysis methods, like regression.

After 1990, publications addressed more complex issues, as energy use, electric cooperatives, highway maintenance, regulatory environments, logistic systems and telecommunication. Furthermore, DEA was recognized by books and specialized magazines as a mainstream analytical tool.

In conclusion, from 1990 on, the practice application of DEA methodology had a huge increase, due to the development of the theory, as well as of computational tools. The most important features that must be considered when using DEA approach are presented below, as well as the latest advances in the literature debate. 


\section{Model orientation}

It is worth to remember that an input-oriented model is used when the objective of a firm is to minimize inputs while producing at least the given output levels. The other type of model, called output-oriented, has a different point of view in its analysis. Output-oriented models are used when a firm intends to maximize outputs while using no more than the observed amount of any input.

The formulation of the linear program problem of an input-oriented CRS model was presented in Equation (23). The output-oriented model formulation is derived directed from the optimal solution of the input-oriented CRS model, inverting the ratio (where $\mathrm{h}_{0}=\frac{1}{\theta_{0}}$ ) and solving the corresponding minimization problem, as Equation (26).

$$
\operatorname{Min} \mathrm{h}_{0}=\sum_{\mathrm{i}=1}^{\mathrm{r}} \mathrm{v}_{\mathrm{i}} \mathrm{x}_{\mathrm{i} 0}
$$

Subject to:

$$
\begin{gathered}
\sum_{j=1}^{s} u_{j} y_{j 0}=1 \\
\sum_{j=1}^{s} u_{j} y_{j k}-\sum_{i=1}^{r} v_{i} x_{i k} \leq 0, \forall k \\
v_{i}, u_{j} \geq 0, \forall i, j
\end{gathered}
$$

Where:

$h_{0}=$ Efficiency of the DMU being evaluated

$r=$ number of inputs

$s=$ number of outputs

$\mathrm{v}_{\mathrm{i}}=$ input weight, where $i=1,2, \ldots, r$

$\mathrm{u}_{\mathrm{j}}=$ output weight, where $j=1,2, \ldots, s$

$\mathrm{x}_{\mathrm{i} 0}=$ input data for DMU being evaluated 
$\mathrm{y}_{\mathrm{j} 0}=$ output data for DMU being evaluated

$\mathrm{x}_{\mathrm{ik}}=$ input data for $\mathrm{DMU}_{\mathrm{k}}$, where $k=1,2, \ldots, n$

$\mathrm{y}_{\mathrm{jk}}=$ output data for $\mathrm{DMU}_{\mathrm{k}}$, where $k=1,2, \ldots, n$

$n=$ number of DMUs

\section{Returns to Scale}

Regarding alternative assumptions of returns to scale for DEA models, Banker, Charnes, and Cooper (1984) extended the CRS model, which assumes constant returns to scale of activities, proposing a model with variable returns to scale (VRS). Figure 8 illustrates the difference of the production frontier between both methods. The CRS' production frontier has a linear form, while the VRS' production frontier has a concave form. The VRS frontier enable DMUs with low input to have increasing returns to scale (e.g. segment from point 1 to 2 ) and the ones with high inputs can operate with decreasing returns to scale (e.g. segments from point 2 to 3 and from point 3 to 4 ).
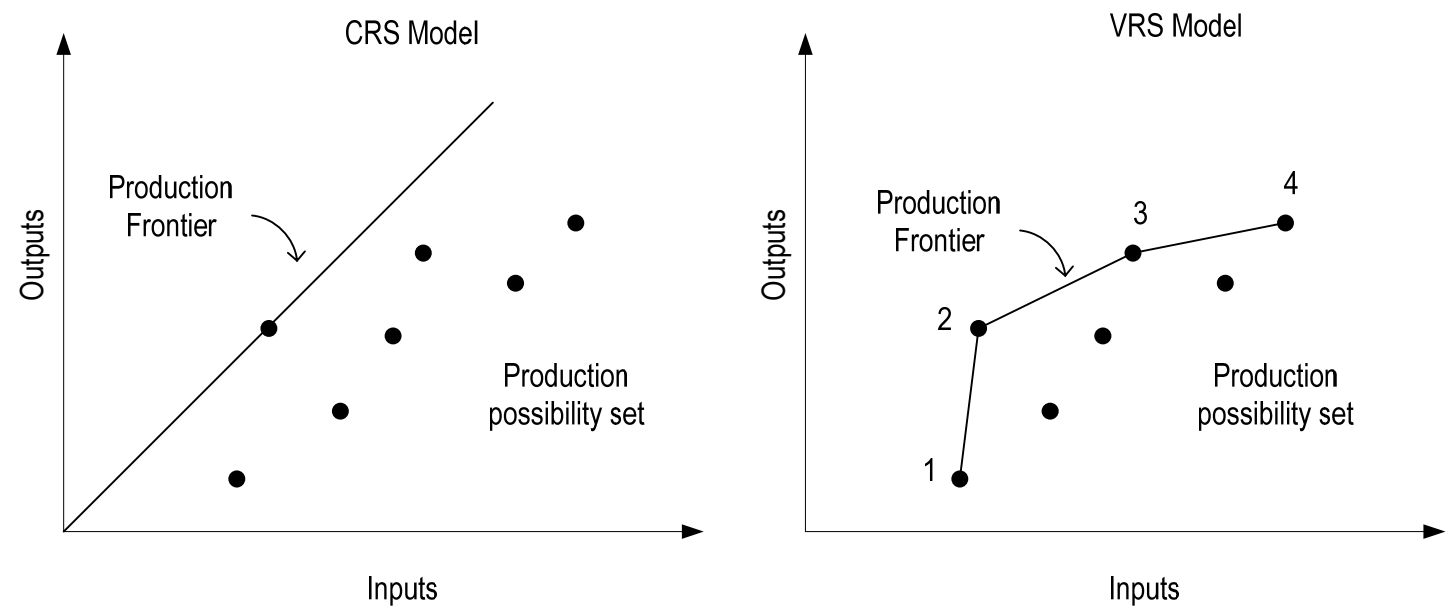

Source: Adapted from Cooper, Seiford and Tone (2007).

Figure 8 - Production Frontier of CRS and VRS Models

As VRS model replaces the proportional relation between input and output used in CRS to the convexity relation. The formulation of both models differs only in that VRS includes an additional condition in its constraints: $\sum_{\mathrm{k}=1}^{\mathrm{n}} \lambda_{\mathrm{k}}=1$ (see Equation (20)). Therefore, the linear programming to a VRS input-oriented model is shown in Equation (29). 


$$
\operatorname{Max} \theta_{0}^{*}=\sum_{j=1}^{s} u_{j} y_{j 0}+u_{*}
$$

Subject to:

$$
\begin{gathered}
\sum_{i=1}^{r} v_{i} x_{i 0}=1 \\
\sum_{j=1}^{s} u_{j} y_{j k}-\sum_{i=1}^{r} v_{i} x_{i k}+u_{*} \leq 0, \forall k \\
v_{i}, u_{j} \geq 0, u_{*} \in \Re
\end{gathered}
$$

Where:

$\theta_{0}^{*}=$ Efficiency of the DMU being evaluated

$r=$ number of inputs

$s=$ number of outputs

$\mathrm{v}_{\mathrm{i}}=$ input weight, where $i=1,2, \ldots, r$

$\mathrm{u}_{\mathrm{j}}=$ output weight, where $j=1,2, \ldots, s$

$\mathrm{x}_{\mathrm{i} 0}=$ input data for DMU being evaluated

$\mathrm{y}_{\mathrm{j} 0}=$ output data for DMU being evaluated

$\mathrm{u}_{*}=$ dual variable concerning to the restriction $\sum_{\mathrm{k}=1}^{\mathrm{n}} \lambda_{\mathrm{k}}=1$

$\mathrm{x}_{\mathrm{ik}}=$ input data for $\mathrm{DMU}_{\mathrm{k}}$, where $k=1,2, \ldots, n$

$\mathrm{y}_{\mathrm{jk}}=$ output data for $\mathrm{DMU}_{\mathrm{k}}$, where $k=1,2, \ldots, n$

$n=$ number of DMUs

From this we can conclude that VRS frontier enables small firms to be benchmarked against small firms and big firms against big firms. For that reason, an advantage to use VRS model is that it is possible to remove the effects of scale efficiency from the productivity measures, when estimating the efficiency of regulated firms. 


\section{Radial and non-radial models}

DEA approaches can be divided into two types: radial and non-radial models. The radial approach is represented by the CRS and VRS models, when it is required to distinguish between input-oriented and output-oriented models. The non-radial models combine both orientations in a single model and permits to identify input excesses and output shortfalls simultaneously. The definition of efficiency for an efficient DMU in non-radial model is based on input and output slacks, illustrate by Figure 9. A DMU is efficient only if $\mathrm{s}^{-}=0$ and $\mathrm{s}^{+}=0$.

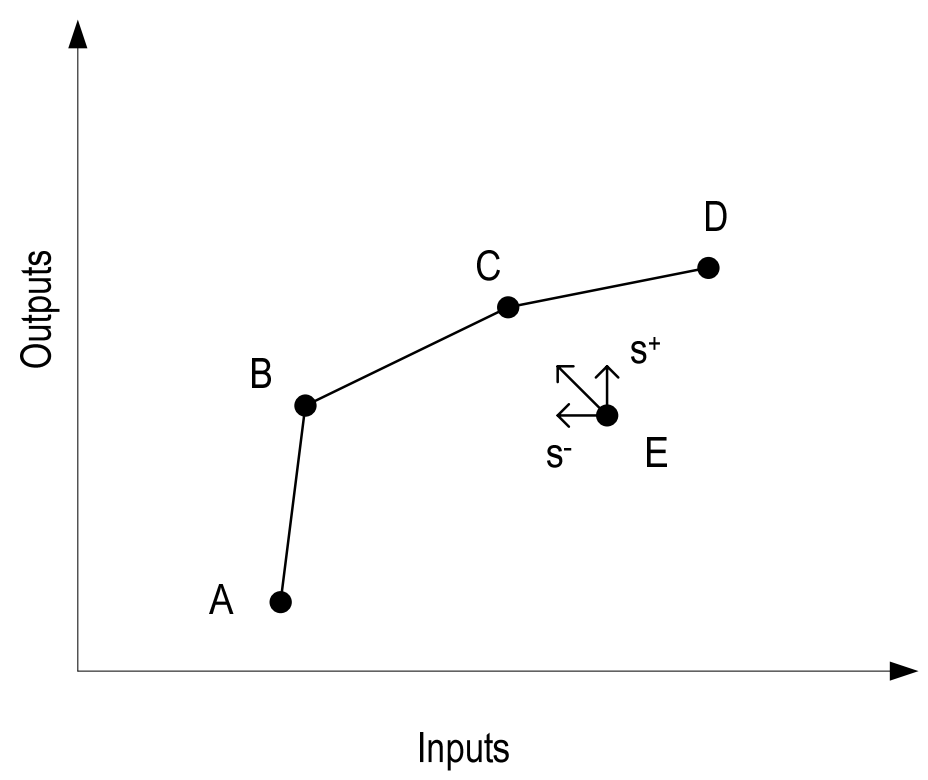

Source: Adapted from Cooper, Seiford and Tone (2007).

Figure 9 - Non-radial models (VRS frontier)

Developed by Charnes et al. (1985), the additive model is the simplest non-radial model in DEA. There are several later versions of the additive model, trying to address the shortcomings of the linear optimization problem. Tone (2001) proposed the slacks-based measure (SBM), introducing two important properties: the measure is invariant with respect to the unit of measurement used for the different inputs and outputs (units invariant); and the measure is monotone decreasing with respect to an increase in each input and output slack (monotone). The SBM efficiency provides a scalar measure ranging from 0 to 1 that encompasses all of the inefficiencies that the model can identify. Another feature is that SBM is derived from the solution of the fractional programming problem and it can be transformed into a linear programming problem. 
Although the methods that use slacks are considered as modern, regarding the theory advances, they estimate the allocative efficiency (Coelli et al., 2003). As seen before, regulators need to estimate the technical efficiency of regulated firms. Therefore the use of methods that treat slacks is not necessary for these cases, whereas DEA radial methods can achieve satisfactory measurement of technical efficiency.

\section{Literature debate}

Applications of DEA have rapidly expanded in the last three decades, theoretical advances also followed this trend. Here we mention the most relevant issues addressed in the literature concerning DEA models. For a more detailed explanation and references, see Cook and Seiford (2009).

DEA models previously seen are considered as single level models, because they are used to evaluate the efficiency status of each member of a given set of DMUs at a given point in time. In the literature, there are also studies regarding multiple level models. These models are used when an efficiency measurement situation can involve having to look at multiple levels. For instance, this approach can be applied to evaluate a supply chain, deriving a measure of overall efficiency as opposed to looking only at the efficiencies of individual members of the chain.

In DEA classic model, the solution of the linear problem selects the weights of inputs and outputs that will result in maximum efficiency of each DMU. However, sometimes there are situations where additional information is available, which lead the decision agent to impose conditions to weights definition, called multiplier restriction. As examples we can cite the absolute multiplier restriction and the assurance restriction regions.

Regarding the variables, there are some cases that particularities of variables can affect performances in ways that they need to be taken into account when effecting evaluations. Some issues investigated are: non-discretionary variables, when certain input variables are not under managerial control; non-controllable variables, whose values must remain fixed; and undesirable factors, when the objective function of an input or output behave opposite to conventional - that is minimize output, rather than maximize, or maximize input, rather than minimize -, then the production process should be reduced to improve the performance (e.g. air pollution as an output of a power plant).

A relevant issue in literature debate of DEA is the data variation. In contrast to DEA models previously seen, which assumed that the data values are fixed and known, researchers are 
investigating DEA models that data may exhibit variation or uncertainty. These studies include: sensitivity analysis, treatment of data variations by statistical methods, the super-efficiency model, when the DMU being evaluated is excluded from the reference set, and times series data, when situation is dynamic or data is time dependent.

Finally, we conclude that DEA made a very considerable progress since its first application in 1978. As topics treated in this section are all under continuing development, there is still much scope for further researches on new applications as well as new developments in DEA. Regarding DEA progress, it can be considered as an appropriate method to evaluate road concessionaires. 
6. PROPOSITION TO SET THE X-FACTOR 

This chapter describes a systematic and theoretical framework to set the X-factor for road concessions in accordance with the objective of this thesis. The X-factor is used in the price cap regulation to provide a suitable incentive to the regulated firm to improve efficiency. Therefore, the $\mathrm{X}$-factor should reflect the gains of the concessionaires due to efficiency improvements. Thus the proposition considers a group of road concessionaires that can be compared and the framework to set the X-factor is based on the concessionaires' efficiency.

Overall, as shown in the Figure 10, the proposed framework to set the $X$-factor consists of three steps: (1) measurement of the efficiency of the concessionaires, (2) analysis of the results and (3) determination of the $\mathrm{X}$-factor.

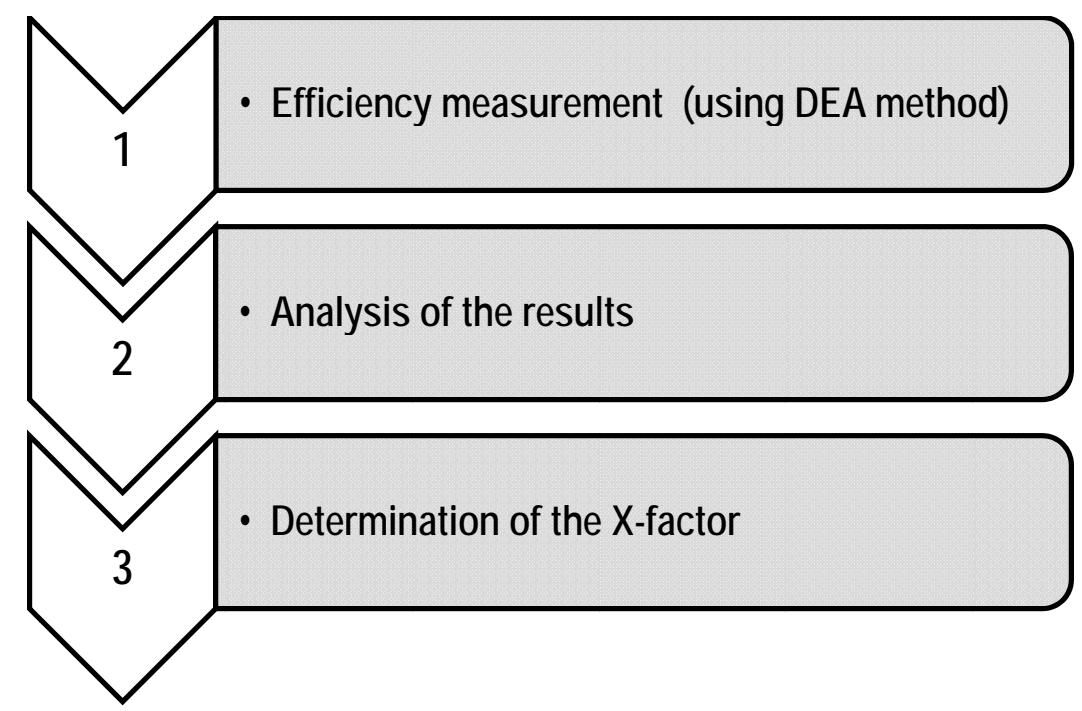

Figure 10 - Proposed Framework to Set the X-factor

In accordance with the literature review, the method used in this work to measure the efficiency of the road concessionaires is the Data Envelopment Analysis (DEA). This method has been widely used in previous works to measure the efficiency of public utility services, due to its features that are adequate to assess the public service provided by private firms.

It is worth to note that the proposed framework uses the benchmark technique, which is the process to compare the performance of an operator to the best practices of the industry. Benchmarking is an incentive regulation approach, as well as the price cap regime, because it can promote competition between comparable firms operating in monopoly markets.

Thus, the proposition to set the $\mathrm{X}$-factor formulated in this thesis contributes to improve the regulatory environment of the toll road sector. In the following sections the proposed framework is 
explained in details, considering the particularities of the road service and the similarities of the concessionaire's contracts.

\subsection{Efficiency Measurement}

The first step of the proposed framework is to measure the efficiency of the regulated firms concerning the road sector. From the analysis of the literature, the Data Envelopment Analysis (DEA) is the approach recommended to measure the efficiency of road concessionaires.

Theoretical basis of DEA was studied and the research regarding the evolution of the method and the features of DEA models were explained in the section 3.2. It is worth to remember that the term Decision Making Unit (DMU) is used in the DEA method to refer to the firms or the element under evaluation.

The present and following sections describe a detailed explanation of the construction of a DEA model that can be applied to evaluate road concessionaires. According to Golany and Roll (1989), there are three main phases in carrying out an efficiency study using DEA: (1) definition and selection of DMU to enter the analysis, (2) determination of input and output factors which are relevant and suitable for assessing the relative efficiency of the selected DMUs, and (3) application of the DEA models and analysis of outcomes.

Regarding these three main phases defined by Golany and Roll (1989), the first one is tackled in section 6.2. The second phase is discussed in section 6.3. Finally, sections 6.4 and 6.5 deal with the last phase.

In order facilitate the comprehension of the proposed framework to measure efficiency, the three main phases can be split in specific activities, regarding the objective of this thesis. Figure 11 shows the flowchart of the steps to be followed in this study for the application of the DEA method. 


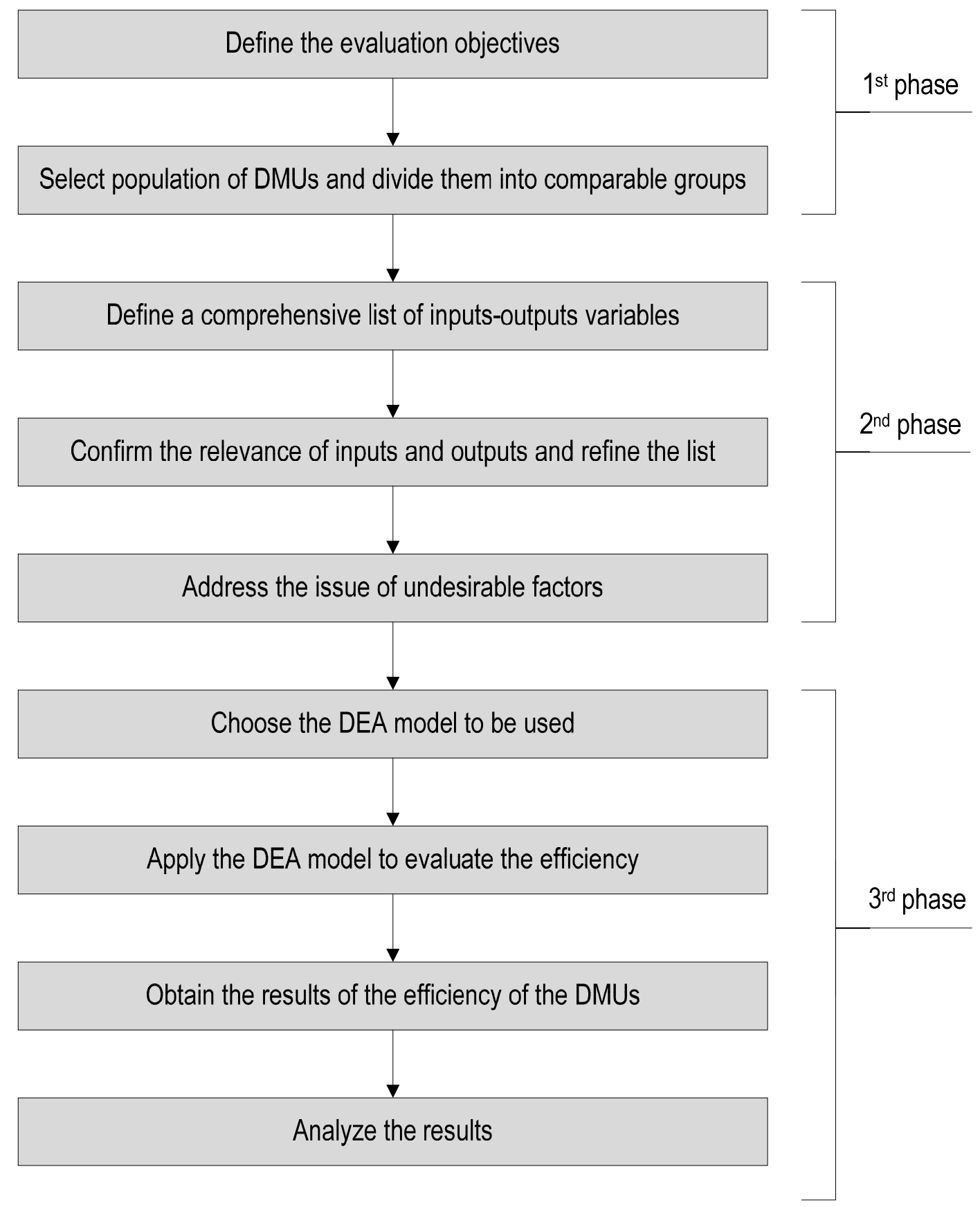

Figure 11 - DEA application flowchart

\subsection{Define Objective and Select DMUs}

It is fundamental to know clearly the aim of the DEA analysis because it will guide the whole process, helping to define the DMUs, the variables, the method to be used and to find the correct results. Then, the first step of the DEA application is to define the main objectives of the 
evaluation process. In this activity, the analysts should describe what they want to reach in the analysis.

This study is directed to toll roads under private operation. Therefore, in order to define the object of the evaluation, it is important to describe briefly the activities in charge of the road concessionaire and its responsibilities.

The road system is part of the transport system. The mission of the transport system is the socioeconomic integration and to promote the development of a region or a country. To perform its function satisfactorily, it is fundamental that the road system remain offering a high level of service, which provides the users essential transport conditions, such as comfort, safety and economy.

In the case of the toll roads, a private firm has the right to manage the road, as well as the responsibility to manage the road project, including maintenance, operation and execution of road works established in the contract. Each concessionaire has the autonomy to plan and execute preventive and corrective services, as the maintenance and rehabilitation road works, according to its management policy to ensure the achievement of the standards of the level of service established in the concession contract.

Thus, the concessionaire is ultimately responsible for the quality of service offered to road users. Through the analysis of efficiency, it is possible to compare the service provided by road concessionaires, and consequently verify which of them apply best practices in managing road projects. Best practices are shown by the higher productivity in key aspects regarding road operation.

In this way, the aim of the efficiency analysis should suit the features of the concession contract under analysis, in order to assess the productivity of the concessionaire in relation to their obligations.

The obligations of road concessionaires include many activities and the management of these activities is a very complex process. Therefore, the productivity of a road concessionaire should be analyzed from the main aspects of the road operation, which can represent the products provided to users. 
Regarding the duties of the road concessionaires of the Brazilian federal toll roads, which were studied in this thesis, DEA can be utilized to analyze the relative efficiency and performance among road concessionaires concerning the following aspects:

- road safety;

- $\quad$ user assistance;

- availability;

- quality.

After defining the evaluation objective, the second step of the DEA application is to select the population of DMU and divide them into comparable groups.

As seen in chapter 3, the efficiency analysis is the comparison of the productivity of firms which perform similar activities. Thus, in order to apply the DEA method to measure the efficiency, the companies that will be evaluated (DMUs) should be divided into comparable groups.

According to Golany and Roll (1989), the group of DMU should be homogeneous and have the following features:

- $\quad$ similar working objective and perform the same tasks;

- $\quad$ similar working environment and market conditions;

- identical inputs and outputs that characterize the performance, except for intensity or magnitude.

It can be a difficult task to find a basis for comparison of roads regarding physical features, as design, type of terrain (level, rolling, mountainous) and region. However, in this thesis the analysis of the efficiency is used as an auxiliary tool in the economic regulation of the concession contract. Thus, the regulatory environment in which the concession is inserted, as well as the features of the contract, can be taken as a reference in order to compare road concessions.

In the case of the Brazilian federal road concessions, considering the main features of the concession contract, discussed in the chapter 4 , concessionaires can be divided into comparable groups concerning the stage of the concession program they belong to, because the contracts of each stage have similar features regarding the key aspects for a regulatory evaluation.

Another important issue in the determination of the DMUs is the size of the comparison group. According to Cooper, Seiford and Tone (2007), as it happens in statistics analysis or other 
empirically oriented methodologies, there is a problem involving degrees of freedom, which is worsen in DEA because of its evaluation of the relative efficiency. In the envelopment model, the number of degrees of freedom will increase with the number of DMUs and decrease with the number of inputs and outputs.

Consequently if the number of DMUs is fewer than the combined number of inputs and outputs, a large portion of the DMUs will be identified as efficient and efficiency discrimination among DMUs is questionable due to an inadequate number of degrees of freedom. Therefore, a rule of thumb which can provide guidance is that the number of DMUs should be three times greater than the number of inputs plus outputs, and the number of DMUs should be equal or larger than the product of the number of inputs and outputs (see Equation (32)).

$$
n \geq \max \{3(m+s), m \times s\}
$$

Where:

$n=$ number of DMUs

$m=$ number of inputs

$s=$ number of outputs

However, it is not recommended to greatly increase the number of DMUs because, in general, the larger the number of units in the analyzed set, the lower is the homogeneity within the set. Then, this fact can increase the possibility that results may be affected by some exogenous factor. Therefore, in some cases, scientific tools can be used, as the cluster analysis, in order to group a set of DMUs in such a way that the DMUs in the same group are more similar than each other than to those in other groups.

In conclusion, the selection of the number of DMUs - the second step of the method - is fundamental for successful application of DEA. In the following section, the second phase of the DEA application is described, where each aspect of the objective of the evaluation will be represented by inputs and outputs variables of a productivity process. 


\subsection{Determination of input and output variables}

The second stage of DEA application is to select input and output variables. In the production process, the input items represent the resources used in the process and the output items represent the product to achieve organization objectives.

As described in chapter 3, DEA method has the feature that it does not require the specification of a functional form. Therefore, any variable can be included in the model without the need to specify functional or parametric relationships. Given this, the first step of this phase is to develop an initial list of factors to be considered for assessing DMU performance, as comprehensive as possible. Every relevant and suitable variable whose change can affect the DMUs to be evaluated should be included in the initial list.

In order to help the development of this list, Ozbek et al. (2010) suggest some questions that should be answered regarding the process whose efficiency is measured, as following:

- What does this process do?

- How does this process accomplish its activities?

- Which outputs does this process produce?

- Which inputs does this process use to produce its outputs?

In the case of road concessions, the initial list, and the answer to these questions, should be based on the processes to achieve the objectives of the efficiency analysis, defined in the previous stage - road safety, user assistance, availability and quality. In addition it is recommended to consider the feasibility and reliability of the data available for the analysis.

At this stage, as all the factors should be listed, this may result in quite a large number of factors in the initial list. Many authors state that the selection of input and output items is crucial for successful application of DEA. Thus, the next step of DEA application is the reduction of the initial list to one that includes the most relevant factors.

Senra et al. (2007) say that the discussion in the literature regarding the issue of selecting variables to be used in DEA application is scarce. Most of the studies select variable according to expert opinion or to the availability of data.

Therefore, in order to reduce the initial list, it is generally recommend a process of selecting a small set of input and output items at the beginning and gradually enlarging the set to 
observe the effects of the added items. Golany and Roll (1989), proposed a method in three stages to refine the list, as following:

(1) Judgmental process: reduce the list by a critical examination of experts in the field where the DMU operate. The process involves methods such as assigning weights to variables based on judgment. In order to structure the judgment process systematic procedures can be used, as Delphi techniques or variations of the Analytic Hierarchy Process (AHP), which require the subjective input of the decision makers. These questions can help to guide the process: "Is the factor related to, or contributing to, one or more of the objectives set for the application?"; "Is the factor conveying pertinent information not included in other factors?"; "Does the factor contain elements which interfere with the notion of technical efficiency?"; "Are data on the factor readily available and generally reliable?";

(2) Non-DEA quantitative analysis: unlike the judgmental process, it depend typically on statistical representations used to identify the relationships among different variables in an effort to remove a variable that is already represented by other variables in the data set or to aggregate multiple variables into one single variable that represents all of these variables. A useful procedure is to carry out a series of regression analyses, of such factors, one at a time, on the factor known to be inputs and outputs. A weak relation to inputs and a strong relation to outputs indicates a preference towards classifying the factor as an input, while the reverse outcome will point towards viewing the factor as an output. A weak relation to all the factors may indicate a need to reexamine the factor and possibly delete it. Alternatively, strong relations may indicate that the information contained in that factor is already represented by other factor and, again, its deletion should be considered in order to eliminate redundancies. The regression process should not be used as reliable rules, but as indicators for a need to examine the factors closer;

(3) DEA based analysis: consist of run DEA models, starting for the most "strict" model, the CRS model. The process is to enter into the model the factors which have remained in the list so far and examine the outcomes closely. Factors which are consistently associated with very small multipliers or which have little impact on the efficiency score may be eliminated. The idea is to test the discrimination power of the different factors and the model is run with a series of combination of these factors.

For the case of road concessions, the expert that will refine the initial list should bear in mind the key aspects of each process related to the objectives of the analysis. Furthermore, the 
limitation of the number of variables should be considered regarding the number of DMU, respecting the rule of thumb of Equation (32).

\subsubsection{Undesirable output}

A basic assumption used in DEA models is that producing more outputs relative to less input resources is a criterion of efficiency. However, there are some processes that inputs should increase and outputs should decrease in order to improve efficiency. For instance, it often occurs when evaluating ecological aspects, as using the pollution generated by an industrial process as output of a DEA model. In this case, output has to be minimized to improve the performance. This problem is identified in DEA literature as undesirable factors.

Regarding the road operation, one of the key aspects is to provide safety conditions to users. For this reason, road safety is one of the objectives of the efficiency analysis. Thus, clearly the number of accidents will be an output of a DEA model, in order to evaluate the performance of the concessionaire concerning road safety.

Therefore, using DEA for road safety evaluation, we note that there is an undesirable output in this evaluation, because productivity increases as the output (i.e. number of accidents) reduces. For this reason, the next step of DEA application is to address the issue of undesirable variables.

There are some studies dealing with undesirable factors in efficiency evaluation. Seiford and Zhu (2002) develop an alternative approach to treat both desirable and undesirable factors in the standard linear VRS DEA model, preserving the linearity and convexity in the model. Their approach uses DEA classification invariance property, so the standard DEA model can be used to improve the performance via increasing the desirable outputs and decreasing the undesirable outputs. This method can also be applied to situations when some inputs need to be increased to improve the performance.

Another case of DEA model adaptation to deal with undesirable factors is presented in the study of Amirteimoori, Kordrostami and Sarparast (2006), which uses an extension of the standard CRS-DEA model to a DEA-like model that determines the relative efficiency via increasing undesirable inputs and decreasing undesirable outputs.

Also, Cooper, Seiford and Tone (2007) present an adjustment of a slacks-based measure of efficiency (SBM) model, which is non-radial and non-oriented model, and utilizes input and 
output slacks directly in producing an efficiency measure. In this study they modify the SBM to take undesirable outputs into account.

Shen et al. (2011) use an adjusted output-oriented DEA model to measures the extent to which the $27 \mathrm{EU}$ countries have improved their productivity on sustainable road transport. The extension of the basic DEA model can be deduced from the basic input-oriented DEA model by switching each of the inputs and outputs into the place of the other. As undesirable output, variables which need to be minimized rather than maximized in road safety performance evaluation, they used: total energy consumption, the greenhouse gas emissions, as well as the number of fatalities in road transport.

Therefore, it is possible to note that there are some extensions of the basic DEA models in the literature to deal with undesirable outputs. However, when it is not possible to use an adapted DEA model, for example due to unavailability of software, there is also two alternatives using DEA basic models: use the inverse value of the undesirable variable as outputs or transfer the undesirable variable to the input side, so DEA model will try to minimize use of inputs.

In conclusion, at the end of this stage, the variables to be used as inputs and outputs in the DEA model should be defined. In the following section, we start the last stage of DEA application, discussing the choice of DEA model to be used.

\subsection{Choose of the type of DEA models}

In the section 3.2, it was discussed the main aspects regarding the different DEA models. In the present section, which is the first step of the last stage of DEA application, it is discussed how to choose the suitable DEA model to evaluate road concessions.

Based on the literature review, first the analyst has to decide between the two DEA approaches: radial or non-radial models. Radial models are the represented by CRS and VRS models and it is required to define the orientation (input or output) of the model. Non-radial models combine both orientations and permits to identify input excesses and output shortfalls at the same time. 
The model type should be selected based on the objectives of the efficiency analysis. In the case of road concessions studied in this thesis, the ultimate aim of measuring the efficiency of the concessionaires is to incentivize the firms to improve productivity.

Before defining the model, it is worth to remember the components of the economy efficiency measures. Technical efficiency is the ability of a firm to achieve minimum input given its set of outputs. Allocative efficiency is when a firm combines input and output in optimal proportions. When the time component is included in the analysis, it is called technical change, which is the improvement due to the technological progress in the industry over the time. It can be represented by an increase in the maximum output that can be produced given an input set.

As it was discussed, in general, regulated firms are not able to alter the output mix because they have to offer minimum service established in the contract. So, when regulators are setting the X-factor, in the most cases, they may remove the allocative efficiency analysis from the performance comparisons among firms, because concessionaires cannot optimize input and outputs simultaneously. Therefore, regulators should focus primarily on measures of technical efficiency (catch-up) and technical change (frontier shift).

Given this, the use of radial DEA models seems to be adequate to measure technical efficiency of road concessionaires, achieving the objectives of the efficiency analysis.

Regarding radial models, they can be mainly grouped as: the returns to scale that the DMUs under investigation are experiencing (constant or variable), and model orientation (input or output).

As depicted in the preceding chapters, the first DEA model developed, CRS model, assumes constant returns to scale of activities of the DMUs. Then, this model was extended to assume variable returns to scale, VRS model, by adding another restriction to the envelopment requirements. As a result, the production function of VRS models will be a convex combination of the observed efficient DMUs.

After deciding to use radial model, first regulator should investigate the process performed by such DMU in order to decide on the returns to scale of these activities. For an activity with constant return to scale, the production possibility set has the following property: if $(x, y)$ is a feasible point, then (tx, ty) for any positive $t$ is also feasible. For the case of road concession, the particularities of each concessionaire should be analyzed. Nevertheless, regarding the features of 
road sector, regulators should consider that, to a given input increase, output should not have the same proportional change, as it could be usual for industrial activities.

The following decision is about the orientation of the model. Input oriented model tries to minimize inputs to a given output levels. Output oriented model tries to maximize outputs to a given input levels.

Therefore, regulators should decide based on the dynamics of the process that is analyzed. If the process is more flexible in modifying the inputs, the input oriented model should be chosen as it seeks the optimization of the inputs utilized, without changing the levels by which outputs are produced. In other cases, when the process is more flexible in modifying the outputs, the output oriented model should be chosen as it seeks the optimization of the output without changing the levels by which inputs are utilized.

The decision to choose either an input orientation or an output orientation for the model is also usually done on the basis of which set of variables, inputs or outputs, the firm has most control over. In the case of regulated utilities of network industries (electricity, water and transport), the input-oriented model is most often used because these firms often have more control over inputs and have little influence over output levels. Figure 12 summarizes the process to choose the DEA model, and shows which decisions regulators should make when use DEA radial models. 


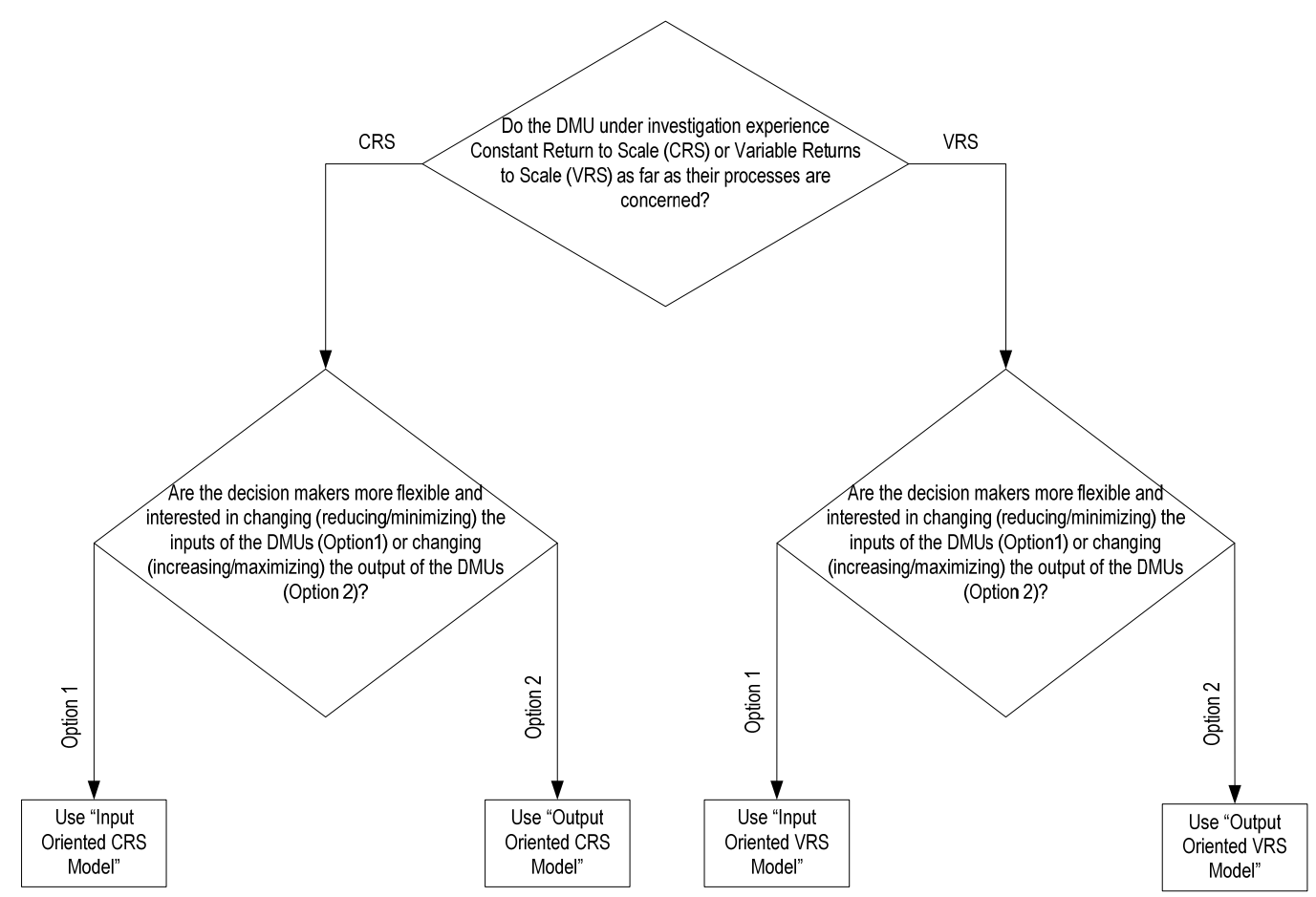

Source: Adapted from Ozbek, de la Garza and Triantis (2010)

Figure 12 - Flowchart of the decisions to choose the DEA model

Finally, at the end of this stage, the DEA model to be used to measure the efficiency should be defined. The following section presents how to run DEA models in specific software and which are the results obtained from this analysis.

\subsection{Applications of DEA models and analysis of results}

In this phase, the analyst will run the DEA model identified in the previous phase. To that end, it is necessary to know the DMUs and variables identified in advance. Usually this phase is performed with the help of a software package, due to the complex computation requirements of DEA models.

As DEA calculation is based on linear programming, any software that is designed to solve linear programming formulations can be used to solve DEA problems. However, DEA applications require solving separate linear programming problems for each DMU that is in the data set, and this can make the process too long. For that reason, it is recommended to use specialized software for DEA, which have the ability to quickly solve DEA problems with a large number of 
DMUs in the data set, and besides it offers solution mechanisms to advanced modeling formulations, graphical user interface and interoperability with other applications.

So, the first step of this phase is to choose the DEA software that will be used to run DEA model. There are many DEA software available in the market. They basically differ in the numbers of DMUs and variables that can be used in the model. However, restrictions that can be applied to the variables or correlation analysis of the results are also a distinction between them.

Therefore, it is necessary to decide which DEA software will satisfy the requirements based on the characteristics of the DEA model, number of DMUs and variables. It is important to consider problem size of data set in computer programs, as the limited number of DMUs allowed to be used, which can be an issue when using software learning or free version. Moreover, when choose the software, the analyst should know which results the software provides and if they achieve the objectives of DEA analysis.

After deciding the DEA software to be used, the analyst should study the software specification, manly regarding the format to input data set, how to choose DEA model to be used and how results are displayed in the program.

Prior to the execution of DEA software, the data set should be prepared in a excel workbook according to the requirements of the software. Despite the spreadsheet format correspond with the software, normally DMU is the first column and input and output variables are the following columns.

At this stage is important to check inappropriate data in the data set, for example when data set exceeds the allowed limits or data set has errors, as non-numerical or negative numbers. Preparing the data correctly permits the analyst uses different DEA models to the same data, and even different software, depending on the results the person needs.

The following step after importing the data set to the software, is to define DEA model details, when it should be specified the model, orientation and returns to scale to be used. The entry of this information will depend on how each software works. It can be using codes to each characteristic of DEA model, or other can have a benefit of visual displays. At this stage it can also be added restrictions to the data set, for example, using AR Model, inserting constraints for the assurance region or the use of BND Model, which imposes lower and upper bounds to inputs and outputs. 
Next step is to run the envelopment model. The results are usually presented in worksheets, summarizing DEA results and include statistics on data set used. For instance, the worksheets of results can contain information regarding: the summary on data and results, the efficiency score, the reference set (targets), the descending order ranking of efficiency scores, the optimal multipliers (weight), the slacks, the projection onto the efficiency frontiers, and also graphs as a bar chart of the scores and a bar chart of scores in ascending order.

Thus, the analyst should clearly know which aspect is the most important to be evaluated by DEA analysis and learn the results each software gives, in order to choose the software that meet the requirements.

After running the DEA model and analyzing the results, it is important to bear in mind that DEA results of efficiency are based on the variables selected. Therefore, there is no guarantee that the initial selection of variables and DMUs is correct. That is the reason why literature recommends to obtain more than one set of results as derived from different selection of DMUs, variables and formulations, pursuing the results that serves the best purpose of the analysis.

So, at this stage the analyst should examine the effect in the results by removing or changing the variables of DEA model, for example, running DEA model again after reducing the number of variables or increasing the number of DMUs. Also one should seek for some inconsistent results that can come from conflict of variables. For instance, if every DMU is efficient it can probably indicate that the DEA model used is not the most suitable to run this analysis.

DEA results can be used to direct decision maker attention to developing a better understanding why some DMU's are located on the efficient frontier and thus efficient and why others are inefficient. To that end, DEA results should be presented in a very concise way, drawing attention of decision makers to the importance of the results. It can be possibly achieved with the use of some charts and easy tables.

The overall objective of DEA is to assign organizational meaning to the observed efficiency differences and to determine the organizational changes that the inefficient DMUs will need to undertake and how to implement such change. It can be obtained by identifying operational and structural characteristic that makes one DMU be more efficient than others. DEA results are also intended to be used as guides for managerial actions and policy making as calculated targets. 
This section finishes the application of DEA method, as shown in Figure 11. This thesis goes further in the use of DEA results comparing to the standard DEA studies. In the next section, it is presented a proposition that uses the efficiency scores of the DMUs, obtained by DEA application, to calculate the $X$-factor of the price cap formula.

\subsection{Set the X-factor}

This section describes the last step of the proposed framework: determination of the Xfactor used in price cap regulation of road concessions. As the X-factor reflects the productivity gains of the concessionaires that will be shared with the consumers, this study proposes to use the efficiency data obtained by DEA models in order to represent the gains of the concessionaires due to efficiency improvements.

As seen in section 3.3 , the literature review shows that DEA approach is widely used by regulators to measure the efficiency of firms. For this reason, DEA method was chosen to be used in this proposition. Furthermore, efficiency is the type of attribute more appropriated to be used in order to incentivize the firms, because it compares the productivity of the firms, which avoid the firm to manipulate its efficiency level over the years.

This research proposes to set one X-factor for each firm, which permits to evaluate and consider the particularities of each concession.

When setting the X-factor, there are two important components regulators should consider regarding efficiency measurement:

i. industry component: reflects the efficiency gains that have resulted from the industry wide technological progress;

ii. firm specific component: reflects each regulated firm's practices that improve the efficiency.

Considering these two components, a practical formula to calculate the $\mathrm{X}$-factor, suggested in section 2.5, is presented in the Equation (13), repeated here. 


$$
X_{i}=T F P G^{I}+\left[\left(T F P_{B}^{F}-T F P_{i}^{F}\right) / n\right]
$$

Where:

$X_{i}=\mathrm{X}$-factor of the firm under analysis

$T F P G^{I}=$ Annual index of the Total Factor Productivity Growth of the industry in the period

$T F P_{B}^{F}=$ Annual index of the Total Factor Productivity of the best firm in the period

$T F P_{i}^{F}=$ Annual index of the Total Factor Productivity of the firm under analysis in the period

$n=$ time period between revisions

With this equation the twofold objectives of the regulator are achieved:

i. $\quad$ share productivity gains of the regulated firms with the users: represented by the first part of the equation $\left(T F P G^{I}\right)$, where the productivity gains achieved by technological improvements in the industry are shared with users;

ii. incentivize the regulated firms to improve productivity: represented by the second part of the equation $\left[\left(T F P_{B}^{F}-T F P_{i}^{F}\right) / n\right]$, where firms below the frontier have to become efficient during the time between revision.

Decomposing the equation, the first part $\left(T F P G^{I}\right)$ can be calculated by the basic formula of Total Factor Productivity, using the Equation (14), seen in section 3.1. To measure the industry component it is necessary to study the efficiency trends in the overall industry. However, it is not simple to have reliable data regarding the industry as a whole and these formulas are most used to define the economic theory.

In practice, there is an alternative way to calculate the Total Factor Productivity Growth using the efficiency change of the sector where the firms are inserted. It can be measured by the technological change component of DEA-based Malmquist productivity index, which measure the shift in the productivity frontier over the time (see Equation (19), section 3.2). The main difference is that DEA-based Malmquist productivity index considers as industry only the firms under analysis.

Another way to try to deal with data limitation is comparing the regulated utilities to foreign ones. Although this solution is not recommended because it does not guarantee a correct comparison, because foreign firms can have different technological level in comparison with 
domestic firms, which can lead to an improper X-factor. For example, if foreign companies operate in a technological level not achievable by domestic firms, the productivity gains of the industry will be incorrectly calculated. Therefore, the X-factor may subsequently be set too high, threatening the economic and financial stability of domestic regulated firms.

For the second part of the Equation $\left(\left[\left(T F P_{B}^{F}-T F P_{i}^{F}\right) / n\right]\right)$, which measures the Total Factor Productivity of the firm, it is suggested to use the efficiency data obtained in DEA models, as seen before. In the case of using more than one DEA model, it should be used the average of efficiencies obtained in the years under analysis.

After calculating the $\mathrm{X}$-factor regulators must carry out a feasibility analysis, based on the characteristics of each firm, in order to set $X$-factors that actually incentivize firms to improve efficiency, even the efficient ones. In addition, regulators can establish a maximum $X$-factor, aiming to avoid $\mathrm{X}$-factor values not possible to achieve for the inefficient firms.

When fixing the X-factor, regulators should also pay attention to the following recommendations:

- In the early years of the concession, regulators should use a simple model, with few variables, until the firms can generate enough information to be evaluated;

- Clearly define in the first year of regulatory or revision period what will be done in the next years, because predictability and consistency are essential for any incentive regulatory structure, and the introduction of uncertainty to the process can dilute incentives;

- The X-factor should not be imposed by regulators. In some exceptional cases, when a firm has significant differences from the others that could affect its productivity, it could be applied a percentage to reduce the $X$-factor set by the scientific method. This mechanism intends to correct failures of the process and also to ensure firms' commitment to improve efficiency, adjusting the $X$-factor to an achievable value;

- Evaluate the firm's planned investments for the next five years, because productivity increases faster when investment increases;

- Use comparison between regulated companies, which can be achieved using a method like DEA;

- When comparing firms, consider the maturity of the concessions; 
- Try not to penalize the best firms, by allocating all the productivity gains to the users instead of sharing them;

- Require that inefficient firms improve gradually;

- Regulator must work closely to inefficient firms;

- Changes in laws and regulations may change the productivity of firms in the future years;

- Regulators should always keep in mind that the ultimate goal is to incentivize the firms to improve efficiency continuously and the X-factor should not be seen as a punishment.

After setting the $X$-factor, regulators can also use the results of DEA to seek the best practices of the most efficient firms in order to share them with the inefficient ones. It will allow generate an improvement in the industry, besides help inefficient firms to improve their performance.

In conclusion, this chapter proposed a complete framework to set the X-factor for road concessions. The discussions presented here will be the guidance to the implementation in practice of the proposed framework, in the following chapter. 


\section{APPLICATION OF THE FRAMEWORK PROPOSED TO SET THE X-FACTOR}


This is the chapter in which the framework developed in Chapter 6 is applied to real life data of road concession projects. It is worth to remember that the proposition of this thesis is to develop a framework to set the X-factor, using a benchmarking study based on the concessionaires' efficiency. Thus, this chapter presents a case study, applying the proposed framework to the current Brazilian road concessions.

This chapter, first, presents a briefly overview of the Brazilian road concessions, showing the reason why this country has a proper road concession program to apply this study. Then, it begins the implementation of the proposed framework to the Brazilian case, following the steps showed in Figure 10.

In the first step it is defined the evaluation objectives and selected the DMUs to enter the analysis. Then, it presents the comprehensive list of variables that have initially been decided to be included in the DEA study. After refining this list, it presents the final list of variables to be used in actual implementation of DEA. After that, it illustrates the data preparation process performed to make such data ready to be used in the DEA model. Then, it discusses the reason for the selection of the particular DEA model that is used in this study and presents the results of the application of DEA model. Finally, it uses the efficiency data obtained by DEA models to calculate the X-factor. By the conclusion of this chapter, the results are discussed and the specific objectives of this research as listed in Section 5.2 will have been achieved.

It is important to note that this section possesses a full implementation example of the framework proposed to set the X-factor, as developed in Chapter 6, applied for the road concessions.

\subsection{Brazilian road concessions}

The application of the method proposed in this thesis was based on the Brazilian federal road concessions. This section presents a briefly overview of the Brazilian concession program and the reason to choose this country as an example to the proposed framework to set the $X$ factor. The experience of road concession in Brazil was described in more detail in Chapter 4, which also provides the main aspects about regulation and innovation of the contracts. 
In Brazil, the first toll road concession program was launched by the Federal Government in 1995 as part of the National Privatization Program. The government aimed to increase investments and quality in roads, without spending the public budget.

By 2015, the federal government had granted concessions to the private sector amounting to $9,969 \mathrm{~km}$ of roads. Brazil has one of the longest road networks, under private concessions, in the entire world. Figure 13 shows the expansion of the program from it beginning, in total length of federal road concession. Therefore, the expansion of Brazilian road concession program over the last decades consolidated its important position in developing and implementing toll road projects.

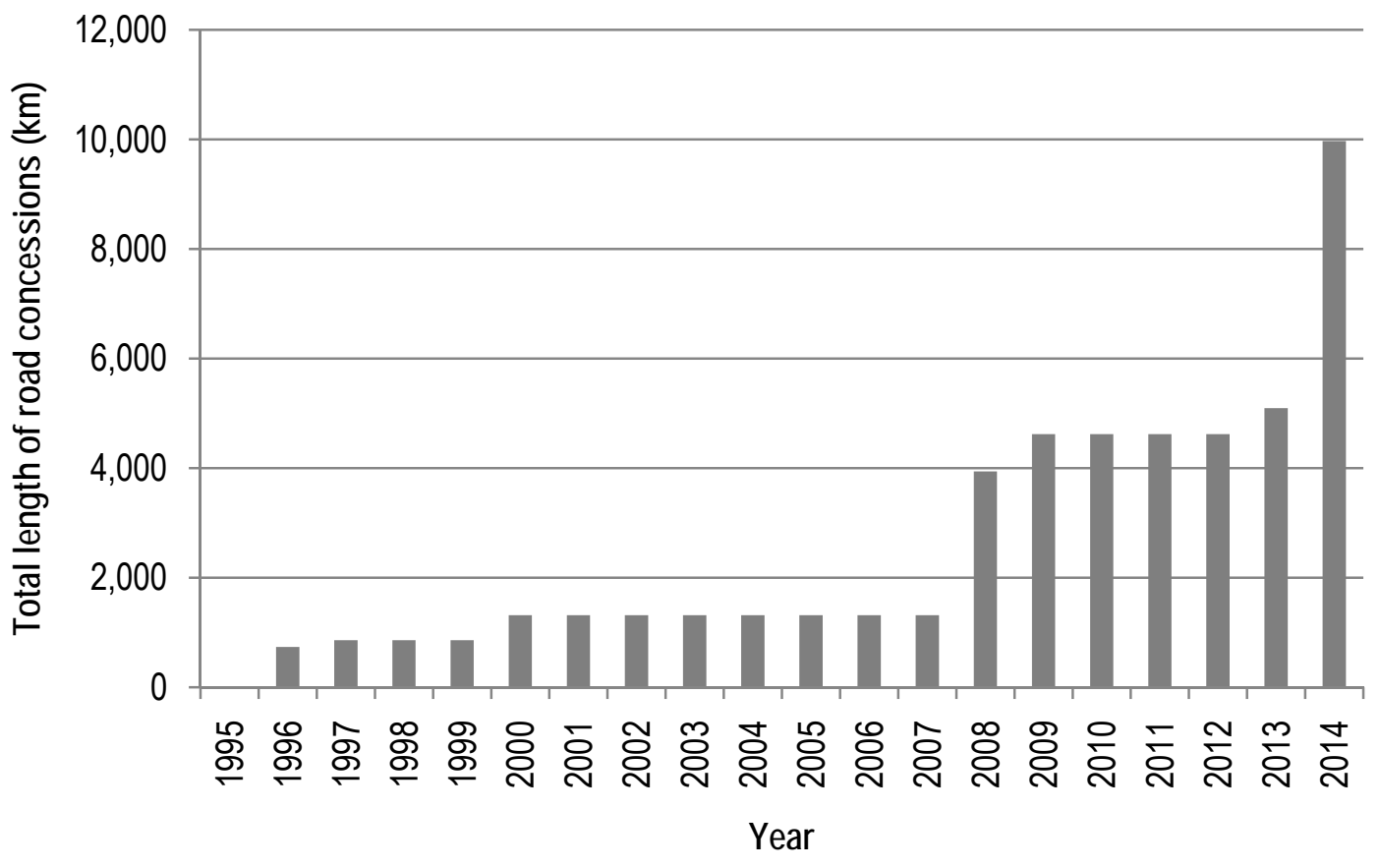

Data taken from www.antt.gov.br

Figure 13 - Expansion of the federal road concession program in Brazil

Furthermore, Brazil is a developing country which has a high demand for investments in infrastructure in order to achieve sustained economic growth. In the road sector, investments are mostly funded by the private sector. So it is important to develop the regulatory system which is the foundation of the road concession programs. Moreover, study the case of Brazil should be of interest for emerging countries intending to promote extensive programs of road-building using the concession method. 
Regarding the regulatory system of the Brazilian federal road concessions, the contracts awarded from 2012 adopted the price cap regulation. This innovation in the contracts aims to enhance and adapt them to modern regulatory methods of incentive regulation.

As seen in Chapter 4, in the price cap regulation, the adjustment index is set on the basis of RPI - X, which uses the RPI less the efficiency factor, called the X-factor. The reduction of the $X$-factor in the toll rate adjustment is to incentivize efficiency and to share productivity gains made by the concessionaires with the users. For this reason, it is essential to set the X-factor correctly.

However, the contracts in Brazil do not establish a method to calculate the X-factor. Therefore, the main reason to use Brazil as an example is because their road concession contracts use the price cap regulation, and lack a method to set the $\mathrm{X}$-factor.

In addition, the data to perform this task is made available in the Regulatory Agency ANTT Annual Reports, which provide enough historic data regarding the operational aspects of the current concessions to apply the method proposed.

Another aspect is that the Brazilian federal government had granted road concessions to the private sector in three different stages. As each stage has quite similar contracts, there are groups of road concessionaires that can be compared, when applied the benchmarking study based on the concessionaires' efficiency.

\subsection{Objectives of the evaluation}

Following the steps to measure the efficiency of the road concessionaires, using DEA method, this section defines the evaluation objectives that will guide the whole process of DEA analysis.

As discussed in section 6.2 , the private firm that manages the toll road, called concessionaires, has the responsibility to offer the road users the standards of the level of service established in the concession contract. To that end, the firm is responsible for carrying out the road services needed to achieve the standards, including maintenance, operation and road works. 
Brazilian federal road concession contracts include a large range of performance parameters. Hence, concessionaires have to meet the requirements established for each aspect of the road system (pavement, road signs, drain system, buildings, operation etc).

Therefore, the objective of the efficiency analysis should assess if the concessionaires are meeting the requirements specified in the contract. Thus, the efficiency analysis should evaluate the productivity of the concessionaires in relation to their contractual obligations. Moreover, in order to represent the productivity of a road concessionaire, the analysis should be based on the main aspects of the road operation.

According to the features of Brazilian federal road concession contracts (seen in Chapter 4) and as suggested in section 6.2, the objective when considering Brazilian federal road concessionaires is to analyze the relative efficiency and performance among road concessionaires using DEA method, concerning the following aspects: road safety, user assistance, availability and quality.

Regarding the contract requirements for road work and operation, in addition to the operational data that should be monitored by the concessionaires, each aspect of the objective can be evaluated using the following information:

- $\quad$ road safety: accident data;

- user assistance: number of user assistances;

- $\quad$ availability: traffic service data;

- quality: number of infractions that the concessionaires receive from the inspections of the regulatory agency.

Considering the available data in the Regulatory Agency ANTT Annual Reports, which is the official report regarding federal road concessions in Brazil, in the application of the methodology proposed it is possible to develop the analysis on twofold aspects: road safety and user assistance.

In order to evaluate the availability, it would be necessary to have data regarding the level of service (LOS) of the road, which measures the quality of traffic service, and to evaluate the quality, it would be necessary to have data regarding the number of infractions that the concessionaire received. However, there is no sufficient data available in the reports to develop the DEA method for these two aspects: availability and quality. 
Thus, the objective of this evaluation is to analyze the relative efficiency and performance among road concessionaires of the Brazilian federal toll roads, regarding road safety and user assistance.

\subsection{Select DMUs}

The next step of the DEA application, after defining the evaluation objective, is to select the population of DMU and divide them into comparable groups.

DMUs represent the companies that will be evaluated. Therefore, in order to develop an accurate comparison among them, DMUs should have similar objective, identical resources and products and work in similar environment and market conditions. DMUs will differ in the amount of inputs they consume and the quantity of outputs they produce.

In the present study the DMUs are the federal road concessionaires in Brazil. However, as seen in Chapter 4, each stage of the road concession program in Brazil has different features regarding the key aspects of its regulatory system and contracts. Thus, concessionaires (DMUs) should be divided into comparable groups.

As this thesis studies a particularity of the price cap regulation regime, which is the $\mathrm{X}$ factor, the comparable group of DMUs has to be defined based on the regulatory environment in which the concessionaires operate.

Regarding the Brazilian federal road concession, the contracts of the same stage of the concession program have similar regulatory characteristics. Hence, in order to compare the concessionaires, they should be divided concerning the stage of the road concession program they belong.

There are three stages in Brazilian road concession program. The concessions of first stage were granted from 1995 to 1998. The second stage granted concessions between 2008 and 2009. Finally, the third stage began in 2012 and continuous in present-day.

Due to data availability constraint, currently it is possible to analyze only the concessionaires from the first and second stages. As the third stage started in 2012, there is no data available to carry out an efficiency analysis. 
After define the DMUs groups (first and second stage of federal road concessions), it is necessary to evaluate the number of DMUs regarding the rule of thumb seen in Equation 31, section 6.2 .

The first stage has 6 concessionaires and the second stage has 7 concessionaires. If we consider each concessionaire as one DMU, it will limit to use DEA model with only one input and one output, because the number of DMUs should be three times greater than the number of inputs plus outputs. Aiming to carry out a comprehensive efficiency analysis, the number of DMUs should be increased. For this purpose, we considered each year of the concessions as one DMU. This way the number of DMUs increases, allowing an analysis of the efficiency over the time.

The use of this alternative is not an issue, because the X-factor needs to be calculated for each revision period, which in general occurs every 5 years.

\subsection{Determination of inputs and outputs variables}

After defining the evaluation objectives and DMUs, we start the second stage of DEA flowchart that is to select inputs and outputs variables. These variables are used to assess DMUs performance and they should reflect the main aspects of resources used in the activity concerned.

Most authors recommend beginning this stage by developing a comprehensive list of inputs-outputs variables. After, this list should be reinvestigated and refined to include only the most relevant and important variables, in order to increase the discriminating power of DEA models. Then the investigator must address any issue among the variables used.

Following the suggestion presented in Section 6.3, the initial list is developed with all the information available regarding the Brazilian federal roads under concession, as shown in Table 8. As seen, this first list is very comprehensive and it was obtained from the ANTT Annual Reports. 
Table 8 - Information available in ANTT Annual Reports

\begin{tabular}{|c|c|c|c|c|c|c|c|c|c|c|}
\hline \multirow{2}{*}{ Information } & \multicolumn{10}{|c|}{ Year of the Annual Report } \\
\hline & 2004 & 2005 & 2006 & 2007 & 2008 & 2009 & 2010 & 2011 & 2012 & 2013 \\
\hline $\begin{array}{l}\text { Number of vehicles of the } \\
\text { concessionaire }\end{array}$ & $\mathrm{X}$ & $x$ & $x$ & $x$ & $x$ & $x$ & $x$ & $x$ & $x$ & $x$ \\
\hline Number of employees & $x$ & $x$ & $x$ & $x$ & $x$ & $x$ & $x$ & $x$ & $x$ & $x$ \\
\hline $\begin{array}{l}\text { Type of road (minimum } \\
\text { radius of horizontal curve } \\
\text { and maximum gradient) }\end{array}$ & & & & & $X$ & $\mathrm{X}$ & $\mathrm{X}$ & $x$ & $x$ & $X$ \\
\hline Length of road lighting & & & & & $x$ & $x$ & $x$ & $\mathrm{X}$ & $\mathrm{X}$ & $x$ \\
\hline $\begin{array}{l}\text { Length of road that can } \\
\text { present fog }\end{array}$ & & & & & $\mathrm{X}$ & $\mathrm{X}$ & $\mathrm{X}$ & $x$ & $X$ & $X$ \\
\hline Number of toll plaza & $\mathrm{X}$ & $x$ & $x$ & $\mathrm{X}$ & $x$ & $x$ & $x$ & $x$ & $x$ & $x$ \\
\hline Number of toll booth & & & & & $x$ & $x$ & $x$ & $x$ & $x$ & $x$ \\
\hline $\begin{array}{l}\text { Number of lanes in the toll } \\
\text { plaza }\end{array}$ & & & & & $X$ & $x$ & $\mathrm{X}$ & $x$ & $x$ & $X$ \\
\hline Number of weighing stations & & & & & $x$ & $x$ & $x$ & $x$ & $x$ & $x$ \\
\hline $\begin{array}{l}\text { Length of engineering } \\
\text { structure (bridges and } \\
\text { tunnels) }\end{array}$ & & & & & $X$ & $\mathrm{X}$ & $\mathrm{X}$ & $x$ & $x$ & $x$ \\
\hline Number of operational base & & & & & $X$ & $x$ & $x$ & $x$ & $x$ & $x$ \\
\hline Number of police station & & & & & $x$ & $x$ & $x$ & $x$ & $x$ & $x$ \\
\hline $\begin{array}{l}\text { Number of variable } \\
\text { message sign }\end{array}$ & & & & & $X$ & $x$ & $x$ & $x$ & $x$ & $x$ \\
\hline Number of video cameras & & & & & $X$ & $x$ & $x$ & $x$ & $x$ & $x$ \\
\hline Level of service & & & & & & $x$ & $x$ & $x$ & $x$ & $x$ \\
\hline Number of accidents & $X$ & $x$ & $x$ & $X$ & $X$ & $\mathrm{X}$ & $x$ & $X$ & $x$ & $x$ \\
\hline Number of user assistances & & $x$ & $x$ & $X$ & $X$ & $\mathrm{X}$ & $x$ & $x$ & $x$ & $x$ \\
\hline Number of infraction notice & & & & & & $x$ & $x$ & $x$ & $x$ & $x$ \\
\hline Number of irregularity report & & & & & & $\mathrm{X}$ & $x$ & $x$ & $x$ & $x$ \\
\hline Length (km) & $x$ & $x$ & $x$ & $x$ & $x$ & $x$ & $x$ & $x$ & $x$ & $X$ \\
\hline Number of lanes & & & & & $x$ & $x$ & $x$ & $x$ & $x$ & $x$ \\
\hline Annual traffic volume & $x$ & $x$ & $\mathrm{X}$ & $X$ & $X$ & $x$ & $\mathrm{X}$ & $X$ & $X$ & $X$ \\
\hline
\end{tabular}

Source: ANTT Annual Reports 
From this first list, it is important to compare the variables available in the present study with the variables used in the publications that used DEA method to measure the efficiency in the road sector, as showed in Table 2 (section 3.3).

The most used variables in the previous studies are: revenue and costs information, infrastructure performance parameters, number of employees, number of equipments, length of road, number of lanes of the road, annual traffic and number of accidents.

The information available in ANTT Annual Reports has considerable similarities to the variables used in the literature. However, we can note that this first list includes only physical aspects of the road and operational factors concerning concessionaire's responsibilities. As revenue and cost information is widely used to represent the inputs and outputs of a process in DEA analysis, it is important to discuss about the financial information of the concessionaires in the Brazilian road concession model.

ANTT published information concerning costs, investments and revenues of the concessionaires until 2008. However, this data was obtained from the balance sheet used to calculate the toll rate. Under the project finance arrangement, the values in the balance sheet are used to calculate the toll rate and they are defined at the time of the bid proposal. In the Brazilian road concessions, it is concessionaires' risk to spend less or earn more money than its bid proposal. Therefore, these predefined values of the balance sheet do not change over the years with the aim to update to actual costs and revenues of the firms.

Consequently, this financial information provided in the ANTT Annual Reports does not represent actual expenditures, revenues and investments of the concessionaire. For that reason, they cannot be used to represent the efficiency or the productivity gains of the concessionaire. Thus, in the present study, as there is no actual information about cost or investment, we use information regarding operational duties of concessionaires, which can represent the cost of the process.

After these considerations, we will start the first refinement of the list. As we are using each year as a DMU, it is not recommend using information that does not differ in time. Furthermore, as these variables are not manageable by the concessionaire, they cannot be used as an input. Moreover, as these variables are fixed and they will not represent the efficiency of the company, they cannot be used as an output. 
Then, in order to reduce the initial list we will eliminate the information that is a contractual parameter and it will not change in time or it is very hard to change. At this stage we remove the following information from the list: number of toll plaza; number of weighing stations and number of police station.

It is worth to say that the length of the road and the number of lanes will not change in time, but they can be used to rescale the variables, so they cannot be discarded.

The second refinement of the list is to separate into inputs and outputs, where input items represent the resources used in the process and output items represent the product to achieve organization objectives. Table 9 shows the division of the variables, regarding the formulation of the Cobb-Douglas production function, which is frequently used in economics to represent the relationship among the amounts of two or more inputs, particularly physical capital and labor, and the amount of output that can be produced by those inputs. 
Table 9 - Variables divided into input and output

\begin{tabular}{|c|c|c|}
\hline \multicolumn{2}{|r|}{ Characteristic } & Variable \\
\hline \multirow{10}{*}{ Inputs } & Capital & Number of vehicles of the concessionaire \\
\hline & Labor & Number of employees \\
\hline & \multirow{7}{*}{ Infrastructure } & Length of road lighting \\
\hline & & Number of toll booth \\
\hline & & Number of lanes in the toll plaza \\
\hline & & Length of engineering structure (bridges and tunnels) \\
\hline & & Number of operational base \\
\hline & & Number of variable message sign \\
\hline & & Number of video cameras \\
\hline & $\begin{array}{l}\text { Climatic factor (uncontrollable } \\
\text { factor) }\end{array}$ & Length of road that can present fog \\
\hline \multirow{5}{*}{ Output } & Availability & Level of service \\
\hline & Safety & Number of accidents \\
\hline & User assistance & Number of user assistances \\
\hline & \multirow{2}{*}{ Quality } & Number of infraction notice \\
\hline & & Number of irregularity report \\
\hline \multirow{4}{*}{\multicolumn{2}{|c|}{ Rescale }} & $\begin{array}{l}\text { Type of road (minimum radius of horizontal curve and } \\
\text { maximum gradient) }\end{array}$ \\
\hline & & Length (km) \\
\hline & & Number of lanes \\
\hline & & Annual traffic volume \\
\hline
\end{tabular}


The next refinement of the list is to eliminate the variables that are established in the contract with minimum values and which are very expensive to the concessionaire to increase their number. Therefore, due to their costly implementation, in all likelihood these variables will not change over time.

In this step we also exclude the physical characteristics of the road that are not related to the objectives of the processes that are being evaluated using DEA, which are road safety and user assistance.

Thus, these are the variables excluded in this last refinement: length of road lighting; number of toll booth; number of lanes in the toll plaza; length of engineering structure (bridges and tunnels); number of operational base; number of variable message sign; number of video cameras; length of road that can present fog and type of road (minimum radius of horizontal curve and maximum gradient). Table 10 shows the final reduced list, obtained after the refinements.

Table 10 - Final reduced list of variables

\begin{tabular}{l|l|l}
\hline \multirow{2}{*}{ Inputs } & Capital & \multicolumn{1}{c}{ Variable } \\
\cline { 2 - 3 } & Labor & Number of vehicles of the concessionaire \\
\hline \multirow{4}{*}{ Output } & Availability & Number of employees \\
\cline { 2 - 3 } & Safety & Level of service \\
\cline { 2 - 3 } & \multirow{2}{*}{ Quality } & Number of accidents \\
\cline { 2 - 3 } & & Number of user assistances \\
\hline \multirow{2}{*}{ Rescale } & & Number of infraction notice \\
\cline { 3 - 3 } & & Number of irregularity report \\
\hline & & Length (km) \\
\cline { 3 - 3 } & & Number of lanes \\
\cline { 3 - 3 } & & Annual traffic volume \\
\hline
\end{tabular}


Now, we start to focus attention on the two fold objectives of the analysis: road safety and user assistance. To that end, it is necessary to run two DEA models separately.

For each model we will define the inputs by identifying which variable best represent the duties of the concessionaire to achieve the objective of the process and defining the outputs by choosing which variable best represent the products of the process.

After, we carried out this two steps analysis with the aim of evaluating each model:

(1) Correlation analysis among variables: in order to remove a variable that is already represented by other variables in the data set and eliminate redundancies, because strong relations may indicate that the information contained in that factor is already represented by other factor. In addition, when we find a weak relation to all the factors may indicate a need to reexamine the factor and possibly delete it, because it probably has little influence in the process.

(2) Analyze the outcomes of DEA model: run a series of DEA model combining the variables and examine the outcomes. Factors which are consistently associated with very small multipliers or which have little impact on the efficiency score may be eliminated.

Starting with the Road Safety (SF) models, we used the following variables to define the model:

- Input: number of employees, number of vehicles of the concessionaire.

- Output: $1 /$ number of accidents.

- Rescale: length $(\mathrm{km})$, number of lanes, annual traffic volume.

It is important to remember that the number of accident is an undesirable output, and it cannot be used directly in the model. Therefore, we tried two alternatives: use the inverse of the number (models SF1 to SF7) and use this variable as input (models SF8 and SF9).

It is important to note that to handle with undesirable output it is also possible to use an extension of the DEA basic model. However, as in the present study we are working with two objectives (road safety and user assistance), it is crucial to use the same DEA model for both evaluations because their results will be combined at the end of the process.

The annual traffic volume is the total volume of vehicle traffic of a road for a year. As the concessionaire income come from the toll revenue paid by the users, the annual traffic volume is a useful and simple variable that represents the income of the concessionaire in the year. 
Table 11 shows the combinations among the variables that were tested and the results. The present analysis uses data of the concessionaires of 1 st stage from 2002 to 2006 . The correlations between variable are presented in the Appendix II.

Table 11 - Road Safety DEA models tested

\begin{tabular}{|c|c|c|c|c|}
\hline Model & Input & Output & $\begin{array}{l}\text { Correlation } \\
\text { Analysis }\end{array}$ & DEA outcomes \\
\hline SF1 & $\begin{array}{l}\text { number of employees, } \\
\text { number of vehicles of the } \\
\text { concessionaire, annual } \\
\text { traffic volume }\end{array}$ & $\begin{array}{l}1 / \text { number of } \\
\text { accidents }\end{array}$ & normal & $\begin{array}{l}\text { many efficient } \\
\text { DMUs } \\
\text { some DMUs with } \\
\text { very small } \\
\text { efficiencies }\end{array}$ \\
\hline SF2 & $\begin{array}{l}\text { number of employees, } \\
\text { number of vehicles of the } \\
\text { concessionaire, annual } \\
\text { traffic volume }\end{array}$ & $\begin{array}{l}\text { length }(\mathrm{km}) \text { / number } \\
\text { of accidents }\end{array}$ & $\begin{array}{c}\text { weak for } \\
\text { output }\end{array}$ & $\begin{array}{l}\text { many efficient } \\
\text { DMUs } \\
\text { some DMUs with } \\
\text { very small } \\
\text { efficiencies } \\
\end{array}$ \\
\hline SF3 & $\begin{array}{l}\text { number of employees, } \\
\text { number of vehicles of the } \\
\text { concessionaire, annual } \\
\text { traffic volume }\end{array}$ & $\begin{array}{l}\text { (length } \mathrm{x} \text { number of } \\
\text { lanes ) / number of } \\
\text { accidents }\end{array}$ & $\begin{array}{l}\text { weak for } \\
\text { output }\end{array}$ & $\begin{array}{l}\text { many efficient } \\
\text { DMUs } \\
\text { some DMUs with } \\
\text { very small } \\
\text { efficiencies }\end{array}$ \\
\hline SF4 & $\begin{array}{l}\text { number of employees/ } \\
\text { length }(\mathrm{km}) \text {, } \\
\text { number of vehicles of the } \\
\text { concessionaire/ length }(\mathrm{km})\end{array}$ & $\begin{array}{l}\text { annual traffic volume / } \\
\text { number of accidents }\end{array}$ & good & normal \\
\hline SF5 & $\begin{array}{l}\text { number of employees/ } \\
\text { (length } x \text { number of lanes), } \\
\text { number of vehicles of the } \\
\text { concessionaire/ (length } x \\
\text { number of lanes) }\end{array}$ & $\begin{array}{l}\text { annual traffic volume / } \\
\text { number of accidents }\end{array}$ & good & $\begin{array}{l}\text { some DMUs with } \\
\text { very small } \\
\text { efficiencies }\end{array}$ \\
\hline SF6 & $\begin{array}{l}\text { number of employees, } \\
\text { number of vehicles of the } \\
\text { concessionaire }\end{array}$ & $\begin{array}{l}\text { 1/number of } \\
\text { accidents, } \\
\text { annual traffic volume }\end{array}$ & normal & $\begin{array}{l}\text { many efficient } \\
\text { DMUs }\end{array}$ \\
\hline SF7 & $\begin{array}{l}\text { number of employees, } \\
\text { number of vehicles of the } \\
\text { concessionaire }\end{array}$ & $\begin{array}{l}1 / \text { number of } \\
\text { accidents, } \\
\text { annual traffic volume, } \\
\text { length }(\mathrm{km}) \times \text { number } \\
\text { of lanes }\end{array}$ & normal & $\begin{array}{l}\text { many efficient } \\
\text { DMUs }\end{array}$ \\
\hline SF8 & $\begin{array}{l}\text { annual traffic volume, } \\
\text { number of accidents }\end{array}$ & $\begin{array}{l}\text { number of } \\
\text { employees, } \\
\text { number of vehicles of } \\
\text { the concessionaire }\end{array}$ & good & $\begin{array}{l}\text { many efficient } \\
\text { DMUs }\end{array}$ \\
\hline SF9 & $\begin{array}{l}\text { annual traffic volume, } \\
\text { number of accidents, length } \\
(\mathrm{km}) \times \text { number of lanes }\end{array}$ & $\begin{array}{l}\text { number of } \\
\text { employees, } \\
\text { number of vehicles of } \\
\text { the concessionaire }\end{array}$ & good & $\begin{array}{l}\text { many efficient } \\
\text { DMUs }\end{array}$ \\
\hline
\end{tabular}


From the analysis of the models tested, we can note that when we used the length or number of lanes to rescale the output the models presented weak correlation or a lot of efficient DMUs (models SF2, SF3 and SF7). It is recommended to avoid the models with a lot of efficient DMUs, because it does not enhance the discriminatory power of DEA method to compare DMUs.

However, the length worked well to rescale the inputs as seen in the models SF4, SF5 and SF6.

Regarding the annual traffic volume variable, it can be used on both sides, as input and as output. On one hand, increasing the annual traffic volume results in higher costs for the process, then it can be used as an input. On the other hand, the vehicles have to pay the toll in the roads under concession, so the annual traffic volume also reflects the income of the firm and can be used as an output.

The results of the models tested indicate that the annual traffic volume is related more closely to the output (models SF4 and SF5) than the inputs. It can be explained because there are some fixed costs that do not vary with the annual traffic.

In order to deal with the number of accidents as an undesirable factor, we can note that using the inverse of the value works better than using the variable in the input side.

After analyzing all the combinations and outcomes, we decide to adopt the SF4 model, as illustrated in Figure 14.

Inputs

Process

Output
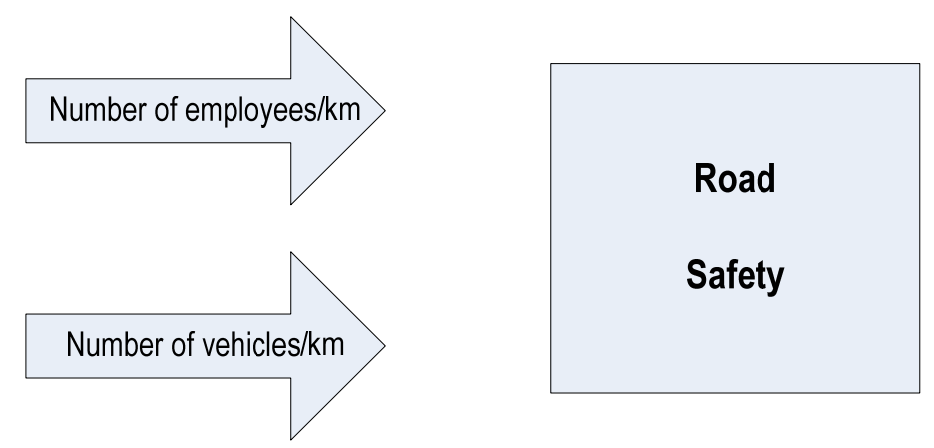

Figure 14 - DEA model to evaluate the Road Safety 
For the other objective evaluation, we used the following variables to define the user assistance (AT) model:

- Input: number of employees, number of vehicles of the concessionaire.

- Output: number of user assistances, annual traffic volume.

- Rescale: length (km).

In this analysis we consider that the number of lanes of the roads do not affect the process of user assistance by the concessionaires. That is the reason why we did not used this variable to rescale the inputs and outputs in this model.

Table 12 shows the combinations among the variables that were tested and the results. The present analysis uses data of the concessionaires of $1^{\text {st }}$ stage from 2005 to 2011. The correlations between variable are presented in the Appendix II.

Table 12 - User assistance DEA models tested

\begin{tabular}{lllll}
\hline Model & \multicolumn{1}{c}{ Input } & \multicolumn{1}{c}{ Output } & $\begin{array}{c}\text { Correlation } \\
\text { Analysis }\end{array}$ & DEA outcomes \\
\hline AT1 & $\begin{array}{l}\text { number of employees, } \\
\text { number of vehicles of } \\
\text { the concessionaire }\end{array}$ & $\begin{array}{l}\text { number of user } \\
\text { assistances, } \\
\text { annual traffic volume }\end{array}$ & good & normal \\
\hline AT2 & $\begin{array}{l}\text { number of employees, } \\
\text { number of vehicles of } \\
\text { the concessionaire }\end{array}$ & $\begin{array}{l}\text { number of user } \\
\text { assistances/ length } \\
(\mathrm{km}),\end{array}$ & weak \\
annual traffic volume & normal & & \\
\hline AT3 & $\begin{array}{l}\text { number of employees/ } \\
\text { length (km), } \\
\text { number of vehicles of } \\
\text { the concessionaire/ } \\
\text { length (km) }\end{array}$ & $\begin{array}{l}\text { number of user } \\
\text { assistances, } \\
\text { annual traffic volume }\end{array}$ & weak & $\begin{array}{l}\text { many efficient } \\
\text { DMUs } \\
\text { some DMUs with } \\
\text { very small } \\
\text { efficiencies }\end{array}$ \\
\hline AT4 & $\begin{array}{l}\text { number of employees, } \\
\text { number of vehicles of } \\
\text { the concessionaire }\end{array}$ & $\begin{array}{l}\text { number of user } \\
\text { assistances/ annual } \\
\text { traffic volume }\end{array}$ & weak & $\begin{array}{l}\text { some DMUs with } \\
\text { very small } \\
\text { efficiencies }\end{array}$ \\
\hline
\end{tabular}

From the results of the DEA models tested, we can note that the correlation analysis got worse if we rescaling the input or the output with the length of the road (see models AT2 and AT3).

We also tried to use the variable annual traffic volume in two different ways: as an output and to rescale the output. The model that has the annual traffic volume as an output (AT1) 
produced better results that when it was used to rescale. For this reason, we adopt the model AT1, as seen in Figure 15.

Inputs

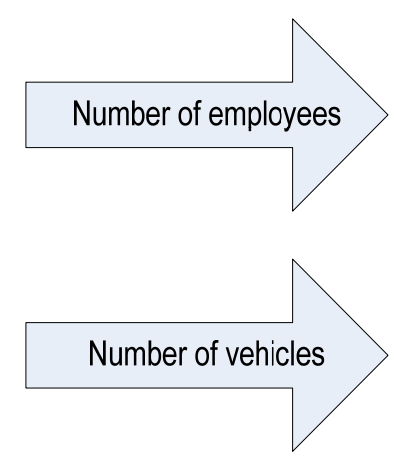

Process

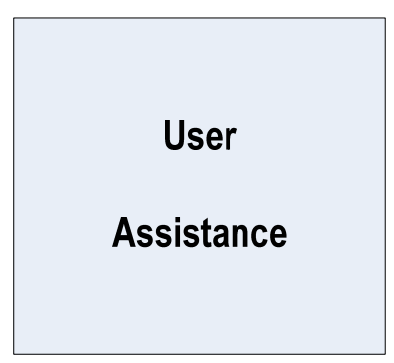

Outputs

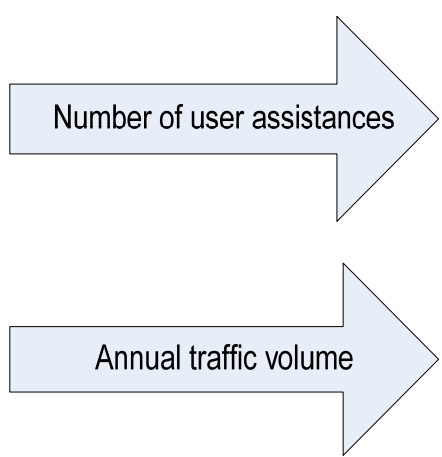

Figure 15 - DEA model to evaluate the User Assistance

In summary, in this section we defined the inputs and outputs to be used in the DEA models to evaluate the Brazilian road concessions, under two aspects: road safety and user assistance. The final models were chosen based in a list that contains each relevant and suitable controllable variable which characterize the process and is strongly related with the objectives of the DMUs, also affects the efficiency of them.

In addition, we deal with the number of accidents, which is an undesirable factor, by using its inverse value. Due to data limitation regarding Brazilian road concessions, we opted to limit the scope of our analysis to these two main objectives and to the period from 2004 to 2013.

It is worth to remember that regulators do not intend to define the optimal amount of inputs and outputs that should be used by the firms. Conversely, regulators role is to identify the relative inefficiencies among the concessionaires and fix goals in order to incentivize them to achieve these goals. That is the reason why in the present study the requirements to choose an input is that the variables have to represent an operational activity and should be totally manageable by the concessionaire, and the variables used as an outputs should represent the result of the work done by the concessionaire. 


\subsection{Application of DEA model and analysis of results}

This section describes the last step of the application of DEA model. Thus, after defining DMUs, studying available data and deciding the variables to be used as input and output, this section presents the application of DEA models and analyzes the results.

In order to analyze the results of DEA model application, first we study the efficiency score for each concessionaire and ranking them. In addition, we point out the most efficient DMUs, which will be used as benchmark for the other ones. Then, we study the evolution of the efficiency scores for each DMU over time. Finally, we present a general analysis for each firm, including suggestions for the firms to improve the process.

It is also worth to remember that we decided to use the data of each firm for different years as different DMUs. In other words, each DMU will be treated as different one for each period of time. Many authors assert that the average of the efficiency scores obtained for each period of time for a particular DMU results in an acceptable estimate of the overall efficiency of such DMU. By this approach, we have significantly increased the number of DMUs included in the DEA model, and also have addressed the issue of discrimination power. Besides it will make possible to examine the variations in the efficiency over time for a particular DMU.

\section{DEA model selection}

Before starting the application of DEA model, we have to select the type of DEA model that will be used in the study. As seen in chapter 6 , among the two approaches of DEA model (radial and non-radial), the use of radial model seems to be the most appropriate in order to measure the technical efficiency of road concessionaires and achieve the objectives of the efficiency analysis.

Concerning radial models, also in chapter 6, Figure 12 shows the process to choose the type of DEA model, regarding returns to scale and orientation. This decision should be made based on the characteristics of the process under analysis.

Following this guidance and considering the characteristics of the group of the concessionaires of the Brazilian Federal Road Concession Program, seen in chapter 4, we employ the assumption of variable return to scales (VRS) to account for the fact that the length of road managed for each firm vary greatly, as well as the characteristics of the terrain, ranging from mountainous to in level terrains. 
It is also necessary to decide on the orientation (input oriented or output oriented) of the model. This decision should be based on the choice of the decision makers to seek either input reductions or output increases in the process.

In the case of road concession, regulators focus on the technical efficiency (catch-up), which is to reduce the input to produce the same amount of output, and technical change (frontier shift), which is technological progress in time. Thus, regulators are interested in changing the input and keeping output constant, because in general outputs are fixed or not manageable by the concessionaire.

For that reason, the model to be used in this study is input oriented model. However, for the models that have undesirable output, it is necessary to use output orientation, because regulators seek to change the output, given that Road Safety DEA model assesses safety provided by the concessionaire, measured by the reduction in the number of accidents (undesirable output) using the same amount of resources (inputs).

\section{DEA Software}

The software package that is chosen to be used to solve DEA models developed in this research is MaxDEA, because besides its professional features, it possesses a very friendly interface and it is simple to use. It also has an added benefit to users, because there is no need to install a new software in the computer, as it runs in the Microsoft Access software.

In order to enter the data in the software users can import them from a Microsoft Excel file. For that end, users need to prepare in advance the data in an Excel spreadsheet. The first row of the Excel sheet must contain columns names. One column should be used for the DMU names and the other ones for each input and output of the model. When users import the Excel file they must indicate which column is the DMU name, which column are inputs and which column are outputs. If it is necessary to eliminate some input or output from the model temporarily, the user just needs to deactivate the check box. Figure 16 illustrates the screenshot of the software in the step where data is loaded. 


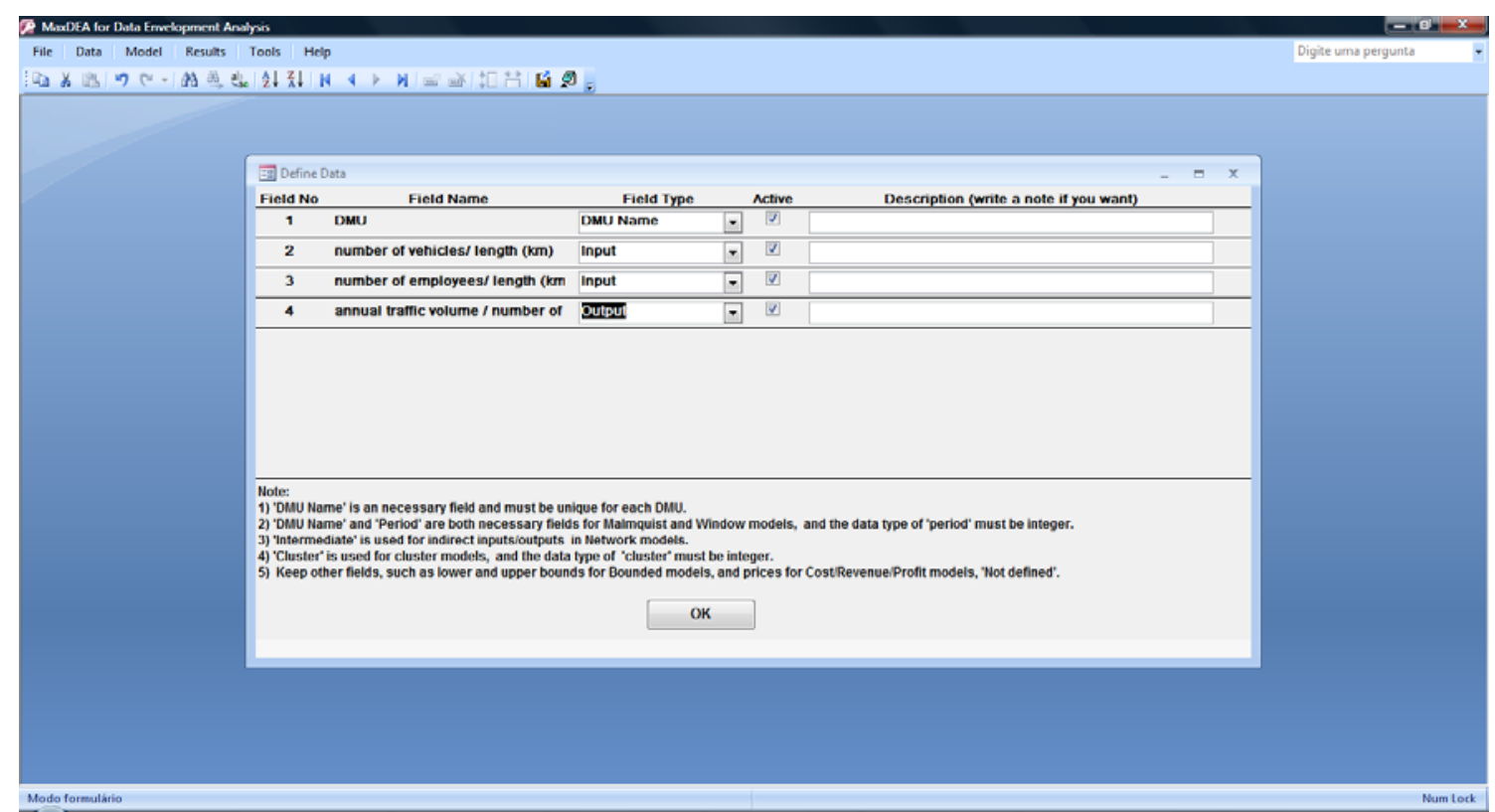

Figure 16 - MaxDEA Data loading step screenshot

The next step is to set specifications and option for the DEA model (distance, orientation and returns to scale). As seen in Figure 17, in the present study we use: radial model, input orientation and variable returns to scale (VRS). It is worth to remember that for the models with undesirable output (Road Safety model), we use output-orientation.

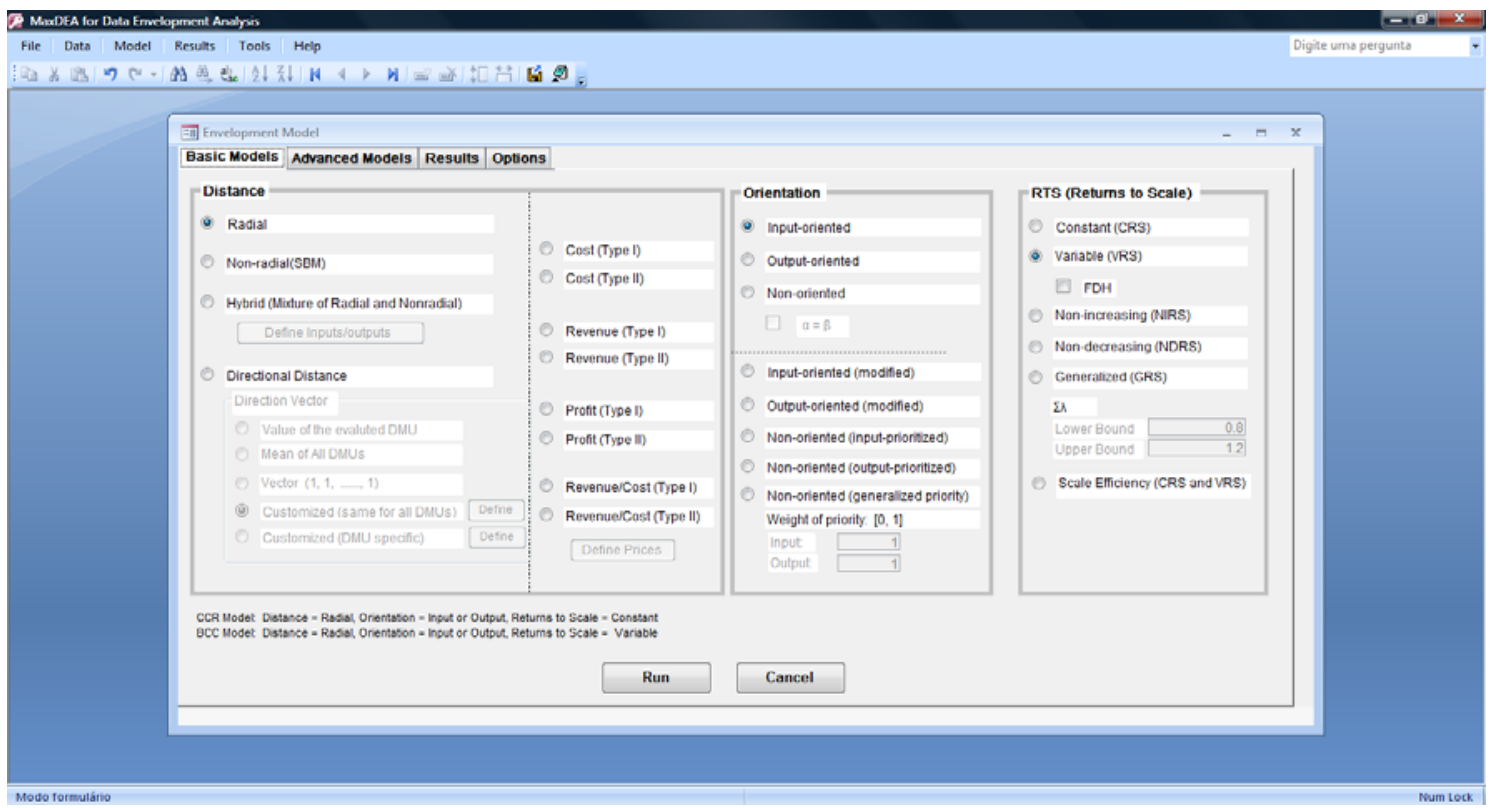

Figure 17 - MaxDEA Specifications of DEA model screenshot 
Then, the software is ready to be run and the results are displayed in the screen, as seen in Figure 18. All the results are shown in Microsoft Excel format and the user can export the results, by copying and pasting the results in an Excel spreadsheet, in order to organize and analyze the results as it is needed.

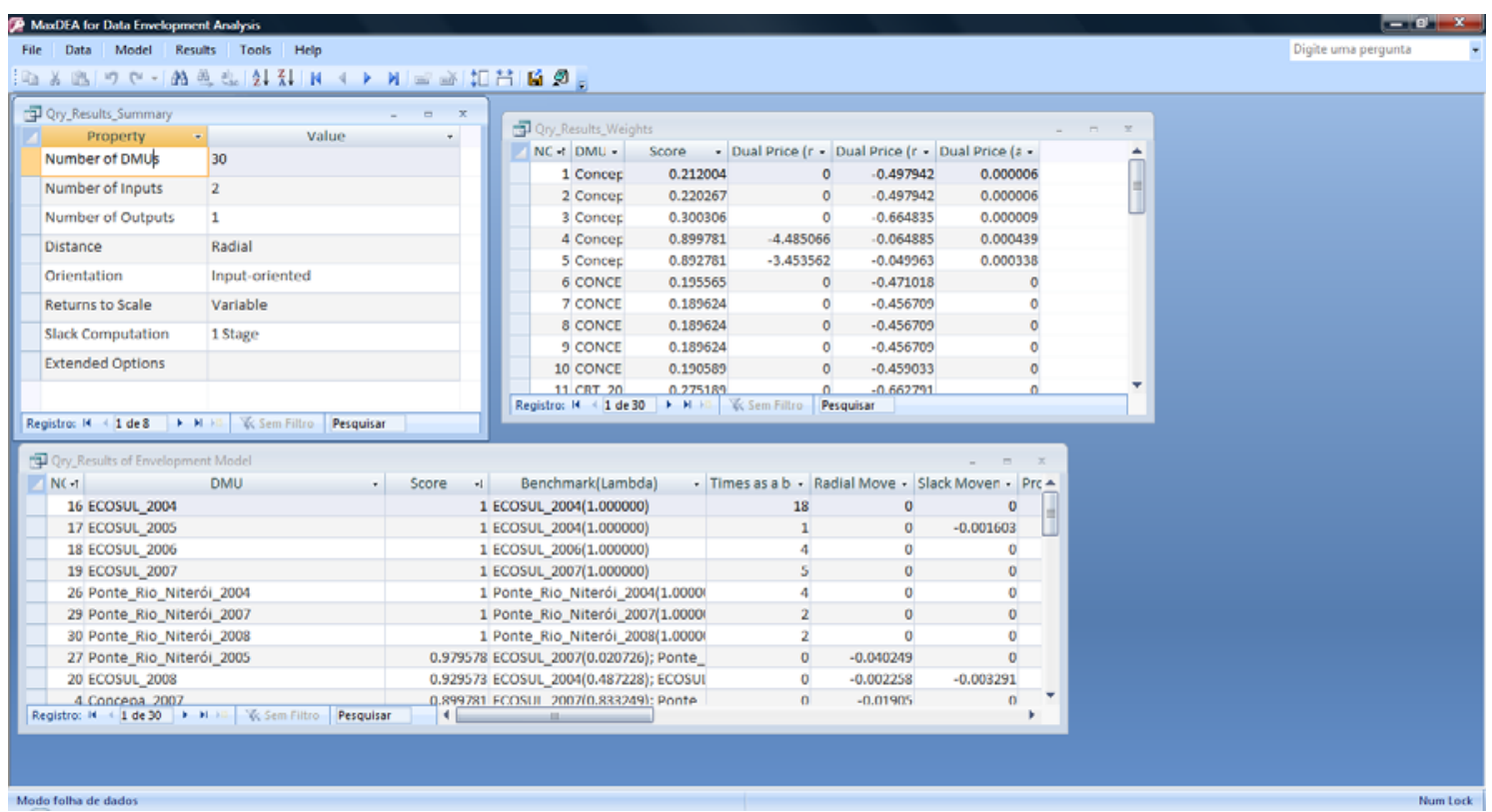

Figure 18 - MaxDEA Results of the Model screenshot

\section{DEA model Results}

This section presents the results obtained in the DEA models. Based on DEA models defined in previous sections and the available data, Table 13 shows the models that are used in the present research. DEA models that evaluate Road Safety are represented by the initials "SF", as well as the models that evaluate User Assistance are represented by the initials "AT".

DMU groups are divided regarding the stage of the Road Concession Program that the road was granted (as seen in Chapter 4). They are also divided in time periods. The time period of five years was used because the literature considers that it is an adequate time period for the revision of the X-factor.

Data are available from 2004 to 2013 , and as seen before, in order to increase the number of DMUs also the discrimination power of the DEA model, data of each firm for different years was used as a different DMU. The variables used as inputs and outputs as well as the orientation were discussed in details in the previous sections. 
Table 13 - DEA models used

\begin{tabular}{|c|c|c|c|c|c|}
\hline Model & DMU group & $\begin{array}{c}\text { Number of } \\
\text { DMUs }\end{array}$ & Input & Output & Orientation \\
\hline SF_1.1 & $\begin{array}{c}1 \text { st Stage } \\
2004-2008\end{array}$ & 30 & \multirow{3}{*}{$\begin{array}{l}\text { Number of } \\
\text { employees } / \mathrm{km} \text {; } \\
\text { Number of } \\
\text { vehicles of the } \\
\text { concessionaire } / \mathrm{km}\end{array}$} & \multirow{3}{*}{$\begin{array}{l}\text { Annual traffic } \\
\text { volume/number } \\
\text { of accidents }\end{array}$} & \multirow{3}{*}{ output } \\
\hline SF_1.2 & $\begin{array}{c}1 \text { st Stage } \\
2009-2013\end{array}$ & 30 & & & \\
\hline SF_2.1 & $\begin{array}{l}2^{\text {nd }} \text { Stage } \\
2009-2013\end{array}$ & 35 & & & \\
\hline AT_1.1 & $\begin{array}{c}\text { 1st Stage } \\
2005-2009\end{array}$ & 30 & \multirow{3}{*}{$\begin{array}{c}\text { Number of } \\
\text { employees; } \\
\text { Number of } \\
\text { vehicles of the } \\
\text { concessionaire }\end{array}$} & \multirow{3}{*}{$\begin{array}{l}\text { Number of user } \\
\text { attendances; } \\
\text { Annual traffic } \\
\text { volume }\end{array}$} & \multirow{3}{*}{ input } \\
\hline AT_1.2 & $\begin{array}{c}\text { 1st Stage } \\
2009-2013\end{array}$ & 30 & & & \\
\hline AT_2.1 & $\begin{array}{l}2^{\text {nd }} \text { Stage } \\
2009-2013\end{array}$ & 35 & & & \\
\hline
\end{tabular}

It is important to explain that we had to deal with data limitation problem in the present research. As the results of Road Safety and User Attendance DEA models will be combined at the end of the analysis, in order to calculate the X-factor, it is necessary that both models evaluate the same time period. However, there is no data available regarding the number of user assistances in the year 2004 (see Table 8). In order to keep the same number of DMUs (30) used in the other models, it was decided to adopt for the model AT_1.1 the 5 years time period: 20052009. This time period is different from the used for the model SF_1.1 (2004-2008). Therefore, exceptionally due to data availability issues, it will be considered that SF_1.1 and AT_1.1 DEA models evaluate the same time period, which is quite acceptable for academic purposes, as this Chapter presents an example of the implementation of the framework proposed.

The data used to run DEA models are presented in the Appendix I.

In the next paragraphs the result of DEA models are presented, with the following analysis for each model: the efficiency scores of the DMUs, the mean of the efficiency score for each firm, the ranking of the most efficient firms by year, the evolution over time of the efficiency scores of each DMU illustrated in a bar chart, and the DMUs used as benchmark. 
It is important to remember that based on this information it is possible to identify which DMUs are more efficient and, using these DMUs as example, investigate the organizational changes that inefficient DMUs need to undertake in order to improve efficiency.

Despite the objective of the present research is to use the results of the efficiency obtained from DEA models to calculate the $X$-factor, it is important to note that the analysis of DEA results can also help the regulator to identify the best practices and provide information about managerial actions used by the efficient firms to decisions makers.

First it is presented the results of the model SF_1.1, which evaluates the Road Safety of the concessionaires of 1 st stage from 2004 to 2008.

Table 14 - Efficiency scores - SF_1.1

\begin{tabular}{|c|c|c|c|c|c|c|}
\hline \multirow{2}{*}{ DMU } & \multicolumn{5}{|c|}{ Efficiency Scores - SF_1.1 - 1st Stage (2004-2008) } & \multirow{2}{*}{ Mean } \\
\hline & 2004 & 2005 & 2006 & 2007 & 2008 & \\
\hline Concepa & 0.80 & 0.86 & 0.91 & 0.99 & 0.99 & 0.91 \\
\hline Concer & 0.36 & 0.38 & 0.29 & 0.42 & 0.29 & 0.35 \\
\hline CRT & 0.78 & 0.68 & 0.58 & 0.58 & 0.18 & 0.56 \\
\hline Ecosul & 1.00 & 1.00 & 1.00 & 1.00 & 0.90 & 0.98 \\
\hline Nova_Dutra & 0.56 & 0.40 & 0.45 & 0.56 & 0.60 & 0.51 \\
\hline Ponte_Rio_Niterói & 1.00 & 0.99 & 0.75 & 1.00 & 1.00 & 0.95 \\
\hline
\end{tabular}

Table 15 - Ranking of efficiency scores - SF_1.1

\begin{tabular}{|c|c|c|c|c|c|}
\hline \multicolumn{5}{|c|}{ Ranking of Efficiency Scores - SF_1.1 - 1'st Stage (2004-2008) } & \multirow{2}{*}{ Mean } \\
\hline 2004 & 2005 & 2006 & 2007 & 2008 & \\
\hline $\begin{array}{l}\text { Ecosul } \\
(1.00)\end{array}$ & $\begin{array}{l}\text { Ecosul } \\
(1.00)\end{array}$ & $\begin{array}{l}\text { Ecosul } \\
(1.00)\end{array}$ & $\begin{array}{l}\text { Ecosul } \\
(1.00)\end{array}$ & $\begin{array}{c}\text { Ponte_Rio_Niterói } \\
(1.00)\end{array}$ & $\begin{array}{l}\text { Ecosul } \\
(0.98)\end{array}$ \\
\hline $\begin{array}{c}\text { Ponte_Rio_Niterói } \\
(1.00)\end{array}$ & $\begin{array}{c}\text { Ponte_Rio_Niterói } \\
(0.99)\end{array}$ & $\begin{array}{l}\text { Concepa } \\
(0.91)\end{array}$ & $\begin{array}{c}\text { Ponte_Rio_Niterói } \\
(1.00)\end{array}$ & $\begin{array}{l}\text { Concepa } \\
(0.99)\end{array}$ & $\begin{array}{c}\text { Ponte_Rio_Niterói } \\
(0.95)\end{array}$ \\
\hline $\begin{array}{l}\text { Concepa } \\
(0.80)\end{array}$ & $\begin{array}{l}\text { Concepa } \\
(0.86)\end{array}$ & $\begin{array}{c}\text { Ponte_Rio_Niterói } \\
(0.75)\end{array}$ & $\begin{array}{l}\text { Concepa } \\
(0.99)\end{array}$ & $\begin{array}{l}\text { Ecosul } \\
(0.90)\end{array}$ & $\begin{array}{l}\text { Concepa } \\
(0.91)\end{array}$ \\
\hline $\begin{array}{l}\text { CRT } \\
(0.78)\end{array}$ & $\begin{array}{l}\text { CRT } \\
(0.68)\end{array}$ & $\begin{array}{c}\text { CRT } \\
(0.58)\end{array}$ & $\begin{array}{l}\text { CRT } \\
(0.58)\end{array}$ & $\begin{array}{c}\text { Nova_Dutra } \\
(0.60)\end{array}$ & $\begin{array}{l}\text { CRT } \\
(0.56) \\
\end{array}$ \\
\hline $\begin{array}{l}\text { Nova_Dutra } \\
(0.56)\end{array}$ & $\begin{array}{l}\text { Nova_Dutra } \\
(0.40)\end{array}$ & $\begin{array}{l}\text { Nova_Dutra } \\
\quad(0.45)\end{array}$ & $\begin{array}{l}\text { Nova_Dutra } \\
(0.56)\end{array}$ & $\begin{array}{l}\text { Concer } \\
(0.29)\end{array}$ & $\begin{array}{l}\text { Nova_Dutra } \\
(0.51)\end{array}$ \\
\hline $\begin{array}{l}\text { Concer } \\
(0.36)\end{array}$ & $\begin{array}{l}\text { Concer } \\
(0.38)\end{array}$ & $\begin{array}{l}\text { Concer } \\
(0.29)\end{array}$ & $\begin{array}{l}\text { Concer } \\
(0.42)\end{array}$ & $\begin{array}{l}\text { CRT } \\
(0.18)\end{array}$ & $\begin{array}{l}\text { Concer } \\
(0.35)\end{array}$ \\
\hline
\end{tabular}


Table 14 shows that out of 30 DMUs, only seven are efficient and three get an efficiency score of $99 \%$. Ecosul was $100 \%$ efficient over four years, out of five years that have been analyzed. It is also important to highlight that Ponte Rio Niterói was efficient during three years.

Based on the mean of the efficiency scores, the most efficient concessionaire is Ecosul (98\%). For the remainder, two concessionaires reach efficiency scores above $90 \%$, and the other two above $50 \%$. Particular concessionaire of concern is Concer, whose DMUs average a mere $35 \%$ efficiency.

From the ranking presented in Table 15, it is possible to confirm that Ecosul and Ponte Rio Niterói are the best performers. On the other hand, Nova Dutra and Concer are in the last positions of the ranking, they are the ones to focus the attention in order to improve efficiency.

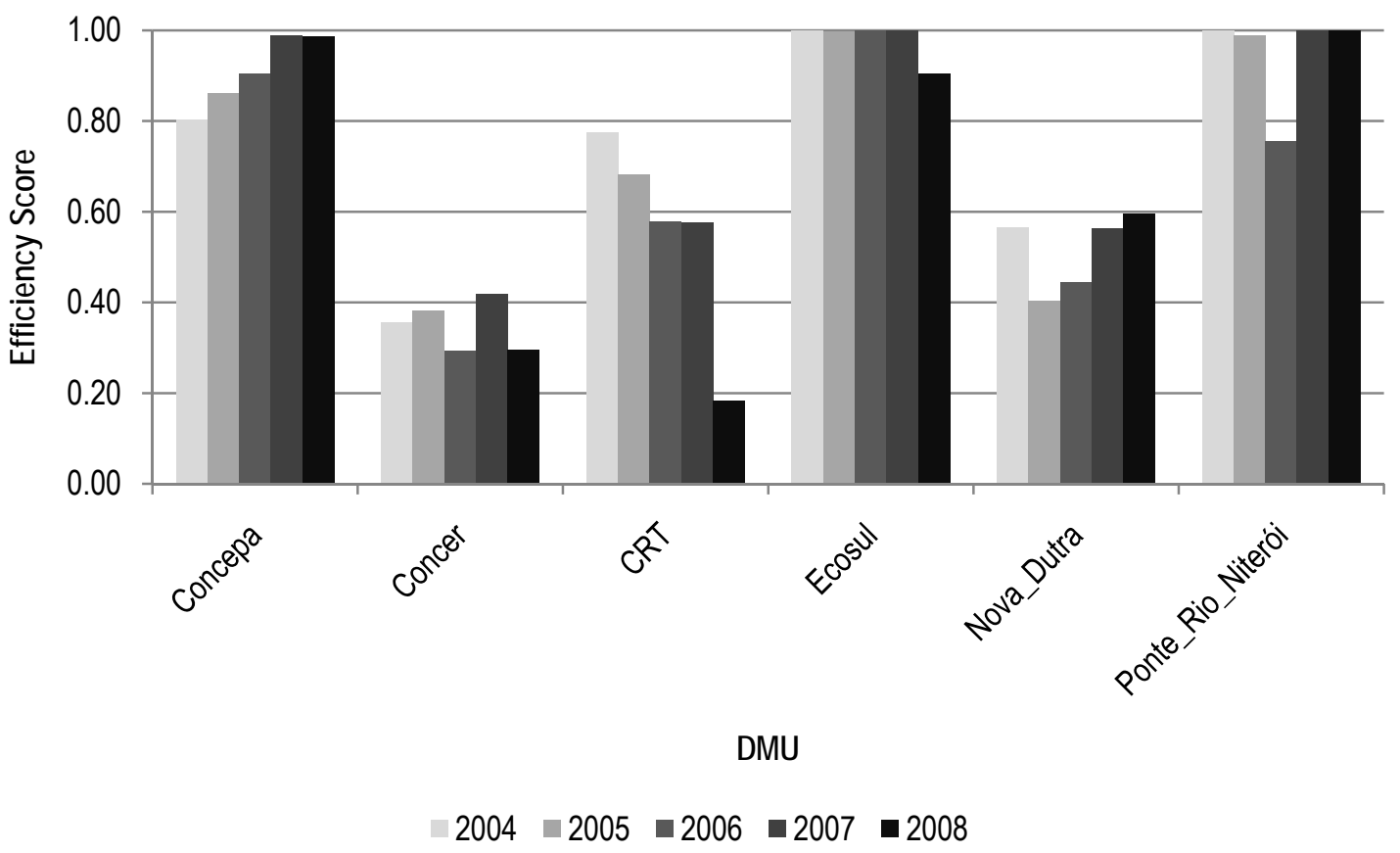

Figure 19 - Efficiency score evolution over time - SF_1.1

From Figure 19 it is possible to note that Concepa and Nova Dutra (excluding the first year) consistently improved efficiency over time period, despite the fact that Nova Dutra needs to increase the average efficiency score of $51 \%$. 
In contrast, CRT is the concessionaire which consistently worsened its efficiency score over the time period, and drastically dropped its efficiency in 2008. To address this sudden efficiency drop, the decision makers should try to identify the changes that were introduced to the process in the previous years. Such changes are most likely the causes for the efficiency drop, and the decision makers should try to reformulate them.

In addition, we can note that Ponte Rio Niterói had an issue in 2006 and Ecosul in 2008, which result in a reduction in the efficiency score in these years.

Concer has the average efficiency score much lower than the other concessionaires and keeps its performance stable over the time period. Regulators should give priority in the analysis of this firm and work closely to the decision makers, in order to incentivize to improve its efficiency.

Table 16 - DMUs used as benchmark - SF_1.1

\begin{tabular}{|c|c|c|}
\hline $\begin{array}{c}\text { DMU - SF_1.1 } \\
1^{\text {st }} \text { Stage (2004-2008) }\end{array}$ & Benchmark & $\begin{array}{c}\text { Times as a benchmark } \\
\text { for another DMU }\end{array}$ \\
\hline Concepa_2004 & $\begin{array}{l}\text { Ecosul_2007 (0.836); Ponte_Rio_Niterói_2004 (0.051); } \\
\text { Ponte_Rio_Niterói_2008 (0.112) }\end{array}$ & 0 \\
\hline Concepa_2005 & $\begin{array}{l}\text { Ecosul_2007 (0.836); Ponte_Rio_Niterói_2004 (0.064); } \\
\text { Ponte_Rio_Niterói_2008 (0.099) }\end{array}$ & 0 \\
\hline Concepa_2006 & $\begin{array}{l}\text { Ecosul_2007 (0.888); Ponte_Rio_Niterói_2004 (0.080); } \\
\text { Ponte_Rio_Niterói_2008 (0.030) }\end{array}$ & 0 \\
\hline Concepa_2007 & $\begin{array}{l}\text { Ecosul_2007 (0.809); Ponte_Rio_Niterói_2004 (0.022); } \\
\text { Ponte_Rio_Niterói_2008 (0.168) }\end{array}$ & 0 \\
\hline Concepa_2008 & $\begin{array}{l}\text { Ecosul_2007 (0.805); Ponte_Rio_Niterói_2004 (0.073); } \\
\text { Ponte_Rio_Niterói_2008 (0.121) }\end{array}$ & 0 \\
\hline Concer_2004 & $\begin{array}{l}\text { Ecosul_2007 (0.823); Ponte_Rio_Niterói_2004 (0.100); } \\
\text { Ponte_Rio_Niterói_2008 (0.075) }\end{array}$ & 0 \\
\hline Concer_2005 & $\begin{array}{l}\text { Ecosul_2007 (0.816); Ponte_Rio_Niterói_2004 (0.096); } \\
\text { Ponte_Rio_Niterói_2008 (0.086) }\end{array}$ & 0 \\
\hline Concer_2006 & $\begin{array}{l}\text { Ecosul_2007 (0.816); Ponte_Rio_Niterói_2004 (0.096); } \\
\text { Ponte_Rio_Niterói_2008 (0.086) }\end{array}$ & 0 \\
\hline Concer_2007 & $\begin{array}{l}\text { Ecosul_2007 (0.816); Ponte_Rio_Niterói_2004 (0.096); } \\
\text { Ponte_Rio_Niterói_2008 (0.086) }\end{array}$ & 0 \\
\hline Concer_2008 & $\begin{array}{l}\text { Ecosul_2007 (0.817); Ponte_Rio_Niterói_2004 (0.097); } \\
\text { Ponte_Rio_Niterói_2008 (0.084) }\end{array}$ & 0 \\
\hline CRT_2004 & $\begin{array}{l}\text { Ecosul_2007 (0.888); Ponte_Rio_Niterói_2004 (0.055); } \\
\text { Ponte_Rio_Niterói_2008 (0.056) }\end{array}$ & 0 \\
\hline CRT_2005 & $\begin{array}{l}\text { Ecosul_2007 (0.883);Ponte_Rio_Niterói_2004 (0.040); } \\
\text { Ponte_Rio_Niterói_2008 (0.076) }\end{array}$ & 0 \\
\hline CRT_2006 & $\begin{array}{l}\text { Ecosul_2007 (0.879);Ponte_Rio_Niterói_2004 (0.049); } \\
\text { Ponte_Rio_Niterói_2008 (0.070) }\end{array}$ & 0 \\
\hline CRT_2007 & $\begin{array}{l}\text { Ecosul_2007 (0.877); Ponte_Rio_Niterói_2004 (0.048); } \\
\text { Ponte_Rio_Niterói_2008 (0.074) }\end{array}$ & 0 \\
\hline CRT_2008 & $\begin{array}{l}\text { Ecosul_2007 (0.866); Ponte_Rio_Niterói_2004 (0.048); } \\
\text { Ponte_Rio_Niterói_2008 (0.084) }\end{array}$ & 0 \\
\hline Ecosul_2004 & Ecosul_2004 (1.000) & 1 \\
\hline Ecosul_2005 & Ecosul_2004 (1.000) & 0 \\
\hline
\end{tabular}

continues 
continues

\begin{tabular}{llc}
\hline $\begin{array}{l}\text { DMU - SF_1.1 } \\
\text { 1st Stage (2004-2008) }\end{array}$ & \multicolumn{1}{c}{ Benchmark } & $\begin{array}{c}\text { Times as a benchmark } \\
\text { for another DMU }\end{array}$ \\
\hline Ecosul_2006 & Ecosul_2006 (1.000) & 0 \\
\hline Ecosul_2007 & Ecosul_2007 (1.000) & 21 \\
\hline Ecosul_2008 & $\begin{array}{l}\text { Ecosul_2007 (0.998); Ponte_Rio_Niterói_2004 (0.001); } \\
\text { Ponte_Rio_Niterói_2007 (0.001) }\end{array}$ & 0 \\
\hline Nova_Dutra_2004 & $\begin{array}{l}\text { Ecosul_2007 (0.774); Ponte_Rio_Niterói_2004 (0.138); } \\
\text { Ponte_Rio_Niterói_2008 (0.086) }\end{array}$ & 0 \\
\hline Nova_Dutra_2005 & $\begin{array}{l}\text { Ecosul_2007 (0.766); Ponte_Rio_Niterói_2004 (0.115); } \\
\text { Ponte_Rio_Niterói_2008 (0.118) }\end{array}$ & 0 \\
\hline Nova_Dutra_2006 & $\begin{array}{l}\text { Ecosul_2007 (0.791); Ponte_Rio_Niterói_2004 (0.113); } \\
\text { Ponte_Rio_Niterói_2008 (0.094) }\end{array}$ & 0 \\
\hline Nova_Dutra_2007 & Ecosul_2007 (0.786);Ponte_Rio_Niterói_2004 (0.110); & 0 \\
\hline Nova_Dutra_2008 & Ecosul_2007 (0.767); Ponte_Rio_Niterói_2004 (0.090); & \multirow{2}{*}{ Ponte_Rio_Niterói_2008 (0.142) } \\
\hline Ponte_Rio_Niterói_2004 & Ponte_Rio_Niterói_2004 (1.000) & 23 \\
\hline Ponte_Rio_Niterói_2005 & Ponte_Rio_Niterói_2004 (1.000) & 0 \\
\hline Ponte_Rio_Niterói_2006 & Ponte_Rio_Niterói_2004 (1.000) & 0 \\
\hline Ponte_Rio_Niterói_2007 & Ponte_Rio_Niterói_2007 (1.000) & 1 \\
\hline Ponte_Rio_Niterói_2008 & Ponte_Rio_Niterói_2008 (1.000) & 20 \\
\hline
\end{tabular}

Table 16 shows that Ecosul in 2007 and Ponte Rio Niterói in 2004 and 2008 are benchmark for more than $66 \%$ of the DMUs. Therefore, regulators should study the operational and strategic policies of these firms in these specific years. These results can also be a consequence of the increase in the investment level of previous years.

Following the DEA results, it is presented the model SF_1.2, which evaluates the Road Safety of the concessionaires of 1 st stage from 2009 to 2013.

Table 17 - Efficiency scores - SF_1.2

\begin{tabular}{lllllll}
\hline \multirow{2}{*}{ DMU } & \multicolumn{7}{c}{ Efficiency Scores - SF_1.2 - 1st Stage (2009-2013) } & \multirow{2}{*}{ Mean } \\
\cline { 2 - 6 } & $\mathbf{2 0 0 9}$ & $\mathbf{2 0 1 0}$ & $\mathbf{2 0 1 1}$ & $\mathbf{2 0 1 2}$ & $\mathbf{2 0 1 3}$ & \\
\hline Concepa & 0.97 & 0.82 & 0.94 & 0.95 & 0.98 & 0.93 \\
\hline Concer & 0.34 & 0.30 & 0.33 & 0.34 & 0.35 & 0.33 \\
\hline CRT & 0.21 & 0.14 & 0.13 & 0.15 & 0.49 & 0.22 \\
\hline Ecosul & 1.00 & 0.88 & 0.96 & 1.00 & 1.00 & 0.97 \\
\hline Nova_Dutra & 0.61 & 0.66 & 0.67 & 0.66 & 0.71 & 0.66 \\
\hline Ponte_Rio_Niterói & 0.97 & 0.84 & 0.80 & 0.76 & 1.00 & 0.88 \\
\hline
\end{tabular}


Table 18 - Ranking of efficiency scores - SF_1.2

\begin{tabular}{|c|c|c|c|c|c|}
\hline \multicolumn{5}{|c|}{ Ranking of Efficiency Scores - SF_1.2 - $1^{\text {st }}$ Stage $(2009-2013)$} & \multirow{2}{*}{ Mean } \\
\hline 2009 & 2010 & 2011 & 2012 & 2013 & \\
\hline $\begin{array}{l}\text { Ecosul } \\
(1.00)\end{array}$ & $\begin{array}{c}\text { Ecosul } \\
(0.88)\end{array}$ & $\begin{array}{l}\text { Ecosul } \\
(0.96)\end{array}$ & $\begin{array}{l}\text { Ecosul } \\
(1.00)\end{array}$ & $\begin{array}{l}\text { Ecosul } \\
(1.00)\end{array}$ & $\begin{array}{l}\text { Ecosul } \\
(0.97)\end{array}$ \\
\hline $\begin{array}{l}\text { Concepa } \\
(0.97)\end{array}$ & $\begin{array}{c}\text { Ponte_Rio_Niterói } \\
(0.84)\end{array}$ & $\begin{array}{l}\text { Concepa } \\
(0.94)\end{array}$ & $\begin{array}{l}\text { Concepa } \\
(0.95)\end{array}$ & $\begin{array}{c}\text { Ponte_Rio_Niterói } \\
(1.00)\end{array}$ & $\begin{array}{l}\text { Concepa } \\
(0.93)\end{array}$ \\
\hline $\begin{array}{c}\text { Ponte_Rio_Niterói } \\
(0.97)\end{array}$ & $\begin{array}{l}\text { Concepa } \\
(0.82)\end{array}$ & $\begin{array}{c}\text { Ponte_Rio_Niterói } \\
(0.80)\end{array}$ & $\begin{array}{c}\text { Ponte_Rio_Niterói } \\
(0.76)\end{array}$ & $\begin{array}{l}\text { Concepa } \\
(0.98)\end{array}$ & $\begin{array}{c}\text { Ponte_Rio_Niterói } \\
(0.88)\end{array}$ \\
\hline $\begin{array}{l}\text { Nova_Dutra } \\
\quad(0.61)\end{array}$ & $\begin{array}{l}\text { Nova_Dutra } \\
(0.66)\end{array}$ & $\begin{array}{l}\text { Nova_Dutra } \\
\quad(0.67)\end{array}$ & $\begin{array}{l}\text { Nova_Dutra } \\
(0.66)\end{array}$ & $\begin{array}{l}\text { Nova_Dutra } \\
\quad(0.71)\end{array}$ & $\begin{array}{l}\text { Nova_Dutra } \\
\quad(0.66)\end{array}$ \\
\hline $\begin{array}{l}\text { Concer } \\
(0.34)\end{array}$ & $\begin{array}{l}\text { Concer } \\
(0.30)\end{array}$ & $\begin{array}{l}\text { Concer } \\
(0.33)\end{array}$ & $\begin{array}{l}\text { Concer } \\
(0.34)\end{array}$ & $\begin{array}{l}\text { CRT } \\
(0.49)\end{array}$ & $\begin{array}{l}\text { Concer } \\
(0.33)\end{array}$ \\
\hline $\begin{array}{l}\text { CRT } \\
(0.21)\end{array}$ & $\begin{array}{l}\text { CRT } \\
(0.14)\end{array}$ & $\begin{array}{l}\text { CRT } \\
(0.13)\end{array}$ & $\begin{array}{l}\text { CRT } \\
(0.15)\end{array}$ & $\begin{array}{l}\text { Concer } \\
(0.35)\end{array}$ & $\begin{array}{l}\text { CRT } \\
(0.22)\end{array}$ \\
\hline
\end{tabular}

Table 17 shows that out of 30 DMUs, only four are efficient, reducing the number in comparison with the previous time period of analysis (SF_1.1). Ecosul was $100 \%$ efficient over three years, out of five years that have been analyzed. Besides Ecosul, only Ponte Rio Niterói was efficient in 2013.

It is important to highlight that none of DMUs were efficient in the years 2010 and 2011.

Regarding the average efficiency scores, Ecosul (97\%) follows as the most efficient concessionaire. Based on the overall average efficiency scores, two firms reach efficiency score above $90 \%$, other two above $65 \%$, and other two under $50 \%$.

From the ranking presented in Table 18, it is possible to note that despite the fact that Ecosul did not keep the same performance in comparison with the last time period, it continued to lead the ranking every year.

A changed that has occurred in the ranking is that Concer is sharing the last positions with CRT. 


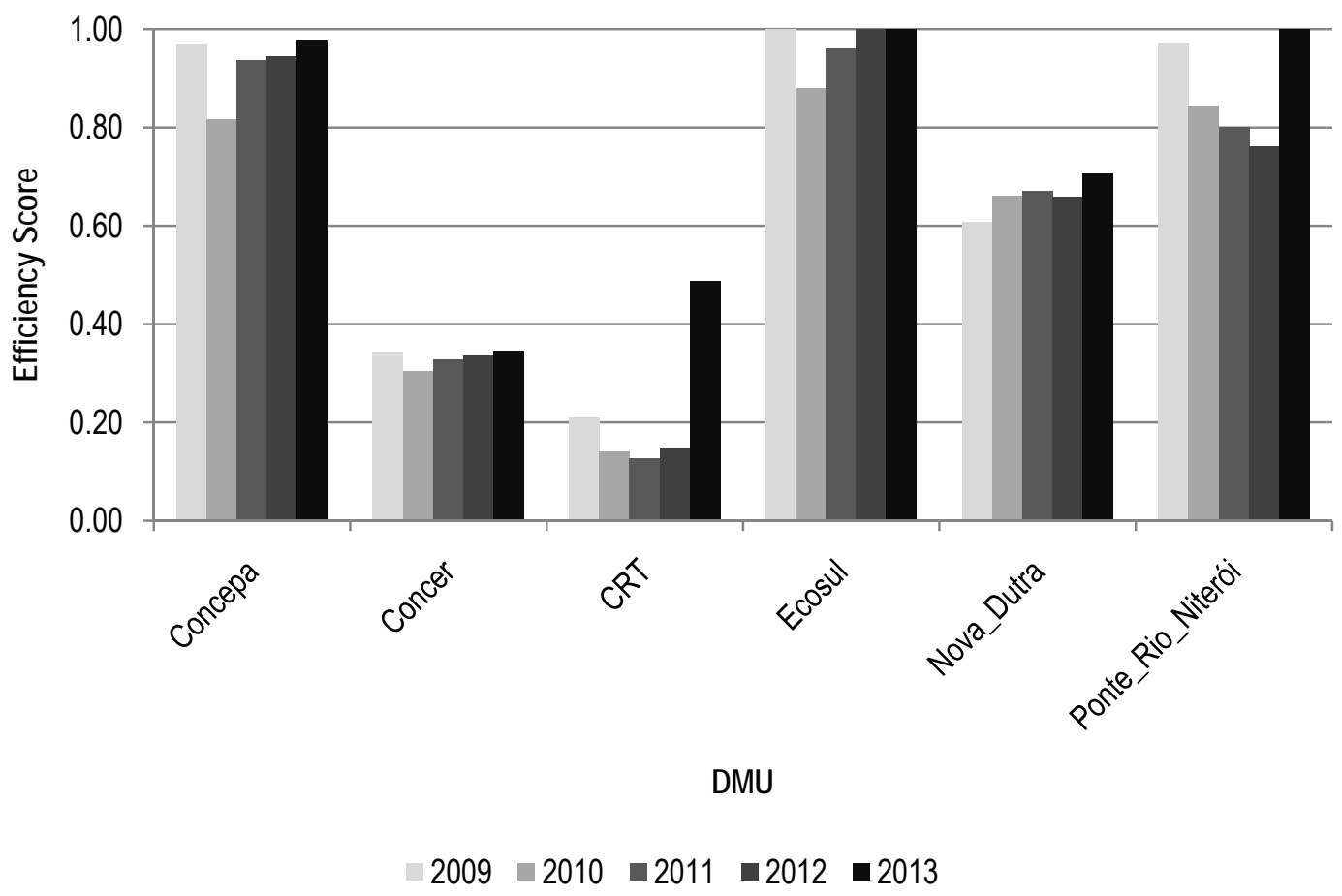

Figure 20 - Efficiency score evolution over time - SF_1.2

Figure 20 illustrates that Ecosul, which is the most efficient concessionaire, faced an efficiency drop, but it was able to recover and in the last year reached $100 \%$ efficiency. Likewise, Concepa faced a reduction in the efficiency in the first years and then improved its results, however could not achieve $100 \%$ efficiency in any year.

Ponte Rio Niterói is the concessionaire which consistently worsened its efficiency score over the time period, and drastically increased its efficiency to $100 \%$ in the last year.

Concer and Nova Dutra keep their performance stable over the time period. As they seem to be stagnate, regulators need to implement regulatory mechanisms to provide more incentives for concessionaires to improve efficiency.

The results of CRT were under $20 \%$ in the most of the time period. Despite it drastically increased efficiency in the last year, it did not achieved a satisfactory performance $(49 \%$ efficiency). Regulators should work with the concessionaire to seek which changes implemented in the last year has brought noticeable improvements, in order to expand good practices. 
Table 19 - DMUs used as benchmark - SF_1.2

\begin{tabular}{|c|c|c|}
\hline $\begin{array}{c}\text { DMU - SF_1.2 } \\
1^{\text {st }} \text { Stage (2009-2013) }\end{array}$ & Benchmark(Lambda) & $\begin{array}{c}\text { Times as a benchmark for } \\
\text { another DMU }\end{array}$ \\
\hline Concepa_2009 & Ecosul_2013 (0.923); Ponte_Rio_Niterói_2013 (0.076) & 0 \\
\hline Concepa_2010 & Ecosul_2012 (0.764); Ponte_Rio_Niterói_2013 (0.235) & 0 \\
\hline Concepa_2011 & Ecosul_2012 (0.784); Ponte_Rio_Niterói_2013 (0.215) & 0 \\
\hline Concepa_2012 & Ecosul_2013 (0.784); Ponte_Rio_Niterói_2013 (0.215) & 0 \\
\hline Concepa_2013 & Ecosul_2013 (0.816697); Ponte_Rio_Niterói_2013 (0.183303) & 0 \\
\hline Concer_2009 & Ecosul_2012 (0.801); Ponte_Rio_Niterói_2013 (0.198) & 0 \\
\hline Concer_2010 & Ecosul_2012 (0.783); Ponte_Rio_Niterói_2013 (0.216) & 0 \\
\hline Concer_2011 & Ecosul_2012 (0.843); Ponte_Rio_Niterói_2013 (0.156) & 0 \\
\hline Concer_2012 & Ecosul_2012 (0.838); Ponte_Rio_Niterói_2013 (0.161) & 0 \\
\hline Concer_2013 & Ecosul_2012 (0.755); Ponte_Rio_Niterói_2013 (0.244) & 0 \\
\hline CRT_2009 & Ecosul_2013 (0.926); Ponte_Rio_Niterói_2013 (0.073) & 0 \\
\hline CRT_2010 & Ecosul_2013 (0.860); Ponte_Rio_Niterói_2013 (0.139) & 0 \\
\hline CRT_2011 & Ecosul_2013 (0.865); Ponte_Rio_Niterói_2013 (0.134) & 0 \\
\hline CRT_2012 & Ecosul_2013 (0.865); Ponte_Rio_Niterói_2013 (0.134) & 0 \\
\hline CRT_2013 & Ecosul_2013 (0.829); Ponte_Rio_Niterói_2013 (0.170) & 0 \\
\hline Ecosul_2009 & Ecosul_2009 (1.000) & 2 \\
\hline Ecosul_2010 & Ecosul_2009 (0.099); Ecosul_2012 (0.867); Ecosul_2013 (0.033) & 0 \\
\hline Ecosul_2011 & Ecosul_2009 (0.578); Ecosul_2012 (0.229); Ecosul_2013 (0.192) & 0 \\
\hline Ecosul_2012 & Ecosul_2012(1.000) & 9 \\
\hline Ecosul_2013 & Ecosul_2013 (1.000) & 18 \\
\hline Nova_Dutra_2009 & Ecosul_2013 (0.841); Ponte_Rio_Niterói_2013 (0.158) & 0 \\
\hline Nova_Dutra_2010 & Ecosul_2013 (0.784); Ponte_Rio_Niterói_2013 (0.215) & 0 \\
\hline Nova_Dutra_2011 & Ecosul_2013 (0.779); Ponte_Rio_Niterói_2013 (0.220) & 0 \\
\hline Nova_Dutra_2012 & Ecosul_2013 (0.774); Ponte_Rio_Niterói_2013 (0.225) & 0 \\
\hline Nova_Dutra_2013 & Ecosul_2013 (0.772); Ponte_Rio_Niterói_2013 (0.227) & 0 \\
\hline Ponte_Rio_Niterói_2009 & Ecosul_2013 (0.315); Ponte_Rio_Niterói_2013 (0.684) & 0 \\
\hline Ponte_Rio_Niterói_2010 & Ecosul_2013 (0.077); Ponte_Rio_Niterói_2013 (0.922) & 0 \\
\hline Ponte_Rio_Niterói_2011 & Ecosul_2013 (0.111); Ponte_Rio_Niterói_2013 (0.888) & 0 \\
\hline Ponte_Rio_Niterói_2012 & Ponte_Rio_Niterói_2013 (1.000) & 0 \\
\hline Ponte_Rio_Niterói_2013 & Ponte_Rio_Niterói_2013 (1.000) & 24 \\
\hline
\end{tabular}

From Table 19 it is possible to note that only two DMUs had been widely used as benchmark, they are: Ponte Rio Niterói 2013 (24 times) and Ecosul 2013 (18 times). This result supports the evidence that the process used in 2013 by Ponte Rio Niterói should be studied, because it also had a suddenly growth this year.

Next DEA result presented is the model SF_2.1, which evaluates the Road Safety of the concessionaires of $2^{\text {nd }}$ stage from 2009 to 2013. 
Table 20 - Efficiency scores - SF_2.1

\begin{tabular}{lcccccc}
\hline \multirow{2}{*}{ DMU } & \multicolumn{7}{c}{ Efficiency Scores - SF_2.1-2 } & 2nd & Stage (2009-2013) & \multirow{2}{*}{ Mean } \\
\cline { 2 - 6 } & $\mathbf{2 0 0 9}$ & $\mathbf{2 0 1 0}$ & $\mathbf{2 0 1 1}$ & $\mathbf{2 0 1 2}$ & $\mathbf{2 0 1 3}$ & \\
\hline Autopista_Fernao_Dias & 0.40 & 0.57 & 0.65 & 0.64 & 0.63 & 0.58 \\
\hline Autopista_Fluminense & 0.30 & 0.45 & 0.42 & 0.42 & 0.42 & 0.40 \\
\hline Autopista_Litoral_Sul & 0.11 & 0.50 & 0.40 & 0.52 & 0.44 & 0.39 \\
\hline Autopista_Planalto_Sul & 1.00 & 1.00 & 0.93 & 0.65 & 0.48 & 0.81 \\
\hline Autopista_Regis_Bittencourt & 0.70 & 0.90 & 0.91 & 0.95 & 1.00 & 0.89 \\
\hline Rodovia_do_Aço & 0.47 & 0.72 & 0.78 & 0.54 & 0.55 & 0.61 \\
\hline Transbrasiliana & 1.00 & 1.00 & 1.00 & 0.96 & 0.92 & 0.98 \\
\hline
\end{tabular}

Table 21 - Ranking of efficiency scores - SF_2.1

\begin{tabular}{|c|c|c|c|c|c|}
\hline \multicolumn{5}{|c|}{ Ranking of Efficiency Scores - SF_2.1 - 2 ${ }^{\text {nd }}$ Stage (2009-2013) } & \multirow{2}{*}{ Mean } \\
\hline 2009 & 2010 & 2011 & 2012 & 2013 & \\
\hline $\begin{array}{l}\text { Autopista__ } \\
\text { Planalto_Sul } \\
(1.00)\end{array}$ & $\begin{array}{l}\text { Autopista__ } \\
\text { Planalto_Sul } \\
\quad(1.00)\end{array}$ & $\begin{array}{c}\text { Transbrasiliana } \\
(1.00)\end{array}$ & $\begin{array}{c}\text { Transbrasiliana } \\
(0.96)\end{array}$ & $\begin{array}{c}\text { Autopista_ } \\
\text { Regis_Bittencourt } \\
\underset{(1.00)}{ }\end{array}$ & $\begin{array}{c}\text { Transbrasiliana } \\
(0.98)\end{array}$ \\
\hline $\begin{array}{c}\text { Transbrasiliana } \\
(1.00)\end{array}$ & $\begin{array}{c}\text { Transbrasiliana } \\
(1.00)\end{array}$ & $\begin{array}{l}\text { Autopista__ } \\
\text { Planalto_Sul } \\
(0.93)\end{array}$ & $\begin{array}{c}\text { Autopista_ } \\
\text { Regis_Bittencourt } \\
\underset{(0.95)}{ }\end{array}$ & $\begin{array}{c}\text { Transbrasiliana } \\
(0.92)\end{array}$ & $\begin{array}{c}\text { Autopista_ } \\
\text { Regis_Bittencourt } \\
(0.89)\end{array}$ \\
\hline $\begin{array}{c}\text { Autopista_ } \\
\text { Regis_Bittencourt } \\
(0.70)\end{array}$ & $\begin{array}{c}\text { Autopista_ } \\
\text { Regis_Bittencourt } \\
(0.90)\end{array}$ & $\begin{array}{c}\text { Autopista_ } \\
\text { Regis_Bittencourt } \\
(0.91)\end{array}$ & $\begin{array}{l}\text { Autopista_- } \\
\text { Planalto_Sul } \\
(0.65)\end{array}$ & $\begin{array}{l}\text { Autopista_- } \\
\text { Fernao_Dias } \\
(0.63)\end{array}$ & $\begin{array}{l}\text { Autopista__ } \\
\text { Planalto_Sul } \\
(0.81)\end{array}$ \\
\hline $\begin{array}{c}\text { Rodovia_do_Aço } \\
(0.47)\end{array}$ & $\begin{array}{c}\text { Rodovia_do_Aço } \\
(0.72)\end{array}$ & $\begin{array}{c}\text { Rodovia_do_Aço } \\
(0.78)\end{array}$ & $\begin{array}{l}\text { Autopista_- } \\
\text { Fernao_Dias } \\
(0.64)\end{array}$ & $\begin{array}{c}\text { Rodovia_do_Aço } \\
(0.55)\end{array}$ & $\begin{array}{c}\text { Rodovia_do_Aço } \\
(0.61)\end{array}$ \\
\hline $\begin{array}{l}\text { Autopista_ } \\
\text { Fernao_Dias } \\
(0.40)\end{array}$ & $\begin{array}{l}\text { Autopista_ } \\
\text { Fernao_Dias } \\
(0.57)\end{array}$ & $\begin{array}{l}\text { Autopista_ } \\
\text { Fernao_Dias } \\
(0.65)\end{array}$ & $\begin{array}{c}\text { Rodovia_do_Aço } \\
(0.54)\end{array}$ & $\begin{array}{l}\text { Autopista__ } \\
\text { Planalto_Sul } \\
(0.48)\end{array}$ & $\begin{array}{l}\text { Autopista_- } \\
\text { Fernao_Dias } \\
\quad(0.58)\end{array}$ \\
\hline $\begin{array}{l}\text { Autopista_ } \\
\text { Fluminense } \\
(0.30)\end{array}$ & $\begin{array}{l}\text { Autopista_ } \\
\text { Litoral_Sul } \\
(0.50)\end{array}$ & $\begin{array}{c}\text { Autopista_ } \\
\text { Fluminense } \\
(0.42)\end{array}$ & $\begin{array}{l}\text { Autopista_- } \\
\text { Litoral_Sul } \\
\quad(0.52)\end{array}$ & $\begin{array}{l}\text { Autopista_ } \\
\text { Litoral_Sul } \\
(0.44)\end{array}$ & $\begin{array}{c}\text { Autopista_ } \\
\text { Fluminense } \\
(0.40)\end{array}$ \\
\hline $\begin{array}{l}\text { Autopista__ } \\
\text { Litoral_Sul } \\
(0.11)\end{array}$ & $\begin{array}{l}\text { Autopista } \\
\text { Fluminense } \\
(0.45)\end{array}$ & $\begin{array}{l}\text { Autopista__ } \\
\text { Litoral_Sul } \\
(0.40)\end{array}$ & $\begin{array}{l}\text { Autopista_ } \\
\text { Fluminense } \\
(0.42)\end{array}$ & $\begin{array}{l}\text { Autopista_ } \\
\text { Fluminense } \\
(0.42)\end{array}$ & $\begin{array}{c}\text { Autopista_ } \\
\text { Litoral_Sul } \\
(0.39)\end{array}$ \\
\hline
\end{tabular}

Table 20 shows that out of 35 DMUs, only 6 are 100\% efficient. Transbrasiliana reaches $100 \%$ of efficiency over three years, and Autopista Planalto Sul over two years.

It is important to highlight that none of DMUs were efficient in the year 2012. 
Based on the mean of the efficiency scores, the most efficient concessionaire is Transbrasilia (98\%). For the remainder, two concessionaires reach efficiency score above $80 \%$, two above $50 \%$, and the other two under $50 \%$.

From the ranking of the Table 21, it is possible to note that Transbrasiliana, Autopista Planalto Sul e Autopista Régis Bittencourt share the first positions. On the other hand, Autopista Fluminense e Autopista Litoral Sul presented the worst performance.

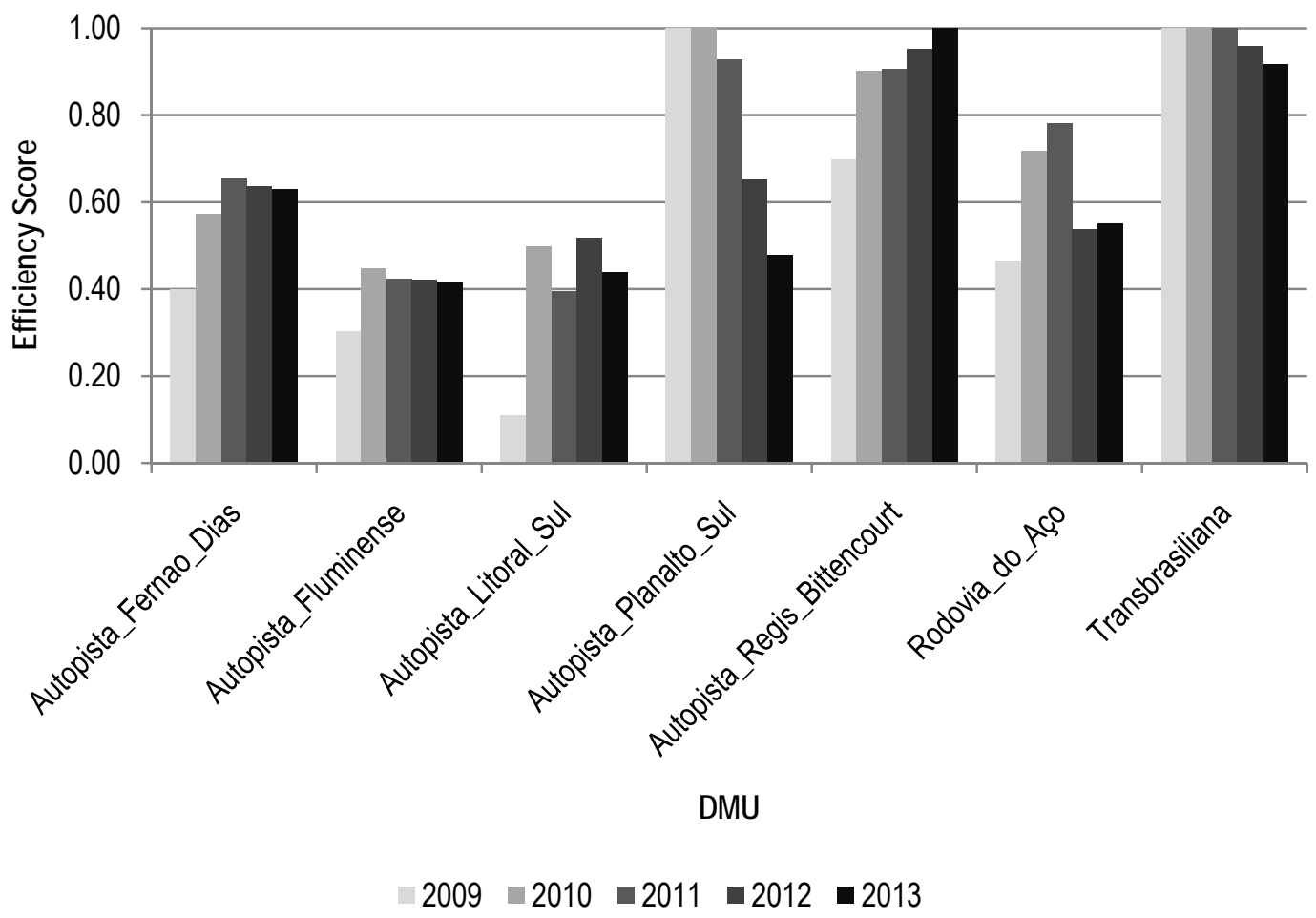

Figure 21 - Efficiency score evolution over time - SF_2.1

Figure 21 illustrates that despite Transbrasiliana, its satisfactory performance, its efficiency drop in the last years. The same was true for Autopista Planalto Sul, but on a larger scale. Regulators should be alert, investigate what could happen and try to incentivize the recovery of the efficiency of these firms.

Unlikely, Autopista Régis Bittencourt is the concessionaire which improved the efficiency over the years, achieving $100 \%$ in the last years. Process implemented in this period should be studied and spread as best practices to other concessionaires. 
Table 22 - DMUs used as benchmark - SF_2.1

\begin{tabular}{|c|c|c|}
\hline $\begin{array}{c}\text { DMU - SF_2.1 } \\
2^{\text {nd }} \text { Stage (2009-2013) }\end{array}$ & Benchmark & $\begin{array}{c}\text { Times as a benchmark for } \\
\text { another DMU }\end{array}$ \\
\hline Autopista_Fernao_Dias_2009 & $\begin{array}{l}\text { Autopista_Regis_Bittencourt_2013 (0.268); } \\
\text { Transbrasiliana_2011 (0.731) }\end{array}$ & 0 \\
\hline Autopista_Fernao_Dias_2010 & $\begin{array}{l}\text { Autopista_Regis_Bittencourt_2013 (0.008); } \\
\text { Transbrasiliana_2011 (0.991) }\end{array}$ & 0 \\
\hline Autopista_Fernao_Dias_2011 & $\begin{array}{l}\text { Autopista_Regis_Bittencourt_2013 (0.028); } \\
\text { Transbrasiliana_2011 (0.971) }\end{array}$ & 0 \\
\hline Autopista_Fernao_Dias_2012 & $\begin{array}{l}\text { Autopista_Regis_Bittencourt_2013 (0.038); } \\
\text { Transbrasiliana_2011 (0.961) }\end{array}$ & 0 \\
\hline Autopista_Fernao_Dias_2013 & $\begin{array}{l}\text { Autopista_Regis_Bittencourt_2013 (0.589); } \\
\text { Transbrasiliana_2011 }(0.410)\end{array}$ & 0 \\
\hline Autopista_Fluminense_2009 & $\begin{array}{l}\text { Autopista_Regis_Bittencourt_2013 (0.407); } \\
\text { Transbrasiliana_2011 (0.592) }\end{array}$ & 0 \\
\hline Autopista_Fluminense_2010 & $\begin{array}{l}\text { Autopista_Regis_Bittencourt_2013 (0.232); } \\
\text { Transbrasiliana_2009 }(0.767)\end{array}$ & 0 \\
\hline Autopista_Fluminense_2011 & $\begin{array}{l}\text { Autopista_Regis_Bittencourt_2013 (0.372); } \\
\text { Transbrasiliana_2011 (0.627) }\end{array}$ & 0 \\
\hline Autopista_Fluminense_2012 & $\begin{array}{l}\text { Autopista_Regis_Bittencourt_2013 (0.636); } \\
\text { Transbrasiliana_2011 (0.363) }\end{array}$ & 0 \\
\hline Autopista_Fluminense_2013 & Autopista_Regis_Bittencourt_2013 (1.000) & 0 \\
\hline Autopista_Litoral_Sul_2009 & $\begin{array}{l}\text { Autopista_Regis_Bittencourt_2013 (0.197); } \\
\text { Transbrasiliana_2011 (0.802) }\end{array}$ & 0 \\
\hline Autopista_Litoral_Sul_2010 & $\begin{array}{l}\text { Autopista_Regis_Bittencourt_2013 (0.035); } \\
\text { Transbrasiliana_2011 (0.964) }\end{array}$ & 0 \\
\hline Autopista_Litoral_Sul_2011 & $\begin{array}{l}\text { Autopista_Regis_Bittencourt_2013 (0.550); } \\
\text { Transbrasiliana_2011 (0.449) }\end{array}$ & 0 \\
\hline Autopista_Litoral_Sul_2012 & $\begin{array}{l}\text { Autopista_Regis_Bittencourt_2013 (0.521); } \\
\text { Transbrasiliana_2011 (0.478) }\end{array}$ & 0 \\
\hline Autopista_Litoral_Sul_2013 & $\begin{array}{l}\text { Autopista_Regis_Bittencourt_2013 (0.943); } \\
\text { Transbrasiliana_2009 }(0.056)\end{array}$ & 0 \\
\hline Autopista_Planalto_Sul_2009 & Autopista_Planalto_Sul_2009 (1.000) & 0 \\
\hline Autopista_Planalto_Sul_2010 & Autopista_Planalto_Sul_2010 (1.000) & 4 \\
\hline Autopista_Planalto_Sul_2011 & $\begin{array}{l}\text { Autopista_Planalto_Sul_2010 (0.731); } \\
\text { Transbrasiliana_2011 (0.268196) }\end{array}$ & 0 \\
\hline Autopista_Planalto_Sul_2012 & $\begin{array}{l}\text { Autopista_Planalto_Sul_2010 (0.731804); } \\
\text { Transbrasiliana_2011 (0.268) }\end{array}$ & 0 \\
\hline Autopista_Planalto_Sul_2013 & $\begin{array}{l}\text { Autopista_Regis_Bittencourt_2013 (0.083); } \\
\text { Transbrasiliana_2009 }(0.916)\end{array}$ & 0 \\
\hline Autopista_Regis_Bittencourt_2009 & $\begin{array}{l}\text { Autopista_Planalto_Sul_2010 (0.048); } \\
\text { Transbrasiliana_2011 }(0.951)\end{array}$ & 0 \\
\hline Autopista_Regis_Bittencourt_2010 & $\begin{array}{l}\text { Autopista_Planalto_Sul_2010 (0.048); } \\
\text { Transbrasiliana_2011 (0.951) }\end{array}$ & 0 \\
\hline Autopista_Regis_Bittencourt_2011 & $\begin{array}{l}\text { Autopista_Regis_Bittencourt_2013 (0.018); } \\
\text { Transbrasiliana_2011 (0.981) }\end{array}$ & 0 \\
\hline Autopista_Regis_Bittencourt_2012 & $\begin{array}{l}\text { Autopista_Regis_Bittencourt_2013 (0.130); } \\
\text { Transbrasiliana_2011 (0.869) }\end{array}$ & 0 \\
\hline Autopista_Regis_Bittencourt_2013 & Autopista_Regis_Bittencourt_2013 (1.000) & 25 \\
\hline Rodovia_do_Aço_2009 & $\begin{array}{l}\text { Autopista_Regis_Bittencourt_2013 (0.286); } \\
\text { Transbrasiliana_2011 }(0.713)\end{array}$ & 0 \\
\hline Rodovia_do_Aço_2010 & $\begin{array}{l}\text { Autopista_Regis_Bittencourt_2013 (0.117); } \\
\text { Transbrasiliana_2011 (0.882) }\end{array}$ & 0 \\
\hline Rodovia_do_Aço_2011 & $\begin{array}{l}\text { Autopista_Regis_Bittencourt_2013 (0.089); } \\
\text { Transbrasiliana_2011 (0.910) }\end{array}$ & 0 \\
\hline Rodovia_do_Aço_2012 & Autopista_Regis_Bittencourt_2013 (1.000) & 0 \\
\hline Rodovia_do_Aço_2013 & Autopista_Regis_Bittencourt_2013 (1.000) & 0 \\
\hline
\end{tabular}


continues

\begin{tabular}{|c|c|c|}
\hline $\begin{array}{c}\text { DMU - SF_2.1 } \\
2^{\text {nd }} \text { Stage (2009-2013) }\end{array}$ & Benchmark & $\begin{array}{l}\text { Times as a benchmark for } \\
\text { another DMU }\end{array}$ \\
\hline Transbrasiliana_2009 & Transbrasiliana_2009 (1.000) & 3 \\
\hline Transbrasiliana_2011 & Transbrasiliana_2011 (1.000) & 23 \\
\hline Transbrasiliana_2012 & $\begin{array}{l}\text { Autopista_Regis_Bittencourt_2013 (0.017); } \\
\text { Transbrasiliana_2011 (0.982) }\end{array}$ & 0 \\
\hline Transbrasiliana_2013 & $\begin{array}{l}\text { Autopista_Regis_Bittencourt_2013 (0.122); } \\
\text { Transbrasiliana_2011 (0.877) }\end{array}$ & 0 \\
\hline
\end{tabular}

Table 22 shows that the DMUs most used as benchmark are Transbrasiliana 2011 (23 times) and Autopista Régis Bittencourt 2013 (25 times). These concessionaires are benchmarks for more than $65 \%$ of the DMUs, therefore can be used as reference of best practice for the others concessionaires.

Following to DEA models which evaluate the User Assistance, it is presented the model

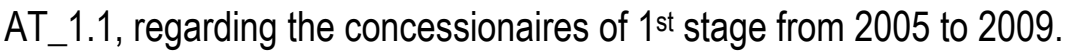

Table 23 - Efficiency scores - AT_1.1

\begin{tabular}{|c|c|c|c|c|c|c|}
\hline \multirow{2}{*}{ DMU } & \multicolumn{5}{|c|}{ Efficiency Scores - AT_1.1 - 1 ${ }^{\text {st }}$ Stage (2005-2009) } & \multirow{2}{*}{ Mean } \\
\hline & 2005 & 2006 & 2007 & 2008 & 2009 & \\
\hline Concepa & 0.82 & 1.00 & 0.81 & 0.74 & 1.00 & 0.87 \\
\hline Concer & 0.48 & 0.48 & 0.50 & 0.50 & 0.34 & 0.46 \\
\hline CRT & 0.92 & 0.88 & 0.88 & 0.83 & 0.91 & 0.89 \\
\hline Ecosul & 1.00 & 0.91 & 0.90 & 0.84 & 0.84 & 0.90 \\
\hline Nova_Dutra & 0.86 & 1.00 & 1.00 & 1.00 & 0.97 & 0.97 \\
\hline Ponte_Rio_Niterói & 0.80 & 0.76 & 1.00 & 1.00 & 0.78 & 0.87 \\
\hline
\end{tabular}


Table 24 - Ranking of efficiency scores - AT_1.1

\begin{tabular}{|c|c|c|c|c|c|}
\hline \multicolumn{5}{|c|}{ Ranking of Efficiency Scores - AT_1.1 - 1 1 st Stage (2005-2009) } & \multirow{2}{*}{ Mean } \\
\hline 2005 & 2006 & 2007 & 2008 & 2009 & \\
\hline $\begin{array}{l}\text { Ecosul } \\
(1.00)\end{array}$ & $\begin{array}{l}\text { Concepa } \\
(1.00)\end{array}$ & $\begin{array}{l}\text { Nova_Dutra } \\
(1.00)\end{array}$ & $\begin{array}{l}\text { Nova_Dutra } \\
\quad(1.00)\end{array}$ & $\begin{array}{l}\text { Concepa } \\
(1.00)\end{array}$ & $\begin{array}{l}\text { Nova_Dutra } \\
(0.97)\end{array}$ \\
\hline $\begin{array}{l}\text { CRT } \\
(0.92)\end{array}$ & $\begin{array}{l}\text { Nova_Dutra } \\
(1.00)\end{array}$ & $\begin{array}{c}\text { Ponte_Rio_Niterói } \\
\qquad(1.00)\end{array}$ & $\begin{array}{c}\text { Ponte_Rio_Niterói } \\
(1.00)\end{array}$ & $\begin{array}{l}\text { Nova_Dutra } \\
(0.97)\end{array}$ & $\begin{array}{l}\text { Ecosul } \\
(0.90)\end{array}$ \\
\hline $\begin{array}{l}\text { Nova_Dutra } \\
(0.86)\end{array}$ & $\begin{array}{l}\text { Ecosul } \\
(0.91)\end{array}$ & $\begin{array}{l}\text { Ecosul } \\
(0.90)\end{array}$ & $\begin{array}{l}\text { Ecosul } \\
(0.84)\end{array}$ & $\begin{array}{l}\text { CRT } \\
(0.91)\end{array}$ & $\begin{array}{l}\text { CRT } \\
(0.89)\end{array}$ \\
\hline $\begin{array}{l}\text { Concepa } \\
(0.82)\end{array}$ & $\begin{array}{l}\text { CRT } \\
(0.88)\end{array}$ & $\begin{array}{l}\text { CRT } \\
(0.88)\end{array}$ & $\begin{array}{l}\text { CRT } \\
(0.83)\end{array}$ & $\begin{array}{l}\text { Ecosul } \\
(0.84)\end{array}$ & $\begin{array}{l}\text { Concepa } \\
(0.87)\end{array}$ \\
\hline $\begin{array}{c}\text { Ponte_Rio_Niterói } \\
(0.80)\end{array}$ & $\begin{array}{c}\text { Ponte_Rio_Niterói } \\
(0.76)\end{array}$ & $\begin{array}{l}\text { Concepa } \\
(0.81)\end{array}$ & $\begin{array}{l}\text { Concepa } \\
(0.74)\end{array}$ & $\begin{array}{c}\text { Ponte_Rio_Niterói } \\
(0.78)\end{array}$ & $\begin{array}{c}\text { Ponte_Rio_Niterói } \\
(0.87)\end{array}$ \\
\hline $\begin{array}{l}\text { Concer } \\
(0.48)\end{array}$ & $\begin{array}{l}\text { Concer } \\
(0.48)\end{array}$ & $\begin{array}{l}\text { Concer } \\
(0.50)\end{array}$ & $\begin{array}{l}\text { Concer } \\
(0.50)\end{array}$ & $\begin{array}{l}\text { Concer } \\
(0.34)\end{array}$ & $\begin{array}{l}\text { Concer } \\
(0.46)\end{array}$ \\
\hline
\end{tabular}

Table 23 shows that out of 30 DMUs, only eight are $100 \%$ efficient. It is important to highlight that Nova Dutra achieve 100\% efficiency over three years, out of five years that have been analyzed.

Regarding the average efficiency scores, five concessionaires reach efficiency score above $87 \%$. Particular concessionaire of concern is Concer, whose DMUs average is above $50 \%$ efficiency.

From the ranking presented in Table 24, it is possible to note that there are a lot of DMUs with high scores of efficiency, and the best firm varies considerably, but the highlight is for Nova Dutra which has best concessionaire. On the other hand, Concer is in the last position of the ranking over all time period. 


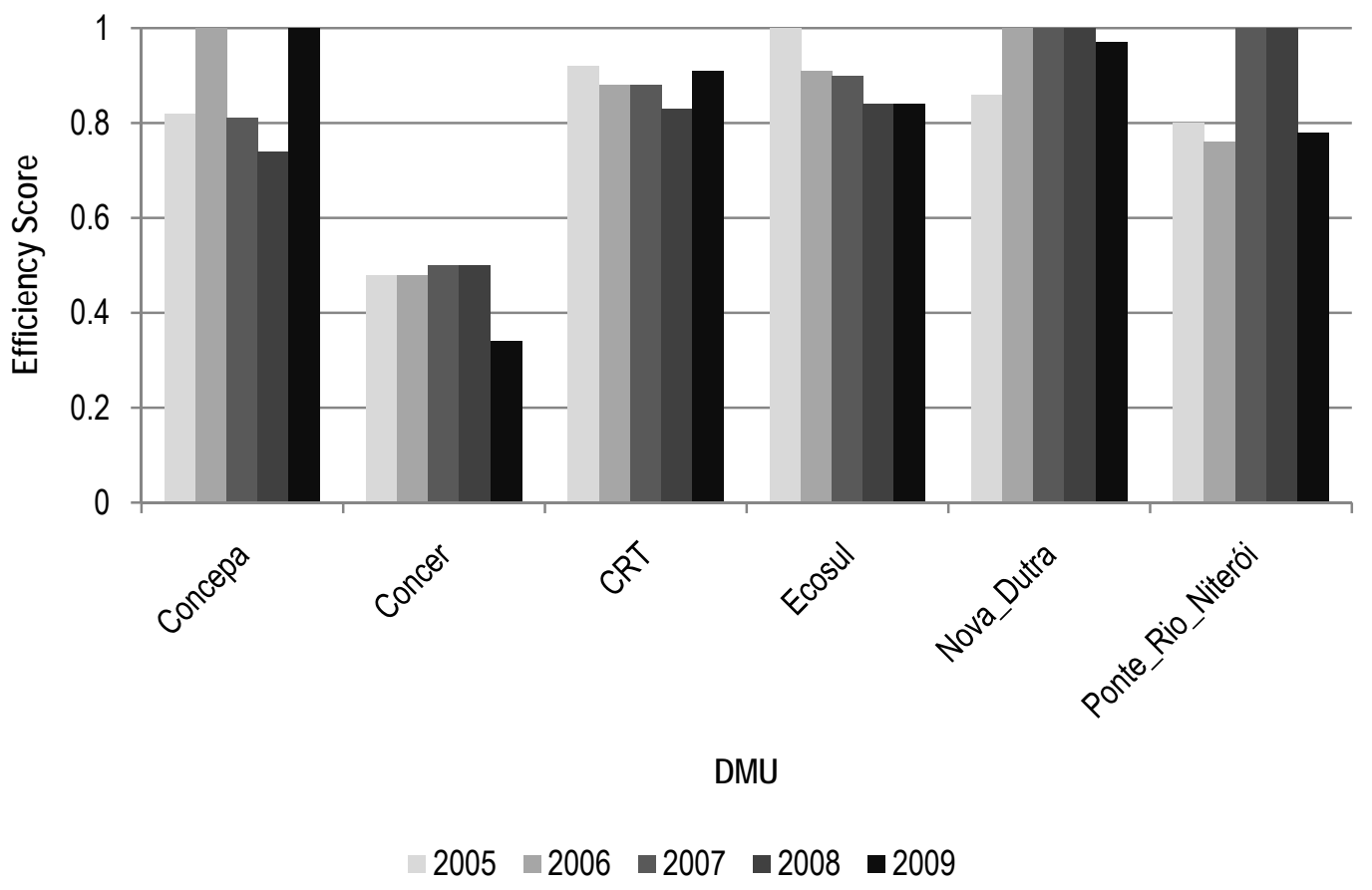

Figure 22 - Efficiency score evolution over time - AT_1.1

Figure 22 illustrates another highlight for Nova Dutra that achieved the best performance.

Despite the fact that Ponte Rio Niterói improved efficiency over the time period, it could not maintain the same performance in the last year. CRT, Concepa and Ecosul results are consistently.

Concer, besides having low and constant efficiency, the concessionaire reduced its efficiency in the last year. Regulators and decision makers should be alert because the changes made in the process were for the worse.

Table 25 - DMUs used as benchmark - AT_1.1

\begin{tabular}{llc}
\hline $\begin{array}{c}\text { DMU - AT_1.1 } \\
\text { 1 }{ }^{\text {st }} \text { Stage (2005-2009) }\end{array}$ & \multicolumn{1}{c}{ Benchmark } & $\begin{array}{c}\text { Times as a benchmark for } \\
\text { another DMU }\end{array}$ \\
\hline Concepa_2005 & Concepa_2006 (0.653); Ponte_Rio_Niterói_2008 (0.346) & 0 \\
\hline Concepa_2006 & Concepa_2006 (1.000) & 13 \\
\hline Concepa_2007 & Concepa_2006 (0.208); Ponte_Rio_Niterói_2008 (0.791) & 0 \\
\hline Concepa_2008 & $\begin{array}{l}\text { Concepa_2006 (0.201); Concepa_2009 (0.431); } \\
\text { Ponte_Rio_Niterói_2008 (0.367) }\end{array}$ & 0 \\
\hline Concepa_2009 & Concepa_2009 (1.000) & 1 \\
\hline Concer_2005 & Concepa_2006 (0.788); Ponte_Rio_Niterói_2007 (0.027); \\
\hline
\end{tabular}

continues 
continues

\begin{tabular}{|c|c|c|}
\hline $\begin{array}{c}\text { DMU - AT_1.1 } \\
\text { 1st Stage }(2005-2009)\end{array}$ & Benchmark & $\begin{array}{l}\text { Times as a benchmark for } \\
\text { another DMU }\end{array}$ \\
\hline Concer_2006 & $\begin{array}{l}\text { Concepa_2006 (0.749); Ponte_Rio_Niterói_2007 (0.041); } \\
\text { Ponte_Rio_Niterói_2008 (0.209) }\end{array}$ & 0 \\
\hline Concer_2007 & $\begin{array}{l}\text { Concepa_2006 (0.467); Ponte_Rio_Niterói_2007 (0.140); } \\
\text { Ponte_Rio_Niterói_2008 (0.391) }\end{array}$ & 0 \\
\hline Concer_2008 & $\begin{array}{l}\text { Concepa_2006 (0.338); Ponte_Rio_Niterói_2007 (0.189); } \\
\text { Ponte_Rio_Niterói_2008 (0.471) }\end{array}$ & 0 \\
\hline Concer_2009 & Ecosul_2005 (0.209); Ponte_Rio_Niterói_2008 (0.791) & 0 \\
\hline CRT_2005 & Concepa_2006 (0.533); Ponte_Rio_Niterói_2008 (0.466) & 0 \\
\hline CRT_2006 & Concepa_2006 (0.631); Ponte_Rio_Niterói_2008 (0.368) & 0 \\
\hline CRT_2007 & Concepa_2006 (0.610); Ponte_Rio_Niterói_2008 (0.389) & 0 \\
\hline CRT_2008 & Concepa_2006 (0.579); Ponte_Rio_Niterói_2008 (0.420) & 0 \\
\hline CRT_2009 & Concepa_2006 (0.609); Ponte_Rio_Niterói_2008 (0.390) & 0 \\
\hline Ecosul_2005 & Ecosul_2005 (1.000) & 5 \\
\hline Ecosul_2006 & Ecosul_2005 (0.661); Ponte_Rio_Niterói_2008 (0.338) & 0 \\
\hline Ecosul_2007 & Ecosul_2005 (0.795); Ponte_Rio_Niterói_2008 (0.204) & 0 \\
\hline Ecosul_2008 & Ecosul_2005 (0.274); Ponte_Rio_Niterói_2008 (0.725) & 0 \\
\hline Ecosul_2009 & Ecosul_2005 (0.274); Ponte_Rio_Niterói_2008 (0.725) & 0 \\
\hline Nova_Dutra_2005 & $\begin{array}{l}\text { Nova_Dutra_2007 (0.873); Nova_Dutra_2008 (0.032); } \\
\text { Ponte_Rio_Niterói_2008 (0.094) }\end{array}$ & 0 \\
\hline Nova_Dutra_2006 & Nova_Dutra_2006 (1.000) & 0 \\
\hline Nova_Dutra_2007 & Nova_Dutra_2007 (1.000) & 2 \\
\hline Nova_Dutra_2008 & Nova_Dutra_2008 (1.000) & 3 \\
\hline Nova_Dutra_2009 & Nova_Dutra_2008 (0.993); Ponte_Rio_Niterói_2007 (0.006) & 0 \\
\hline Ponte_Rio_Niterói_2005 & $\begin{array}{l}\text { Nova_Dutra_2007 (0.015); Ponte_Rio_Niterói_2007 (0.631708); } \\
\text { Ponte_Rio_Niterói_2008 (0.353) }\end{array}$ & 0 \\
\hline Ponte_Rio_Niterói_2006 & $\begin{array}{l}\text { Concepa_2006 (0.028); Ponte_Rio_Niterói_2007 (0.607); } \\
\text { Ponte_Rio_Niterói_2008 (0.364) }\end{array}$ & 0 \\
\hline Ponte_Rio_Niterói_2007 & Ponte_Rio_Niterói_2007 (1.000) & 8 \\
\hline Ponte_Rio_Niterói_2008 & Ponte_Rio_Niterói_2008 (1.000) & 21 \\
\hline Ponte_Rio_Niterói_2009 & $\begin{array}{l}\text { Nova_Dutra_2008 (0.009); Ponte_Rio_Niterói_2007 (0.617); } \\
\text { Ponte_Rio_Niterói_2008 (0.373) }\end{array}$ & 0 \\
\hline
\end{tabular}

Table 25 does not show the same highlight for Nova Dutra as it had in the previous analysis, because it was used as benchmark only 5 times.

The DMUs most used as benchmark are Ponte Rio Niterói 2008 (21 times) and Concepa 2006 (13 times).

Next DEA result presented is the model AT_1.2, which evaluates the User Assistance of the concessionaires of $1{ }^{\text {st }}$ stage from 2009 to 2013. 
Table 26 - Efficiency scores - AT_1.2

\begin{tabular}{lcccccc}
\hline \multirow{2}{*}{ DMU } & \multicolumn{6}{c}{ Efficiency Scores - AT_1.2 - 1 1st $^{\text {Stage (2009-2013) }}$ Mean } \\
\cline { 2 - 6 } & $\mathbf{2 0 0 9}$ & $\mathbf{2 0 1 0}$ & $\mathbf{2 0 1 1}$ & $\mathbf{2 0 1 2}$ & $\mathbf{2 0 1 3}$ & \\
\hline Concepa & 1.00 & 0.73 & 0.84 & 0.78 & 0.76 & 0.82 \\
\hline Concer & 0.56 & 0.51 & 0.77 & 0.78 & 0.52 & 0.63 \\
\hline CRT & 1.00 & 0.69 & 0.69 & 0.69 & 0.60 & 0.73 \\
\hline Ecosul & 1.00 & 0.87 & 0.91 & 0.91 & 0.71 & 0.88 \\
\hline Nova_Dutra & 1.00 & 1.00 & 1.00 & 1.00 & 1.00 & 1.00 \\
\hline Ponte_Rio_Niterói & 1.00 & 0.87 & 0.87 & 0.81 & 1.00 & 0.91 \\
\hline
\end{tabular}

Table 27 - Ranking of efficiency scores - AT_1.2

\begin{tabular}{cccccc}
\hline \multicolumn{7}{c}{ Ranking of Efficiency Scores - AT_1.2- $\mathbf{1}^{\text {st }}$ Stage (2009-2013) } & & \multirow{2}{*}{ Mean } \\
\cline { 1 - 4 } $\mathbf{2 0 0 9}$ & $\mathbf{2 0 1 0}$ & $\mathbf{2 0 1 1}$ & $\mathbf{2 0 1 2}$ & $\mathbf{2 0 1 3}$ & \\
\cline { 1 - 4 } Concepa & Nova_Dutra & Nova_Dutra & Nova_Dutra & Nova_Dutra & Nova_Dutra \\
$(1.00)$ & $(1.00)$ & $(1.00)$ & $(1.00)$ & $(1.00)$ & $(1.00)$ \\
\hline CRT & Ecosul & Ecosul & Ecosul & Ponte_Rio_Niterói & Ponte_Rio_Niterói \\
$(1.00)$ & $(0.87)$ & $(0.91)$ & $(0.91)$ & $(1.00)$ & $(0.91)$ \\
\hline Ecosul & Ponte_Rio_Niterói & Ponte_Rio_Niterói & Ponte_Rio_Niterói & Concepa & Ecosul \\
$(1.00)$ & $(0.87)$ & $(0.87)$ & $(0.81)$ & $(0.76)$ & $(0.88)$ \\
\hline Nova_Dutra & Concepa & Concepa & Concepa & Ecosul & Concepa \\
$(1.00)$ & $(0.73)$ & $(0.84)$ & $(0.78)$ & $(0.71)$ & $(0.82)$ \\
\hline Ponte_Rio_Niterói & CRT & Concer & Concer & CRT & CRT \\
(1.00) & $(0.69)$ & $(0.77)$ & $(0.78)$ & $(0.60)$ & $(0.73)$ \\
\hline Concer & Concer & CRT & CRT & Concer & Concer \\
$(0.56)$ & $(0.51)$ & $(0.69)$ & $(0.69)$ & $(0.52)$ & $(0.63)$ \\
\hline
\end{tabular}

Table 26 shows that out of 30 DMUs, nine are $100 \%$ efficient. In 2009, out of 6 DMUs, five are $100 \%$ efficient.

In this model, Nova Dutra continues as the highlight, reaching $100 \%$ efficient over all years under analysis.

Regarding the average of the efficiency scores, two concessionaires reached an efficiency score above $90 \%$, other two above $80 \%$, and the other two above $60 \%$. Concer continues in the last position, but it increased its efficiency in comparison with the previous time period. 
Obviously, Nova Dutra leads the ranking shown in Table 27. CRT and Concer share the last positions.

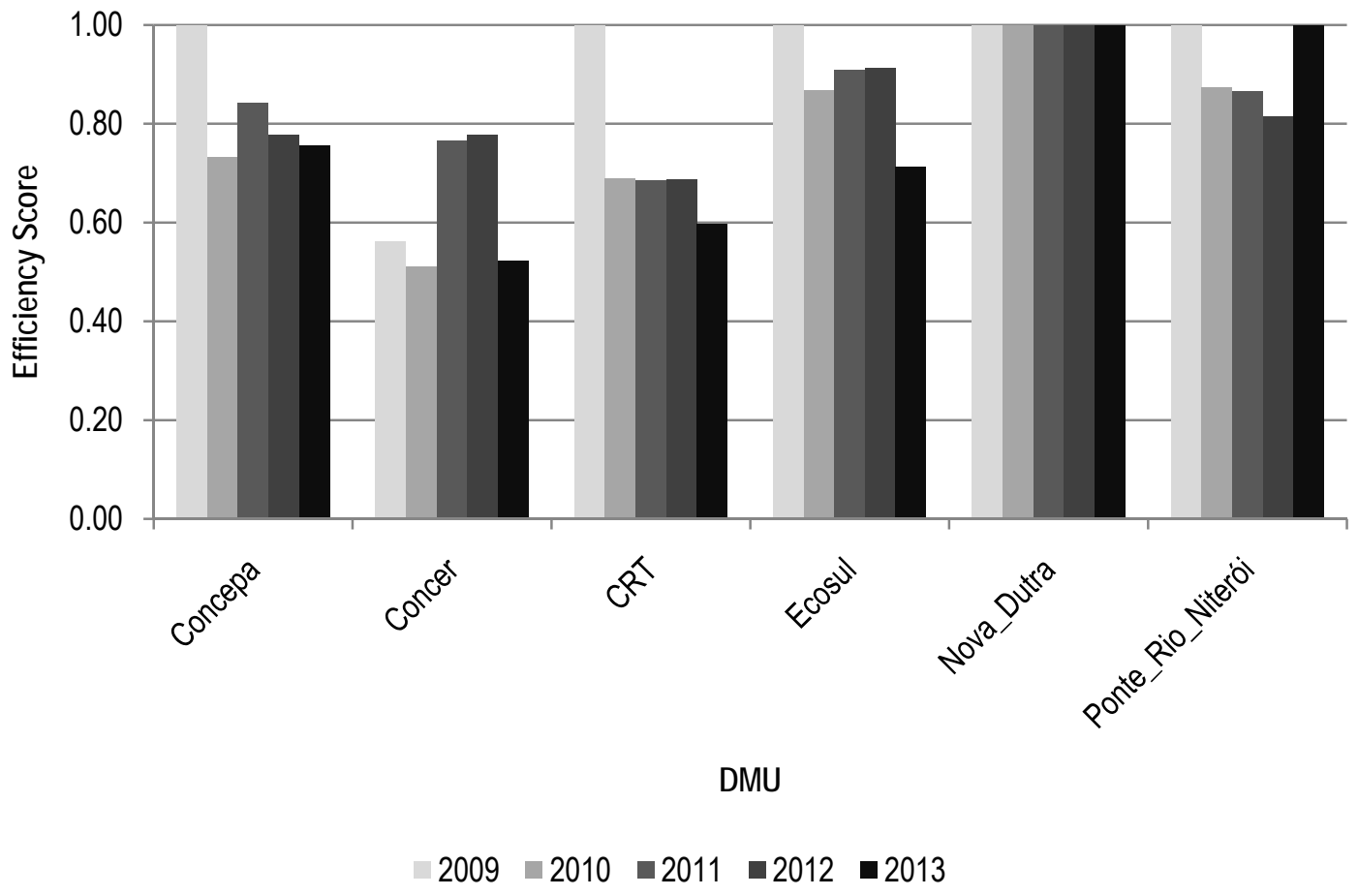

Figure 23 - Efficiency score evolution over time - AT_1.2

Figure 23 illustrates the excellent performance of Nova Dutra. Ponte Rio Niterói is the concessionaire which consistently worsened its efficiency score over the time period, and drastically increased its efficiency to $100 \%$ in the last year.

Ecosul average efficiency (88\%) is a good result, but it presents a consistently worsened its efficiency score over the time period, which is a concern and the process of this firm should be monitored.

Concepa e CRT present a drastically drop in its efficiency in the first year, but after keep their performance stable over the time period.

Concer achieved a better efficiency score over two years, however was not able to maintain this performance. It should investigate the innovations implemented in these years in the process, in order to improve the average efficiency score. 
Table 28 - DMUs used as benchmark - AT_1.2

\begin{tabular}{|c|c|c|}
\hline $\begin{array}{c}\text { DMU - AT_1.2 } \\
1^{\text {st }} \text { Stage (2009-2013) }\end{array}$ & Benchmark & $\begin{array}{l}\text { Times as a benchmark for } \\
\text { another DMU }\end{array}$ \\
\hline Concepa_2009 & Concepa_2009 (1.000) & 10 \\
\hline Concepa_2010 & Ecosul_2009 (0.044); Ponte_Rio_Niterói_2013 (0.955) & 0 \\
\hline Concepa_2011 & Nova_Dutra_2010 (0.013); Ponte_Rio_Niterói_2013 (0.986) & 0 \\
\hline Concepa_2012 & $\begin{array}{l}\text { Concepa_2009 (0.361); Nova_Dutra_2010 (0.043); } \\
\text { Ponte_Rio_Niterói_2013 (0.594) }\end{array}$ & 0 \\
\hline Concepa_2013 & $\begin{array}{l}\text { Concepa_2009 (0.931); Nova_Dutra_2011 (0.025); } \\
\text { Nova_Dutra_2013 (0.042) }\end{array}$ & 0 \\
\hline Concer_2009 & Ecosul_2009 (0.095); Ponte_Rio_Niterói_2013 (0.904) & 0 \\
\hline Concer_2010 & Ecosul_2009 (0.155); Ponte_Rio_Niterói_2013 (0.844) & 0 \\
\hline Concer_2011 & Nova_Dutra_2010 (0.024); Ponte_Rio_Niterói_2013 (0.975) & 0 \\
\hline Concer_2012 & Nova_Dutra_2010 (0.036); Ponte_Rio_Niterói_2013 (0.963) & 0 \\
\hline Concer_2013 & Nova_Dutra_2010 (0.024); Ponte_Rio_Niterói_2013 (0.975) & 0 \\
\hline CRT_2009 & CRT_2009 (1.000) & 5 \\
\hline CRT_2010 & Concepa_2009 (0.001); CRT_2009 (0.686); Ecosul_2009 (0.313) & 0 \\
\hline CRT_2011 & Concepa_2009 (0.070); CRT_2009 (0.708); Ecosul_2009 (0.221) & 0 \\
\hline CRT_2012 & Concepa_2009 (0.136); CRT_2009 (0.605); Ecosul_2009 (0.257) & 0 \\
\hline CRT_2013 & Concepa_2009 (0.151); CRT_2009 (0.404); Ecosul_2009 (0.444) & 0 \\
\hline Ecosul_2009 & Ecosul_2009 (1.000) & 11 \\
\hline Ecosul_2010 & Ecosul_2009 (0.905); Ponte_Rio_Niterói_2013 (0.094) & 0 \\
\hline Ecosul_2011 & $\begin{array}{l}\text { Concepa_2009 (0.064); Ecosul_2009 (0.782); } \\
\text { Ponte_Rio_Niterói_2013 (0.153) }\end{array}$ & 0 \\
\hline Ecosul_2012 & Ecosul_2009 (0.788); Ponte_Rio_Niterói_2013 (0.211) & 0 \\
\hline Ecosul_2013 & $\begin{array}{l}\text { Concepa_2009 (0.266); CRT_2009 (0.475); Ecosul_2009 (0.048); } \\
\text { Ponte_Rio_Niterói_2013 (0.208) }\end{array}$ & 0 \\
\hline Nova_Dutra_2009 & Nova_Dutra_2009 (1.000) & 0 \\
\hline Nova_Dutra_2010 & Nova_Dutra_2010 (1.000) & 8 \\
\hline Nova_Dutra_2011 & Nova_Dutra_2011 (1.000) & 1 \\
\hline Nova_Dutra_2012 & Nova_Dutra_2012 (1.000) & 0 \\
\hline Nova_Dutra_2013 & Nova_Dutra_2013 (1.000) & 1 \\
\hline Ponte_Rio_Niterói_2009 & Ponte_Rio_Niterói_2009 (1.000) & 3 \\
\hline Ponte_Rio_Niterói_2010 & $\begin{array}{l}\text { Nova_Dutra_2010 (0.004); Ponte_Rio_Niterói_2009 (0.680); } \\
\text { Ponte_Rio_Niterói_2013 (0.314) }\end{array}$ & 0 \\
\hline Ponte_Rio_Niterói_2011 & $\begin{array}{l}\text { Concepa_2009 (0.137); Nova_Dutra_2010 (0.008); } \\
\text { Ponte_Rio_Niterói_2009 (0.650); Ponte_Rio_Niterói_2013 (0.202) }\end{array}$ & 0 \\
\hline Ponte_Rio_Niterói_2012 & $\begin{array}{l}\text { Concepa_2009 (0.124); Nova_Dutra_2010 (0.010); } \\
\text { Ponte_Rio_Niterói_2009 (0.499); Ponte_Rio_Niterói_2013 (0.365) }\end{array}$ & 0 \\
\hline Ponte_Rio_Niterói_2013 & Ponte_Rio_Niterói_2013 (1.000) & 15 \\
\hline
\end{tabular}

Table 28 shows that this analysis had five concessionaries used as benchmarks in their best years of efficiency scores, they are: Concepa 2009, CRT 2009, Ecosul 2009, Dutra 2010 and Ponte 2013. This indicates that such concessionaires already have the means to be efficient and do not need to identify the practices of the other firms as best practices. 
Finally, the last DEA model that evaluates the User Assistance is presented. The model AT_2.1 evaluates the concessionaires of $2^{\text {nd }}$ stage from 2009 to 2013.

Table 29 - Efficiency scores - AT_2.1

\begin{tabular}{lcccccc}
\hline \multirow{2}{*}{ DMU } & \multicolumn{7}{c}{ Efficiency Scores - AT_2.1 - 2 ${ }^{\text {nd }}$ Stage (2009-2013) } & \multirow{2}{*}{ Mean } \\
\cline { 2 - 6 } & $\mathbf{2 0 0 9}$ & $\mathbf{2 0 1 0}$ & $\mathbf{2 0 1 1}$ & $\mathbf{2 0 1 2}$ & $\mathbf{2 0 1 3}$ & \\
\hline Autopista_Fernao_Dias & 0.44 & 0.66 & 0.87 & 1.00 & 1.00 & 0.79 \\
\hline Autopista_Fluminense & 0.67 & 0.93 & 0.53 & 0.43 & 0.29 & 0.57 \\
\hline Autopista_Litoral_Sul & 0.66 & 0.90 & 0.59 & 0.81 & 0.79 & 0.75 \\
\hline Autopista_Planalto_Sul & 0.79 & 0.87 & 0.77 & 0.78 & 0.75 & 0.79 \\
\hline Autopista_Regis_Bittencourt & 1.00 & 1.00 & 1.00 & 0.94 & 1.00 & 0.99 \\
\hline Rodovia_do_Aço & 1.00 & 0.96 & 1.00 & 0.53 & 0.42 & 0.78 \\
\hline Transbrasiliana & 1.00 & 1.00 & 1.00 & 0.88 & 0.78 & 0.93 \\
\hline
\end{tabular}

Table 30 - Ranking of efficiency scores - AT_2.1

\begin{tabular}{|c|c|c|c|c|c|}
\hline \multicolumn{5}{|c|}{ Ranking of Efficiency Scores - AT_2.1 - 2 ${ }^{\text {nd }}$ Stage (2009-2013) } & \multirow{2}{*}{ Mean } \\
\hline 2009 & 2010 & 2011 & 2012 & 2013 & \\
\hline $\begin{array}{c}\text { Autopista_ } \\
\text { Regis_Bittencourt } \\
(1.00)\end{array}$ & $\begin{array}{c}\text { Autopista_ } \\
\text { Regis_Bittencourt } \\
(1.00)\end{array}$ & $\begin{array}{c}\text { Autopista_ } \\
\text { Regis_Bittencourt } \\
(1.00)\end{array}$ & $\begin{array}{l}\text { Autopista_- } \\
\text { Fernao_Dias } \\
(1.00)\end{array}$ & $\begin{array}{l}\text { Autopista_- } \\
\text { Fernao_Dias } \\
(1.00)\end{array}$ & $\begin{array}{c}\text { Autopista_ } \\
\text { Regis_Bittencourt } \\
(0.99)\end{array}$ \\
\hline $\begin{array}{c}\text { Rodovia_do_Aço } \\
(1.00)\end{array}$ & $\begin{array}{c}\text { Transbrasiliana } \\
(1.00)\end{array}$ & $\begin{array}{c}\text { Rodovia_do_Aço } \\
(1.00)\end{array}$ & $\begin{array}{c}\text { Autopista_ } \\
\text { Regis_Bittencourt } \\
(0.94)\end{array}$ & $\begin{array}{c}\text { Autopista_ } \\
\text { Regis_Bittencourt } \\
(1.00)\end{array}$ & $\begin{array}{l}\text { Transbrasiliana } \\
(0.93)\end{array}$ \\
\hline $\begin{array}{c}\text { Transbrasiliana } \\
(1.00)\end{array}$ & $\begin{array}{c}\text { Rodovia_do_Aço } \\
(0.96)\end{array}$ & $\begin{array}{c}\text { Transbrasiliana } \\
(1.00)\end{array}$ & $\begin{array}{l}\text { Transbrasiliana } \\
(0.88)\end{array}$ & $\begin{array}{l}\text { Autopista_- } \\
\text { Litoral_Sul } \\
(0.79)\end{array}$ & $\begin{array}{l}\text { Autopista_ } \\
\text { Fernao_Dias } \\
(0.79)\end{array}$ \\
\hline $\begin{array}{l}\text { Autopista__ } \\
\text { Planalto_Sul } \\
(0.79)\end{array}$ & $\begin{array}{l}\text { Autopista_ } \\
\text { Fluminense } \\
(0.93)\end{array}$ & $\begin{array}{l}\text { Autopista_ } \\
\text { Fernao_Dias } \\
(0.87)\end{array}$ & $\begin{array}{l}\text { Autopista__ } \\
\text { Litoral_Sul } \\
(0.81)\end{array}$ & $\begin{array}{l}\text { Transbrasiliana } \\
(0.78)\end{array}$ & $\begin{array}{l}\text { Autopista_- } \\
\text { Planalto_Sul } \\
(0.79)\end{array}$ \\
\hline $\begin{array}{l}\text { Autopista_ } \\
\text { Fluminense } \\
(0.67)\end{array}$ & $\begin{array}{l}\text { Autopista_ } \\
\text { Litoral_Sul } \\
(0.90)\end{array}$ & $\begin{array}{l}\text { Autopista_ } \\
\text { Planalto_Sul } \\
\quad(0.77)\end{array}$ & $\begin{array}{l}\text { Autopista__ } \\
\text { Planalto_Sul } \\
(0.78)\end{array}$ & $\begin{array}{l}\text { Autopista__ } \\
\text { Planalto_Sul } \\
(0.75)\end{array}$ & $\begin{array}{c}\text { Rodovia_do_Aço } \\
(0.78)\end{array}$ \\
\hline $\begin{array}{l}\text { Autopista_- } \\
\text { Litoral_Sul } \\
\quad(0.66)\end{array}$ & $\begin{array}{l}\text { Autopista_ } \\
\text { Planalto_Sul } \\
(0.87)\end{array}$ & $\begin{array}{l}\text { Autopista_ } \\
\text { Litoral_Sul } \\
\quad(0.59)\end{array}$ & $\begin{array}{c}\text { Rodovia_do_Aço } \\
(0.53)\end{array}$ & $\begin{array}{c}\text { Rodovia_do_Aço } \\
(0.42)\end{array}$ & $\begin{array}{l}\text { Autopista__ } \\
\text { Litoral_Sul } \\
(0.75)\end{array}$ \\
\hline $\begin{array}{l}\text { Autopista_ } \\
\text { Fernao_Dias } \\
(0.44)\end{array}$ & $\begin{array}{l}\text { Autopista_ } \\
\text { Fernao_Dias } \\
(0.66)\end{array}$ & $\begin{array}{l}\text { Autopista_ } \\
\text { Fluminense } \\
(0.53)\end{array}$ & $\begin{array}{l}\text { Autopista_ } \\
\text { Fluminense } \\
\quad(0.43)\end{array}$ & $\begin{array}{l}\text { Autopista_ } \\
\text { Fluminense } \\
(0.29)\end{array}$ & $\begin{array}{l}\text { Autopista_ } \\
\text { Fluminense } \\
\quad(0.57)\end{array}$ \\
\hline
\end{tabular}

Table 29 shows that out of 35 DMUs, only 11 are 100\% efficient. Autopista Régis Bittencourt reaches $100 \%$ efficiency over four years and also has the higher average efficiency. 
Based on the mean of the efficiency scores, two concessionaires reach efficiency score above $90 \%$, four above $75 \%$, and Autopista Fluminense (57\%) has the worst efficiency score.

From the ranking presented in Table 30, it is possible to confirm the highlight for Autopista Régis Bittencourt. Although Autopista Fluminense has the smaller efficiency score, it shares the last position with Autopista Fernão Dias in the first years.

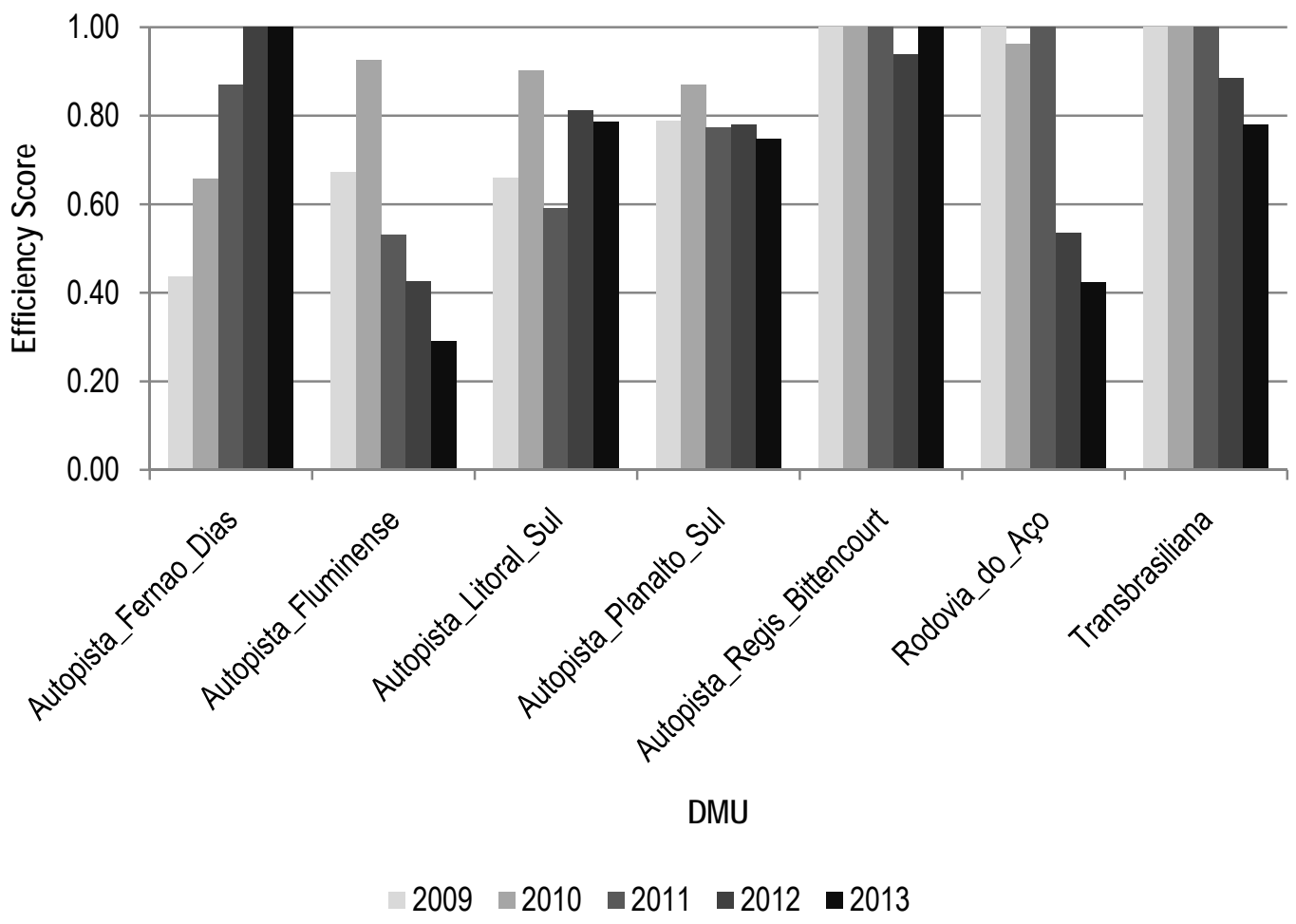

Figure 24 - Efficiency score evolution over time - AT_2.1

Figure 24 illustrates that Autopista Régis Bittencourt achieves the best efficiency scores.

Transbrasiliana, Rodovia do Aço and Autopista Fluminense are the concessionaires which consistently worsened their efficiency score over the time period. Rodovia do Aço and Autopista Fluminense drastically drop theirs efficiencies, which is a warning indicator.

On the other hand, Autopista Fernão Dias constantly improved its efficiency, reaching $100 \%$ efficiency in the last year and can be used as best practices. 
Autopista Litoral Sul and Autopista Planalto Sul presented an satisfactory average efficiency score and keep their performance stable over the time period.

Table 31 - DMUs used as benchmark - AT_2.1

\begin{tabular}{|c|c|c|}
\hline $\begin{array}{c}\text { DMU - AT_2.1 } \\
2^{\text {nd }} \text { Stage (2009-2013) }\end{array}$ & Benchmark & $\begin{array}{c}\text { Times as a } \\
\text { benchmark for } \\
\text { another DMU }\end{array}$ \\
\hline Autopista_Fernao_Dias_2009 & $\begin{array}{l}\text { Autopista_Regis_Bittencourt_2009 (0.457); } \\
\text { Autopista_Regis_Bittencourt_2011 (0.240); } \\
\text { Rodovia_do_Aço_2009 (0.044); Rodovia_do_Aço_2011 (0.257) }\end{array}$ & 0 \\
\hline Autopista_Fernao_Dias_2010 & $\begin{array}{l}\text { Autopista_Regis_Bittencourt_2010 (0.876; } \\
\text { Rodovia_do_Aço_2011 (0.123) }\end{array}$ & 0 \\
\hline Autopista_Fernao_Dias_2011 & $\begin{array}{l}\text { Autopista_Fernao_Dias_2012 (0.534); } \\
\text { Autopista_Regis_Bittencourt_2011 (0.465) }\end{array}$ & 0 \\
\hline Autopista_Fernao_Dias_2012 & Autopista_Fernao_Dias_2012 (1.000) & 2 \\
\hline Autopista_Fernao_Dias_2013 & Autopista_Fernao_Dias_2013 (1.000) & 1 \\
\hline Autopista_Fluminense_2009 & $\begin{array}{l}\text { Autopista_Regis_Bittencourt_2009 (0.225); } \\
\text { Transbrasiliana_2009 }(0.774)\end{array}$ & 0 \\
\hline Autopista_Fluminense_2010 & $\begin{array}{l}\text { Autopista_Regis_Bittencourt_2009 (0.267); } \\
\text { Transbrasiliana_2009 (0.732) }\end{array}$ & 0 \\
\hline Autopista_Fluminense_2011 & $\begin{array}{l}\text { Autopista_Regis_Bittencourt_2010 (0.262); } \\
\text { Rodovia_do_Aço_2011 (0.737) }\end{array}$ & 0 \\
\hline Autopista_Fluminense_2012 & $\begin{array}{l}\text { Autopista_Regis_Bittencourt_2010 (0.292); } \\
\text { Rodovia_do_Aço_2011 (0.707) }\end{array}$ & 0 \\
\hline Autopista_Fluminense_2013 & $\begin{array}{l}\text { Autopista_Regis_Bittencourt_2010 (0.272); } \\
\text { Rodovia_do_Aço_2011 (0.727) }\end{array}$ & 0 \\
\hline Autopista_Litoral_Sul_2009 & $\begin{array}{l}\text { Autopista_Regis_Bittencourt_2009 (0.625); } \\
\text { Autopista_Regis_Bittencourt_2010 (0.002); } \\
\text { Rodovia_do_Aço_2011 (0.371) }\end{array}$ & 0 \\
\hline Autopista_Litoral_Sul_2010 & $\begin{array}{l}\text { Autopista_Regis_Bittencourt_2010 (0.817); } \\
\text { Rodovia_do_Aço_2011 (0.182) }\end{array}$ & 0 \\
\hline Autopista_Litoral_Sul_2011 & $\begin{array}{l}\text { Autopista_Regis_Bittencourt_2009 (0.639); } \\
\text { Autopista_Regis_Bittencourt2011 (0.360) }\end{array}$ & 0 \\
\hline Autopista_Litoral_Sul_2012 & $\begin{array}{l}\text { Autopista_Regis_Bittencourt_2009 (0.468); } \\
\text { Autopista_Regis_Bittencourt2011 (0.531) }\end{array}$ & 0 \\
\hline Autopista_Litoral_Sul_2013 & $\begin{array}{l}\text { Autopista_Regis_Bittencourt_2009 (0.573); } \\
\text { Autopista_Regis_Bittencourt_2011 (0.426) }\end{array}$ & 0 \\
\hline Autopista_Planalto_Sul_2009 & $\begin{array}{l}\text { Autopista_Regis_Bittencourt_2011 (0.036); } \\
\text { Rodovia_do_Aço_2009 (0.154); Rodovia_do_Aço_2011 (0.808) }\end{array}$ & 0 \\
\hline Autopista_Planalto_Sul_2010 & $\begin{array}{l}\text { Autopista_Regis_Bittencourt_2010 (0.060); } \\
\text { Rodovia_do_Aço_2011 }(0.939)\end{array}$ & 0 \\
\hline Autopista_Planalto_Sul_2011 & $\begin{array}{l}\text { Autopista_Regis_Bittencourt_2010 (0.070); } \\
\text { Rodovia_do_Aço_2011 (0.929) }\end{array}$ & 0 \\
\hline Autopista_Planalto_Sul_2012 & $\begin{array}{l}\text { Autopista_Regis_Bittencourt_2010 (0.083); } \\
\text { Rodovia_do_Aço_2011 (0.916) }\end{array}$ & 0 \\
\hline Autopista_Planalto_Sul_2013 & $\begin{array}{l}\text { Autopista_Regis_Bittencourt_2009 (0.090); } \\
\text { Transbrasiliana_2009 }(0.909)\end{array}$ & 0 \\
\hline Autopista_Regis_Bittencourt_2009 & Autopista_Regis_Bittencourt_2009 (1.000) & 12 \\
\hline Autopista_Regis_Bittencourt_2010 & Autopista_Regis_Bittencourt_2010(1.000) & 9 \\
\hline Autopista_Regis_Bittencourt_2011 & Autopista_Regis_Bittencourt_2011 (1.000) & 10 \\
\hline Autopista_Regis_Bittencourt_2012 & $\begin{array}{l}\text { Autopista_Fernao_Dias_2012 (0.082); } \\
\text { Autopista_Fernao_Dias_2013 (0.041); } \\
\text { Autopista_Regis_Bittencourt_2011 (0.876) }\end{array}$ & 0 \\
\hline
\end{tabular}

continues 
continues

\begin{tabular}{|c|c|c|}
\hline $\begin{array}{l}\text { DMU - AT_2.1 } \\
2^{\text {nd }} \text { Stage (2009-2013) }\end{array}$ & Benchmark & $\begin{array}{l}\text { Times as a } \\
\text { benchmark for } \\
\text { another DMU }\end{array}$ \\
\hline Autopista_Regis_Bittencourt_2013 & Autopista_Regis_Bittencourt_2013 (1.000) & 0 \\
\hline Rodovia_do_Aço_2009 & Rodovia_do_Aço_2009 (1.000) & 5 \\
\hline Rodovia_do_Aço_2010 & Rodovia_do_Aço_2011 (1.000) & 0 \\
\hline Rodovia_do_Aço_2011 & Rodovia_do_Aço_2011 (1.000) & 14 \\
\hline Rodovia_do_Aço_2012 & $\begin{array}{l}\text { Autopista_Regis_Bittencourt_2009 }(0.044) ; \\
\text { Autopista_Regis_Bittencourt_2011 (0.005); } \\
\text { Rodovia_do_Aço_2009 (0.929); Transbrasiliana_2011 (0.020) }\end{array}$ & 0 \\
\hline Rodovia_do_Aço_2013 & $\begin{array}{l}\text { Autopista_Regis_Bittencourt_2009 (0.012); } \\
\text { Transbrasiliana_2009 }(0.987)\end{array}$ & 0 \\
\hline Transbrasiliana_2009 & Transbrasiliana_2009 (1.000) & 4 \\
\hline Transbrasiliana_2010 & Transbrasiliana_2010(1.000) & 0 \\
\hline Transbrasiliana_2011 & Transbrasiliana_2011 (1.000) & 1 \\
\hline Transbrasiliana_2012 & $\begin{array}{l}\text { Autopista_Regis_Bittencourt_2009 (0.052); } \\
\text { Autopista_Regis_Bittencourt_2011 (0.071); } \\
\text { Rodovia_do_Aço_2009 (0.640); Rodovia_do_Aço_2011 (0.235) }\end{array}$ & 0 \\
\hline Transbrasiliana_2013 & $\begin{array}{l}\text { Autopista_Regis_Bittencourt_2009 (0.080); } \\
\text { Autopista_Regis_Bittencourt_2011 (0.058); } \\
\text { Rodovia_do_Aço_2009 (0.739); Rodovia_do_Aço_2011 (0.121) }\end{array}$ & 0 \\
\hline
\end{tabular}

Table 31 shows that Autopista Régis Bittencourt in 2009, 2010 and 2011 are benchmark for more than $88 \%$ of the DMUs (31 times).

Rodovia do Aço in 2011 was used as benchmark for 14 DMUs, however using its operational and strategic policies as best practice should be avoided because it drastically drops its efficiency after 2011.

After presenting all the results of DEA models, Table 32 summarizes the main results and observations obtained from the analysis. 
Table 32 - Summary of the results

\begin{tabular}{|c|c|c|c|c|}
\hline Model & Most efficient & Less efficient & Benchmark & Observations \\
\hline SF_1.1 & $\begin{array}{l}\text { Ecosul, Ponte } \\
\text { Rio Niterói }\end{array}$ & Concer & $\begin{array}{l}\text { Ecosul 2007, } \\
\text { Ponte Rio } \\
\text { Niterói } 2004 \\
\text { and } 2008\end{array}$ & $\begin{array}{l}\text { Particulary concern is Concer, its case } \\
\text { should be studied in order to improve } \\
\text { efficiency. } \\
\text { Ecosul and Ponte Rio Niterói should } \\
\text { be used as best practices. }\end{array}$ \\
\hline SF_1.2 & $\begin{array}{l}\text { Ecosul, } \\
\text { Concepa }\end{array}$ & CRT, Concer & $\begin{array}{l}\text { Ecosul 2013, } \\
\text { Ponte Rio } \\
\text { Niterói } 2013\end{array}$ & $\begin{array}{l}\text { Concer and Nova Dutra are very } \\
\text { constantly, which means that they } \\
\text { have to seek innovations and } \\
\text { implement them in order to increase } \\
\text { efficiency. } \\
\text { Ecosul and Ponte Rio Niterói remain } \\
\text { as reference for best practices. }\end{array}$ \\
\hline SF_2.1 & Transbrasiliana & $\begin{array}{l}\text { Autopista } \\
\text { Litoral Sul, } \\
\text { Autopista } \\
\text { Fluminense }\end{array}$ & $\begin{array}{l}\text { Transbrasiliana } \\
\text { 2011, Autopista } \\
\text { Régis } \\
\text { Bittencourt } 2013\end{array}$ & $\begin{array}{l}\text { Transbrasiliana and Autopista Régis } \\
\text { Bittencourt should be used as best } \\
\text { practices. Autopista Régis Bittencourt } \\
\text { highlights due to constantly improve } \\
\text { its efficiency. } \\
\text { Concessionaires with constant } \\
\text { efficiency scores over time period } \\
\text { should seek innovations. } \\
\text { Regulators should be alert with } \\
\text { Autopista Planalto Sul, which presents } \\
\text { a satisfactory average efficiency } \\
\text { score, but constantly drops its } \\
\text { efficiency over the years. }\end{array}$ \\
\hline
\end{tabular}

continues 


\begin{tabular}{|c|c|c|c|c|}
\hline Model & Most efficient & Less efficient & Benchmark & Observations \\
\hline AT_1.1 & Nova Dutra & Concer & $\begin{array}{l}\text { Ponte Rio } \\
\text { Niterói 2008, } \\
\text { Concepa 2006 }\end{array}$ & $\begin{array}{l}\text { Five concessionaires, out of six, have } \\
\text { average efficiency score above } 87 \% \text {. } \\
\text { Exception is Concer, which presented } \\
\text { constantly drop in the efficiency score, } \\
\text { mainly in the last year. } \\
\text { Although the highlight was Nova } \\
\text { Dutra, } 100 \% \text { efficient over three years, } \\
\text { it was not used as benchmark. }\end{array}$ \\
\hline AT_1.2 & Nova Dutra & Concer, CRT & $\begin{array}{l}\text { Concepa 2009, } \\
\text { CRT 2009, } \\
\text { Ecosul 2009, } \\
\text { NovaDutra } \\
\text { 2010, Ponte Rio } \\
\text { Niterói } 2013\end{array}$ & $\begin{array}{l}\text { Nova Dutra highlight, because } \\
\text { achieved } 100 \% \text { efficient over all years. } \\
\text { The overall average efficiency scores } \\
\text { of all concessionaires are satisfactory } \\
\text { and Concer improved its efficiency, in } \\
\text { comparison with the last period under } \\
\text { analysis. } \\
\text { Particular concern is CRT that } \\
\text { drastically drop its efficiency over } \\
\text { years. } \\
\text { Five concessionaries, out of six, were } \\
\text { used as benchmarks in their best } \\
\text { years of efficiency scores. It indicates } \\
\text { that such concessionaires already } \\
\text { have the means to be efficient and do } \\
\text { not need to identify the practices of } \\
\text { the other firms as best practices. }\end{array}$ \\
\hline
\end{tabular}

Autopista Régis Bittencourt reached $100 \%$ efficiency over four years and is the concessionaire most efficient, regarding average efficiency score.

Autopista Régis Bittencourt 2009, 2010 and 2011, Rodovia do Aço 2011
Regulators should be alert with Autopista Fluminense and Rodovia do Aço, which constantly drop their efficiency over the years.

Autopista Fernão Dias constantly improved its efficiency, reaching $100 \%$ efficiency in the last year and can be used as best practices.

To evaluate the results of efficiency it is necessary to investigate the characteristics of each company, the particularities of their operations, as well as the investment plan of the firms. As this study includes companies that manage infrastructure assets, one of the main factors that affect the efficiency of the companies is the annual investment. Therefore, in order to carry out a 
brief analysis of the results obtained, it is possible to evaluate the firms that had its efficiency results highlighted, by comparing annual investment with efficiency scores.

Following it is presented the analysis for the highlighted companies: Concer, concessionaire of the 1 st Stage, which was the less efficient company; and Autopista Fernão Dias, concessionaire of the $2^{\text {nd }}$ Stage, which was indicated as company model for best practices. To carry out this analysis, it was compared the efficiency score of the company during the analysis time period with the intangible asset in the same time period.

To represent the annual investment it was used the intangible asset value, obtained in the balance sheet published annually by the companies. It is worth to mention that, according to the rules of accounting, the right to charge tolls from road-users in a determined time period is recognized as an intangible asset of the concessionaires. It is important to clarify that, according to the Brazilian accounting standards, the road concessionaires should measure the intangible asset by the cost of the road works and services, and amortize it based in the forecast traffic.

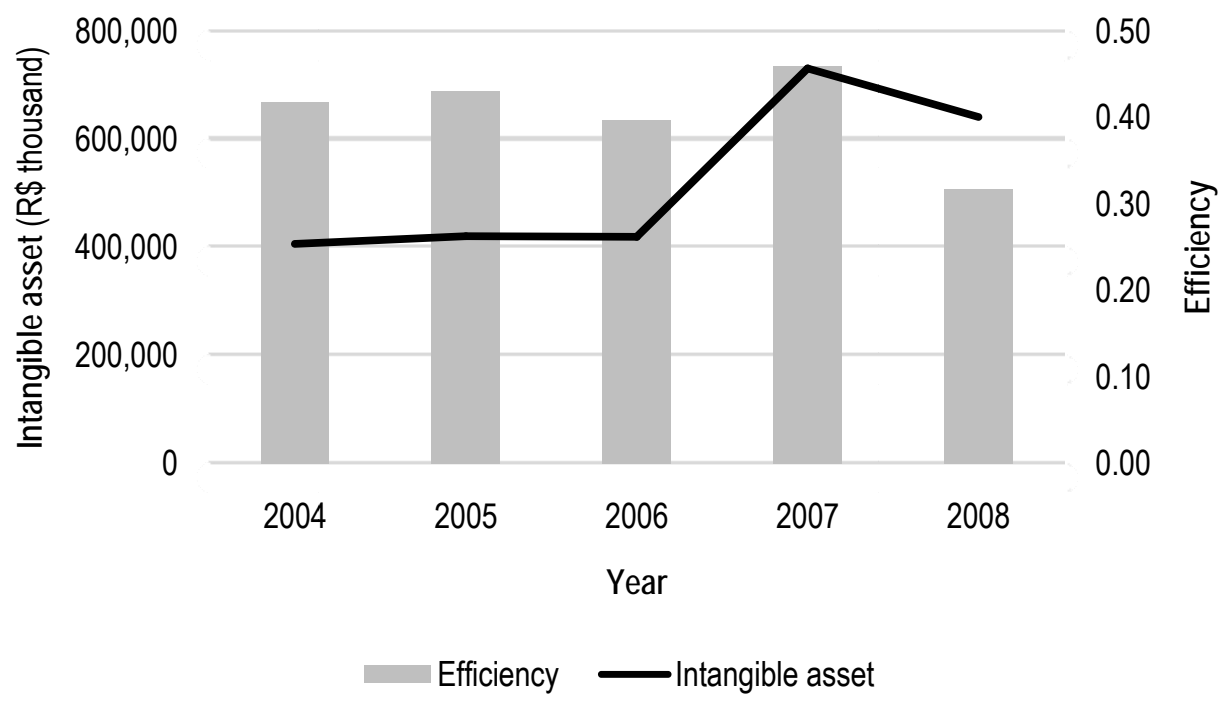

Figure 25 - Evolution of Intangible asset x Efficiency - Concer (2004-2008)

In the first period of analysis (2004-2008), for the case of Concer it is possible to note that the intangible asset was almost constant until 2006, than it had a large increase in 2007 and registered a drop in the following year (see Figure 25). Efficiency scores seem to follow the same tendency intangible asset, presenting a significant reduction in 2008. 
It is possible to note that efficiency scores were unsatisfactory, reaching less than 0.5 during this time period. In 2006, the concession contract of Concer completed 10 years and this is not the period of the contract with higher investments. However, concessionaire should try to increase investment, which can lead to an improvement in the efficiency of the firm, as seen in 2007.

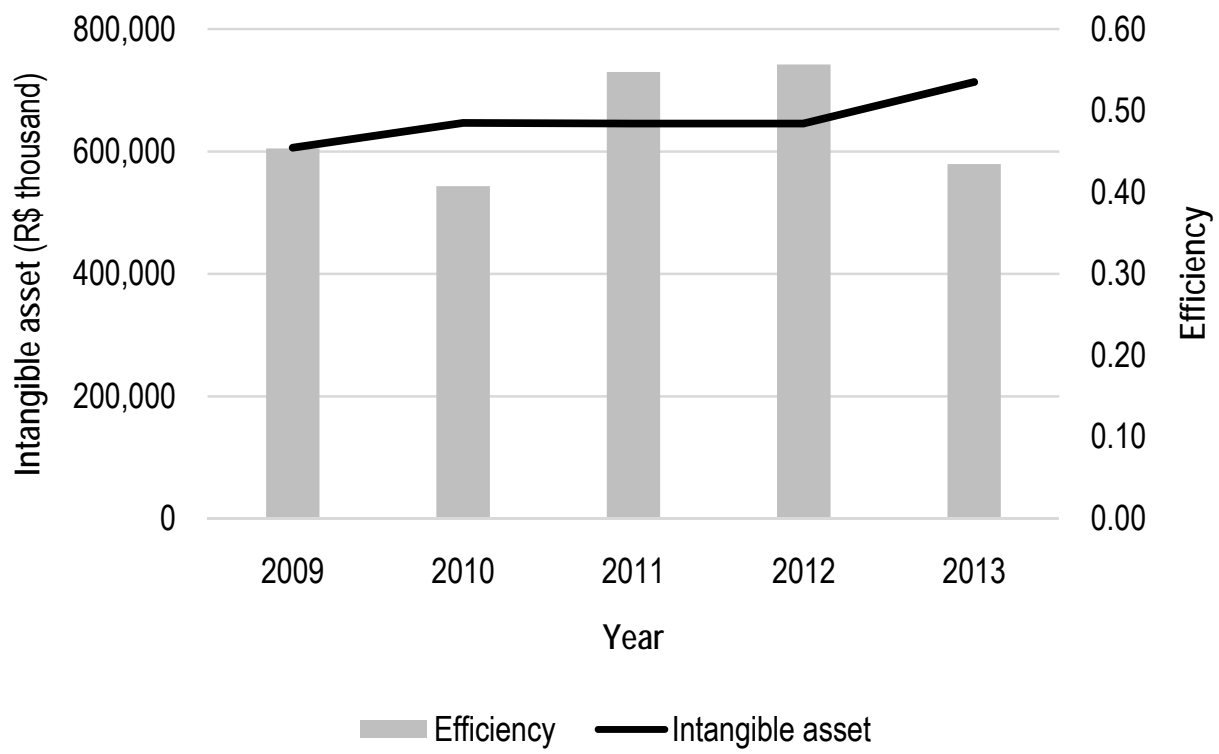

Figure 26 - Evolution of Intangible asset x Efficiency - Concer (2009-2013)

In the second period of analysis (2009-2013), for the case of Concer, on one hand the intangible asset were more stable than in the previous period and presented a small increase in the first and last year under analysis (see Figure 26). On the other hand, efficiency scores do not follow this tendency and in 2011 it has a satisfactory increase, but in 2013 it dropped again.

It is important to note that efficiency scores presented higher values than in the previous period under analysis. It seems that increasing the investment, even if it is small, can lead to an improvement in the efficiency of the firm. 


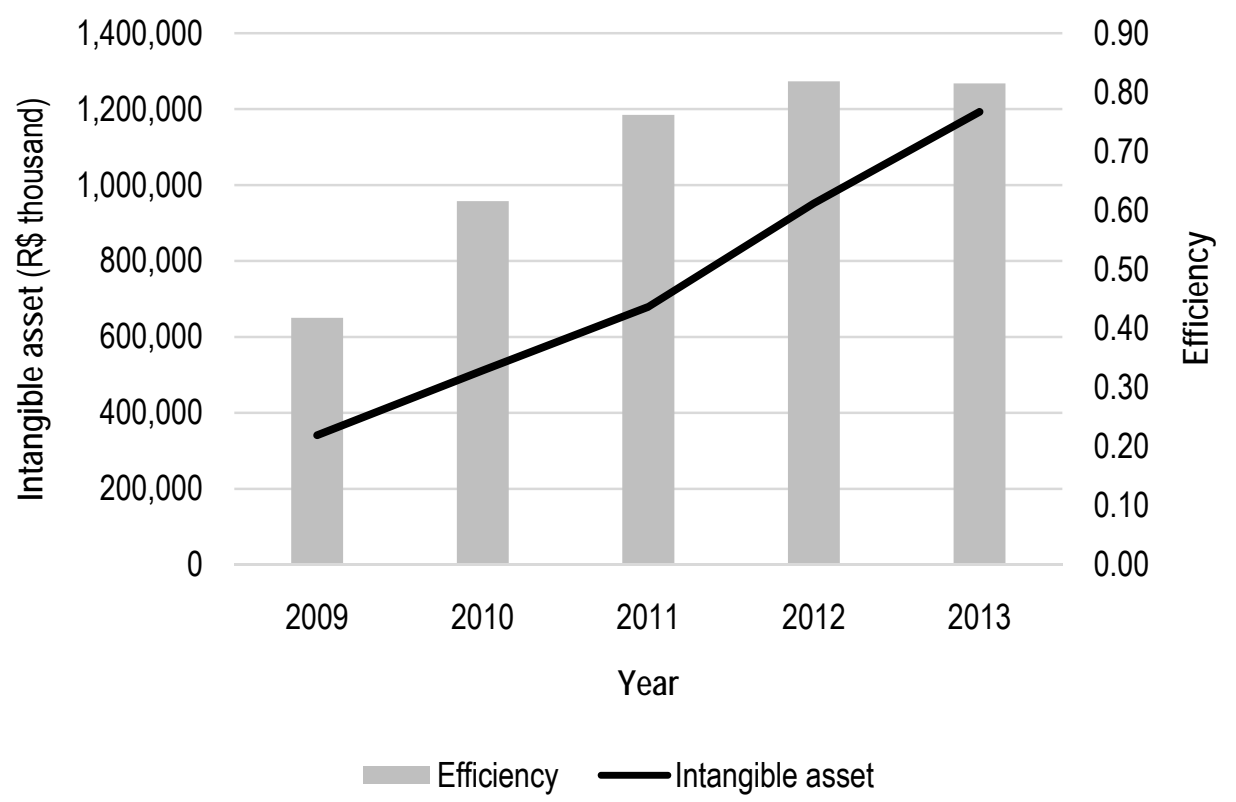

Figure 27 - Evolution of Intangible asset x Efficiency - Autopista Fernão Dias (2009-2013)

Figure 27 shows the case of Autopista Fernão Dias, in which the analysis was conducted for the second period (2009-2013).

It is possible to note that intangible asset increased more than three times in the period, with a constant growth. As well as the efficiency score, which double its value in the same time period.

It is important to say that the analysis time period includes the first five years of the concession contract, when the majority of the investments in road works are done. It seems that the raise in the investment affects positively the efficiency scores of the concessionaire.

However, in the last years under analysis the pace of the efficiency improvement dropped. It indicates that, although increasing investment can improve efficiency, other factors also become important when a firm reaches a high level of efficiency. Therefore, companies have to seek opportunities to improve, besides the investment, as innovation in products or management practices.

This section finishes the application of DEA method, presenting its results. From the results and its analysis, regulators and decision makers can study best practices and use them in order 
to improve the efficiency of the concessionaires. In the next section, the efficiency scores obtained in the DEA application will be used to calculate the X-factor of the price cap formula.

\subsection{Set the X-factor}

This section presents the last step of the application of the proposed framework to set the $X$-factor used in price cap regulation of road concessions.

The efficiency scores obtained applying DEA method, presented in the previous section, will be used to represent the productivity gains of the concessionaires, regarding the $X$-factor function in the price cap formula, as seen in section 2.5 .

As suggested in the proposition described in the Chapter 6, we will use a practical formula to calculate the $\mathrm{X}$-factor, repeated here.

$$
X_{i}=T F P G^{I}+\left[\left(T F P_{B}^{F}-T F P_{i}^{F}\right) / n\right]
$$

Where:

$X_{i}=\mathrm{X}$-factor of the firm under analysis

$T F P G^{\mathrm{I}}=$ Annual index of the Total Factor Productivity Growth of the industry in the period $T F P_{B}^{F}=$ Annual index of the Total Factor Productivity of the best firm in the period $T F P_{i}^{F}=$ Annual index of the Total Factor Productivity of the firm under analysis in the period $n=$ time period between revisions

It is worth to remember that the first part of the equation $T F P G^{I}$ represents the growth in the industry achieved by technological improvements. It is assumed that every firm has the same productivity gain due to the progress in the industry, therefore the same index should be applied for all firms, including the efficient ones.

As seen in section 6.6, this part of the equation can be measured by the DEA-based Malmquist productivity index, through its technological change component. As seen in Equation (19), section 3.2, the DEA-based Malmquist index formula requires data from two different time periods. However, in the present research, data from two different time period are not available, 
because we used the data of each firm for different years as a different DMU in order to improve the discrimination power of the DEA model.

As an alternative and for academic purpose, it is possible to present a full implementation of the framework proposed, by calculating the productivity growth of the industry for the second time period (2009-2013) of the concessionaires of first stage, using the average of the mean of the efficiency scores of the two time periods.

To calculate the second part of the equation $\left[\left(T F P_{B}^{F}-T F P_{i}^{F}\right) / n\right]$, it will be used the mean of the efficiency scores of each company and the best firm, defined through DEA models as seen in the previous section. In the present example we are measuring the efficiency of the concessionaire concerning two aspects: Road Safety and User Assistance. For that reason, it is necessary to combine the efficiency scores of these two models, in order to define the efficiency score for each firm to be applied in the formula.

For the present implementation we will use a simple average of the mean of the efficiency scores obtained in each model (Road Safety and User Assistance). However, this combination of the efficiency scores obtained from two DEA models can also be done using a weighted, it can be used a higher weight to the efficiency scores obtained from the Road Safety DEA average, assigning higher weight to the aspect the regulator considers more important. For example, if regulator's priority is to increase road safety model.

Given the above considerations, in the following paragraphs we present the data used in the $\mathrm{X}$-factor formula and its results. It was assumed a five years time period between revisions, as it is considered an adequate time period for price revision, as previously discussed.

It is important to note that the X-factor is set every five years for each stage, using the same division adopted in DEA application (see Table 6), because it considers the characteristics of concession contracts and the maturity of the firms.

Table 33 presents the calculation of the X-factor concerning the $1^{\text {st }}$ period under analysis (2004-2008) for the concessionaires of $1^{\text {st }}$ stage. 
Table 33 - X-factor calculation for concessionaires of 1 st stage -1 st period

\begin{tabular}{lcccc}
\hline $\begin{array}{c}\text { Concessionaires } \\
\text { 1st Stage } \\
\text { 1st period }^{\text {Concepa }}\end{array}$ & $\begin{array}{c}\text { SF_1.1 } \\
\text { Mean } \\
(\mathrm{A})\end{array}$ & $\begin{array}{c}\text { AT_1.1 } \\
\text { Mean } \\
(\mathrm{B})\end{array}$ & $\begin{array}{c}\text { Average of } \\
\text { efficiency score } \\
\left(\mathbf{T F P} \mathbf{F}_{\mathbf{i}}^{\mathbf{F}}\right) \\
(\mathrm{C})=(\mathrm{A}+\mathrm{B}) / 2\end{array}$ \\
\hline Concer & 0.91 & 0.87 & 0.89 & $\begin{array}{c}\mathbf{X}_{\mathbf{i}} \\
\text { CRT }\end{array}$ \\
\hline Ecosul & 0.35 & 0.46 & 0.41 & $1.0 \%$ \\
\hline Nova_Dutra & 0.56 & 0.89 & 0.73 & $10.7 \%$ \\
\hline Ponte_Rio_Niterói & 0.98 & 0.90 & 0.94 & $4.3 \%$ \\
\hline
\end{tabular}

$\mathrm{C}_{B}=$ Average of efficiency score of the best firm;

$\mathrm{C} i=$ Average of efficiency score of the firm under analysis.

It is worth to remember that there is no data available to calculate the productivity growth in the industry (first part of the equation) for the concessionaires of $1^{\text {st }}$ period. That is the reason why for the $1^{\text {st }}$ period the $\mathrm{X}$-factor is calculated using only the second part of the equation.

In Table 33, columns (A) and (B) are the mean of efficiency scores calculated in DEA application for each DEA model (Road Safety - SF and User Assistance - AT). From this, it is possible to calculate the average of efficiency score for each concessionaire (column $(C)$ ), which represents the annual index of the Total Factor Productivity of the firms.

The column (D) shows the X-factor for each concessionaire. It is important to note that the best firm, in this case Ecosul, has the $X$-factor value equal to zero, because it was not possible to calculate the productivity growth in the industry. However, it does not mean that the best firm cannot improve productivity, because DEA approach measures the efficiency, which is a comparison of the productivity of the firms. Therefore, there is still room for improvement in the next five years, since the best firm is not $100 \%$ efficient and DEA is based in a benchmark study.

For the other firms, the $\mathrm{X}$-factor means that each company will be required to raise their level of individual efficiency in this amount every year, during the next five years. It can also be called as efficiency improvement target. For example, Concer is the firm with the higher X-factor, which means that it has to improve its productivity in $10.7 \%$ per year, in order to become efficient until the next revision. Other two firms, CRT and Nova Dutra, have the X-factor around $4 \%$ per year and the other two, Concepa and Ponte Rio-Niterói, 1\% per year or less. 
Next, Table 34 presents the calculation of the X-factor concerning the $2^{\text {nd }}$ period under analysis (2009-2013) for the concessionaires of 1 st stage.

Table 34 - X-factor calculation for concessionaires of 1 st Stage $-2^{\text {nd }}$ period

\begin{tabular}{|c|c|c|c|c|c|c|}
\hline $\begin{array}{c}\text { Concessionaires } \\
1^{\text {st }} \text { Stage } \\
2^{\text {nd }} \text { Period }\end{array}$ & $\begin{array}{l}\text { SF_1.2 } \\
\text { Mean } \\
\text { (A) }\end{array}$ & $\begin{array}{l}\text { AT_1.2 } \\
\text { Mean } \\
\text { (B) }\end{array}$ & $\begin{array}{l}\text { Average of } \\
\text { efficiency } \\
\text { score } \\
\left(\text { TFP }_{i}^{\mathrm{F}}\right) \\
(\mathrm{C})=(\mathrm{A}+\mathrm{B}) / 2\end{array}$ & $\begin{array}{l}\text { Productivity } \\
\text { growth of } \\
\text { Industry } \\
\text { (TFPG } \\
\text { (D) }\end{array}$ & $\begin{array}{c}\text { Efficiency } \\
\text { improvement targets } \\
{\left[\frac{\left(\mathbf{T F P}_{\mathbf{B}}^{\mathbf{F}}-\mathbf{T F P}_{\mathbf{i}}^{\mathbf{F}}\right)}{\mathbf{n}}\right]} \\
(\mathrm{E})=\left(\mathrm{C}_{B}-\mathrm{C}_{i}\right) / 5\end{array}$ & $\begin{array}{c}\mathbf{X}_{\mathbf{i}} \\
(\mathrm{F})=\mathrm{D}+\mathrm{E}\end{array}$ \\
\hline Concepa & 0.93 & 0.82 & 0.88 & $0.75 \%$ & $1.0 \%$ & $1.75 \%$ \\
\hline Concer & 0.33 & 0.63 & 0.48 & $0.75 \%$ & $8.9 \%$ & $9.65 \%$ \\
\hline CRT & 0.22 & 0.73 & 0.48 & $0.75 \%$ & $9.0 \%$ & $9.75 \%$ \\
\hline Ecosul & 0.97 & 0.88 & 0.93 & $0.75 \%$ & $0.0 \%$ & $0.75 \%$ \\
\hline Nova_Dutra & 0.66 & 1.00 & 0.83 & $0.75 \%$ & $1.9 \%$ & $2.65 \%$ \\
\hline Ponte_Rio_Niterói & 0.88 & 0.91 & 0.90 & $0.75 \%$ & $0.6 \%$ & $1.35 \%$ \\
\hline
\end{tabular}

$\mathrm{C}_{B}=$ Average of efficiency score of the best firm;

$\mathrm{C} i=$ Average of efficiency score of the firm under analysis.

In Table 34, as well in the previous analysis, columns (A) and (B) are the mean of efficiency score calculated in DEA application for each DEA model, and column (C) the average of efficiency score for each concessionaire, which represents the annual index of the Total Factor Productivity of the firms. From this, the efficiency improvement targets for each firm are calculated in the column $(E)$, which represents the second part of the X-factor formula.

In the analysis of the $2^{\text {nd }}$ period, it is possible to estimate the first part of the X-factor formula, which represents the productivity growth in the industry in the period. It should be calculated with DEA Malmquist approach, but as we used the data of each firm for different years as a different DMU, we cannot apply this method. However, for academic purpose in order to present a full implementation of the methodology proposed in the thesis, it is possible to estimate the productivity growth industry in the period using the difference between the averages of efficiency score of both periods under analysis.

The column (D) represents the productivity growth in the industry. It was calculated subtracting the average of efficiency score for all concessionaires of the $2^{\text {nd }}$ period $(0.85)$ from the average of efficiency score for all concessionaires of the 1 st period $(0.81)$, which results in a 
productivity growth in the industry of $4 \%$. Dividing by five, which is time revision, we find the productivity growth in the industry for all concessionaires of $0.75 \%$ per year.

The column $(F)$ shows the $X$-factor for each concessionaire. Differently from the previous analysis (1st period), there is no X-factor equal to zero, because we are using the complete formula and the best firms will be required to achieve the same improvement of the industry. In this period of analysis, Ecosul is once again the concessionaire with the less $X$-factor value, but now it has to improve efficiency at $0.75 \%$ per year.

For the other concessionaires, it will be required not only to achieve the same technological advances as the other firms in the industry, but also to increase efficiency in order to achieve the efficiency frontier during the time period between revisions. Concepa and Ponte Rio Niterói have the X-factor less than 2\% per year and Nova Dutra has 2.65\% per year. Concer e CRT have higher $\mathrm{X}$-factor values, around $9.7 \%$ per year.

Finally, Table 35 presents the calculation of the X-factor concerning the 1 st period under analysis (2009-2013) for the concessionaires of $2^{\text {nd }}$ stage.

Table 35 - X-factor calculation for concessionaires of $2^{\text {nd }}$ stage $-1^{\text {st }}$ period

\begin{tabular}{|c|c|c|c|c|}
\hline $\begin{array}{c}\text { Concessionaires } \\
2^{\text {nd }} \text { Stage } \\
1^{\text {st }} \text { Period }\end{array}$ & $\begin{array}{l}\text { SF_2.1 } \\
\text { Mean } \\
\text { (A) }\end{array}$ & $\begin{array}{l}\text { AT_2.1 } \\
\text { Mean } \\
\text { (B) }\end{array}$ & $\begin{array}{l}\text { Average of } \\
\text { efficiency score } \\
\left(\mathbf{T F P}_{i}^{\mathbf{F}}\right) \\
(\mathrm{C})=(\mathrm{A}+\mathrm{B}) / 2\end{array}$ & {$\left[\begin{array}{c}\mathbf{X}_{\mathbf{i}} \\
\frac{\left(\mathbf{T F P}_{\mathbf{B}}^{\mathbf{F}}-\mathbf{T F P}_{\mathbf{i}}^{\mathbf{F}}\right)}{\mathbf{n}} \\
(\mathrm{D})=\left(C_{B}-C_{i}\right) / 5\end{array}\right]$} \\
\hline Autopista_Fernao_Dias & 0.58 & 0.79 & 0.68 & $5.4 \%$ \\
\hline Autopista_Fluminense & 0.40 & 0.57 & 0.48 & $9.4 \%$ \\
\hline Autopista_Litoral_Sul & 0.39 & 0.75 & 0.57 & $7.7 \%$ \\
\hline Autopista_Planalto_Sul & 0.81 & 0.79 & 0.80 & $3.1 \%$ \\
\hline Autopista_Regis_Bittencourt & 0.89 & 0.99 & 0.94 & $0.3 \%$ \\
\hline Rodovia_do_Aço & 0.61 & 0.78 & 0.69 & $5.2 \%$ \\
\hline Transbrasiliana & 0.98 & 0.93 & 0.95 & $0.0 \%$ \\
\hline
\end{tabular}

$\mathrm{C}_{B}=$ Average of efficiency score of the best firm;

$\mathrm{C} i=$ Average of efficiency score of the firm under analysis.

Once again, the $\mathrm{X}$-factor for the concessionaires of 1 st period is calculated using only the second part of the equation, due to data availability to calculate the productivity growth in the industry (first part of the equation). 
In Table 35, columns (A) and (B) are the mean of efficiency scores calculated in DEA application for each DEA model (Road Safety - SF and User Assistance - AT). From this, it is possible to calculate the average of efficiency score for each concessionaire (column $(C)$ ), which represents the annual index of the Total Factor Productivity of the firms.

The column (D) shows the X-factor for each concessionaire. Transbrasiliana, which is the best firm, has the X-factor value equal to zero. Autopista Régis Bittencout, which has the average of efficiency score is very close to the best firm, has an $\mathrm{X}$-factor of $0.3 \%$ per year.

For the other firms, Autopista Planalto Sul has to impove efficiency at $3.1 \%$ per year. Autopista Fernão Dias and Rodovia do Aço have the X-factor around 5.3\% per year. The concessionaires with higher improvement targets are: Autopista Litoral Sul with $7.7 \%$ per year and Autopista Fluminense with $9.4 \%$ per year.

\section{Applicability analysis of the results}

In order to evaluate the applicability of the results, it is possible to calculated the annually tariff adjustment for each Concessionaire from the $X$-factor estimated. For that end, it is necessary to subtract the X-factor value from the inflation rate of Brazil (IPCA) in the five years subsequent to the period of $X$-factor analysis. Therefore, concerning the first period under analysis (2004-2008), it was used the inflation rate from 2009 to 2013. For the next period under analysis (2009-2013), it was possible to evaluate only two years: 2014 and 2015.

It is worth to mention that this applicability analysis was carried out for academic purpose, and the results of tariff adjustment obtained do not represent the values that have to be applied in practice. However, this analysis is important in the present research because it allows evaluate the results achieved in implementation of the framework proposed. Following it is presented the calculated values for tariff adjustment. 
Table 36 - Tariff Adjustment from 2009 to 2013

\begin{tabular}{|c|c|c|c|c|c|c|}
\hline \multirow{3}{*}{$\begin{array}{c}\text { Concessionaires } \\
1^{\text {st }} \text { Stage } \\
1^{\text {st }} \text { period }\end{array}$} & \multirow{3}{*}{$X$-factor } & \multicolumn{5}{|c|}{ Tariff Adjustment from 2009-2013 (RPI - X) } \\
\hline & & 2009 & 2010 & 2011 & 2012 & 2013 \\
\hline & & $\mathrm{RPI}=4.31 \%$ & $\mathrm{RPI}=5.91 \%$ & $\mathrm{RPI}=6.50 \%$ & $\mathrm{RPI}=5.84 \%$ & $\mathrm{RPI}=5.91 \%$ \\
\hline Concepa & $1.00 \%$ & $3.31 \%$ & $4.91 \%$ & $5.50 \%$ & $4.84 \%$ & $4.91 \%$ \\
\hline Concer & $10.70 \%$ & $-6.39 \%$ & $-4.79 \%$ & $-4.20 \%$ & $-4.86 \%$ & $-4.79 \%$ \\
\hline CRT & $4.30 \%$ & $0.01 \%$ & $1.61 \%$ & $2.20 \%$ & $1.54 \%$ & $1.61 \%$ \\
\hline Ecosul & $0.00 \%$ & $4.31 \%$ & $5.91 \%$ & $6.50 \%$ & $5.84 \%$ & $5.91 \%$ \\
\hline Nova_Dutra & $4.00 \%$ & $0.31 \%$ & $1.91 \%$ & $2.50 \%$ & $1.84 \%$ & $1.91 \%$ \\
\hline Ponte_Rio_Niterói & $0.60 \%$ & $3.71 \%$ & $5.31 \%$ & $5.90 \%$ & $5.24 \%$ & $5.31 \%$ \\
\hline
\end{tabular}

Table 36 shows the tariff adjustment for the X-factor determined in the first period under analysis (2004-2008) for the concessionaires of first Stage. It is important to note that the mean of Brazilian inflation rate in this period was around $5 \%$ per year.

Regarding the tariff adjustments calculated, it is possible to note that Concer has negative values because it is the firm with higher X-factor (10.7\%). Besides, in some years CRT and Nova Dutra present toll rate adjustment near to zero, because they have the $X$-factor value close to inflation rate.

Despite of these cases, it is important to highlight that the most of the tariff adjustments calculated (83\% of the data) are realistic values and could be applied in practice. Therefore, regulators can consider the cases with negative or near zero values as special ones, in which there is a need to investigate if there is some particular problem in the firms, seeking to set an achievable X-factor and keep the incentives for the concessionaires. 
Table 37 - Tariff Adjustment from 2014 to 2015

\begin{tabular}{|c|c|c|c|c|}
\hline & \multirow{3}{*}{$\begin{array}{l}\text { Concessionaires } \\
2^{\text {nd }} \text { Period }\end{array}$} & \multirow{3}{*}{ X-factor } & \multicolumn{2}{|c|}{ Tariff Adjustment from 2014-2015 (RPI - X) } \\
\hline & & & 2014 & 2015 \\
\hline & & & $\mathrm{RPI}=6.41 \%$ & $\mathrm{RPI}=10.67 \%$ \\
\hline \multirow{6}{*}{$1^{\text {st }}$ Stage } & Concepa & $1.75 \%$ & $4.66 \%$ & $8.92 \%$ \\
\hline & Concer & $9.65 \%$ & $-3.24 \%$ & $1.02 \%$ \\
\hline & CRT & $9.75 \%$ & $-3.34 \%$ & $0.92 \%$ \\
\hline & Ecosul & $0.75 \%$ & $5.66 \%$ & $9.92 \%$ \\
\hline & Nova_Dutra & $2.65 \%$ & $3.76 \%$ & $8.02 \%$ \\
\hline & Ponte_Rio_Niterói & $1.35 \%$ & $5.06 \%$ & $9.32 \%$ \\
\hline \multirow{7}{*}{$2^{\text {nd }}$ Stage } & Autopista_Fernao_Dias & $5.40 \%$ & $1.01 \%$ & $5.27 \%$ \\
\hline & Autopista_Fluminense & $9.40 \%$ & $-2.99 \%$ & $1.27 \%$ \\
\hline & Autopista_Litoral_Sul & $7.70 \%$ & $-1.29 \%$ & $2.97 \%$ \\
\hline & Autopista_Planalto_Sul & $3.10 \%$ & $3.31 \%$ & $7.57 \%$ \\
\hline & Autopista_Regis_Bittencourt & $0.30 \%$ & $6.11 \%$ & $10.37 \%$ \\
\hline & Rodovia_do_Aço & $5.20 \%$ & $1.21 \%$ & $5.47 \%$ \\
\hline & Transbrasiliana & $0.00 \%$ & $6.41 \%$ & $10.67 \%$ \\
\hline
\end{tabular}

Table 37 presents the tariff adjustment for the X-factor determined in the $2^{\text {nd }}$ period under analysis $(2009-2013)$ for the concessionaires of $1^{\text {st }}$ and $2^{\text {nd }}$ Stage. In this period the Brazilian inflation rate rose very fast, from $6.41 \%$ in 2014 to more than $10 \%$ in the following year.

It is worth to remember that the $\mathrm{X}$-factor values of the concessionaires of $1^{\text {st }}$ Stage for this period were the only ones that could be calculated using the complete equation to set the Xfactor, which also consider the productivity growth in the industry.

Concerning the tariff adjustments results for the concessionaires of $1^{\text {st }}$ Stage, it is possible to note that only CRT and Concer have negative adjustment in 2014, because these firms have the highest $X$-factor values.

For the case of the concessionaires of $2^{\text {nd }}$ Stage, also two firms had negative results in 2014, which were Autopista Fluminense and Autopista Litoral Sul. These firms also presented high X-factor values. 
In 2015, for all concessionaires under analysis the increase in the inflation rate compensated the X-factor effect.

As well as in the previous period, although these negative results, the most of the tariff adjustments calculated (more than 80\%) are realist, as the X-factor values could be considered as achievable. Therefore, regulators should focus on these four firms, in order to investigate some particularity that could be affecting the results, trying to determine viable $X$-factor values.

These results reinforce the perception that in the case of countries that have low rates of inflation, the X-factor would have a more significant impact in the adjustment.

It is evident that the main goal of regulators is that all concessionaires achieve the average of the efficiency score of the best firm in the time period between revisions (five years). However, before applying tariff adjustment as calculated, regulators have to evaluate if the firms can achieve the expected productivity improvement, mainly in the case of higher $\mathrm{X}$-factors. At this phase, regulators can make adjustments in the X-factor value, making it achievable, in order to maintain firm's incentive to improve.

To that end, regulators should investigate if there is any particularity regarding the concession management to justify the difference in the productivity among the firms. Also there may be a case that some concessionaire will never be able to achieve the same efficiency as the others. Then, in these cases can be applied a percentage to reduce the X-factor set by the scientific method. For example, if some concessionaire, given its characteristics, can only achieve $70 \%$ of the productivity of the best firm, regulator can use the same reduction in the X-factor value. This mechanism can set a feasible goal for the firm and also correct failures of the process.

Despite the fact that the $X$-factor means that the company will have that percentage of discount in the tariff adjustment, regulator have to make an effort in order to the concessionaires consider the $\mathrm{X}$-factor as an incentive or even a goal to be achieved in the next time period.

After analyzing the feasibility of the X-factor values obtained, regulator can choose to use a different time period to the inefficient firms converge to the same productivity level of the best firms. For example, regulator can establish that the X-factor should be achieved in two or three time periods of five years, which would reduce the X-factor of the inefficient firms. 
Besides, regulators can also use a progressive X-factor during the time period, with lower values in the early years and higher values in the end of the five years period. In addition, it can be set a maximum value for the X-factor. Furthermore, the X-factor can also be evaluated according to the planning of investments of the concessionaire for the next 5 years. If there will be a reduction in the investments in the next five years comparing with the previous period, regulators can use a deflator in the $\mathrm{X}$-factor or vice versa.

Finally, regulators should work together with firms, promoting the dissemination of best practices, as knowledge, technological advances and the use of innovative materials. Thus, DEA results can help regulators to improve incentives generated by the use of the price cap regulation.

At this point, we complete the application of the methodology to set the X-factor and specific objectives of this research, as listed in Section 5.2, have been achieved.

\subsection{Data issues}

This chapter presents relevant considerations when applying the framework proposed to real data, in order to ensure its effective implementation. However, it is important to summarize the information concerning data issues faced on this research.

In order to apply the proposed framework to the current Brazilian road concessions, it was used the available data in the Regulatory Agency ANTT Annual Reports, which is the official report regarding federal road concessions in Brazil and is published at the ANTT website (www.antt.gov.br).

ANTT publishes information concerning costs, investments and revenues of the concessionaires until 2008. However this information does not represent real expenditures, revenues and investments of the concessionaire, because it was obtained from the balance sheet used to calculate the toll rate. For that reason, they cannot be used to represent the efficiency or the productivity gains of the concessionaire.

Therefore the majority of the information from the ANTT Reports refers to operational aspects. Among all information, the variables that are not manageable by the concessionaire cannot be used as an input. Moreover, the variables that do not differ in time cannot be used as an output, as they do not represent the efficiency of the company. 
Thus, in the present study, as there is no real information about costs, investments and revenues, we used information regarding operational duties of concessionaires, which can represent the cost of the process. For example, the traffic volume can represent the revenue of the concessionaire, as the income came from the payment of the toll by the users. On the other hand, the number of employees and number of vehicles of the concessionaires can be a good proxy of the costs of the concessionaires.

It also should be pointed out that there is no data available for every year. Therefore, when we combined the results of Road Safety and User Assistance DEA models to calculate the Xfactor, it was necessary to consider that SF_1.1 (2004-2008) and AT_1.1 (2005-2009) DEA models evaluated the same time period, which is quite acceptable for academic purposes.

Concerning to the selection of DMUs, it is important to explain that the federal road concession program in Brazil is divided into three stages. Currently it is possible to analyze only the concessions from the first and second stages. As the third stage started in 2012, there is no data available to carry out an efficiency analysis.

The first stage has 6 concessionaires and the second stage has 7 concessionaires. If each concessionaire was considered as a single DMU, it would limit to use DEA model with only one input and one output, because the number of DMUs should be three times greater than the number of inputs plus outputs. Due to the small number of firms in each stage, it was used the data of each firm for different years as different DMUs. By using each year of the concessionaires as a single DMU, I was able to increase the number of DMUs which allows an analysis of the efficiency over the time.

However, it also prevents the application of DEA-based Malmquist productivity index because it requires data from two different time periods. This index is suggested to be used to calculate the first part of the equation of the X-factor, the Annual index of the Total Factor Productivity Growth of the industry in the period, which represents the growth in the industry achieved by technological improvements.

Finally, in Table 38 I present the data that I would consider necessary to apply the proposed framework in a more comprehensive form for each DEA model. 
Table 38 - Recommended data to be used to run DEA models

\begin{tabular}{lll}
\hline DEA model & Input Variables & Output Variables \\
\hline Road safety & $\begin{array}{l}\text { Operational costs; } \\
\text { Investment in road safety }\end{array}$ & Accident data \\
\hline User Assistance & $\begin{array}{l}\text { Operational costs; } \\
\text { Number of operational vehicles; } \\
\text { Maintenance expenditure }\end{array}$ & Number of user assistance \\
\hline Availability & $\begin{array}{l}\text { Number of lanes offered; } \\
\text { Investment to increase road } \\
\text { capacity }\end{array}$ & Level of service \\
\hline Quality & $\begin{array}{l}\text { Investment in road; } \\
\text { Maintenance expenditure }\end{array}$ & $\begin{array}{l}\text { Number of infractions that } \\
\text { concessionaire receives }\end{array}$ \\
\hline
\end{tabular}

It is worth to say that the length of the road and the traffic volume can be used to rescale the variables. 

8. CONCLUSIONS AND FURTHER RESEARCH 

This chapter contains the overall conclusion of this thesis, according to its objectives and contributions as described in Chapter 5.

Within such a context, first a summary of the work and the specific findings related to the objective of this research are presented. Furthermore, the data availability issues faced in this study are discussed. Then, the contribution of this research to the body of knowledge is presented. This section provides also some recommendations for the prospective users of the framework developed by this research. Finally, further research areas, which emerge from this work, are provided.

\section{Summary of this research}

For the last two decades, infrastructure concession extends for all over the world. The main reason for this is due to the budget restriction of the governments. Therefore, the infrastructure has been moving to be financed by private operators, through concession contracts. This new way to finance infrastructure by private firms bring institutional changes, predominant for regulators, which has the challenge to achieve maximum performance from the system.

In this regard, the arrangements to regulate the tariffs used in concessions contracts are evolving over the years. For this reason, economic regulation has been gaining attention in the academic research arena, in order to debate the advances in tariff regulatory theories, also to develop methodologies to optimize the practical application of these theories.

Incentive regulation is a modern approach used in tariff regulation. Among the various methods to control the price level of the operator, price cap regulation is a notable innovation in utility regulation. That is the reason why the price cap was chosen to be studied in the present research.

Price cap regulation set a ceiling to the price level according to an index formula based on the rate of inflation, which is RPI - X. The X-factor is an efficiency factor, which should reflect the expected efficiency gains of the firms and has to be reviewed every revision period ( 3 to 5 years). Therefore, the price cap formula was conceived to provide stronger incentives for the firms to reduce costs and share these efficiency gains with the users.

Despite the importance of the X-factor regarding the economic viability of the concession project, many contracts do not define the methodology to set the X-factor ex-ante. Due to the 
importance of the $X$-factor, it makes imperative for regulators to implement a comprehensive system to define the X-factor.

In the literature, it is possible to find surveys concerning setting the X-factor in some infrastructure areas, as electricity distribution utilities. However, researches regarding the experiences of the price cap regulation in road concessions are scarce. Given this, there is a need to develop and implement a comprehensive framework to set the X-factor considering the overall efficiency of road concessionaires.

For this reason and with the aim to propose a new way for regulators to set the $\mathrm{X}$-factor for road concessions, the present research has developed a framework to set the X-factor, used in the price cap formula, which considers the productivity of the firms.

For that end, the Data Envelopment Analysis (DEA) was used to measure the efficiency of the firms, which is a method widely used in the transport sector, as well as in roads. In addition to include the productivity of the firms in the calculation of the X-factor, the use of DEA method allows evaluating the efficiency of the firms, making a comparison among the productivities and identifying best practices.

In summary, this research developed a replicable, generic and comprehensive framework (presented in Chapter 6) which focuses on setting the X-factor, used in the price cap formula, considering the efficiency of the road concessionaires, by utilizing DEA approach.

After the establishment of the framework, Chapter 7 presents a full scale example, based on data available belonging to the Brazilian federal road concessions, in an effort to present the implementation of the framework and challenges associated with it, testing the hypothesis and achieving specific objectives of this research.

As the efficiency is the comparison of the productivity results of similar firms, in the implementation of the proposed framework the road concessionaires were divided according to the features of their concession contracts and management aspects. Hence, in order to compare the Brazilian road concessionaires, they were divided concerning the stage of the road concession program they belong to.

After this definition, it was conducted a detailed analysis in order to select the variables to be used and it was presented the data preparation process to make such data ready to be used 
in the DEA model. In addition, it was presented a discussion about the definition of which DEA model should be used.

\section{Data availability issues}

With regard to data availability issues, the analysis in this research compares the performance of 6 road concessionaires of the $1^{\text {st }}$ stage of Brazilian road concession program for the period from 2004 to 2013 and 7 road concessionaires of the $2^{\text {nd }}$ stage of the Brazilian road concession program for the period from 2009 to 2013.

After dividing the firms according to their stage of the Brazilian road concession program, it is possible to note that for each year of analysis there are only 6 DMUs for 1 st stage and 7 DMUs for $2^{\text {nd }}$ stage. Therefore, data of each firm for different years was used as a different DMU in order to increase the number of DMUs also the discrimination power of the DEA model.

Furthermore, it was used only the data available at the Annual Reports of the Brazilian Regulatory Agency (ANTT). In addition, there was no data available for every year. For this reason it was not possible to evaluate the efficiency concerning the four aspects suggested: road safety, user assistance, availability and quality. For the last two aspects there was insufficient data to run DEA models. Thus, in the real life, regulators are recommended to define in advance which variables will be used to achieve the most appropriate and reliable data.

\section{Findings and conclusions}

This research runs two different DEA models: road safety and user assistance. The data obtained from both DEA models were combined at the end of the process, to set one $\mathrm{X}$-factor for each concessionaire.

The X-factor values calculated for the $1^{\text {st }}$ period (2004-2008) of the concessionaires of $1^{\text {st }}$ stage ranged from 0 to $10.7 \%$, with a mean of $2.5 \%$. This is the amount that each firm will be required to raise their level of individual efficiency every year, during the next five years. It is important to note that the best firm has the $X$-factor value equal to zero, because it was not possible to calculate the productivity growth in the industry for the $1{ }^{\text {st }}$ period.

For the $2^{\text {nd }}$ period (2009-2013) of the concessionaires of $1^{\text {st }}$ stage, the X-factors ranged from $0.75 \%$ to $9.75 \%$, with an average of $2.2 \%$. It is worth to note that, despite the fact that for the $2^{\text {nd }}$ period it is added the productivity growth in the industry, the X-factor values and the mean are lower than for the $1^{\text {st }}$ period. 
Concerning the $1^{\text {st }}$ period (2009-2013) of the concessionaires of $2^{\text {nd }}$ stage, the $X$-factor values calculated ranged from 0 to $9.40 \%$, with a mean of $4.15 \%$. It is possible to note that the $X$-factor values of the $2^{\text {nd }}$ stage are similar to the values of the $1^{\text {st }}$ stage, but the average was higher for the $2^{\text {nd }}$ stage.

It is important to note that for the two DEA models mentioned above, road concessionaires have different efficiency scores. This fact confirms the hypothesis of this research that the development of a methodology to set the X-factor based on the efficiency of the operators can improve the use of price cap regulation in road concessions contracts. Therefore, it is possible and crucial to set the X-factor based on the efficiency of the concessionaires. In addition, measuring the efficiency of the firms allows regulators to identify benchmarks and best practices that can help inefficient firms to improve their performance.

From the analysis of the results, the framework proposed and the use of DEA method to measure the efficiency of road concessionaires showed to be effective to set the X-factor. However, it is worth highlighting the importance of using appropriate data, in order to obtain reliable results.

\section{Contributions of this research}

The contributions of this research to the body of knowledge are believed to be related to two different areas of knowledge: economic regulation of road concessions and performance measurement of road infrastructure, specifically by using DEA method.

Concerning economic regulation, this thesis develops a framework to set the $\mathrm{X}$-factor for road concessions, which is an index used in price cap regulatory regime. In the literature, there are some studies to set the X-factor regarding other granted infrastructures, but not in the road sector.

With regard to efficiency measurement, the results of this research shows that DEA is a valid method to measure the efficiency of road concessionaires, which also provides the regulator with information about best practices in the industry that can be used to help inefficient firms to improve their productivity.

The impact of such framework is believed to be broad, significant, and relevant to all regulators that work with transport infrastructure concessions, because it is fully applicable in 
practice. Therefore, the proposed framework can easily be utilized by any regulator that needs to set the X-factor in a systematic way, based on the efficiency of road concessionaires.

By presenting a fully implementation of the framework proposed, this thesis also contributes to encourage regulators to use price cap regime in road concession contracts, which is an advanced economic regulatory regime in the incentive regulation area.

It is important to note that when implementing the framework proposed in practice, after getting the results, it is recommended that regulators should make adjustments in the X-factor value, making it achievable, in order to maintain firm's incentive to improve. For example, regulators should investigate if there is any particularity regarding the road management to justify the difference in the productivity among the firms

Therefore, in order to verify and make use of the framework suggested, collaborations from the decision makers of the concessionaires and regulators are essential. Through such collaboration, possible causes of inefficiencies can be pinpointed and suggestions to the decision makers to help them overcome such inefficiencies can be provided. In addition, regulators have to make an effort in order to lead concessionaires to consider the $\mathrm{X}$-factor as an incentive or even a goal to be achieved in the next revision time period.

Finally, all stakeholders in the regulatory sector can potentially benefit from this research: regulators, concessionaires and users. First, regulators are more confident to set the $X$-factor when using price cap and they can provide companies with incentives to achieve better performance. Second, concessionaires can compare their performance against the rest of the sector and identify any weaknesses relative to best practice. Third, road users have the benefit of win a share of the productivity gains of the firms and evaluate the standards of service they receive.

\section{Further Research}

From the research developed in this thesis, it is possible to suggest some further research areas, which can complement and improve the present study.

It is suggested to apply the proposed framework considering all the road aspects, as presented in Chapter 6: road safety, user assistance, availability and quality. The last two aspects (availability and quality) were not used due to data availability issues, but their use could allow carrying out a wider analysis of the efficiency of the firms. 
With regard to the data and variables used in DEA models, if there is data available, it can be included in the model an external factor, as an environmental variable. In addition, it can also be used financial data, as cost, revenue and investment information of the concessionaires, which can represent input and output variables in the productivity analysis.

Another suggestion is to include variables in DEA model that measure the performance of the physical components of the road, for example using the International Roughness Index (IRI) in order to evaluate the pavement of the road.

The proposed framework can also be applied to a case study in which it would be possible to have a panel data that can provide one efficiency frontier by year, which allow calculating the productivity growth in the industry using the DEA- based Malmquist productivity index.

Finally, it is possible to use another method to measure the efficiency of the firms and compare its results with the results obtained in this research, in order to evaluate the most appropriate method to be applied. 
9. REFERENCES 

Agência Nacional de Transportes Terrestres (ANTT) (2011). "Relatório Anual de Rodovias Federais Concedidas", <www.antt.gov.br> (Sept. 5, 2012).

Albalate, D., Bel, G. and Fageda, X. (2009). "Privatization and Regulatory Reform of Toll Motorways in Europe", Governance: an International Journal of Policy, Administration, and Institutions, Volume 22, Issue 2, pp. 295-318.

Amirteimoori, A., Kordrostami, S. and Sarparast, M. (2006). "Modeling undesirable factors in data envelopment analysis", Applied Mathematics and Computation, Volume 180, Issue 2, pp. 444452.

ASECAP - European Association of Motorway Concessionaries (2006). Toll Tariffs Calculation amongst ASECAP Members, ASECAP Publications.

Azevedo, G., Roboredo, M., Aizemberg, L., Silveira, J. and Soares de Mello, J. (2012). "Uso de análise envoltória de dados para mensurar eficiência temporal de rodovias federais concessionadas", Journal of Transport Literature, Volume 6, Issue 1, pp. 37-56.

Baeza, M. and Vassallo, J. (2010). "Private concession contracts for toll roads in Spain: analysis and recommendations", Public Money \& Management, Volume 30, Issue 5, pp. 299-304.

Banco Nacional de Desenvolvimento Econômico e Social (BNDES) (2011). "Annual Report Financial Statements", <www.bndes.gov.br> (Aug. 13, 2012).

Banker, D., Charnes, A. and Cooper, W. (1984). "Some Models for Estimating Technical and Scale Inefficiencies in Data Envelopment Analysis", Management Science, Volume 30, Issue 9, pp. 1078-1092.

Barbo, A. R. de C., Correia, D. E. R., Engelmann, E. T., Guzen, E. R., Gois, G. de A., Quebaud, M. R., Ali, M. M., Souza, N. M. and Quebaud, S. (2010). "A Evolução da Regulação nas Rodovias Federais Concedidas", Revista ANTT, Volume 2, Issue 2, Brasília.

Barros, C., Managi, S. and Yoshida, Y. (2010). "Productivity growth and biased technological change in Japanese airports", Transport Policy, Volume 17, Issue 4, pp. 259-265.

Barros, C. and Peypoch, N. (2010). "Productivity changes in Portuguese bus companies", Transport Policy, Volume 17, Issue 5, pp. 295-302. 
Benfratello, L., lozzi, A. and Valbonesi, P. (2009). "Technology and incentive regulation in the Italian motorways industry", Journal of Regulatory Economics, Volume 35, Issue 2, pp 201-221.

Bernstein, J. I., and Sappington, D. E. M. (1999). "Setting the X-Factor in Price-Cap Regulation Plans", Journal of Regulatory Economics, Volume 16, Issue 1, pp. 5-25.

Bolsa de Valores de São Paulo (BOVESPA) (2012). "Acompanhamento de Leilões", $<$ www.bmfbovespa.com.br> (Aug. 13, 2012).

Borgia, R (2006). "The development of the price-cap system in Italy: the experience of Autostrade per l'Italia", Pula 2006, European Association of Motorway Concessionaries - ASECAP, pp. 244248.

Bousquet, F. and Fayard, A. (2001). "Road Infrastructure Concession Practice in Europe", Working Paper, World Bank.

Brochado, M.R. and Vassallo, J. M. (2012). "Infrastructure Finance in Developing Countries by State and Multilateral Development Banks", Proceedings of the International Conference on Industrial Engineering and Operations Management, ABEPRO, Guimarães, Portugal.

Carpintero, S. and Barcham, R. (2012). "Private toll roads: lessons from Latin America", IPCSIT, Volume 26, pp. 98-102.

Carpintero, S. and Gomez-Ibañez, J.A. (2011). "Mexico's private toll road program reconsidered", Transport Policy, Volume 18, Issue 6, pp. 848-855.

Carpintero, S., Vassallo, J.M and Soliño, A. S. (2012). "Dealing with traffic risk in Latin American toll roads", Working paper.

Caves D. W., Christensen L. R. and Diewert W. E. (1982). "The economic theory of index numbers and the measurement of input, output and productivity", Econometrica, Volume 50, pp. 1393-1414.

Charnes, A., Cooper, W., Golany, B., Seiford, L. and Stutz, J. (1985). "Foundations of Data Envelopment Analysis for Pareto- Koopmans Efficient Empirical Production Functions", Journal of Econometrics, Volume 30, pp. 91-107.

Charnes, A., Cooper, W., and Rhodes, E., (1978). "Measuring the efficiency of decision making units", European Journal of Operational Research, Volume 2, pp. 429-444. 
Clímaco, J., Soares de Mello, J. and Maeza, L. (2010). "A Study of Highways Performance with a Molp-Dea Model and an Interactive Tri-Criteria Linear Programming Package (Trimap)", Brazilian Journal of Operations \& Production Management, Volume 7, Issue 1, pp. 163-179.

Coelli, T. J., (1996). "A guide to FRONTIER version 4.1: a computer program for stochastic frontier production and cost function estimation", CEPA Working Paper n. 96/07, Department of Econometrics, University of New England, Armidale.

Coelli, T., Estache, A., Perelman, S. and Trujillo, L. (2003). "A Primer on Efficiency Measurement for Utilities and Transport Regulators", Development Studies, Washington, D.C., The World Bank.

Coelli, T. J., Rao, D. S. P., O'Donnell, C. J., and Battese, G. E. (2005). An Introduction to Efficiency and Productivity Analysis, Second Edition, Springer.

Confederação Nacional do Transporte (CNT) (2012). "Boletim Estatístico Agosto 2012", $<$ www.cnt.org.br> (Sept. 20, 2012).

Cook, W., and Seiford, L. (2009). "Data Envelopment Analysis (DEA) - Thirty years on", European Journal of Operational Research, Volume 192, Issue 1, pp. 1-17.

Cook, W. and Zhu, J. (2005). Modeling Performance Measurement: Applications and Implementation Issues in DEA, Springer Science.

Cooper, W., Seiford, L. and Tone, K. (2007). Introduction to Data Envelopment Analysis and Its Uses: With DEA Solver Software and References, Second Edition, Springer, New York.

Demsetz, H. (1968). “Why Regulate Utilities?", Journal of Law and Economics, Volume 11, Issue 1 , pp. $55-65$.

Diewert, E. and Nakamura, A. (2002). "The Measurement of Agregate Total Factor Productivity Growth", Handbook of Econometrics, Volume 6.

Engel, E., Fischer, R. and Galetovic, A. (2009). "Public-Private Partnerships: When and How", Working Paper n. 257, Centro de Economía Aplicada, Universidad de Chile.

Engel, E., Fischer, R. and Galetovic, A. (2003). "Privatizing Highways in Latin America: Is it Possible to Fix What Went Wrong?", Economic Growth Center, Discussion Paper n. 866, Yale University, New Haven, CT. 
Estache, A., Perelman, S. and Trujillo, L. (2005). "Infrastructure Performance and Reform in Developing and Transition Economies: Evidence from a Survey of Productivity Measures", World Bank Policy Research, Working Paper 3514.

Färe, R., Grosskopf, S., Norris, M. and Zhang, Z. (1994). "Productivity growth, technical progress and efficiency changes in industrialized countries", The American Economic Review, Volume 84, Issue 1, pp. 66-83.

Flor, L. and Rojas, O. (2007). “¿Existe regulación por incentivos en las concesiones viales?: El caso peruano", Revista de la competencia y la propiedad intelectual, Volume 3, Issue 5, pp. 141172.

Flyvbjerg, B. (2011). "Case Study", The Sage Handbook of Qualitative Research, Norman K. Denzin and Yvonna S. Lincoln eds., $4^{\text {th }}$ Edition, Chapter 17, pp. 301-316.

de la Garza, J. M., Triantis, K., and Fallah-Fini, S. (2009). "Efficiency Measurement of Highway Maintenance Strategies Using Data Envelopment Analysis", Proceedings of the Engineering Research and Innovation Conference, NSF, Hawaii, United States of America.

Gitto, S. and Mancuso, P. (2012). "Bootstrapping the Malmquist indexes for Italian airports", International Journal of Production Economics, Volume 135, Issue 1, pp. 403-411.

Golany, B. and Roll, Y. (1989). "An application procedure for DEA", Omega, Volume 17, Issue 3, pp. 237-250.

Gomes, E.; Soares de Mello, J.; Biondi Neto, L.; Meza, L.(2004). "Gestão de Auto-Estradas: Análise de Eficiência das Auto-Estradas Federais Brasileiras com Portagens", Revista Portuguesa e Brasileira de Gestão, Volume 3, Issue 2, pp. 68-75.

Green, R. and Rodríguez-Pardina, M. (1999). "Resetting Price Controls for Privatized Utilities, A Manual for Regulators", Development Studies, The World Bank, Washington, D.C.

Guasch, J. L. (2004). "Granting and Renegotiating Infrastructure Concessions: Doing it Right", Development Studies Series, World Bank Institute, Washington, DC.

Guasch, J. L. and Spiller, P. T. (1995). "Regulation and Private Sector Development in Latin America", Reports, Issue 18, The World Bank. 
Instituto Brasileiro de Geografia e Estatística (IBGE) (2012). "Sistema Nacional de Índices de Preços ao Consumidor (IBGE/SNIPC)", <www.ibge.gov.br> (Sept. 20, 2012).

Instituto de Pesquisa Econômica Aplicada (Ipea) (2012a). "Financiamento do desenvolvimento: possibilidades, limites e desafios para esta década", Brasil em desenvolvimento 2011: Estado, planejamento e políticas públicas, Volume 2.

Instituto de Pesquisa Econômica Aplicada (Ipea) (2012b). "Rodovias brasileiras: Investimentos, concessões e tarifas de pedágio", Comunicados do Ipea, Issue 144.

Instituto de Pesquisa Econômica Aplicada (Ipea) (2011). "Gargalos e Demandas da Infraestrutura Rodoviária e os Investimentos do PAC: Mapeamento Ipea de Obras Rodoviárias", Texto para Discussão, Issue 1592.

Instituto de Pesquisa Econômica Aplicada (Ipea) (2010). "Rodovias Brasileiras: Gargalos, Investimentos, Concessões e Preocupações com o Futuro", Comunicados do Ipea, Issue 52.

Jasmab, T. and Pollitt, M. (2000). "Benchmarking and Regulation of Electricity Distribution and Transmission Utilities: Lessons from International Experience", DAE Working Paper 01/01, Department of Applied Economics, University of Cambridge.

Jamasb, T. and Pollit, M. (2001). "Benchmarking and Regulation: International Electricity Experience", Utilities Policy, Volume 9, pp. 107-130.

Jamison, M. A, Berg, S. V., Gasmi, F. and Távara, J. I. (2004). "An Annotated Reading List for a Body of Knowledge on the Regulation of Utility Infrastructure and Services", World Bank, Washington, D.C.

Jordà Lope, P. (2012). "Metodología de Evaluación de la Eficiencia de los Servicios de Autobús Urbano: Aplicación a las grandes ciudades españolas en el periodo 2004-2009", Tesis Doctoral, Universidad Politécnica de Madrid, E.T.S.I. Caminos Canales y Puertos.

Joskow, P. L. (2013). "Incentive Regulation in Theory and Practice: Electricity Distribution and Transmission Networks," Economic Regulation and Its Reform: What Have We Learned?, National Bureau of Economic Research.

Ke, Y., Wang, S. and Chan, A. (2010). "Risk Allocation in Public-Private Partnership Infrastructure Projects: Comparative Study", Journal of Infrastructure Systems, Volume 16, Issue 4, pp. 343351. 
Kumbhakar, S. C. and Lovell, C. A. K. (2000). "Stochastic Frontier analysis", Cambridge University Press, Cambridge.

Lacerda, S. M. (2005). "O financiamento da infra-estrutura rodoviária através de contribuintes e usuários", BNDES Setorial, Issue 21, pp. 141-159.

Lai, P., Potter, A. and Beynon, M. (2012). "The development of benchmarking techniques in airport performance evaluation research", Transportation Journal, Volume: 51, Issue 3, pp. 305337.

Malyshev, N. (2006). "Regulatory Policy: OECD Experience and Evidence", Oxford Review of Economic Policy, Volume 22, Issue 2, pp. 274-299.

Markovits-Somogyi, R. (2011a). "Measuring efficiency in transport: the state of the art of applying data envelopment analysis", Transport, Volume 26, Issue 1, pp. 11-19.

Markovits-Somogyi, R. (2011b). "Review and Systematization of Efficiency Measurement Methods Used in the Transport Sector", Traffic \& Transportation, Volume. 23, Issue 1, pp. 39-47.

Marques, R. C. and Berg. S. V. (2010). "Revisiting the Strengths and Limitations of Regulatory Contracts in Infrastructure Industries", Journal of Infrastructure Systems, Volume 16, Issue 4, pp. 334-342.

Odeck, J. (2008). "How efficient and productive are road toll companies? Evidence from Norway", Transport Policy, Volume 15, Issue 4, pp. 232-241.

Ozbek, M. E., de la Garza, J. M. and Triantis, K. (2010). "Data and Modeling Issues Faced during the Efficiency Measurement of Road Maintenance Using Data Envelopment Analysis", Journal of Infrastructure Systems, Volume 16, Issue 1, pp. 21-30.

OECD (2005). "OECD Guiding Principles for Regulatory Quality and Performance", $<w w w . o e c d . o r g / f r / r e f o r m e r e g / 34976533 . p d f>$ (May 6, 2013).

OECD (1997). "OECD Report on Regulatory Reform”, Paris.

Ondrej, M. and Jiri, H. (2012). "Total Factor Productivity Approach in Competitive and Regulated World", Procedia - Social and Behavioral Sciences, Volume 57, pp. 223-230.

Peltzman, S. (1989). "The Economic Theory of Regulation after a Decade of Deregulation", Brookings Papers on Economic Activity: Microeconomics, pp. 1 - 41. 
Pires, J. C. L. and Piccinini, M. S. (1999). "A Regulação dos Setores de Infra-estrutura", A Economia Brasileira nos Anos 90: A regulação dos Setores de Infra-estrutura no Brasil, BNDES.

Posner, R. A. (1974). "Theories of Economic Regulation", Bell Journal of Economics and Management Science, Volume 5, Issue 2, pp. 335-358.

Possamai, R. (2006). "Avaliação de Eficiência Técnica de Concessionárias de Rodovias utilizando Análise Envoltória de Dados", Dissertação de Mestrado, Universidade Federal do Rio Grande do Sul, Engenharia de Produção.

Priest, G. L. (1993). "The Origins of Utility Regulation and the "Theories of Regulation" Debate", Journal of Law and Economics, Volume 36, Issue 1, Part 2, pp. 289-323.

Rosa, M. V. F., Senna, L. A. D. S. and Lindau, L. A. (2010). "Highways concessions: Brazilian view", Proceedings Media of the 12th World Conference on Transport Research, Volume 1, pp. 114.

Seiford, L. M. (1996). "Data envelopment analysis: The evolution of the state of the art (19781995)", Journal of Productivity Analysis, Volume 7, Issue 2-3, pp. 99-137.

Seiford, L. M. and Zhu, J. (2002). "Modeling undesirable factors in efficiency evaluation", European Journal of Operational Research, Volume 142, Issue 1, pp. 16-20.

Senra, L. F. A. de C., Nanci, L. C., Mello, J. C. C. B. S. and Meza, L. A. (2007). "Estudo sobre métodos de seleção de variáveis em DEA", Pesquisa Operacional, Volume 27, Issue 2, pp.191207.

Shen, Y., Hermans, E., Brijs, T., Wets, G. and Vanhoof, K. (2012). "Road safety risk evaluation and target setting using data envelopment analysis and its extensions", Accident Analysis and Prevention, Volume 48, pp.430- 441.

Shen, Y., Ruan, D., Hermans, E., Brijs, T., Wets, G. and Vanhoof, K. (2011). "Changes in Undesirable Impacts on Sustainable Road Transport of a set of European Countries", Transportation Research Record, Volume 2242, pp. 37-44.

Shleifer, A. (1985). "A Theory of Yardstick Competition", Rand Journal of Economics, Volume 16, pp. 319-327. 
Silveira, J., Azevedo, G. and Soares de Mello, J. (2010). "Aplicação da Análise Envoltória de Dados na Avaliação da Eficiência de Rodovias Federais Concessionadas", Proceedings of the XXIV Congresso em Ensino e Pesquisa em Transporte, ANPET, Salvador, Brazil.

Singh, Y. K. (2006). Fundamental Research Methodology and Statistics, New Age International publishers, New Delhi.

Stigler, G. J. (1971). "The Theory of Economic Regulation", Bell Journal of Economics and Management Science, Volume 2, Issue 1, pp. 3-21.

Tone, K. (2001). "A slacks-based measure of efficiency in data envelopment analysis", European Journal of Operational Research, Volume 130, Issue 3, pp. 498-509.

Törnqvist L. (1936). "The Bank of Finland's Consumption Price Index", Bank of Finland Monthly Bulletin, Volume 10, pp. 1-8.

Tulkens, H. (1993). "On FDH Efficiency Analysis: Some Methodological Issues and Application to Retail Banking, Courts, and Urban Transit", $77^{\text {th }}$ Journal of Productivity Analysis, Volume 4, Issue $1 / 2$, pp. 183-210.

Vassallo, J. M. and Izquierdo, R. (2010). Infraestructura Pública y Participación Privada: conceptos y experiencias en América y España, CAF, Madrid.

Vassallo, J.M. (2006). "Traffic risk mitigation in highway concession projects", Journal of Transport Economics and Policy, Volume 40, Issue 3, pp. 359-381.

Vassalo, J. M., Saldaña, P., Sierra, J. and Baeza, M.A. (2010). Proyecto OASIS, Deliverable 1.1.1: Revisión del Marco Concesional, Universidad Politécnica de Madrid, Spain.

Véron, A. and Cellier, J. (2010). "Private Participation in the Road Sector in Brazil: Recent Evolution and Next Steps." Transport Paper, Issue 30, World Bank Group.

Wang, L. and Tsai, H. (2009). "Evaluation of Highway Maintenance Performance Using Data Envelopment analysis (DEA) in Taiwan", Journal of Marine Science and Technology, Volume 17, issue 2 , pp. 145-155

Welde, M. and Odeck, J. (2011). "The efficiency of Norwegian road toll companies", Utilities Policy, Volume 19, Issue 3, pp. 162-171. 
Yamada, Y., Matsui, T. and Sugiyama, M. (1994). "An inefficiency measurement method for management systems", Journal of the Operations Research Society of Japan, Volume 37, Issue 2, pp. 158-167. 

10. APPENDIX 

10.1 Data set used to run DEA model

\begin{tabular}{|c|c|c|c|}
\hline $\begin{array}{c}\text { DMU - SF_1.1 } \\
1^{\text {st }} \text { Stage (2004-2008) }\end{array}$ & $\begin{array}{c}\text { number of } \\
\text { vehicles of the } \\
\text { concessionairel } \\
\text { length }(\mathrm{km})\end{array}$ & $\begin{array}{l}\text { number of } \\
\text { employees } \\
\text { length (km) }\end{array}$ & $\begin{array}{c}\text { annual traffic volume I } \\
\text { number of accidents }\end{array}$ \\
\hline Concepa_2004 & 0.207 & 2.008 & $17,013.646$ \\
\hline Concepa_2005 & 0.223 & 2.008 & $18,388.020$ \\
\hline Concepa_2006 & 0.207 & 1.504 & $19,098.034$ \\
\hline Concepa_2007 & 0.190 & 2.273 & $20,812.473$ \\
\hline Concepa_2008 & 0.256 & 2.306 & $21,403.399$ \\
\hline Concer_2004 & 0.277 & 2.123 & $7,798.631$ \\
\hline Concer_2005 & 0.277 & 2.190 & $8,366.465$ \\
\hline Concer_2006 & 0.277 & 2.190 & $6,430.128$ \\
\hline Concer_2007 & 0.277 & 2.190 & $9,189.787$ \\
\hline Concer_2008 & 0.277 & 2.178 & $6,443.110$ \\
\hline CRT_2004 & 0.175 & 1.509 & $16,108.072$ \\
\hline CRT_2005 & 0.161 & 1.565 & $14,079.260$ \\
\hline CRT_2006 & 0.175 & 1.600 & $11,996.940$ \\
\hline CRT_2007 & 0.175 & 1.621 & $11,960.479$ \\
\hline CRT_2008 & 0.182 & 1.719 & $3,839.330$ \\
\hline Ecosul_2004 & 0.024 & 0.415 & $16,138.696$ \\
\hline Ecosul_2005 & 0.026 & 0.415 & $16,091.029$ \\
\hline Ecosul_2006 & 0.029 & 0.442 & $18,395.907$ \\
\hline Ecosul_2007 & 0.029 & 0.452 & $19,126.024$ \\
\hline Ecosul_2008 & 0.032 & 0.462 & $17,296.130$ \\
\hline Nova_Dutra_2004 & 0.358 & 2.585 & $12,875.119$ \\
\hline Nova_Dutra_2005 & 0.336 & 2.672 & $9,094.217$ \\
\hline Nova_Dutra_2006 & 0.316 & 2.425 & $9,945.364$ \\
\hline Nova_Dutra_2007 & 0.316 & 2.478 & $12,591.873$ \\
\hline Nova_Dutra_2008 & 0.303 & 2.662 & $13,264.040$ \\
\hline Ponte_Rio_Niterói_2004 & 1.971 & 9.854 & $40,336.899$ \\
\hline Ponte_Rio_Niterói_2005 & 1.971 & 9.854 & $39,882.958$ \\
\hline Ponte_Rio_Niterói_2006 & 1.971 & 9.854 & $30,451.943$ \\
\hline Ponte_Rio_Niterói_2007 & 1.971 & 5.913 & $31,481.942$ \\
\hline Ponte_Rio_Niterói_2008 & 0.728 & 10.026 & $27,679.749$ \\
\hline
\end{tabular}




\begin{tabular}{|c|c|c|c|}
\hline 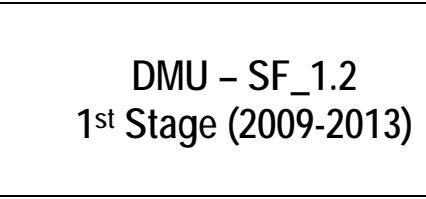 & $\begin{array}{c}\text { number of } \\
\text { vehicles of the } \\
\text { concessionairel } \\
\text { length }(\mathrm{km})\end{array}$ & $\begin{array}{l}\text { number of } \\
\text { employeesl } \\
\text { length (km) }\end{array}$ & $\begin{array}{c}\text { annual traffic volume I } \\
\text { number of accidents }\end{array}$ \\
\hline Concepa_2009 & 0.223 & 1.603 & $19,607.104$ \\
\hline Concepa_2010 & 0.322 & 4.843 & $18,495.798$ \\
\hline Concepa_2011 & 0.298 & 4.917 & $20,947.667$ \\
\hline Concepa_2012 & 0.347 & 3.529 & $21,137.025$ \\
\hline Concepa_2013 & 0.421 & 3.083 & $21,392.898$ \\
\hline Concer_2009 & 0.277 & 4.102 & $7,607.014$ \\
\hline Concer_2010 & 0.299 & 4.008 & $6,795.423$ \\
\hline Concer_2011 & 0.227 & 4.058 & $7,040.499$ \\
\hline Concer_2012 & 0.233 & 4.008 & $7,202.098$ \\
\hline Concer_2013 & 0.333 & 4.850 & $7,879.227$ \\
\hline CRT_2009 & 0.168 & 1.558 & $4,239.763$ \\
\hline CRT_2010 & 0.232 & 2.470 & $2,958.955$ \\
\hline CRT_2011 & 0.239 & 2.400 & $2,695.211$ \\
\hline CRT_2012 & 0.239 & 2.400 & $3,103.677$ \\
\hline CRT_2013 & 0.267 & 2.905 & $10,564.098$ \\
\hline Ecosul_2009 & 0.032 & 0.462 & $17,629.542$ \\
\hline Ecosul_2010 & 0.038 & 0.587 & $16,560.947$ \\
\hline Ecosul_2011 & 0.038 & 0.510 & $17,471.690$ \\
\hline Ecosul_2012 & 0.038 & 0.603 & $18,934.922$ \\
\hline Ecosul_2013 & 0.058 & 0.543 & $18,965.744$ \\
\hline Nova_Dutra_2009 & 0.493 & 2.739 & $13,061.018$ \\
\hline Nova_Dutra_2010 & 0.321 & 3.527 & $14,787.969$ \\
\hline Nova_Dutra_2011 & 0.383 & 3.595 & $15,071.133$ \\
\hline Nova_Dutra_2012 & 0.386 & 3.664 & $14,849.552$ \\
\hline Nova_Dutra_2013 & 0.545 & 3.694 & $15,937.150$ \\
\hline Ponte_Rio_Niterói_2009 & 1.971 & 10.026 & $28,958.695$ \\
\hline Ponte_Rio_Niterói_2010 & 2.014 & 13.325 & $28,318.518$ \\
\hline Ponte_Rio_Niterói_2011 & 2.014 & 12.853 & $26,421.637$ \\
\hline Ponte_Rio_Niterói_2012 & 2.014 & 14.653 & $26,445.213$ \\
\hline Ponte_Rio_Niterói_2013 & 1.243 & 14.396 & $34,737.208$ \\
\hline
\end{tabular}




\begin{tabular}{|c|c|c|c|}
\hline $\begin{array}{c}\text { DMU - SF_2.1 } \\
\text { 2nd Stage (2009-2013) }^{\text {nd }}\end{array}$ & $\begin{array}{c}\text { number of } \\
\text { vehicles of the } \\
\text { concessionairel } \\
\text { length }(\mathrm{km})\end{array}$ & $\begin{array}{l}\text { number of } \\
\text { employees/ } \\
\text { length (km) }\end{array}$ & $\begin{array}{c}\text { annual traffic } \\
\text { volume } I \\
\text { number of accidents }\end{array}$ \\
\hline Autopista_Fernao_Dias_2009 & 0.157 & 1.642 & $9,580.117$ \\
\hline Autopista_Fernao_Dias_2010 & 0.110 & 1.875 & $13,308.758$ \\
\hline Autopista_Fernao_Dias_2011 & 0.114 & 1.969 & $15,190.837$ \\
\hline Autopista_Fernao_Dias_2012 & 0.116 & 2.144 & $14,825.361$ \\
\hline Autopista_Fernao_Dias_2013 & 0.213 & 1.555 & $15,653.009$ \\
\hline Autopista_Fluminense_2009 & 0.181 & 1.056 & $7,388.493$ \\
\hline Autopista_Fluminense_2010 & 0.172 & 0.797 & $10,649.140$ \\
\hline Autopista_Fluminense_2011 & 0.175 & 4.158 & $10,246.166$ \\
\hline Autopista_Fluminense_2012 & 0.222 & 5.514 & $10,503.112$ \\
\hline Autopista_Fluminense_2013 & 0.322 & 4.977 & $10,813.224$ \\
\hline Autopista_Litoral_Sul_2009 & 0.144 & 1.457 & $2,634.330$ \\
\hline Autopista_Litoral_Sul_2010 & 0.115 & 2.116 & $11,567.009$ \\
\hline Autopista_Litoral_Sul_2011 & 0.207 & 1.964 & $9,782.841$ \\
\hline Autopista_Litoral_Sul_2012 & 0.201 & 1.517 & $12,784.491$ \\
\hline Autopista_Litoral_Sul_2013 & 0.306 & 1.512 & $11,348.400$ \\
\hline Autopista_Planalto_Sul_2009 & 0.082 & 0.979 & $5,693.725$ \\
\hline Autopista_Planalto_Sul_2010 & 0.073 & 2.704 & $11,330.546$ \\
\hline Autopista_Planalto_Sul_2011 & 0.082 & 3.540 & $13,460.253$ \\
\hline Autopista_Planalto_Sul_2012 & 0.082 & 3.213 & $9,450.035$ \\
\hline Autopista_Planalto_Sul_2013 & 0.153 & 0.647 & $11,152.415$ \\
\hline Autopista_Regis_Bittencourt_2009 & 0.107 & 0.964 & $15,764.255$ \\
\hline Autopista_Regis_Bittencourt_2010 & 0.107 & 1.370 & $20,391.953$ \\
\hline Autopista_Regis_Bittencourt_2011 & 0.112 & 1.357 & $21,066.352$ \\
\hline Autopista_Regis_Bittencourt_2012 & 0.132 & 1.626 & $22,448.641$ \\
\hline Autopista_Regis_Bittencourt_2013 & 0.286 & 1.569 & $26,032.733$ \\
\hline Rodovia_do_Aço_2009 & 0.160 & 0.918 & $11,156.870$ \\
\hline Rodovia_do_Aço_2010 & 0.130 & 1.861 & $16,869.630$ \\
\hline Rodovia_do_Aço_2011 & 0.125 & 1.667 & $18,312.199$ \\
\hline Rodovia_do_Aço_2012 & 0.304 & 1.821 & $13,984.097$ \\
\hline Rodovia_do_Aço_2013 & 0.454 & 2.166 & $14,327.195$ \\
\hline
\end{tabular}

continues 


\begin{tabular}{lccc}
\hline $\begin{array}{c}\text { DMU - SF_2.1 } \\
\text { 2nd }\end{array}$ & $\begin{array}{c}\text { number of } \\
\text { vehicles of the } \\
\text { concessionairel } \\
\text { length }(\mathbf{k m})\end{array}$ & $\begin{array}{c}\text { number of } \\
\text { employees } / \\
\text { length }(\mathbf{k m})\end{array}$ & $\begin{array}{c}\text { annual traffic } \\
\text { volume I } \\
\text { number of accidents }\end{array}$ \\
\hline Transbrasiliana_2009 & 0.112 & 0.563 & $23,096.732$ \\
\hline Transbrasiliana_2010 & 0.109 & 0.600 & $22,329.197$ \\
\hline Transbrasiliana_2011 & 0.109 & 0.613 & $23,173.960$ \\
\hline Transbrasiliana_2012 & 0.112 & 0.899 & $22,264.209$ \\
\hline Transbrasiliana_2013 & 0.131 & 0.955 & $21,584.191$ \\
\hline
\end{tabular}

\begin{tabular}{lcccc}
\hline $\begin{array}{c}\text { DMU - AT_1.1 } \\
\text { 1st Stage (2005-2009) }\end{array}$ & $\begin{array}{c}\text { number of } \\
\text { vehicles of the } \\
\text { concessionaire }\end{array}$ & $\begin{array}{c}\text { number of } \\
\text { employees }\end{array}$ & $\begin{array}{c}\text { annual traffic } \\
\text { volume }\end{array}$ & $\begin{array}{c}\text { number of } \\
\text { user } \\
\text { assistances }\end{array}$ \\
\hline Concepa_2005 & 18 & 276 & $11,497,442$ & 23,604 \\
\hline Concepa_2006 & 18 & 282 & $13,407,343$ & 24,066 \\
\hline Concepa_2007 & 16 & 259 & $11,086,719$ & 25,596 \\
\hline Concepa_2008 & 20 & 288 & $13,785,016$ & 28,825 \\
\hline Concepa_2009 & 26 & 245 & $14,712,311$ & 30,055 \\
\hline Concer_2005 & 23 & 223 & $12,544,621$ & 31,033 \\
\hline Concer_2006 & 25 & 228 & $12,836,726$ & 33,031 \\
\hline Concer_2007 & 20 & 288 & $14,050,745$ & 33,812 \\
\hline Concer_2008 & 25 & 231 & $13,120,646$ & 34,673 \\
\hline Concer_2009 & 25 & 182 & $22,726,661$ & 35,217 \\
\hline CRT_2005 & 27 & 243 & $21,697,864$ & 35,428 \\
\hline CRT_2006 & 24 & 222 & $13,923,382$ & 36,271 \\
\hline CRT_2007 & 27 & 194 & $26,744,090$ & 36,316 \\
\hline CRT_2008 & 31 & 279 & $26,433,198$ & 37,096 \\
\hline CRT_2009 & 23 & 275 & $24,308,968$ & 37,728 \\
\hline Ecosul_2005 & 50 & 395 & $19,535,695$ & 45,642 \\
\hline Ecosul_2006 & 50 & 395 & $19,264,663$ & 47,657 \\
\hline Ecosul_2007 & 50 & 740 & $24,540,227$ & 61,599 \\
\hline Ecosul_2008 & 50 & 395 & $21,421,394$ & 62,177 \\
\hline Ecosul_2009 & 393 & $22,454,239$ & 68,866 \\
\hline Nova_Dutra_2005 & 23 & 234 & $28,379,521$ & 72,480 \\
\hline Nova_Dutra_2006 & $50,094,945$ & 83,322 \\
\hline continues & 17 & & & \\
\hline
\end{tabular}

continues 
continues

\begin{tabular}{lcccc}
\hline $\begin{array}{c}\text { DMU - AT_1.1 } \\
\text { 1st Stage (2005-2009) }\end{array}$ & $\begin{array}{c}\text { number of } \\
\text { vehicles of the } \\
\text { concessionaire }\end{array}$ & $\begin{array}{c}\text { number of } \\
\text { employees }\end{array}$ & $\begin{array}{c}\text { annual traffic } \\
\text { volume }\end{array}$ & $\begin{array}{c}\text { number of } \\
\text { user } \\
\text { assistances }\end{array}$ \\
\hline Nova_Dutra_2007 & 46 & 230 & $26,340,931$ & 87,779 \\
\hline Nova_Dutra_2008 & 46 & 138 & $27,011,506$ & 92,924 \\
\hline Nova_Dutra_2009 & 46 & 230 & $26,641,816$ & 93,327 \\
\hline Ponte_Rio_Niterói_2005 & 198 & 1,101 & $131,224,052$ & 307,375 \\
\hline Ponte_Rio_Niterói_2006 & 135 & 1,074 & $82,893,784$ & 316,721 \\
\hline Ponte_Rio_Niterói_2007 & 127 & 975 & $84,177,558$ & 335,411 \\
\hline Ponte_Rio_Niterói_2008 & 127 & 996 & $119,849,451$ & 340,959 \\
\hline Ponte_Rio_Niterói_2009 & 122 & 1,070 & $131,910,880$ & 341,365 \\
\hline
\end{tabular}

\begin{tabular}{lcccc}
\hline $\begin{array}{c}\text { DMU - AT_1.2 } \\
\text { 1st Stage (2009-2013) }\end{array}$ & $\begin{array}{c}\text { number of } \\
\text { vehicles of the } \\
\text { concessionaire }\end{array}$ & $\begin{array}{c}\text { number of } \\
\text { employees }\end{array}$ & $\begin{array}{c}\text { annual traffic } \\
\text { volume }\end{array}$ & $\begin{array}{c}\text { number of } \\
\text { user } \\
\text { assistances }\end{array}$ \\
\hline Concepa_2009 & 27 & 194 & $26,744,090$ & 36,316 \\
\hline Concepa_2010 & 39 & 586 & $29,926,201$ & 37,563 \\
\hline Concepa_2011 & 36 & 595 & $32,426,988$ & 38,858 \\
\hline Concepa_2012 & 42 & 427 & $35,024,050$ & 43,401 \\
\hline Concepa_2013 & 51 & 373 & $37,394,786$ & 45,440 \\
\hline Concer_2009 & 50 & 740 & $24,540,227$ & 61,599 \\
\hline Concer_2010 & 54 & 723 & $25,265,383$ & 59,758 \\
\hline Concer_2011 & 41 & 732 & $29,450,407$ & 70,819 \\
\hline Concer_2012 & 42 & 723 & $31,242,699$ & 74,099 \\
\hline Concer_2013 & 60 & 875 & $32,273,314$ & 70,840 \\
\hline CRT_2009 & 24 & 222 & $13,923,382$ & 36,271 \\
\hline CRT_2010 & 33 & 352 & $13,969,226$ & 28,990 \\
\hline CRT_2011 & 34 & 342 & $14,850,610$ & 31,138 \\
\hline CRT_2012 & 34 & 342 & $15,710,812$ & 30,599 \\
\hline CRT_2013 & 38 & 414 & $15,920,095$ & 31,285 \\
\hline Ecosul_2009 & 24 & 288 & $14,050,745$ & 33,812 \\
\hline Ecosul_2010 & 24 & 366 & $15,616,973$ & 36,069 \\
\hline Ecosul_2011 & 36 & 318 & $17,419,275$ & 35,835 \\
\hline Ecosul_2012 & 376 & $17,571,608$ & 37,690 \\
\hline Ecosul_2013 & 339 & $20,843,353$ & 42,056 \\
\hline COntns & & & & \\
\hline
\end{tabular}


continues

\begin{tabular}{lcccc}
\hline $\begin{array}{c}\text { DMU - AT_1.2 } \\
\text { 1st Stage (2009-2013) }\end{array}$ & $\begin{array}{c}\text { number of } \\
\text { vehicles of the } \\
\text { concessionaire }\end{array}$ & $\begin{array}{c}\text { number of } \\
\text { employees }\end{array}$ & $\begin{array}{c}\text { annual traffic } \\
\text { volume }\end{array}$ & $\begin{array}{c}\text { number of } \\
\text { user } \\
\text { assistances }\end{array}$ \\
\hline Nova_Dutra_2009 & 198 & 1,101 & $131,224,052$ & 307,375 \\
\hline Nova_Dutra_2010 & 129 & 1,418 & $162,371,897$ & 324,407 \\
\hline Nova_Dutra_2011 & 154 & 1,445 & $177,537,948$ & 314,840 \\
\hline Nova_Dutra_2012 & 155 & 1,473 & $178,922,255$ & 307,775 \\
\hline Nova_Dutra_2013 & 219 & 1,485 & $183,898,771$ & 290,675 \\
\hline Ponte_Rio_Niterói_2009 & 46 & 234 & $28,379,521$ & 72,480 \\
\hline Ponte_Rio_Niterói_2010 & 47 & 311 & $28,828,251$ & 71,121 \\
\hline Ponte_Rio_Niterói_2011 & 47 & 300 & $29,803,607$ & 68,114 \\
\hline Ponte_Rio_Niterói_2012 & 47 & 342 & $30,411,995$ & 67,707 \\
\hline Ponte_Rio_Niterói_2013 & 29 & 336 & $30,672,955$ & 64,545 \\
\hline
\end{tabular}

\begin{tabular}{lcccc}
\hline $\begin{array}{c}\text { DMU - AT_2.1 } \\
\text { 2nd Stage (2009-2013) }\end{array}$ & $\begin{array}{c}\text { number of } \\
\text { vehicles of the } \\
\text { concessionaire }\end{array}$ & $\begin{array}{c}\text { number of } \\
\text { employees }\end{array}$ & $\begin{array}{c}\text { annual } \\
\text { traffic } \\
\text { volume }\end{array}$ & $\begin{array}{c}\text { number of user } \\
\text { assistances }\end{array}$ \\
\hline Autopista_Fernao_Dias_2009 & 88 & 923 & $84,908,578$ & 179,044 \\
\hline Autopista_Fernao_Dias_2010 & 62 & 1,054 & $121,721,903$ & 220,296 \\
\hline Autopista_Fernao_Dias_2011 & 64 & 1,107 & $152,774,246$ & 253,994 \\
\hline Autopista_Fernao_Dias_2012 & 65 & 1,205 & $160,647,610$ & 284,170 \\
\hline Autopista_Fernao_Dias_2013 & 120 & 874 & $165,186,203$ & 282,571 \\
\hline Autopista_Fluminense_2009 & 58 & 338 & $26,938,444$ & 83,430 \\
\hline Autopista_Fluminense_2010 & 55 & 255 & $42,032,156$ & 87,705 \\
\hline Autopista_Fluminense_2011 & 56 & 1,331 & $46,025,778$ & 90,727 \\
\hline Autopista_Fluminense_2012 & 71 & 1,765 & $48,167,271$ & 97,489 \\
\hline Autopista_Fluminense_2013 & 103 & 1,593 & $48,367,552$ & 92,995 \\
\hline Autopista_Litoral_Sul_2009 & 55 & 557 & $18,861,806$ & 168,661 \\
\hline Autopista_Litoral_Sul_2010 & 44 & 809 & $114,733,164$ & 198,125 \\
\hline Autopista_Litoral_Sul_2011 & 79 & 751 & $114,733,164$ & 215,206 \\
\hline Autopista_Litoral_Sul_2012 & 77 & 580 & $122,462,642$ & 176,427 \\
\hline Autopista_Litoral_Sul_2013 & 117 & 578 & $117,739,648$ & 169,008 \\
\hline Autopista_Planalto_Sul_2009 & 34 & 404 & $22,188,447$ & 37,869 \\
\hline Continiss & & & &
\end{tabular}

continues 
continues

\begin{tabular}{lcccc}
\hline $\begin{array}{l}\text { DMU - AT_2.1 } \\
\text { 2nd Stage (2009-2013) }\end{array}$ & $\begin{array}{c}\text { number of } \\
\text { vehicles of the } \\
\text { concessionaire }\end{array}$ & $\begin{array}{c}\text { number of } \\
\text { employees }\end{array}$ & $\begin{array}{c}\text { annual } \\
\text { traffic } \\
\text { volume }\end{array}$ & $\begin{array}{c}\text { number of } \\
\text { user } \\
\text { assistances }\end{array}$ \\
\hline Autopista_Planalto_Sul_2010 & 30 & 1,116 & $25,946,951$ & 42,387 \\
\hline Autopista_Planalto_Sul_2011 & 34 & 1,461 & $27,122,409$ & 43,992 \\
\hline Autopista_Planalto_Sul_2012 & 34 & 1,326 & $27,055,450$ & 50,141 \\
\hline Autopista_Planalto_Sul_2013 & 63 & 267 & $28,360,592$ & 45,256 \\
\hline Autopista_Regis_Bittencourt_2009 & 43 & 387 & $98,368,954$ & 249,751 \\
\hline Autopista_Regis_Bittencourt_2010 & 43 & 550 & $136,157,072$ & 257,461 \\
\hline Autopista_Regis_Bittencourt_2011 & 45 & 545 & $143,735,722$ & 230,784 \\
\hline Autopista_Regis_Bittencourt_2012 & 53 & 653 & $146,005,958$ & 213,930 \\
\hline Autopista_Regis_Bittencourt_2013 & 115 & 630 & $150,052,672$ & 213,740 \\
\hline Rodovia_do_Aço_2009 & 32 & 184 & $10,777,536$ & 26,709 \\
\hline Rodovia_do_Aço_2010 & 26 & 373 & $17,207,023$ & 29,112 \\
\hline Rodovia_do_Aço_2011 & 25 & 334 & $18,824,941$ & 31,320 \\
\hline Rodovia_do_Aço_2012 & 61 & 365 & $15,662,189$ & 38,145 \\
\hline Rodovia_do_Aço_2013 & 91 & 434 & $17,206,961$ & 37,735 \\
\hline Transbrasiliana_2009 & 36 & 181 & $21,433,767$ & 34,978 \\
\hline Transbrasiliana_2010 & 35 & 193 & $22,865,098$ & 43,765 \\
\hline Transbrasiliana_2011 & 35 & 197 & $24,587,572$ & 46,042 \\
\hline Transbrasiliana_2012 & 36 & 289 & $26,739,315$ & 54,034 \\
\hline Transbrasiliana_2013 & 42 & 307 & $26,548,555$ & 57,069 \\
\hline & & & & \\
\hline
\end{tabular}

\subsection{Correlation between variable of models tested}

Road Safety models

\begin{tabular}{lcccc}
\hline \multicolumn{1}{c}{ SF1 } & $\begin{array}{c}\text { number of } \\
\text { employees }\end{array}$ & $\begin{array}{c}\text { number of vehicles of the } \\
\text { concessionaire }\end{array}$ & $\begin{array}{c}\text { annual traffic } \\
\text { volume }\end{array}$ & $\begin{array}{c}\text { 1/number of } \\
\text { accidents }\end{array}$ \\
\hline number of employees & 1.000 & 0.972 & 0.958 & -0.765 \\
\hline $\begin{array}{l}\text { number of vehicles of the } \\
\text { concessionaire }\end{array}$ & 0.972 & 1.000 & 0.971 & -0.756 \\
\hline annual traffic volume & 0.958 & 0.971 & 1.000 & -0.708 \\
\hline $1 /$ number of accidents & -0.765 & -0.756 & -0.708 & 1.000 \\
\hline
\end{tabular}




\begin{tabular}{lcccc}
\hline \multicolumn{1}{c}{ SF2 } & $\begin{array}{c}\text { number of } \\
\text { employees }\end{array}$ & $\begin{array}{c}\text { number of vehicles of } \\
\text { the concessionaire }\end{array}$ & $\begin{array}{c}\text { annual } \\
\text { traffic } \\
\text { volume }\end{array}$ & $\begin{array}{c}\text { length } \\
(\mathrm{km}) / \text { number of } \\
\text { accidents }\end{array}$ \\
\hline number of employees & 1.000 & 0.972 & 0.958 & -0.258 \\
\hline $\begin{array}{l}\text { number of vehicles of } \\
\text { the concessionaire }\end{array}$ & 0.972 & 1.000 & 0.971 & -0.407 \\
\hline $\begin{array}{l}\text { annual traffic volume } \\
\text { length }(\mathrm{km}) / \text { number of } \\
\text { accidents }\end{array}$ & 0.958 & 0.971 & 1.000 & -0.361 \\
\hline
\end{tabular}

\begin{tabular}{|c|c|c|c|c|}
\hline SF3 & $\begin{array}{l}\text { number of } \\
\text { employees }\end{array}$ & $\begin{array}{c}\text { number of vehicles } \\
\text { of the } \\
\text { concessionaire }\end{array}$ & $\begin{array}{l}\text { annual } \\
\text { traffic } \\
\text { volume }\end{array}$ & $\begin{array}{c}\text { (length } x \text { number of } \\
\text { lanes) / number of } \\
\text { accidents }\end{array}$ \\
\hline number of employees & 1.000 & 0.972 & 0.958 & -0.224 \\
\hline $\begin{array}{l}\text { number of vehicles of } \\
\text { the concessionaire }\end{array}$ & 0.972 & 1.000 & 0.971 & -0.382 \\
\hline annual traffic volume & 0.958 & 0.971 & 1.000 & -0.354 \\
\hline $\begin{array}{llll}\text { length } & \mathrm{x} & \text { number } & \text { of } \\
\text { lanes) I } & \text { number } & \text { of } \\
\text { accidents } & & \\
\end{array}$ & -0.224 & -0.382 & -0.354 & 1.000 \\
\hline
\end{tabular}

\begin{tabular}{lccc}
\hline \multicolumn{1}{c}{ SF4 } & $\begin{array}{c}\text { number of } \\
\text { employees/ } \\
\text { length }(\mathrm{km})\end{array}$ & $\begin{array}{c}\text { number of vehicles of the } \\
\text { concessionaire/ length } \\
(\mathrm{km})\end{array}$ & $\begin{array}{c}\text { annual traffic } \\
\text { volume / number of } \\
\text { accidents }\end{array}$ \\
\hline $\begin{array}{l}\text { number of employees/ } \\
\text { length }(\mathrm{km})\end{array}$ & 1.000 & 0.985 & 0.816 \\
\hline $\begin{array}{l}\text { number of vehicles of the } \\
\begin{array}{l}\text { concessionaire/ length } \\
(\mathrm{km})\end{array}\end{array}$ & 0.985 & 1.000 & 0.852 \\
$\begin{array}{l}\text { annual traffic volume / } \\
\text { number of accidents }\end{array}$ & 0.816 & 0.852 & 1.000 \\
\hline
\end{tabular}




\begin{tabular}{lccc}
\hline \multicolumn{1}{c}{ SF5 } & $\begin{array}{c}\text { number of } \\
\text { employees/ (length } \\
\text { x number of lanes) }\end{array}$ & $\begin{array}{c}\text { number of vehicles of the } \\
\text { concessionaire/ (length } x \\
\text { number of lanes) }\end{array}$ & $\begin{array}{c}\text { annual traffic } \\
\text { volume / number } \\
\text { of accidents }\end{array}$ \\
\hline $\begin{array}{l}\text { number of employees/ } \\
\text { (length x number of lanes) }\end{array}$ & 1.000 & 0.972 & 0.854 \\
\hline $\begin{array}{l}\text { number of vehicles of the } \\
\text { concessionaire/ (length x } \\
\text { number of lanes) }\end{array}$ & 0.972 & 1.000 & 0.877 \\
\hline $\begin{array}{l}\text { annual traffic volume / } \\
\text { number of accidents }\end{array}$ & 0.854 & 0.877 & 1.000 \\
\hline
\end{tabular}

\begin{tabular}{lcccc}
\hline SF6 & $\begin{array}{c}\text { number of } \\
\text { employees }\end{array}$ & $\begin{array}{c}\text { number of vehicles of } \\
\text { the concessionaire }\end{array}$ & $\begin{array}{c}\text { 1/number of } \\
\text { accidents }\end{array}$ & $\begin{array}{c}\text { annual } \\
\text { traffic } \\
\text { volume }\end{array}$ \\
\hline number of employees & 1.000 & 0.972 & -0.765 & 0.958 \\
\hline $\begin{array}{l}\text { number of vehicles of } \\
\text { the concessionaire }\end{array}$ & 0.972 & 1.000 & -0.756 & 0.971 \\
\hline $\begin{array}{l}\text { 1/number of accidents } \\
\text { annual traffic volume }\end{array}$ & -0.765 & -0.756 & 1.000 & -0.708 \\
\hline
\end{tabular}

\begin{tabular}{lcccccc}
\hline \multicolumn{1}{c}{ SF7 } & & $\begin{array}{c}\text { number of } \\
\text { employees }\end{array}$ & $\begin{array}{c}\text { number of vehicles } \\
\text { of the } \\
\text { concessionaire }\end{array}$ & $\begin{array}{c}\text { 1/number of } \\
\text { accidents }\end{array}$ & $\begin{array}{c}\text { annual } \\
\text { traffic } \\
\text { volume }\end{array}$ & $\begin{array}{c}\text { length }(\mathrm{km}) \\
\text { x number of } \\
\text { lanes }\end{array}$ \\
\hline $\begin{array}{l}\text { number } \\
\text { employees }\end{array}$ & of & 1.000 & 0.972 & -0.765 & 0.958 & 0.943 \\
\hline $\begin{array}{l}\text { number of vehicles } \\
\text { of } \\
\text { concessionaire }\end{array}$ & the & 0.972 & 1.000 & -0.756 & 0.971 & 0.873 \\
\hline $\begin{array}{l}\text { 1/number } \\
\text { accidents of }\end{array}$ & -0.765 & -0.756 & 1.000 & -0.708 & -0.778 \\
\hline $\begin{array}{l}\text { annual } \\
\text { volume }\end{array}$ traffic & 0.958 & 0.971 & -0.708 & 1.000 & 0.848 \\
\hline $\begin{array}{l}\text { length } \\
\text { number of lanes }\end{array}$ & $\mathrm{x}$ & 0.943 & 0.873 & -0.778 & 0.848 & 1.000 \\
\hline
\end{tabular}




\begin{tabular}{lcccc}
\hline \multicolumn{1}{c}{ SF8 } & $\begin{array}{c}\text { annual } \\
\text { traffic } \\
\text { volume }\end{array}$ & $\begin{array}{c}\text { number of } \\
\text { accidents }\end{array}$ & $\begin{array}{c}\text { number of } \\
\text { employees }\end{array}$ & $\begin{array}{c}\text { number of vehicles of } \\
\text { the concessionaire }\end{array}$ \\
\hline annual traffic volume & 1.000 & 0.957 & 0.958 & 0.971 \\
\hline number of accidents & 0.957 & 1.000 & 0.989 & 0.972 \\
\hline number of employees & 0.958 & 0.989 & 1.000 & 0.972 \\
\hline $\begin{array}{l}\text { number of vehicles } \\
\text { the concessionaire }\end{array}$ & 0.971 & 0.972 & 0.972 & 1.000 \\
\hline
\end{tabular}

\begin{tabular}{|c|c|c|c|c|c|}
\hline SF9 & $\begin{array}{c}\text { annual } \\
\text { traffic } \\
\text { volume }\end{array}$ & $\begin{array}{l}\text { number of } \\
\text { accidents }\end{array}$ & $\begin{array}{l}\text { length }(\mathrm{km}) \\
x \text { number of } \\
\text { lanes }\end{array}$ & $\begin{array}{l}\text { number of } \\
\text { employees }\end{array}$ & $\begin{array}{c}\text { number of vehicles } \\
\text { of the } \\
\text { concessionaire }\end{array}$ \\
\hline $\begin{array}{ll}\text { annual } & \text { traffic } \\
\text { volume } & \end{array}$ & 1.000 & 0.957 & 0.848 & 0.958 & 0.971 \\
\hline number of accidents & 0.957 & 1.000 & 0.939 & 0.989 & 0.972 \\
\hline $\begin{array}{ll}\text { length } \quad(k m) & x \\
\text { number of lanes } & \end{array}$ & 0.848 & 0.939 & 1.000 & 0.943 & 0.873 \\
\hline $\begin{array}{ll}\text { number } & \text { of } \\
\text { employees } & \\
\end{array}$ & 0.958 & 0.989 & 0.943 & 1.000 & 0.972 \\
\hline $\begin{array}{l}\text { number of vehicles } \\
\text { of } \\
\text { concessionaire }\end{array}$ & 0.971 & 0.972 & 0.873 & 0.972 & 1.000 \\
\hline
\end{tabular}

User assistance models

\begin{tabular}{|c|c|c|c|c|}
\hline AT1 & $\begin{array}{l}\text { number of } \\
\text { employees }\end{array}$ & $\begin{array}{l}\text { number of vehicles of } \\
\text { the concessionaire }\end{array}$ & $\begin{array}{l}\text { number of user } \\
\text { assistances }\end{array}$ & $\begin{array}{c}\text { annual } \\
\text { traffic } \\
\text { volume }\end{array}$ \\
\hline number of employees & 1.000 & 0.887 & 0.873 & 0.909 \\
\hline $\begin{array}{l}\text { number of vehicles of } \\
\text { the concessionaire }\end{array}$ & 0.887 & 1.000 & 0.942 & 0.917 \\
\hline $\begin{array}{l}\text { number of user } \\
\text { assistances }\end{array}$ & 0.873 & 0.942 & 1.000 & 0.934 \\
\hline annual traffic volume & 0.909 & 0.917 & 0.934 & 1.000 \\
\hline
\end{tabular}




\begin{tabular}{|c|c|c|c|c|c|}
\hline AT2 & $\begin{array}{l}\text { number of } \\
\text { employees }\end{array}$ & $\begin{array}{l}\text { number of vehicles of } \\
\text { the concessionaire }\end{array}$ & $\begin{array}{r}\text { nur } \\
\text { assis }\end{array}$ & $\begin{array}{l}\text { Imber of user } \\
\text { stances/ length } \\
(\mathrm{km})\end{array}$ & $\begin{array}{c}\text { annual } \\
\text { traffic } \\
\text { volume }\end{array}$ \\
\hline number of employees & 1.000 & 0.887 & & -0.138 & 0.909 \\
\hline $\begin{array}{l}\text { number of vehicles of } \\
\text { the concessionaire }\end{array}$ & 0.887 & 1.000 & & 0.078 & 0.917 \\
\hline $\begin{array}{lr}\text { number of } & \text { user } \\
\text { assistances/ length } \\
(\mathrm{km})\end{array}$ & -0.138 & 0.078 & & 1.000 & 0.058 \\
\hline annual traffic volume & 0.909 & 0.917 & & 0.058 & 1.000 \\
\hline AT3 & $\begin{array}{l}\text { number of } \\
\text { employees/ } \\
\text { length }(\mathrm{km})\end{array}$ & $\begin{array}{r}\text { number of vehicl } \\
\text { the concessiona } \\
\text { length }(\mathrm{km})\end{array}$ & & $\begin{array}{c}\text { number of } \\
\text { user } \\
\text { assistances }\end{array}$ & $\begin{array}{c}\text { annual } \\
\text { traffic } \\
\text { volume }\end{array}$ \\
\hline $\begin{array}{l}\text { number of employees/ } \\
\text { length }(\mathrm{km})\end{array}$ & 1.000 & 0.900 & & 0.051 & 0.031 \\
\hline $\begin{array}{l}\text { number of vehicles of } \\
\text { the concessionaire/ } \\
\text { length }(\mathrm{km})\end{array}$ & 0.900 & 1.000 & & 0.050 & -0.004 \\
\hline $\begin{array}{l}\text { number of user } \\
\text { assistances }\end{array}$ & 0.051 & 0.050 & & 1.000 & 0.934 \\
\hline annual traffic volume & 0.031 & -0.004 & & 0.934 & 1.000 \\
\hline AT4 & $\begin{array}{l}\text { number of } \\
\text { employees }\end{array}$ & $\begin{array}{l}\text { number of vehic } \\
\text { the concession }\end{array}$ & $\begin{array}{l}\text { es of } \\
\text { aire }\end{array}$ & \multicolumn{2}{|c|}{$\begin{array}{c}\text { number of user } \\
\text { assistances/ annual traffic } \\
\text { volume }\end{array}$} \\
\hline number of employees & 1.000 & 0.887 & & \multicolumn{2}{|c|}{0.107} \\
\hline $\begin{array}{l}\text { number of vehicles of the } \\
\text { concessionaire }\end{array}$ & 0.887 & 1.000 & \multicolumn{3}{|c|}{0.295} \\
\hline $\begin{array}{l}\text { number of user } \\
\text { assistances/ annual traffic } \\
\text { volume }\end{array}$ & 0.107 & 0.295 & \multicolumn{3}{|c|}{1.000} \\
\hline
\end{tabular}

